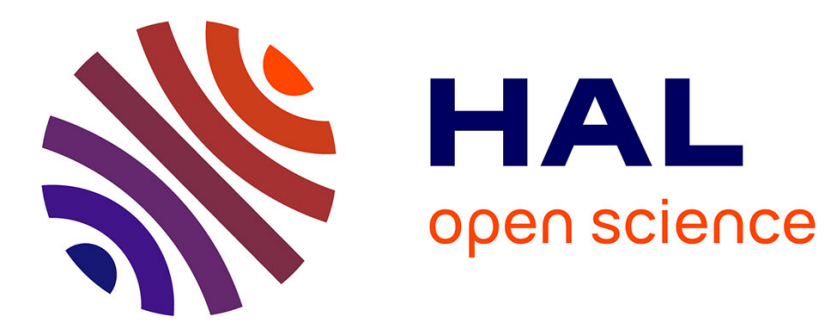

\title{
Seismoacoustic signature of the ocean storms at the center of Eurasia
}

Alexandr Smirnov

\section{To cite this version:}

Alexandr Smirnov. Seismoacoustic signature of the ocean storms at the center of Eurasia. Earth Sciences. Université Paris Cité, 2021. English. NNT : 2021UNIP7044 · tel-03585524

\section{HAL Id: tel-03585524 \\ https://theses.hal.science/tel-03585524}

Submitted on 23 Feb 2022

HAL is a multi-disciplinary open access archive for the deposit and dissemination of scientific research documents, whether they are published or not. The documents may come from teaching and research institutions in France or abroad, or from public or private research centers.
L'archive ouverte pluridisciplinaire HAL, est destinée au dépôt et à la diffusion de documents scientifiques de niveau recherche, publiés ou non, émanant des établissements d'enseignement et de recherche français ou étrangers, des laboratoires publics ou privés. 


\title{
Seismoacoustic Signature of
}

\section{the Ocean Storms at the}

\section{Center of Eurasia}

\author{
Par Alexandr Smirnov \\ Thèse de doctorat de Sciences de la Terre et de \\ I'environnement
}

Dirigée par Alexis Le Pichon et Eléonore Stutzmann

Présentée et soutenue publiquement le 10 mars 2021 Devant un jury composé de:

\begin{tabular}{|c|c|}
\hline $\begin{array}{r}\text { Larmat Carene } \\
\text { Chercheur (Los Alamos National Laboratory) }\end{array}$ & Rapporteur \\
\hline $\begin{array}{c}\text { Hauchecorne Alain } \\
\text { Directeur de Recherche }\end{array}$ & Rapporteur \\
\hline Membre (Observatoire royal de Belgique) & Examinateur \\
\hline $\begin{array}{r}\text { Lognonne Philippe } \\
\text { Directeur de recherche (IPGP) }\end{array}$ & Président \\
\hline $\begin{array}{r}\text { Mikhailova Natalya } \\
\text { Directeur de Recherche (KNDC) }\end{array}$ & Examinatrice \\
\hline $\begin{array}{l}\text { Stutzmann Eléonore } \\
\text { Directeur de recherche (IPGP) }\end{array}$ & Co-Directrice de thèse \\
\hline $\begin{array}{l}\text { Le Pichon Alexis } \\
\text { Chercheur (CEA) }\end{array}$ & Directeur de thèse \\
\hline $\begin{array}{l}\text { Shapiro Nikolai } \\
\text { Directeur de recherche (ISTerre) }\end{array}$ & Membre invité \\
\hline
\end{tabular}


Titre :

Signature sismo-acoustique des dépressions océaniques enregistrées en Eurasie

Résumé :

L'étude des signaux sismiques et acoustiques des fortes tempêtes océaniques est essentielle pour vérifier le respect du Traité d'interdiction complète des essais nucléaires car la houle est une source dominante de bruit de fond. Une retombée attendue de la caractérisation du bruit océanique avec les réseaux sismiques et infrason est l'amélioration des outils opérationnels de surveillance. Cette thèse a poursuivi plusieurs objectifs. Dans un premier temps, les signaux sismiques et acoustiques produits par bruit océanique, enregistrés par le réseau de surveillance kazakh, ont été analysés entre 2014 et 2017. Ensuite, un modèle de source sismo-acoustique a été développé ; les paramètres de ces signaux ont été modélisés pour cette période. Enfin, les observations ont été comparées aux modélisations sur toutes les stations du réseau sismo-acoustique kazakh. Cette analyse a permis d'identifier des cycles saisonniers et de caractériser une source commune, en localisation et intensité, à l'origine des signaux sismiques et infrason observés. Les écarts entre les observations et les modélisations ont été quantifiés et expliqués. Cette étude révèle le potentiel de la synergie entre des technologies complémentaires de surveillance pour mieux décrire les mécanismes de couplage à l'interface océan-atmosphère, améliorer des méthodes de discrimination et évaluer les modèles de propagation dans des milieux complexes.

Mots clefs :

Signaux sismiques et acoustiques, tempêtes océaniques, bruit sismique 
Title :

Seismoacoustic Signature of the Ocean Storms at the Center of Eurasia

\begin{abstract}
:
Studying seismic and acoustic signals from strong storms is important to verify compliance with the Comprehensive Nuclear-Test-Ban Treaty as the ocean swell is one of the main causes of background noise. An expected potential of the study is the improvement of the available monitoring tools (discrimination and propagation methods) through the fusing of seismic and acoustic methods. This thesis pursued several targets. On the first stage, seismic and acoustic signals from ocean storms were detected in observation data for 2014-2017 for the Kazakhstani monitoring network. Then, a seismo-acoustic source model was developed, and expected parameters of signals for this period were predicted. Afterward, actual and predicted microbarom and microseism parameters were compared and analyzed. The analysis resulted in the identification of seasonal regularities in registered microseisms and microbaroms and characterization of their sources: it was proved that the sources are of the same origin. Discrepancies were found for predicted and observed microseism backazimuths, and an attempt to discriminate their nature was made. The results of this study revealed strengths and weaknesses of seismic and acoustic methods, and lead to the conclusion that a fusion of two techniques brought qualitatively new results.
\end{abstract}

Keywords :

Microseisms, microbaroms, oceanic storms, seismic noise 


\section{Contents}

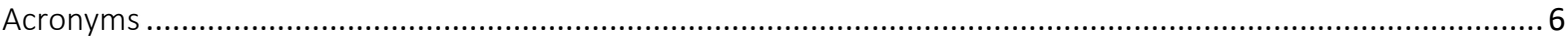

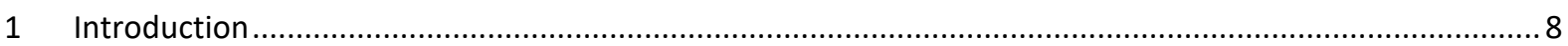

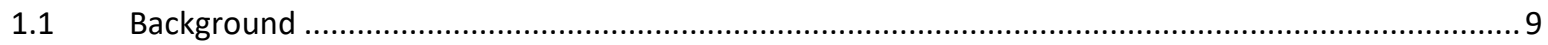

1.2 Analysis of historical detection bulletins at IMS stations ....................................................... 11

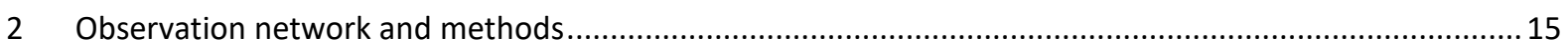

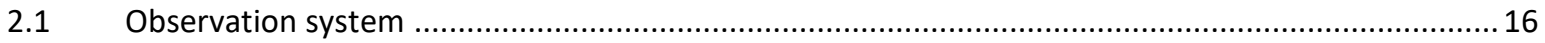

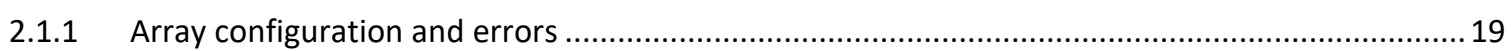

2.1.2 Power spectral density of the noise at seismic and infrasound arrays......................................... 19

2.1.3 Review of existing databases (continuous recordings, detection bulletins, seismicity catalogs) ... 20

2.2 History of the microbarom and microseism observations in Kazakhstan ........................................2 21

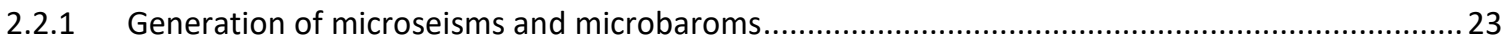

2.2.2 Comparison between the observed backazimuths and microseism/microbarom energy

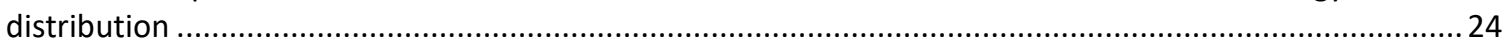

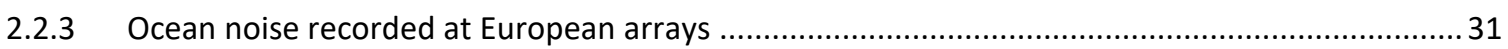

2.3 Assessment of processing methods, propagation of seismic and infrasound waves .........................35

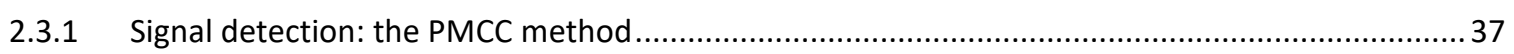

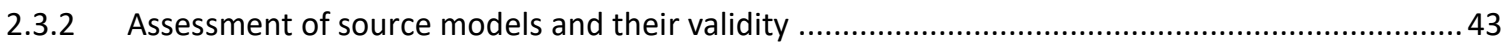

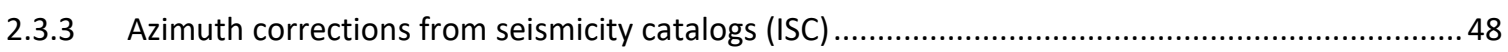

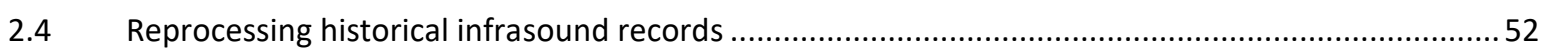

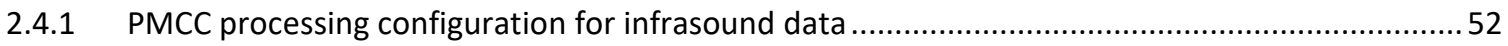

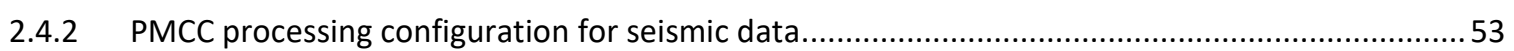

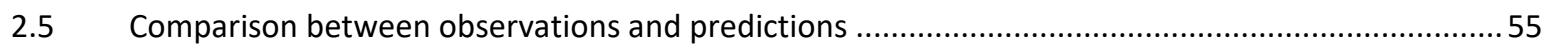

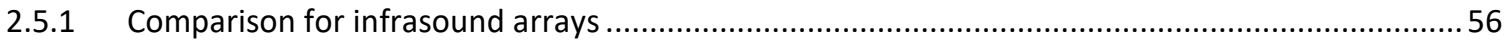

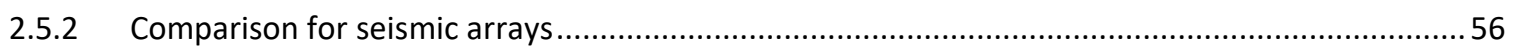

2.5.3 Metrics to compare observations with predictions .............................................................5

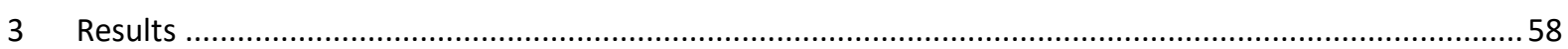

3.1 Microbarom detections as recorded by infrasound subnetwork and simulation results .................58

3.2 Microseism detections as recorded by seismic sub-network and simulation results .........................62

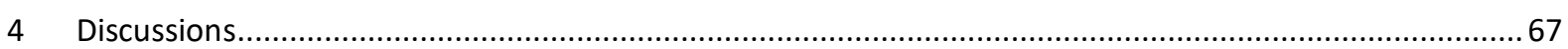

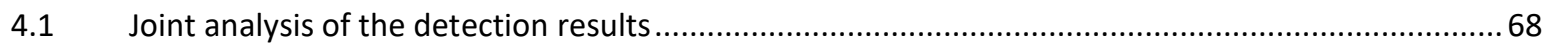

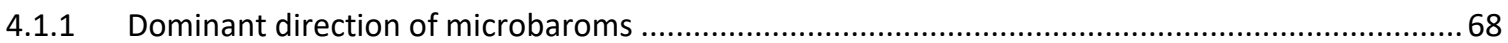

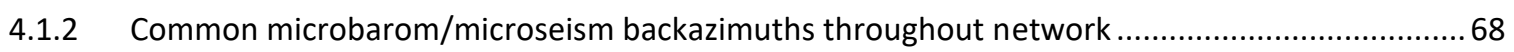

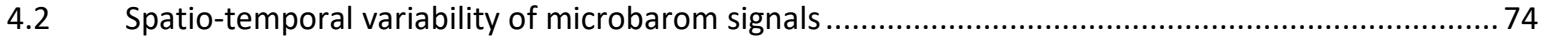

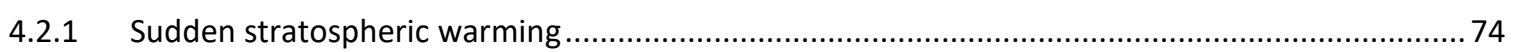

4.2.2 Comparison of the source location results with the IFREMER model ......................................... 75

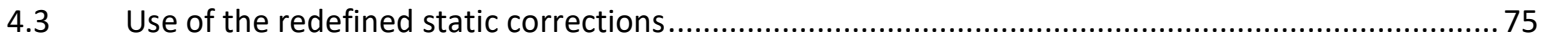

4.3.1 Explanation of the nature of the deviations in backazimuths for the Rayleigh waves ..................8 80

4.4 Joint analysis of the infrasound and seismic detections bulletins for IMS and national stations ....... 89 


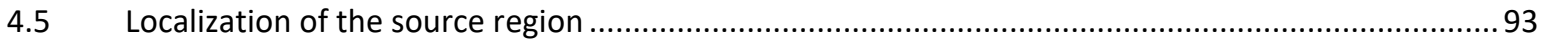

4.6 Catalog of oceanic sources for the reconstruction of atmospheric model ......................................96

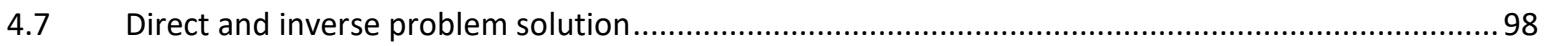

4.8 Comparison between PMCC detections and effective sound speed ratio...................................99

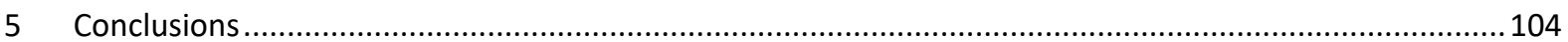

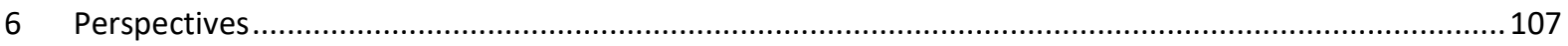

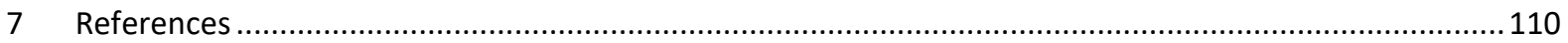

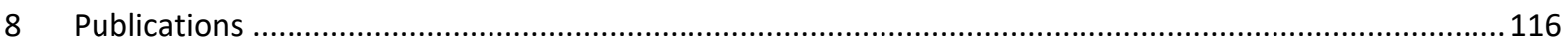




\section{Acronyms}

ABKAR Akbulak Seismic Array

AFTAC Air Force Technical Applications Center

ARCES ARCES seismic array (PS28), Norway

ARISE Atmospheric dynamics Research InfraStructure in Europe

BAZ Backazimuth

BURAR Bucovina seismic array, Romania

CEA Commissariat à l'Energie Atomique et aux Energies Alternatives

CTBTO Comprehensive Nuclear Test Ban Treaty Organization

DASE Département Analyse, Surveillance, Environnement

ECMWF European Centre for Medium-Range Weather Forecasts

EKA Eskdalemuir seismic array, UK

ESDC Sonseca seismic array, Spain

FINES Finnish seismic array

GT Ground Truth event

HRES Atmospheric Model high resolution 10-day forecast

HWM Horizontal Wind Model

I26DE, IS26 German infrasound array, Bavarian forest

I31KZ, IS31 Kazakh infrasound array, Aktyubinsk

I46RU, IS46 Russian infrasound array, Zalesovo

IDC International Data Center

IFREMER L'Institut Français de Recherche pour l'Exploitation de la Mer

IGR Institute of Geophysical Researches

IMS International Monitoring System

IPGP Institut de Physique du Globe de Paris

ISC International Seismological Centre

KKAR Karatau Seismic array, Kazakhstan

KNDC Kazakh National Data Center

KNMI Koninklijk Nederlands Meteorologisch Instituut

KURIS Kurchatov infrasound array, Kazakhstan

LDG Laboratoire de Détection et de Géophysique

Lidar Light Detection And Ranging

MKAR Makanchy seismic array, Kazakhstan 


$\begin{array}{ll}\text { MKIAR } & \text { Makanchy infrasound array, Kazakhstan } \\ \text { NDC } & \text { National Data Center } \\ \text { NOAA } & \text { National Oceanic and Atmospheric Administration } \\ \text { NORSAR } & \text { Norwegian Seismic Array, Norwegian National Data Centre } \\ \text { NRL } & \text { U.S. Naval Research Laboratory } \\ \text { PSD } & \text { Power Spectral Density } \\ \text { PMCC } & \text { Progressive Multi-Channel Correlation } \\ \text { RMS } & \text { Root Mean Square error } \\ \text { SNR } & \text { Signal to Noise Ratio } \\ \text { SSSC } & \text { Source Specific Static Corrections } \\ \text { SSW } & \text { Sudden Stratospheric Warming } \\ \text { SWW } & \text { Standing Water Waves } \\ \text { WW3 } & \text { WAVEWATCH III }{ }^{\circledR} \text { Model }\end{array}$




\section{Introduction}

Monitoring networks are a powerful tool for geophysical monitoring. Integration of arrays into a network ensures solving of new tasks at a totally new level that is not possible in case of single stations. In particular, the key goals of seismic networks are the accurate localization of the earthquakes, warning of seismic hazard, general or specific seismic monitoring, investigation of internal structure of the Earth, and others. Historically, the main goal of infrasound arrays is nuclear tests monitoring, but infrasound technologies could be used as a component in a number of international geophysical hazard-warning systems. An example of such a system is the monitoring of the volcanic ash for civil aviation safety (Marchetti et al., 2019) . One of the most sophisticated monitoring networks is the International Monitoring System (IMS) of the Comprehensive Nuclear-Test-Ban Treaty Organization. IMS includes stations of four (4) types: seismic, infrasound, hydroacoustic, and radionuclide. IMS stations are distributed as uniformly as possible over the face of the globe. When all stations are to be constructed, IMS will include 50 primary and 120 auxiliary seismic stations and 60 infrasound stations. Shared use of IMS stations and arrays of other networks expands the coverage of observations and build denser networks. For example, Kazakh network of seismic and acoustic monitoring stations is used in this way. This study was prepared based on data from four (4) seismic and three (3) infrasound arrays making up the Kazakh network. Among these stations, primary seismic station Makanchy (MKAR, PS23) and I31KZ infrasound array are stations pertaining to the IMS network.

Microbaroms are continuous infrasonic oscillations produced by ocean waves. They are observed everywhere on the Earth and generally determine the ambient noise floor in the 0.1-0.5 Hz frequency band (Bowman et al. 2005). The microbarom peak is in the midst of the detection region for 1-kiloton nuclear explosion tests (Stevens et al., 2002), and thus, microbaroms can obscure an important signal of interest (Le Pichon et al., 2009). Similar to infrasound observations, a major seismic monitoring challenge arises from the fact that ambient ground motion forms a background noise level at every seismic station. This noise is composed of surface motions caused by local weather conditions, vibrations produced by wave interactions in the oceans (microseisms), human-induced activity, and many other localized or distributed sources of seismic waves. It is station specific and establishes a lower bound for detectability of P and S waves from distant sources (National Research Council, 1997). In this paper, we develop a synergetic approach to better constrain microbarom source regions and evaluate propagation effects. To this end, we apply the method developed by Hupe et al. (2018) to the dense Kazakhstani seismo-acoustic network. This dense seismo-acoustic Kazakh network is operated by the Institute of Geophysical Research (IGR) of the National Nuclear Center of the Republic 
of Kazakhstan and includes both seismic and infrasound arrays. Using such experimental setting, we aim at developing synergetic approaches to better constrain microbarom and microseism source and evaluate propagation effects.

The main current task was subdivided into smaller subtasks. Data of the Kazakh arrays records was analyzed for the period over 2014-2017 for the availability of microbaroms and microseisms using Progressive Multi-Channel Correlation technique (PMCC). The source was simulated with the model distributed by IFREMER (IFREMER, 2018) referred to as 'p2l' - as a composite calculated from the waveaction WaveWatch III model (WW3) developed by the National Oceanic and Atmospheric Administration (NOAA). Predictions of microseism parameters were made considering the influence of attenuation effect and bathymetry effect onto the source intensity. The bathymetry effect was assumed as insignificant for microbarom source (De Carlo, 2020). However, the influence of temperature and zonal and meridian wind profiles over the signal distribution was taken into consideration. High-resolution forecast (HRES) atmospheric model was used that is a part of ECMWF's Integrated Forecast System (IFS), cycle 38r2 (Le Pichon et al., 2012).

This document comprises four sections and the conclusion. The introductory part describes the issues of microbaroms and microseisms studies and details historical data for IMS and Kazakh network. The second section covers observation network and methods. The third section contains main findings of the study. Analysis of the findings is summarized in the fourth section, and Conclusions are shared in the last section.

\subsection{Background}

Fundamentals to predict microseism and microbarom source regions were described by LonguetHiggins (Longuet-Higgins, 1950). They demonstrated how counter-propagating waves and their second-order nonlinear interactions can generate propagating acoustic waves in the ocean, and create seismic noise by been repeatedly reflected and transmitted at the seafloor. Hasselmann (Hasselmann, $1963,1966)$ later generalized this theory to random waves, showing that the resulting acoustic frequency is twice the frequency of the ocean waves, by considering nearly opposing waves interacting.

The microseism source model used (IFREMER, 2018), referred to as "p21", is calculated from the waveaction WAVEWATCH III model (WW3) developed by the National Oceanic and Atmospheric Administration (NOAA). While the bathymetry strongly affects the source intensity in microseism modeling (Ardhuin et al., 2011; Ardhuin and Herbers, 2013b; Kedar et al., 2008), a recent modeling study by De Carlo (2020) suggests that bathymetry has negligible impact on microbarom source 
strength in contrast to predictions from the model by Waxler et al. (2007). In this study, the source term for microseisms ("p2l") which does not include coupling with the bathymetry is taken as a proxy to model microbaroms. While microseisms propagate through the static structure of the solid Earth, long-range microbarom propagation is controlled by the strong spatiotemporal variability of the temperature and wind structure of the atmosphere. Therefore, the geometrical spreading and seismic attenuation are the main effects to account for microseism modeling (e.g., Kanamori and Given, 1981; Stutzmann et al., 2012), while the dynamical properties of the middle atmosphere should be taken into account for microbarom modeling.

Seismic noise numerical simulations were introduced by Kedar et al. (Kedar et al., 2008). The good correlation between the observed microseism amplitudes and their predicted values according to the Longuet-Higgins theory was shown, demonstrating that microseism source locations can be tracked using numerical modeling (Shapiro, 2005; Shapiro and Campillo, 2004; Stehly et al., 2006; Stutzmann et al., 2012; Weaver, 2005).

The microbarom frequency band is located at the lower edge of the frequency band of interest to monitor nuclear tests. Recent global scale microbarom observations recorded by the International Monitoring System (IMS) network of the Comprehensive nuclear Test Ban Treaty Organization (СТВTO) confirm that its detection capability is highly variable in space and time (Ceranna et al., 2018). Thus, in order to assess the microbarom source intensity accurately, it is necessary to take into account a realistic description of the middle atmosphere, as infrasound propagate for the long distances mostly at that altitudes (Le Pichon et al., 2012).

Like microseisms, microbaroms are not the impulsive signals but quasi-monochromatic sequences of permanent waves (Olson and Szuberla, 2005); therefore, it is not possible to detect their onset and identify their propagation paths. However, such signals are well detected using standard processing techniques, such as beamforming methods used since the sixties (Capon, 1972; Haubrich and McCamy, 1969; Toksoz and Lacoss, 1968). More recent algorithms are efficient to detect and characterize continuous and global microbarom signals (Evers and Haak, 2001; Garcés, 2004; Hupe et al., 2018; Landès et al., 2012). The above mentioned studies were conducted using IMS infrasound data as well as infrasound records from national networks, e.g. KNMI network (Evers and Haak, 2001).

Other studies were conducted to characterize the ambient infrasound noise. Garcès (Garcés, 2004) compared one year of observed and simulated microbaroms for continuously measuring wind and temperature profiles in the low, middle and upper atmosphere. Smets (2014) compared microbarom observations with the expected values to study the life cycle of Sudden Stratospheric Warming events. Landès (Landès et al., 2014a) compared the modelled source region with microbarom observations at 
operating IMS stations. Le Pichon (2015) compared observations and modelling over a 7-month period to assess the middle atmospheric wind and temperature models distributed by European Centre for Medium-Range Weather Forecasts (ECMWF). More recently, Hupe (Hupe et al., 2018) showed a first order agreement between the simulated and observed microbarom azimuth and amplitude in North Atlantic. These agreements have been improved using more accurate wind profiles obtained from high resolution LIDAR middle atmospheric sounding.

\subsection{Analysis of historical detection bulletins at IMS stations}

Together with the establishment of the International Monitoring System (IMS), record-based studies of microbaroms were published.

The first studies evidenced that microbarom signals originate from oceanic storms. As such, (Bass et al., 2001) showed that the source azimuth determined based on infrasound array data is indicative of the low-pressure center of the storm. Garcès (2004) demonstrated that azimuths of coherent microbaroms signals arrival observed in Hawaii in 2003, are related to the areas of highly active ocean waves in the Pacific region. These studies formulate the following problem: previous reviews discussed the dependency between the microbaroms signals and the height of oceanic waves, however theoretical justification of interrelation between the water waves and acoustic waves in the atmosphere was not completed. Later, Waxler and Guilbert (2006) presented the solution to the emission of atmospheric microbaroms by oceanic waves. The proposed source model was later compared with observations. Stopa (2012) investigated records of hurricanes (Felicia and Neki of 2009) and showed positive correlation between the hurricane signals recorded by IS59, theoretical estimates of microbaroms signals and attenuation of registered signals from high-energy sources, thereby demonstrated the applicability of infrasound signals for measuring tropical cyclone winds.

A number of papers raised the issue of microbarom source localization based on infrasound network data e. g. (Bass et al., 2001). (Landès et al., 2012, 2014b) consistently evaluated the direction of microbarom arrival at all operational IMS stations at that time, localized globally monthly averaged infrasound sources using a cross-bearing method. These studies showed that the monthly averaged data exhibit clear seasonal changes of the most active source area position between the northern and southern hemispheres. Explanation of the nature of a seasonal dependency is included in a number of papers. Bowman (2005) studied coherent background noise for 21 globally distributed infrasound arrays and showed that the background noise significantly depends on the season, time of day and geographic location of the stations. They demonstrated that the median noise level has a maximum at $0.2 \mathrm{~Hz}$ and varies smoothly within a year, having its maximum in local winter. Later, Le Pichon et al. (2006) explained that effect. They illustrated that systematic seasonal variations in signal arrival 
azimuths and amplitudes are primarily governed by the seasonal reversals of the zonal component of stratospheric winds, Figure 1.

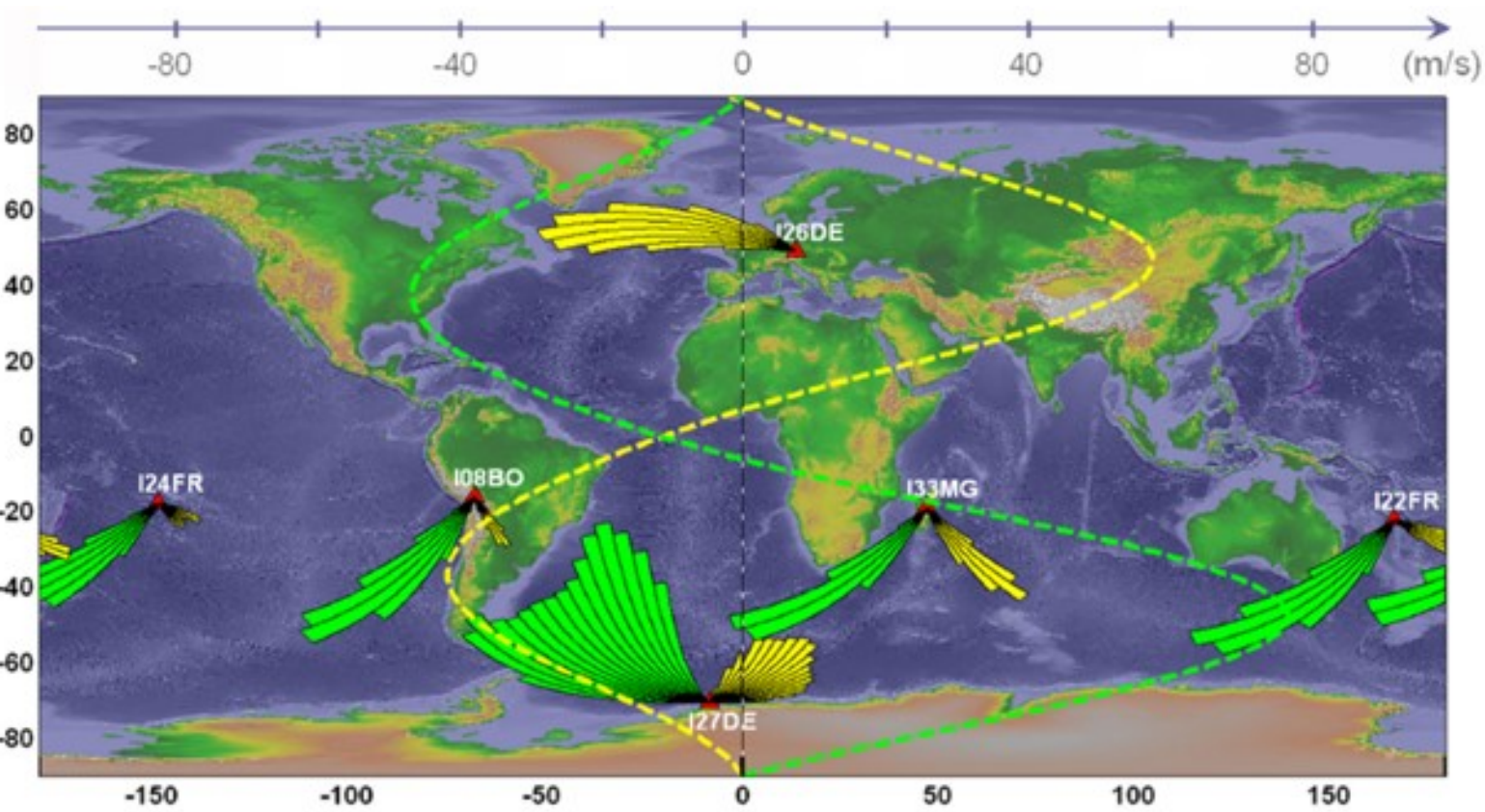

Figure 1. Seasonal variations in microbarom arrival azimuths for several middle- and high latitude IMS stations in 2003. Azimuthal distributions are plotted for every station in Austral winter (green bars) and Austral summer (yellow bars). The strength of the zonal wind (HWM-93) is averaged in longitude (180W-180E) and altitude (35-40 km) for winter and summer (green and yellow curves, respectively, according to the scale). For all the stations, the dominant wind directions match seasonal variability of microbarom detections (From Le Pichon et al., 2006)

Landes $(2012,2014)$ confirmed that this effect is supported with long-term observations at IMS infrasound stations (Figure 2). 


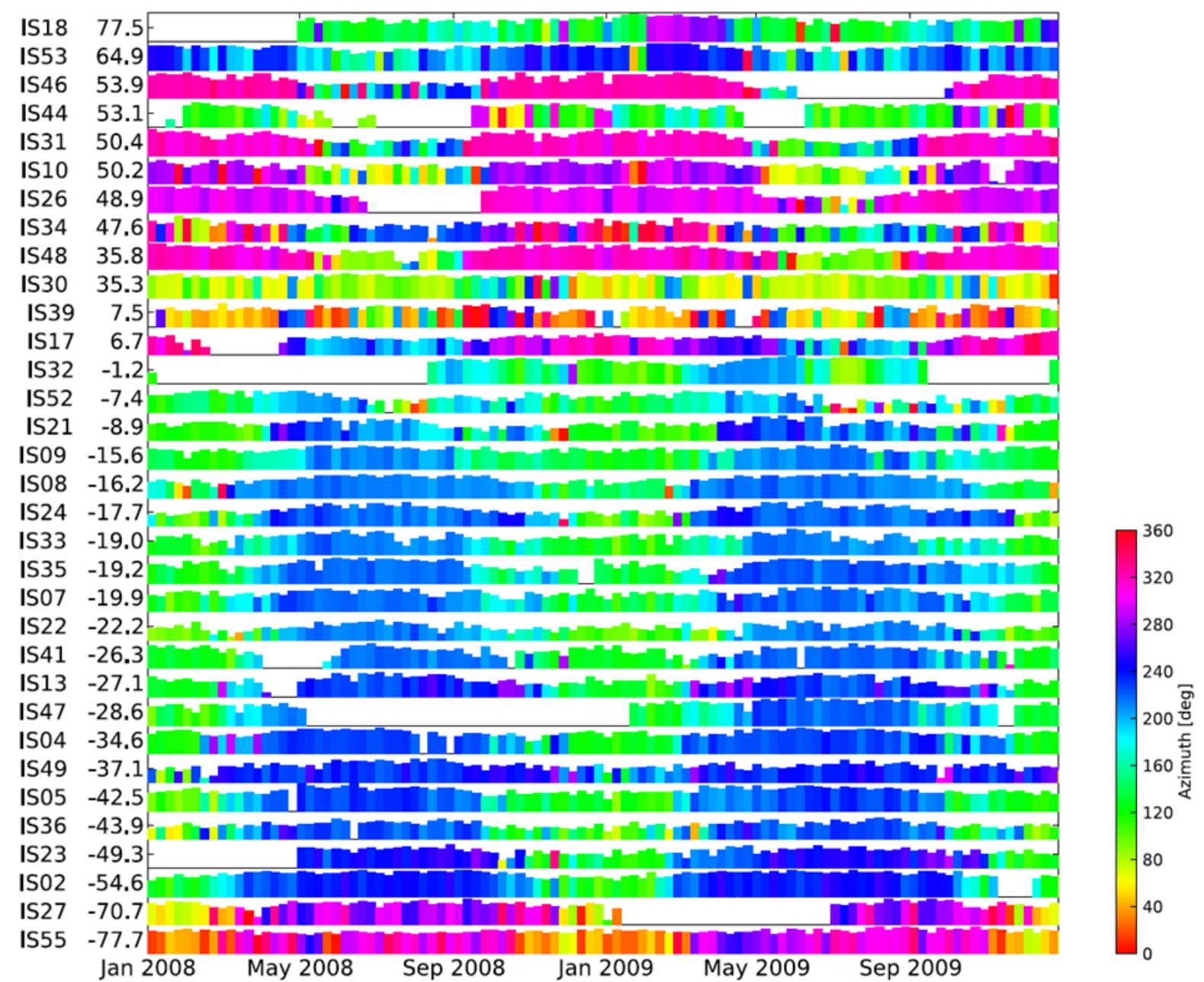

Figure 2. Weekly distribution of the number of detections at 33 IMS stations in 2008-2009.

Numbers near the station name correspond to their latitudes. Stations are sorted by latitudes. The color corresponds to the weekly averaged azimuth. The column height is defined by a logarithm of a number of detections with an upper limit corresponding to 15000 over axis for all stations. (Landès et al., 2014b)

The simulation method of microbarom space-time parameters variation has been developing since the beginning of the studies using IMS data. Garcès (2004) showed that arrival azimuths are influenced significantly by atmospheric structure. Le Pichon et al. (2006) illustrated that microbarom amplitude is defined by the upper air wind speed to a large extent, and demonstrated potential paths of infrasound propagation. Landes et al. (2014), for simulation purposes, considered both the source function model and signal attenuation during propagation due to the effect of stratospheric winds (Figure 3). 


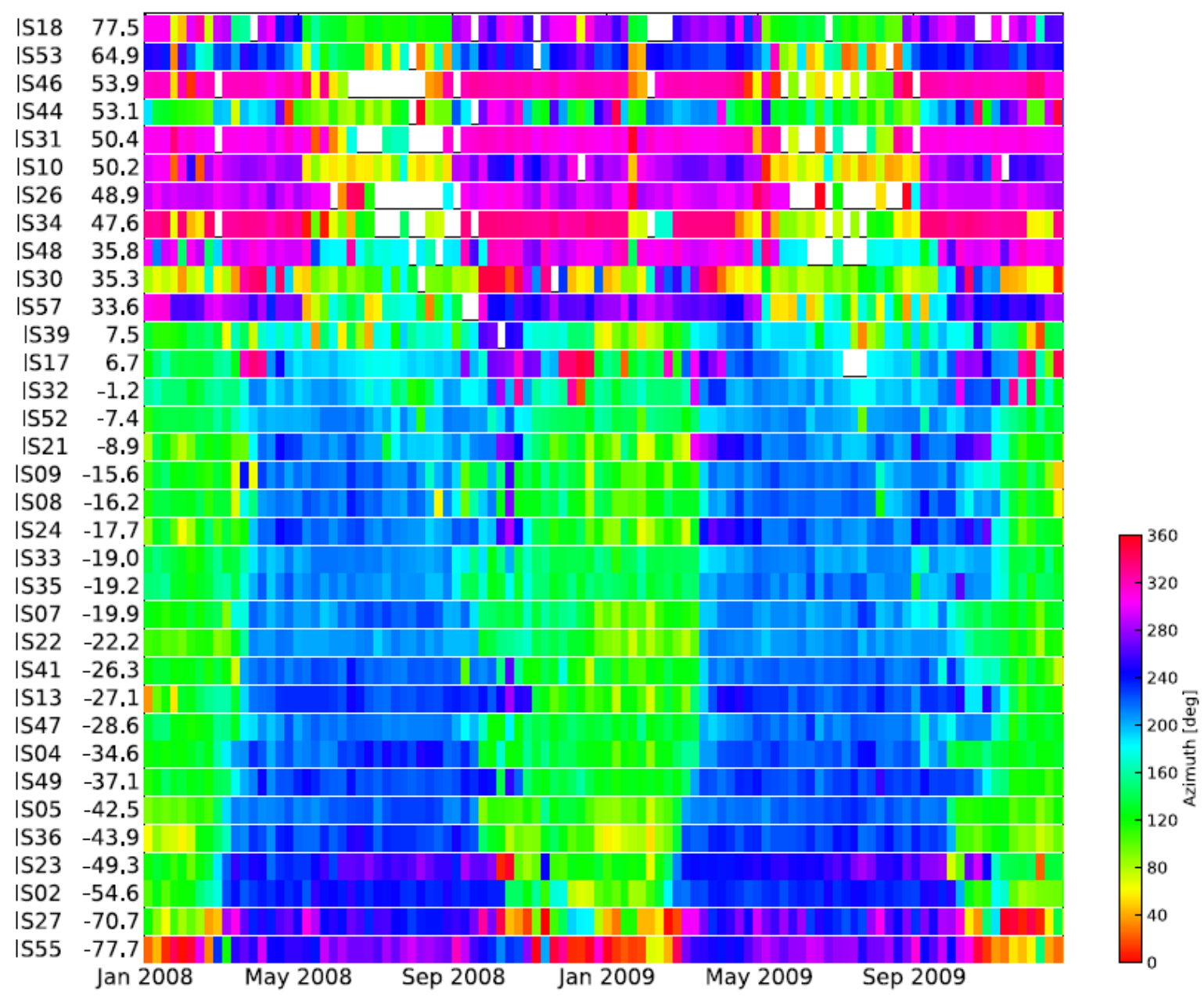

Figure 3. Weekly azimuth of 33 selected IMS stations between 2008 and 2009 obtained from simulation. Numbers near the station name correspond to their latitudes. Stations are sorted by latitude. The color corresponds to the weekly averaged azimuth (Landès et al., 2014b)

This approach explained observations properly, but highlighted the need to improve the accuracy of atmospheric parameters. De Carlo (2018) completed a comparative analysis to define the influence of every factor on modelling accuracies, such as source function and travel path.

The emphasis shall be made on the use of microbarom signals for studying major atmospheric effects. Smets and Evers (2014) presented the Sudden Stratospheric Warming life cycle study technique which applies to observations of background infrasound noise. 


\section{Observation network and methods}

This section describes the observation system and survey methods. Sections relating to the observation system detail not only geometrical network parameters but arrays configuration (both seismic and infrasound) and error estimation for backazimuth and apparent velocity. Such estimations are critical for understanding the reasons for the mismatch between the observed and expected backazimuths. Amplitude and phase-frequency characteristics are included for all the sensors used. This data is very important for the seismic portion of the investigation. The point is that unlike microbaroms, seismic sensors have non-flat amplitude-frequency characteristics within the target frequency band. Noise levels have been compared for each array locations for the summer and winter months. These data are sufficient to testify that within a frequency band of $0.1-0.4 \mathrm{~Hz}$, noise levels in the summer months are lower. It is evident on infrasound records where the microbarom peak is significantly weaker. The similarity of the noise energy spectrum on collocated seismic and infrasound records also indicate that both microseisms and microbaroms registered by these arrays most likely have common sources. In addition to the observation system and tools used, this section also reviews available observation data and processing tools. The introduction section 1 details microbarom survey findings using IMS infrasound subnetwork. Similar surveys were conducted for Kazakh arrays as well (Smirnov et al., 2010). It shall be noted however that a simplified source simulation approach was used in 2010 and a shorter one-year data fragment was studied. Source parameters were simulated for one winter month only, atmospheric temperature and wind profiles influence on infrasound distribution and bathymetry effect on microseism source intensity were not considered. The goal of the 2010 survey was aimed at qualitative analysis and validation of the nature of low-frequency signals registered by the Kazakhstan network. The current survey is conducted to characterize the sources and uses more precise methods for source parameters simulation. The geography for the survey was extended from the North Atlantic to global coverage. The method section details all the applied techniques including PMCC detector, source simulation, a method for consideration of atmospheric influence on infrasound propagation, and bathymetry effect on microseism source intensity. In the 2010 survey it was shown that the expected and observed microseisms backazimuths differ significantly (Smirnov et al., 2010). An attempt was made to explain these differences with heterogeneities in the Earth crust along the microseism propagation path. Source-Specific Static Corrections of the surface waves were assessed based on strong North Atlantic earthquake detection data. In this survey, this method was expanded. Findings of the whole processing tract are presented in the section conclusions (section 5), including signals detection, source simulation, and comparison of the observation data (Smirnov et al., 2018). The tract was tested with the limited data set, and 
validity of the selected configuration was demonstrated. The section ends with a description of the technique for quantitative assessment of the matching expected and observed signal azimuths and amplitudes.

\subsection{Observation system}

The Kazakh seismo-acoustic network (KNDC, 2019) operated by IGR is unique for microbarom and microseism study, as it contains a five seismic and three infrasound arrays Figure 4 (BVAR seismic array is not shown as its data were not used in this study).

Stations in the network are part of other global networks such as the IMS (CTBTO), IRIS consortium, etc. KNDC closely cooperates with the institutions responsible for these networks and leading seismic and infrasound centers such as the International Data Center (IDC, Austria) of the CTBTO, Air Force Technical Applications Center (AFTAC, USA) and Commissariat à l'énergie atomique et aux énergies alternatives (CEA, France).

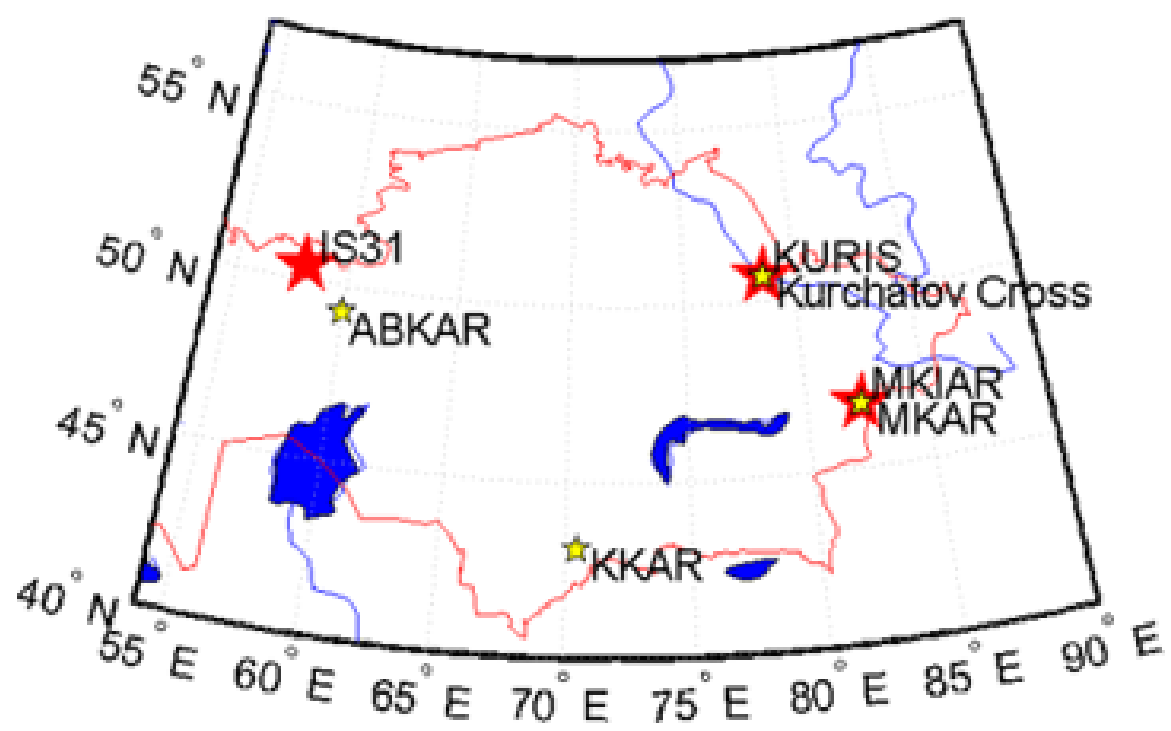

Figure 4. IGR monitoring network. Yellow and red stars are seismic and infrasound arrays, respectively. Seismic and infrasound arrays are collocated at two sites. IS31 infrasound and ABKAR seismic arrays are located $\sim 200 \mathrm{~km}$ apart

The infrasound network consists of the IMS infrasound station IS31 located in north-west Kazakhstan (2.1 km aperture, 8 elements), two national arrays of $1 \mathrm{~km}$ aperture: KURIS ( 4 elements) in Kurchatov, and MKIAR (9 elements) in Makanchy village (Belyashov et al., 2013) (Figure 5).

KURIS and MKIAR have been operating since 2010 and 2016, respectively. Microbarometers MB2000 and MB2005 are used at IS31 and KURIS, and Chaparral Physics M25 microbarometers are installed at 
MKIAR. Figure 6 (a) and (b) shows the frequency and phase responses of the MB2000/MB2005 and Chaparral M25.

The frequency responses of the sensors are flat from 0.01 to $5.0 \mathrm{~Hz}$. Analyzed together infrasound observables recorded by this network allows discriminating regional natural and anthropogenic sources (Smirnov, 2015; Smirnov et al., 2011, 2018).

The seismic network consists of Kurchatov Cross array and MKAR part of the IMS network, ABKAR and KKAR part of the (AFTAC, USA) network (Figure 7 and Table 1). Kurchatov cross array differs from the others with 20 elements arranged as a cross with an aperture of $22 \mathrm{~km}$ (Figure 8).

IS31

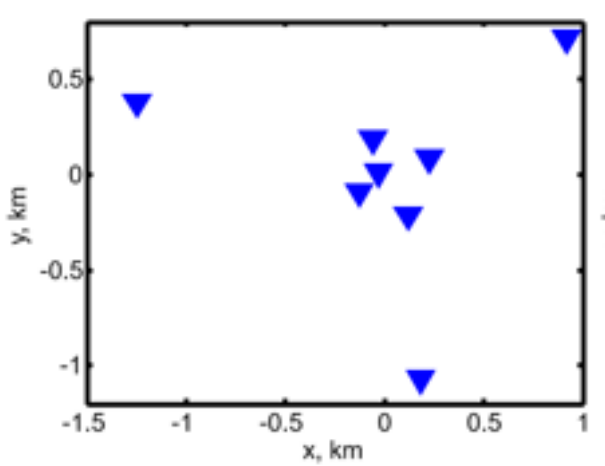

KURIS

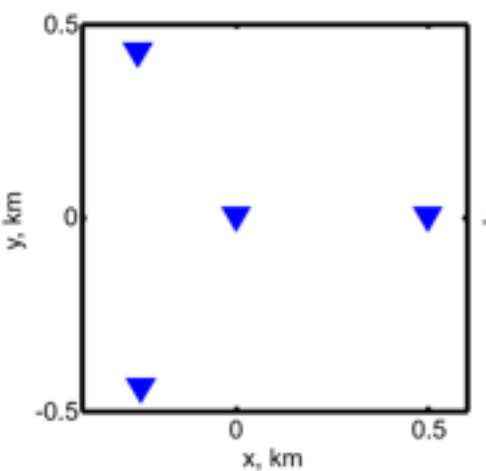

MKIAR

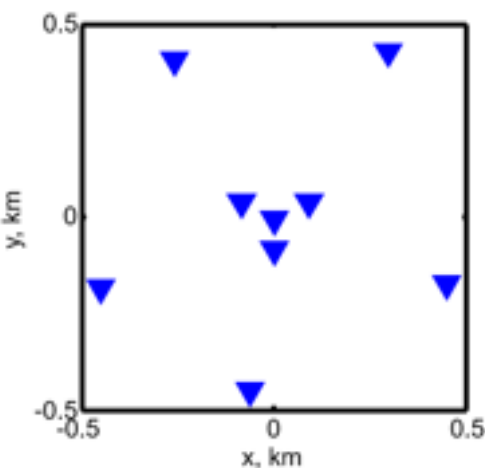

Figure 5. Infrasound arrays of the IGR monitoring network: IS31 (2 km aperture), KURIS and MKIAR (1 km aperture)

a)
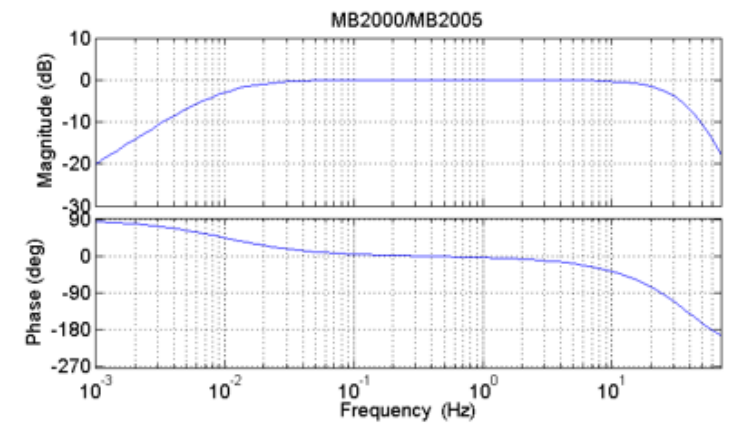

b)

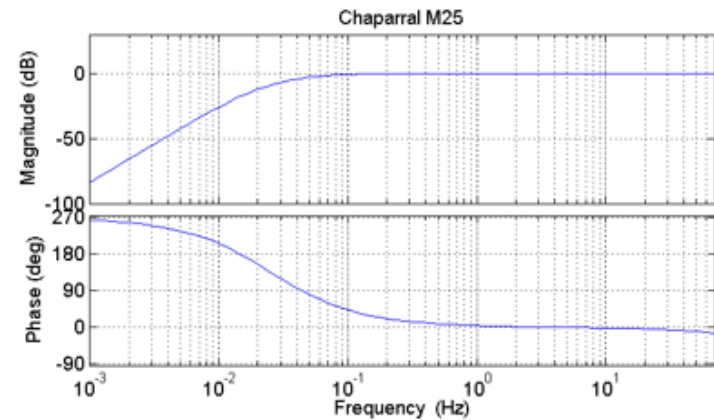

c)

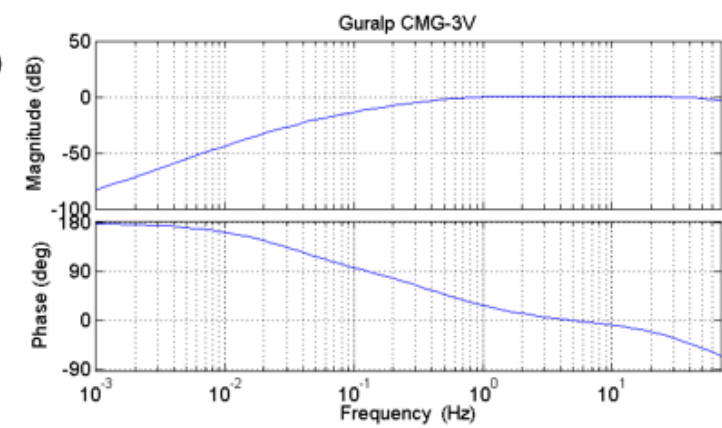

d

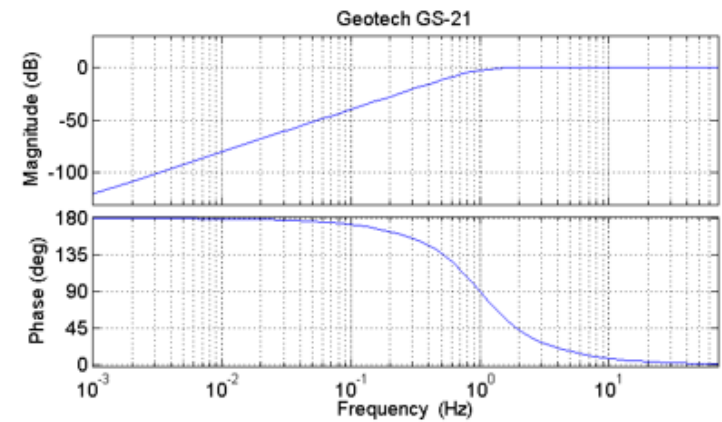

Figure 6. Frequency and phase responses of the MB2000/MB2005 (a), Chaparral M25 (b) microbarometers, CMG-3V (c) and GS-21 (d) seismometers 
Kurchatov Cross consists of CMG-3V sensors. Although the $0.1-0.3 \mathrm{~Hz}$ frequency band is at the edge of the sensors frequency response, they can record microseisms. The configuration of ABKAR, BVAR, KKAR and MKAR are similar with nine elements and an aperture of $\sim 5 \mathrm{~km}$. ABKAR array configuration is shown in Figure 7.

These arrays are equipped with GS-21 short period vertical sensors with flat response for frequencies above $1 \mathrm{~Hz}$. Figure 6 (c) and (d) shows the frequency and phase response of GS-21 and CMG-3V.

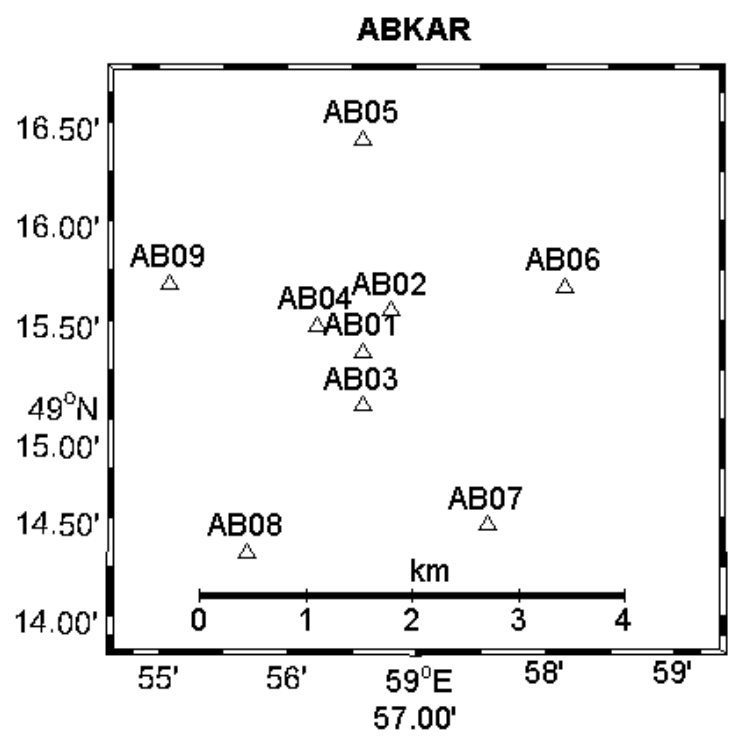

Figure 7. Configuration of ABKAR seismic array, which includes a central point, inner and outer circles of 3 and 5 elements, respectively

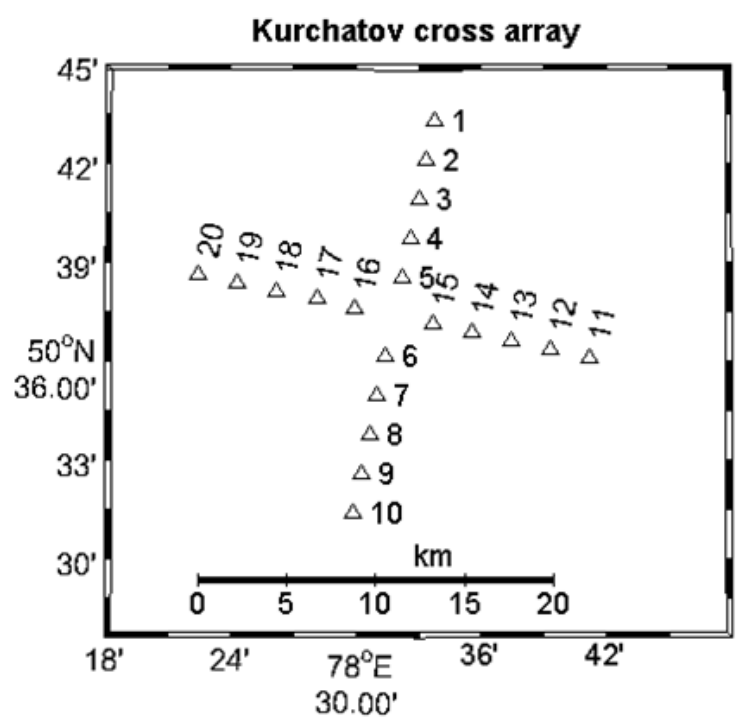

Figure 8. Configuration of Kurchatov Cross seismic array

Surface waves from the ocean storms are well recorded by broadband seismometers. CMG seismometers also record body waves but with much weaker amplitude (Farra et al., 2016). Body 
waves are also registered on GS-21 short period sensors. Although, in the frequency band of interest (0.1-0.3 Hz), the signal attenuation is about $30 \mathrm{~dB}$, all stations detect microseisms effectively due to their large amplitude above the background noise.

A peculiarity of the network is that infrasound and seismic arrays are collocated at two sites (KURIS and Kurchatov Cross; MKIAR and MKAR) or installed relatively close to each other (IS31 and ABKAR are $220 \mathrm{~km}$ apart (Figure 4). With such setting, this network can be used to develop synergetic approaches to better constrain microbarom sources and evaluate propagation effects.

\subsubsection{Array configuration and errors}

It is important to take into account uncertainties in azimuth and apparent velocity estimations identified in microbarom studies. The uncertainties of the estimated wave parameters of microseisms can be large due to the relatively small aperture of the seismic arrays. Uncertainties in wave parameter estimates are calculated considering the array geometry of the above mentioned infrasound and seismic arrays following (Szuberla and Olson, 2004) (Table 1).

Table 1. Uncertainties of azimuth and apparent velocity estimates

\begin{tabular}{|l|c|c|c|c|c|c|c|}
\hline Parameter & IS31 & KURIS & MKIAR & ABKAR & KKAR & MKAR & Kurchatov Cross \\
\hline $\begin{array}{l}\text { Horizontal velocity, } \\
\mathrm{m} / \mathrm{s}\end{array}$ & 340 & 340 & 340 & 3000 & 3000 & 3000 & 3000 \\
\hline$\delta \Theta\left(^{\circ}\right)$ & $0.55-0.74$ & $2.05-2.34$ & $0.58-0.67$ & $4.89-5.64$ & $5.14-6.30$ & $4.55-6.84$ & $0.48-0.49$ \\
\hline$\delta \mathrm{V}(\mathrm{m} / \mathrm{s})$ & $3.8-4.4$ & $12-14$ & $3.5-3.9$ & $250-290$ & $270-330$ & $220-380$ & $25-26$ \\
\hline
\end{tabular}

For the infrasound arrays, the horizontal velocity is set to $340 \mathrm{~m} / \mathrm{s}$. For the seismic arrays, the value of $3000 \mathrm{~m} / \mathrm{s}$ is chosen corresponding to the average speed of the Rayleigh wave. The uncertainties for the seismic arrays are significantly higher for the body waves due to higher velocities.

\subsubsection{Power spectral density of the noise at seismic and infrasound arrays}

The aim of the noise spectral content analysis is the comparison of conditions in summer and in winter. One-day long waveform segments are selected for the analysis. The selection criteria are low wind noise well expressed in the infrasound data. The power Spectral Density (PSD) is calculated in adjacent 1-hour windows with $30 \%$ overlap. Figure 9 shows the processing results for the seismic and infrasound arrays. The situations in winter and summer differ from each other in a similar manner at infrasound and seismic arrays. Microbarometric and microseismic peaks are $0.2 \mathrm{~Hz}$ and have larger amplitudes in October. At infrasound arrays, the summer peak is detected at IS31 only. The difference in spectra in both seismic and infrasound stations is expressed more distinctly in October and December than in July. 

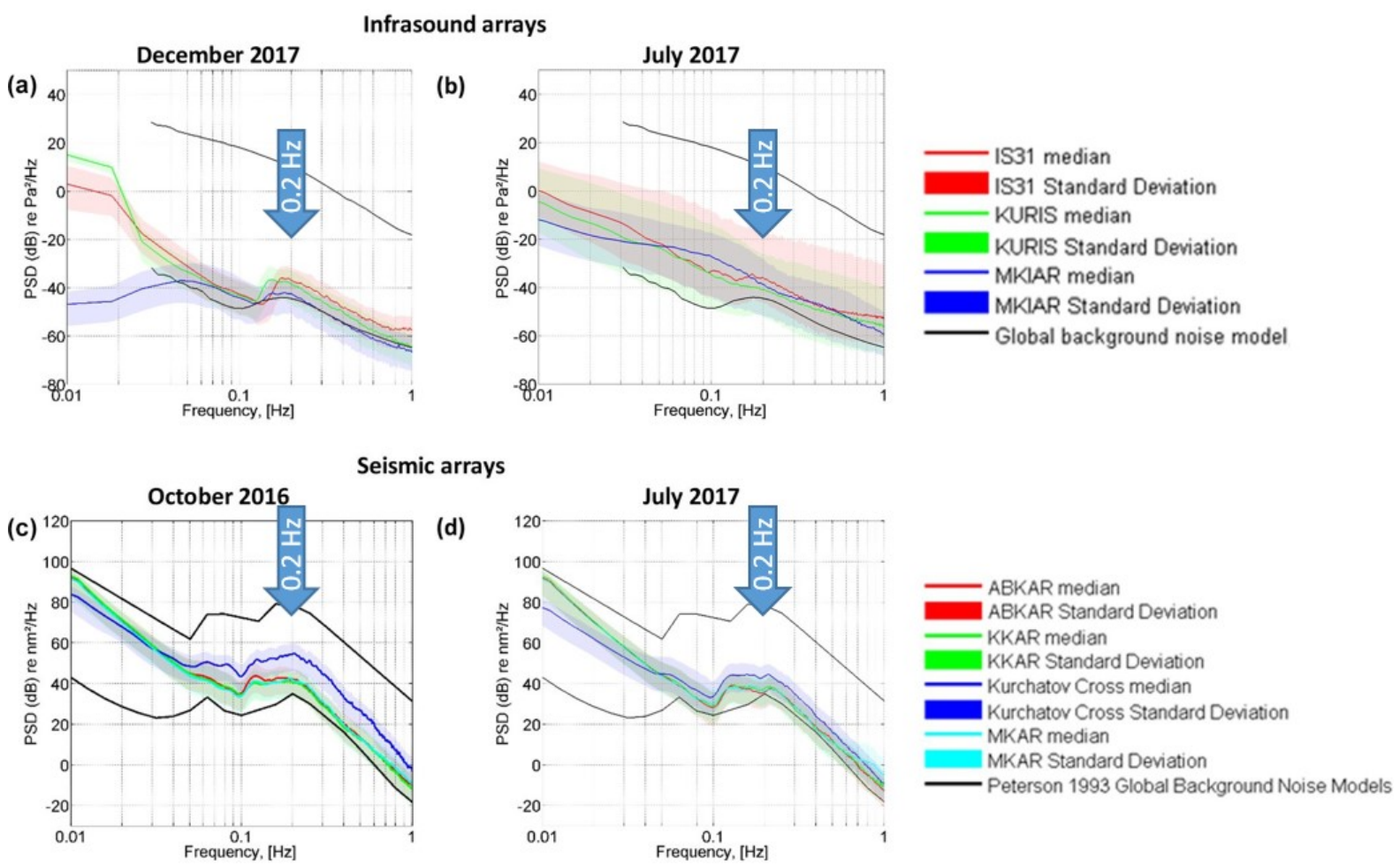

Collocated infrasound and seismic arrays
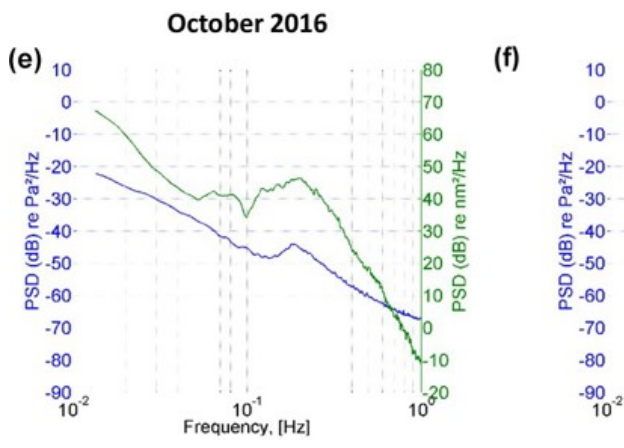

July 2017

Figure 9. One-day long PSD calculated on 1-hour windows for the infrasound arrays of the Kazakh monitoring network. Low-noise one-day long record intervals studied on December, 2017 (a), and July, 2017 (b); for the seismic arrays on October, 2017 (c), and July, 2017 (d). Comparison of noise spectra at collocated KURIS and Kurchatov Cross arrays on October, 2016 (e), and July, 2017 (f)

\subsubsection{Review of existing databases (continuous recordings, detection bulletins, seismicity catalogs)}

\subsubsection{State of the art observations of microbaroms and microseism in Kazakhstan}

Observations of microbaroms and microseism were carried out in Kazakhstan (Smirnov et al., 2018). After the first investigation by Smirnov et al. (2011), the Kazakh infrasound monitoring network increased by two infrasound arrays KURIS and MKIAR. 


\subsubsection{Existing bulletins of detections}

Table 2 presents the data about the existing bulletins of detections and availability of the waveforms for the infrasound and seismic arrays at KNDC.

Table 2. Waveform and bulletin of detections availability.

\begin{tabular}{|c|c|c|c|c|c|c|}
\hline 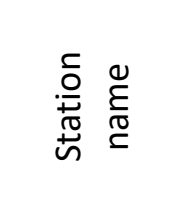 & 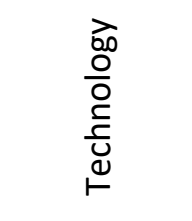 & 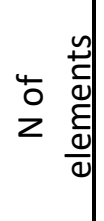 & 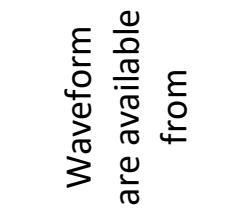 & 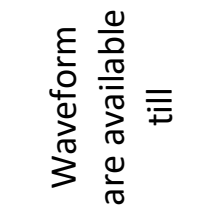 & 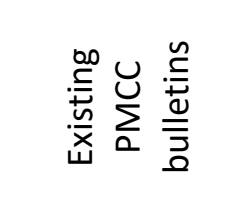 & $\begin{array}{l}\frac{2}{0} \\
\frac{0}{0} \\
\frac{0}{2} \\
\frac{0}{2}\end{array}$ \\
\hline IS31 & Infrasound & 8 & $\begin{array}{c}\text { December } \\
2003\end{array}$ & Present time & $\begin{array}{l}\text { January } 2014 \text { - } \\
\text { present time }\end{array}$ & CEA \\
\hline IS46 & Infrasound & 4 & $\begin{array}{c}\text { November } \\
2006\end{array}$ & Present time & $\begin{array}{c}\text { January } 2014 \text { - } \\
\text { present time }\end{array}$ & CEA \\
\hline $\begin{array}{l}\text { Kurchatov } \\
\text { infrasound }\end{array}$ & Infrasound & 4 & $\begin{array}{c}\text { December } \\
2011\end{array}$ & Present time & $\begin{array}{c}\text { January - } \\
\text { February } 2017\end{array}$ & IGR \\
\hline MKIAR & Infrasound & 9 & August 2016 & Present time & $\begin{array}{c}\text { January - } \\
\text { February } 2017\end{array}$ & IGR \\
\hline ABKAR & Seismic & 9 & $\begin{array}{c}\text { December } \\
2003\end{array}$ & Present time & $\begin{array}{c}\text { January - } \\
\text { February } 2017\end{array}$ & IGR \\
\hline BVAR & Seismic & 9 & February 2003 & Present time & $\begin{array}{c}\text { January - } \\
\text { February } 2017\end{array}$ & IGR \\
\hline KKAR & Seismic & 9 & $\begin{array}{c}\text { December } \\
2001\end{array}$ & Present time & $\begin{array}{c}\text { January - } \\
\text { February } 2017\end{array}$ & IGR \\
\hline MKAR & Seismic & 9 & $\begin{array}{c}\text { September } \\
2000\end{array}$ & Present time & $\begin{array}{c}\text { January - } \\
\text { February } 2017\end{array}$ & IGR \\
\hline $\begin{array}{l}\text { Kurchatov } \\
\text { Cross }\end{array}$ & Seismic & 20 & January 2007 & Present time & $\begin{array}{c}\text { January - } \\
\text { February } 2017\end{array}$ & IGR \\
\hline
\end{tabular}

Actually, the bulletins combine data for a larger time period, but they are not complete and consistent, therefore the table shows IS31 and IS46 bulletins only presented by CEA (for the extended period) and the bulletins specially calculated at IGR for this study.

\subsection{History of the microbarom and microseism observations in Kazakhstan}

Microbarom and microseism observations started in Kazakhstan in the early 2000s with active participation of the author of this work. Since March 2005, a fully automatic signal detector was 
launched for continuous recordings of data from the 8-element I31KZ infrasound array near the city of Aktobe (Aktyubinsk) in Kazakhstan (Smirnov et al., 2011). The detection algorithm is based on the Progressive Multi-Channel Correlation technique (PMCC) (Cansi, 1995).

PMCC detects coherent propagating signals across several sensors of the array, and that are delayed by time-shifts consistent with an acoustic planar wavefront. The coherent wavefront can be either impulsive, or made of transient signals or continual signals of longer duration. PMCC detects and classifies both types of signal efficiently and generates a bulletin of infrasonic signals detected at the array, with the characteristics of each detection described by parameters such as the arrival time, backazimuth, apparent velocity, frequency, and amplitude. Figure 10 shows azimuthal distribution of the signals detected by I31KZ from January 1 to January 31, 2008. Figure 11 shows the azimuthal distribution versus frequency of the detected signals.

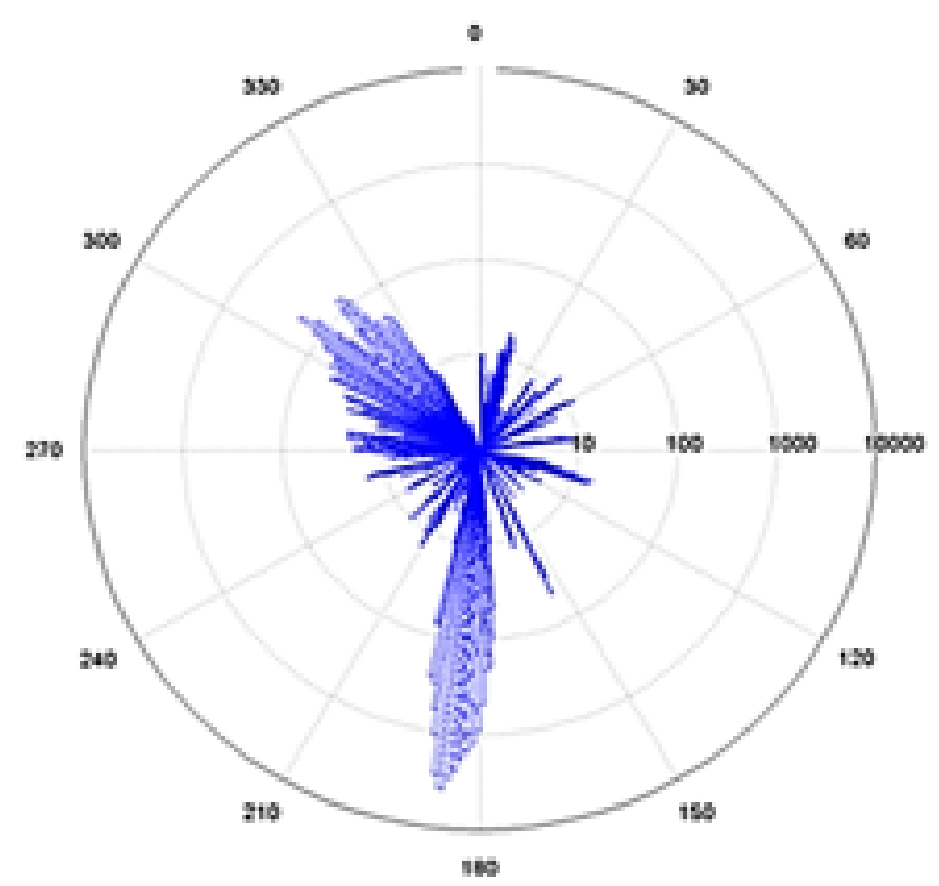

Figure 10. Example of azimuthal distribution of infrasound detections for I31KZ (Aktyubinsk) for January 2008

From Figure 10, it is clear that there are several preferred directions of arrivals, indicating repeating or continual infrasound sources. Two most prominent concentrations of detections are between $180^{\circ}$ and $195^{\circ}$, and between $290^{\circ}$ and $330^{\circ}$. Figure 11 indicates that at $180^{\circ}-195^{\circ}$ back-azimuth range are dominated by signals with high frequencies $(0.5$ to $4 \mathrm{~Hz})$ whereas the signals from $290^{\circ}-30^{\circ}$ are of lower frequency (below $1 \mathrm{~Hz}$ ). A temporary infrasound array installed at Akbulak seismic array, together with satellite images, revealed the source of most of the infrasound detections from the south: gas flares from Zhanazhol gas and oil field (Smirnov, 2007). The back-azimuth estimates 
associated with lower amplitude signals from northwest direction are consistent with microbaroms generated in the North Atlantic Ocean.

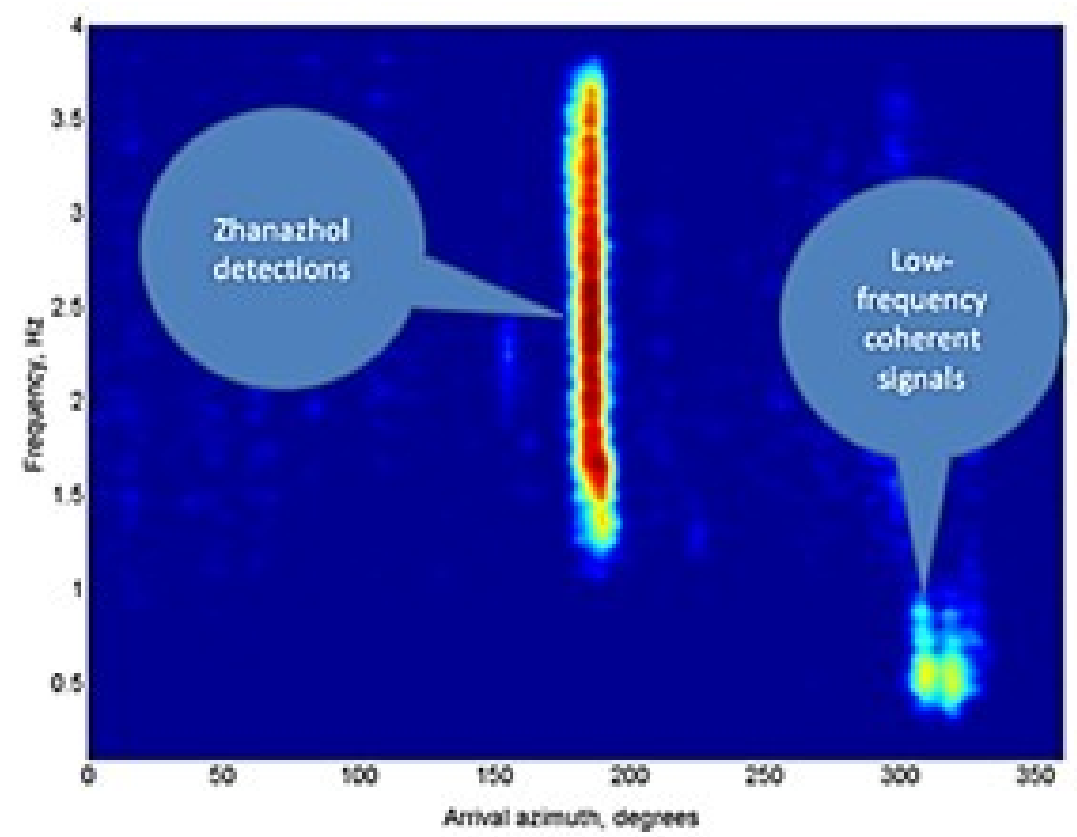

Figure 11. Frequency characteristics of infrasound detections at $131 \mathrm{KZ}$ as a function of backazimuth

\subsubsection{Generation of microseisms and microbaroms}

The following concept was used for source modeling at that stage. Microbaroms were first observed by Benioff and Gutenberg (1939) who noted similarity between the low-frequency signals on an electromagnetic microbarograph and the microseisms typically observed on seismographs. They suggested that the origin of the signals were low pressure systems in the North Pacific Ocean. In 1950, Longuet-Higgins (1950) formulated the basis of modern notions about the generation mechanism for microseisms. He demonstrated that microseisms could be generated by standing waves which resulted from wave groups of approximately the same frequency travelling in opposite directions. (Kedar et al., 2008) first used this theory for modelling seismic microseisms using ocean wave numerical models.

In the area of standing water waves (SWW), pressure changes are generated on the ocean floor which do not attenuate with depth (Longuet-Higgins, 1950; Tabulevich et al., 2001). These pressure changes are manifested in low-frequency seismic signals recorded at distances up to thousands of kilometers and are referred to as storm microseisms. SWW field at the rear side of cyclone (typhoon) is huge, and its area may reach hundreds of square kilometers. There are oscillations similar to piston performing 
reciprocal movements. Moving up "the piston" generates microbaroms, moving down it produces microseisms at the bottom. The oscillations are coherent (co-phased).

The source mechanism theory was proved experimentally at Lamont Doherty Earth Observatory (Tabulevich, 1986). Microseisms from SWW generated by moving cyclones propagate at large distances. Seismic stations all over the world record them. For example, microseism from Atlantic cyclones are recorded not only by European stations but also by Asian stations at Tashkent and Ashkhabad, stations at western part of Kazakhstan (Longuet-Higgins, 1950), Siberian (Irkutsk and Novosibirsk) and others (Tabulevich et al., 2002). Combined analysis of meteorological, seismic and infrasound data was performed to check whether IS31 records microbaroms generated by SWW (Smirnov et al., 2011). Microbaroms and microseisms are generated when SWW have high power.

\subsubsection{Comparison between the observed backazimuths and microseism/microbarom energy distribution}

Having this concept in mind, infrasound and seismic signals origination from the same region at the same time was investigated. The period chosen was July 1 - June 30,2008 . The detector used was PMCC between 0.07 and $0.5 \mathrm{~Hz}$ (Cansi, 1995). Analysis was performed for four Kazakh seismic arrays, namely Akbulak, Borovoe, Karatau and Makanchy, and by infrasound array IS31. Figure 12 shows the detections represented in a $2 \mathrm{D}$ histogram. There are some features in the azimuthal distribution of the signals that are common at all stations but there are also some individual peculiarities.

Results on Akbulak array have a clear trend. The array recorded signals mostly from $300-360^{\circ}$. Similar azimuths are typical for Borovoe array, however, in the summer time, the station records signals arriving from the south. Karatau array behaves in a similar way, and records signals originating in the east. Makanchy array recorded signals arriving from the south over a year except for the period between January and April. Makanchy recorded signals from the north-west from January to April. IS31 infrasound array recorded signal mostly from north-east, similar to Akbulak. There is only a small amount of detections from the south during the summer months. Therefore, all the stations recorded signals from the north-west.

Global maps of the height and period of the ocean waves were used to identify SWW areas of high energy. This was made for each day of the year. These areas of maximum SWW energy should correspond to the source of the detected microseisms and microbaroms. The following is required to get the origin of the SWW generation: calculate the directional spectrum for the ocean waves for each daily map and find the places when there are two systems of waves traveling with opposite direction 
(Willis et al., 2004). To make the process easier, a simpler way was chosen. The regions with the highest ocean wave energy were found using the following estimate of wave energy:

$$
E \sim\left(\frac{A}{T}\right)^{2}
$$

where $A$ is water wave amplitude and $T$ is its period (Evers and Siegmund, 2009). The heights and period of ocean waves from the ECMWF archives (ERA interim) were used. The comparison was carried out for January 2008. The archives provide data on a regular grid with a step of $1.5^{\circ}$. Values at 00 and 12 UTC of each day of January 2008 were used to calculate the ocean wave energy. The values were calculated for each cell of the grid all over the oceans. Figure 13 shows an example of the water wave energy calculation for January 26, 2008.

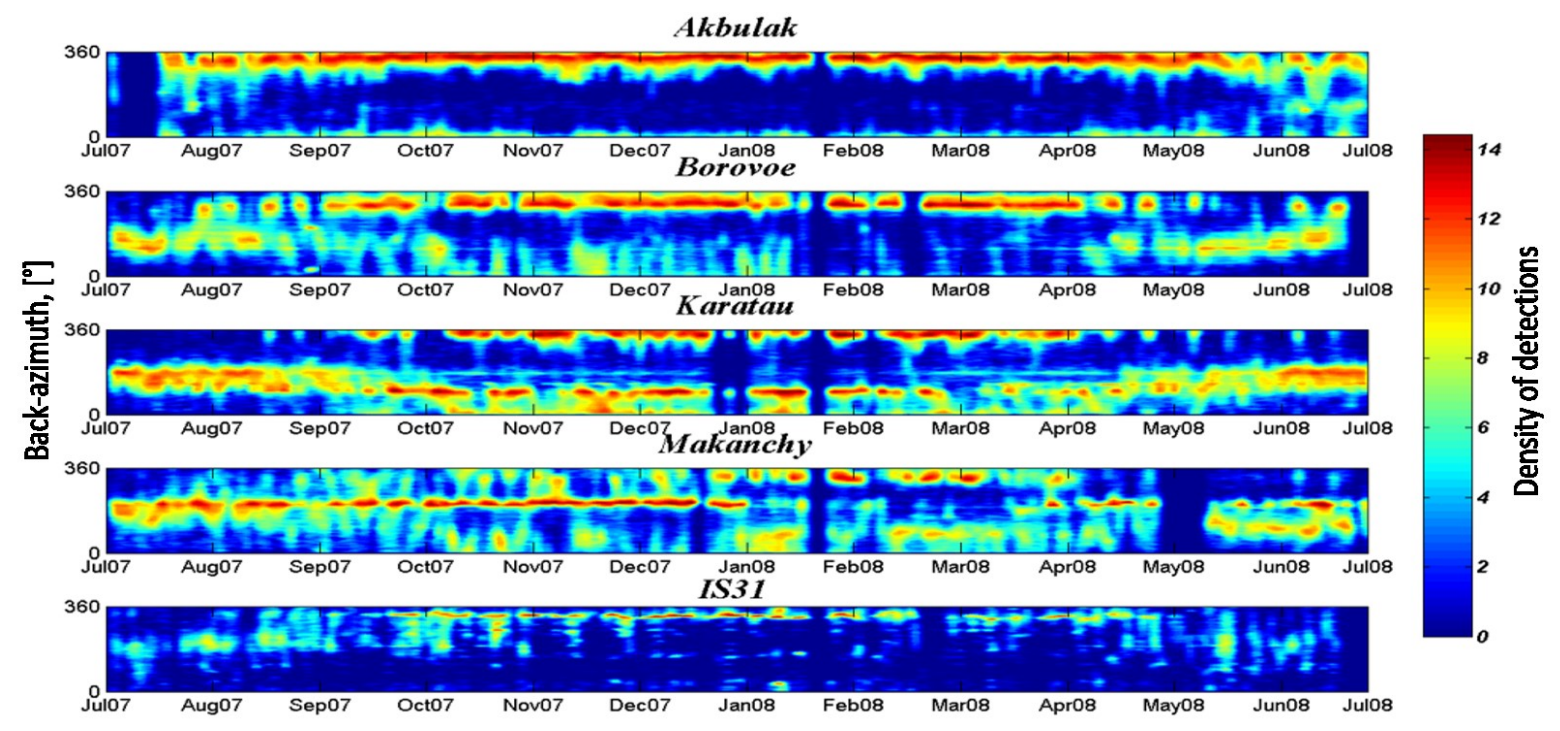

Figure 12. Azimuths of detected signals in the frequency band $0.07-0.5 \mathrm{~Hz}$ from July 1,2007 to June 30, 2008 by Kazakh seismic arrays (upper panels 1 - 4) and infrasound array IS31 (lower panel)

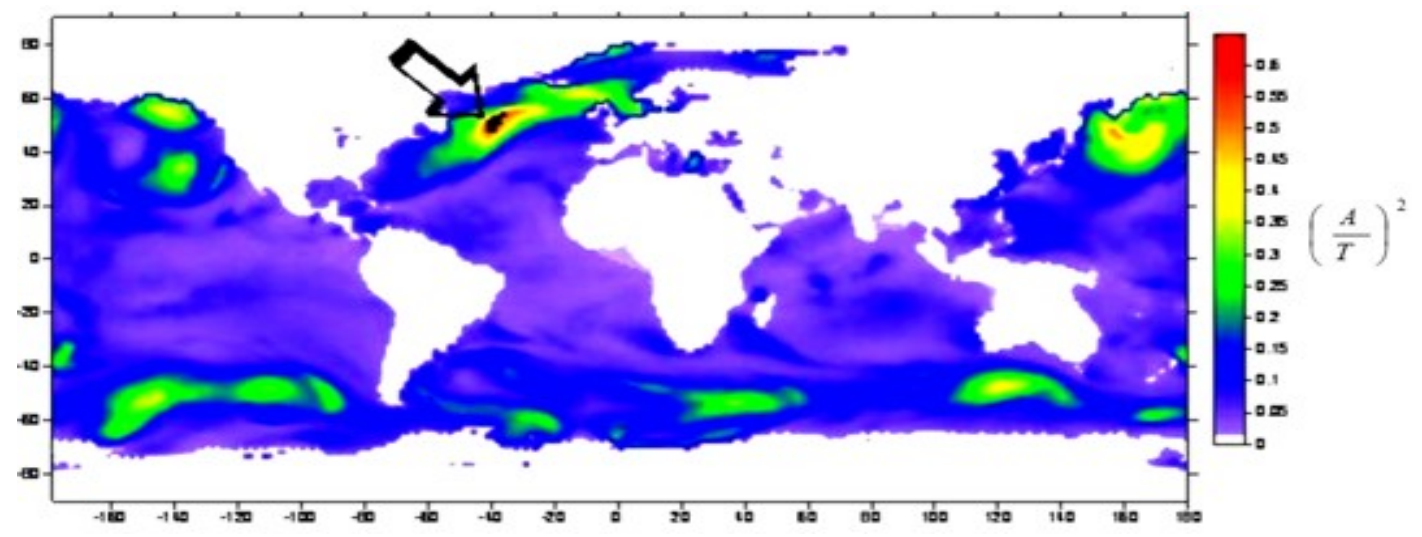

Figure 13. Distribution of the ocean wave energy all over the world calculated by ERA interim (ECMWF) for January 26, 2008. The arrow points to the area of the maximum water wave energy 
Backazimuth of seismic signals were corrected before comparison with the direction from stations to the highest SWW areas. It is known that geological features near a station could distort measured backazimuth and apparent velocity. The bias introduced depends on the back-azimuth and the epicentral distance (Smets et al., 2015; Sinyova, 2005). For the North Atlantic region, corrections were calculated for each station. Five strong earthquakes were selected in the ISC catalog (Website ISC). True azimuths from each seismic array to the event epicenters were found using ISC solutions. Then corresponding azimuths from each array were found using the event records (measured azimuths). The mean differences between the expected and experimental values were used for the corrections needed (Table 3). Table 3 shows that corrections vary from station to station in sign and absolute values. The comparison between the azimuths to the areas of the maximum SWW energy and the corrected azimuths of the detected signals were carried out (Figure 14).
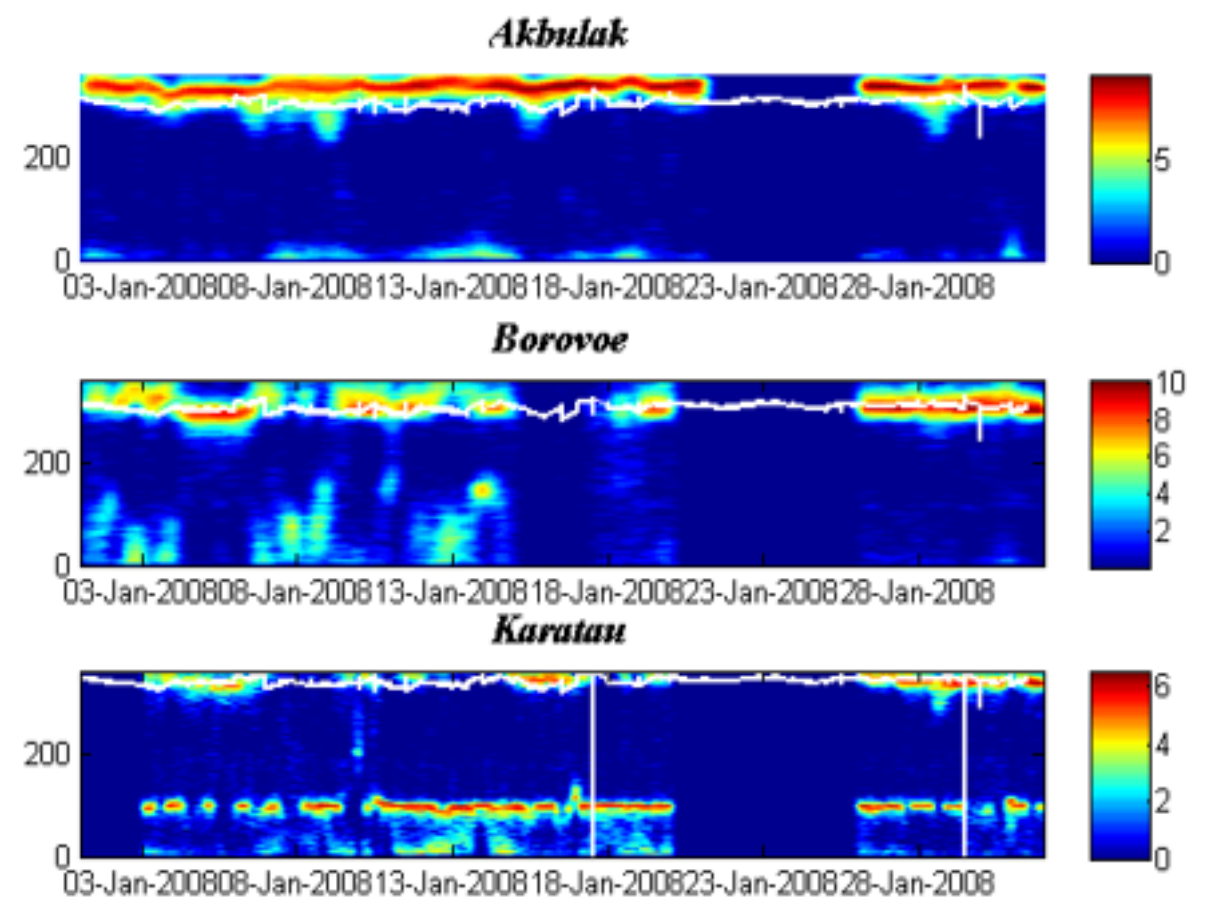

Makanchy

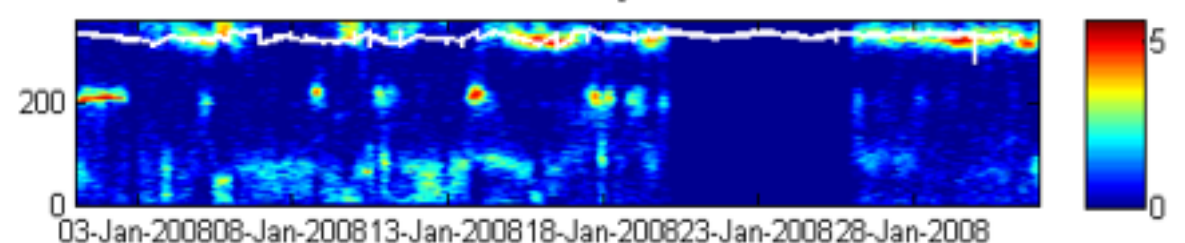

Figure 14. Comparison between signals recorded by seismic arrays in $0.07-0.5 \mathrm{~Hz}$ frequency band on January, 2008 and the direction from the station to the area of the maximum SWW energy (solid white line). Color corresponds to the number of the detections at each elementary cell on the panel 
The detections are represented in a 2D histogram and the azimuths pointing to the maximum SWW areas are shown with solid white lines. Comparison between the measured backazimuths and expected value in accordance with meteorological data shows good match for seismic stations Borovoe, Makanchy and Karatau and for IS31 infrasound array as well (Figure 19). There is a small systematic mismatch for Akbulak seismic array. The result proves that we record microseism/microbaroms from North Atlantic.

Table 3. Earthquakes from the ISC bulletin chosen to estimate azimuthal corrections for the seismic arrays

\begin{tabular}{|c|c|c|c|c|c|c|c|c|c|c|}
\hline \multirow[b]{2}{*}{ 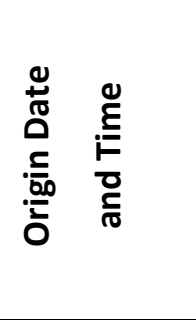 } & \multirow[b]{2}{*}{ 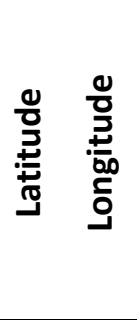 } & \multirow[b]{2}{*}{ 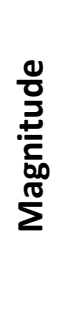 } & \multicolumn{2}{|c|}{ Akbulak } & \multicolumn{2}{|c|}{ Borovoe } & \multicolumn{2}{|c|}{ Karatau } & \multicolumn{2}{|c|}{ Makanchy } \\
\hline & & & 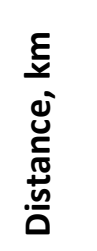 & 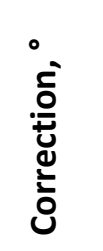 & 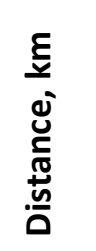 & 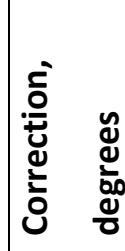 & 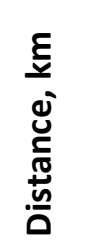 & 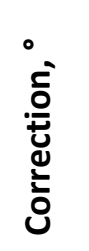 & 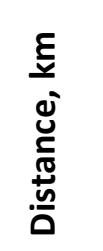 & 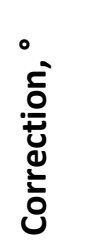 \\
\hline $\begin{array}{c}29.11 .2006 \\
15: 38: 43\end{array}$ & $\begin{array}{l}53.82 \\
-35.41\end{array}$ & 5.3 & 6099 & -6.8 & 6309 & $-5,4$ & 7152 & 15,9 & 7382 & 4,4 \\
\hline $\begin{array}{c}23.05 .2007 \\
4: 41: 47\end{array}$ & $\begin{array}{l}52.37 \\
-31.76\end{array}$ & 5.5 & 6001 & -14.7 & 6254 & $-9,0$ & 7059 & 27,5 & 7337 & 1,6 \\
\hline $\begin{array}{c}06.05 .2008 \\
8: 47: 11\end{array}$ & $\begin{array}{l}53.47 \\
-35.2\end{array}$ & 5.2 & 6112 & -3.9 & 6328 & $-14,2$ & 7166 & 19,3 & 7403 & $-5,9$ \\
\hline $\begin{array}{c}29.05 .2008 \\
15: 45: 57\end{array}$ & $\begin{array}{l}64.02 \\
-21.11\end{array}$ & 6.2 & 4835 & -5.8 & 4964 & $-9,3$ & 5866 & 20,9 & 6021 & 10,8 \\
\hline $\begin{array}{c}21.02 .2009 \\
16: 53: 25\end{array}$ & $\begin{array}{l}55.09 \\
-41.63\end{array}$ & 4.9 & 6325 & -10.7 & 6476 & $-12,8$ & 7366 & 18,8 & 7530 & $-1,4$ \\
\hline $\begin{array}{c}01.01 .2010 \\
9: 37: 10\end{array}$ & $\begin{array}{l}42.39 \\
-30.54\end{array}$ & 5.2 & 6622 & -10.9 & - & - & 7680 & 29,4 & 8098 & 7,3 \\
\hline rerage corr & deg & & & & & 9.3 & & & & \\
\hline
\end{tabular}

However, it may not be correct to select the azimuth of areas with the maximum of SWW energy as the expected direction of microbaroms/microseisms. The source may not be unique as some area with smaller SWW energy may be closer to the station and therefore signals can originate from this region with higher amplitude. Another microbarom/microseism backazimuth prediction way was suggested. It is possible to associate single maximum energy to several places and select the ones with the highest predicted amplitude at the station. Doing so, it is possible to estimate the possibility to get microbarom/microseism prediction for all possible directions. The simulation was made for four Kazakh seismic arrays and for the infrasound array IS31. Figure 15 shows the results obtained for 
Akbulak seismic array. The right panel shows the predicted microseism arrivals, left plot shows observations. For each elementary cell of the ocean wave, we have calculated:

1. The azimuth from Akbulak station.

2. The energy of oceanic wave.

3. The fraction of ocean wave energy propagating to Akbulak station.

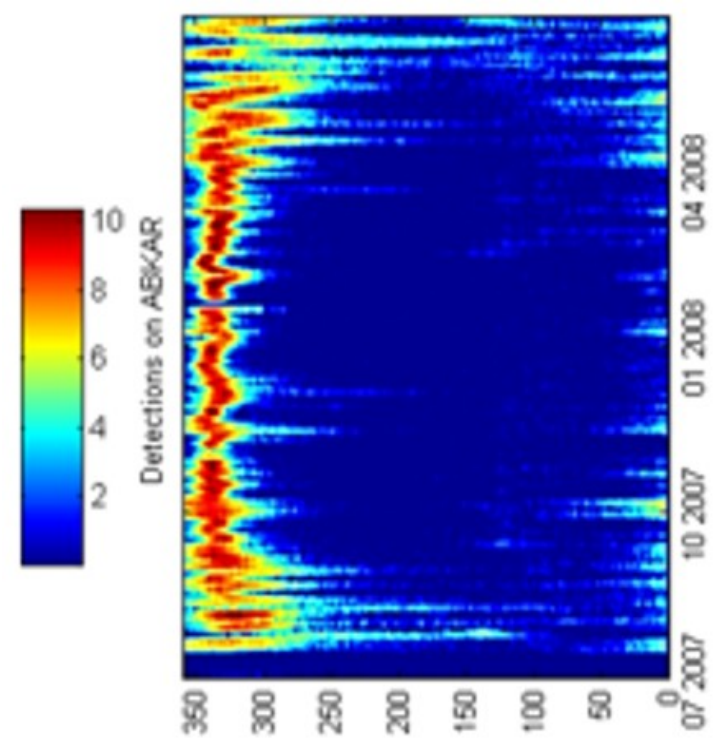

Azimuth, $\left[^{\circ}\right]$

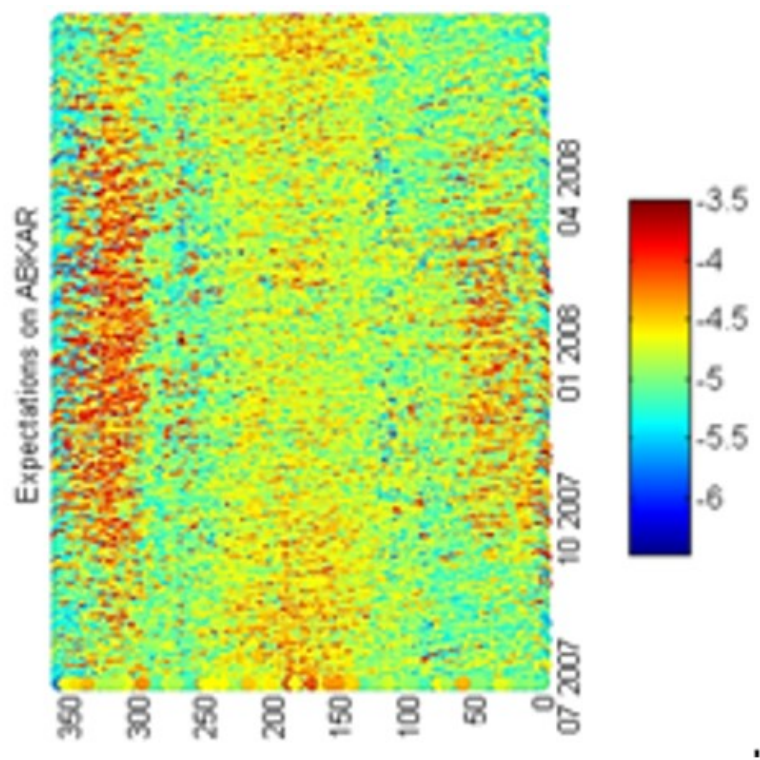

Azimuth, $\left[^{\circ}\right]$

Figure 15. Left: Signals detected at Akbulak seismic array. Detection density is shown in color. Right: Expected backazimuth of microseism arrival are from ECMWF ocean wave height/period. The color of the point in the right panel shows the maximum ratio of the ocean wave energy to the epicentral distance in a given direction. The ratio is growing from blue (small ratio) to red (large ratio)

For each direction to the station, the maximum predicted energy was chosen. The left panel represents the azimuth from Akbulak array to each elementary cell throughout the year. Color of the point in the right panel shows the maximum ratio of the ocean wave energy to the epicentral distance in a given direction. The ratio is increasing from blue to red. Figure 16, Figure 17 and Figure 18 show similar results for Borovoe, Karatau and Makanchy correspondingly. The result for IS31 is shown in Figure 19.

Figure 15, Figure 16, Figure 17 and Figure 18 and Figure 19 show that microbarom and microseism predictions match well with the observations. The coincidence is good for Akbulak, Borovoe, IS31 and Karatau. It is true for North Atlantic microbaroms/microseisms. There are no detections of North Pacific microbarom/microseism. There are two cases where observations do not match with 
predictions. These are detections in the waveforms at Karatau and Makanchy. However, these signals have relatively high frequency and low apparent velocity as seen from Figure 20 for Makanchy in October 2007. That suggests that there is some additional regional source of unknown nature southward of Makanchy.

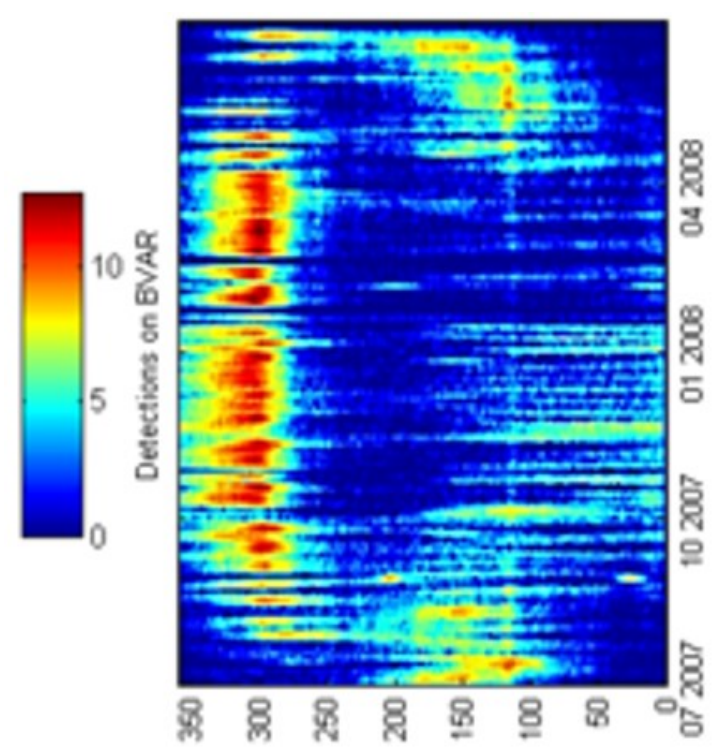

Azimuth, $\left[^{\circ}\right]$

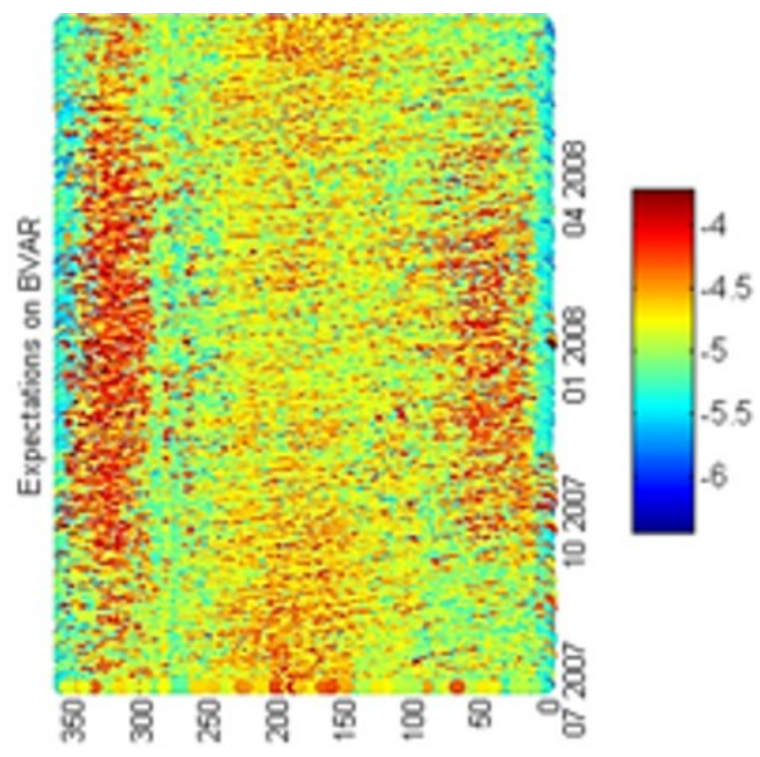

Azimuth, $\left[{ }^{\circ}\right]$

Figure 16. Signals detected at Borovoe seismic array and predicted microseism arrival

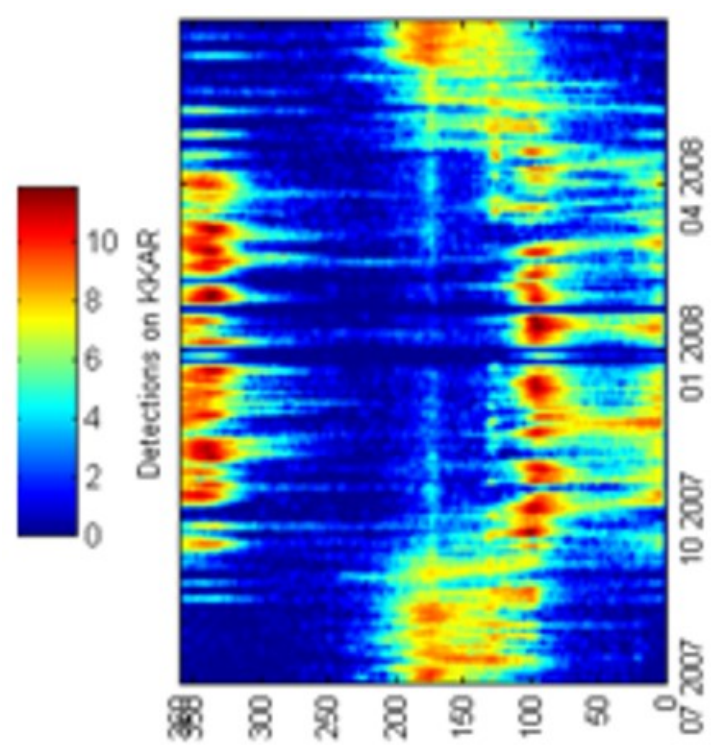

Azimuth, $\left[^{\circ}\right]$

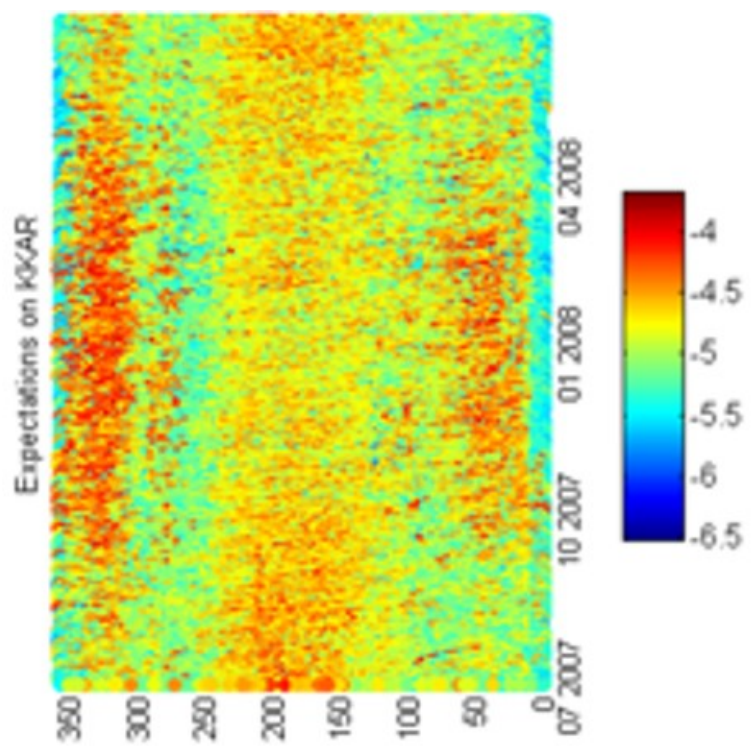

Azimuth, $\left[^{\circ}\right]$

Figure 17. Signals detected at Karatau seismic array and predicted microseism arrival 


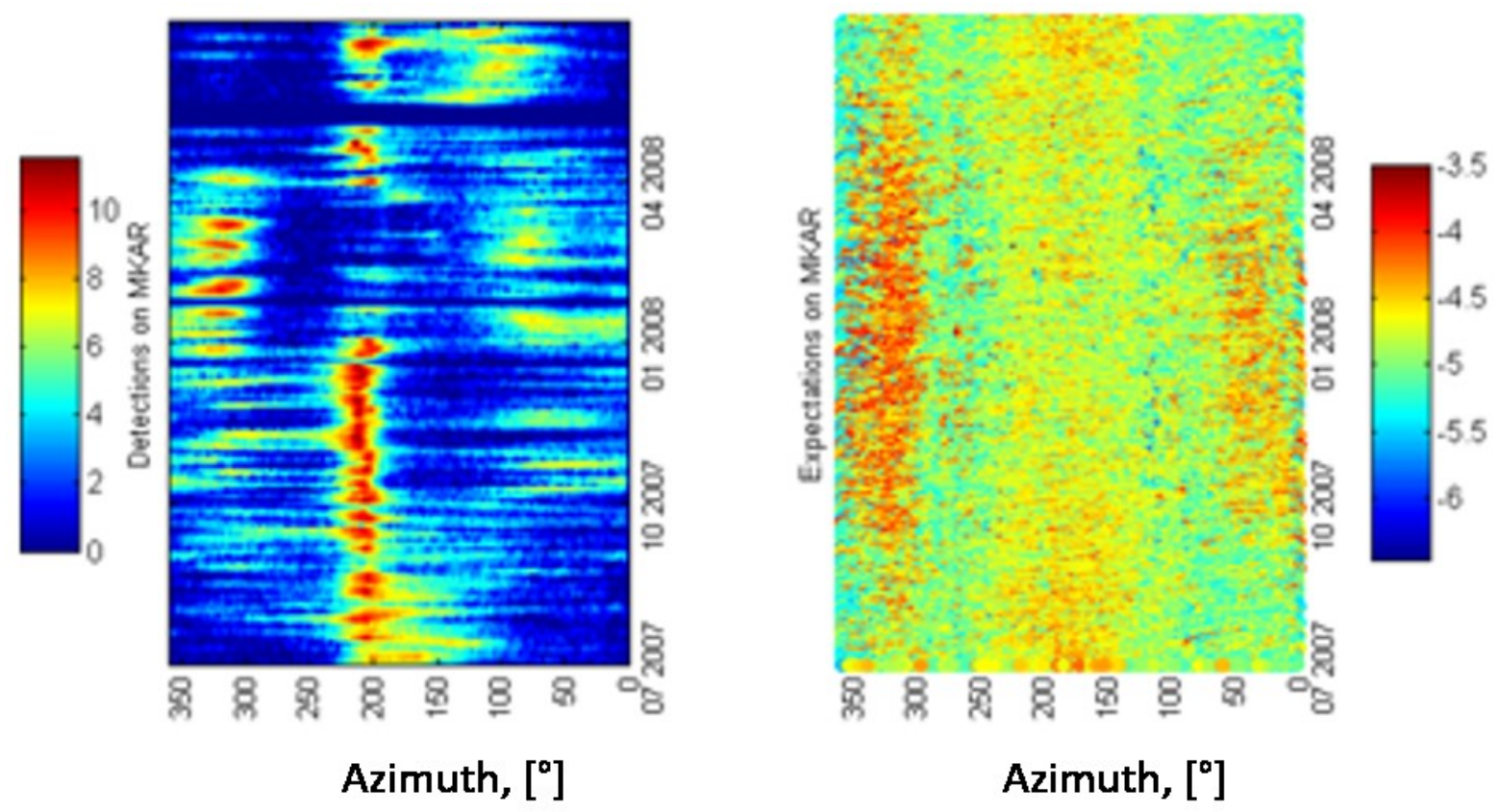

Figure 18. Signals detected at Makanchy seismic array and predicted microseism arrival

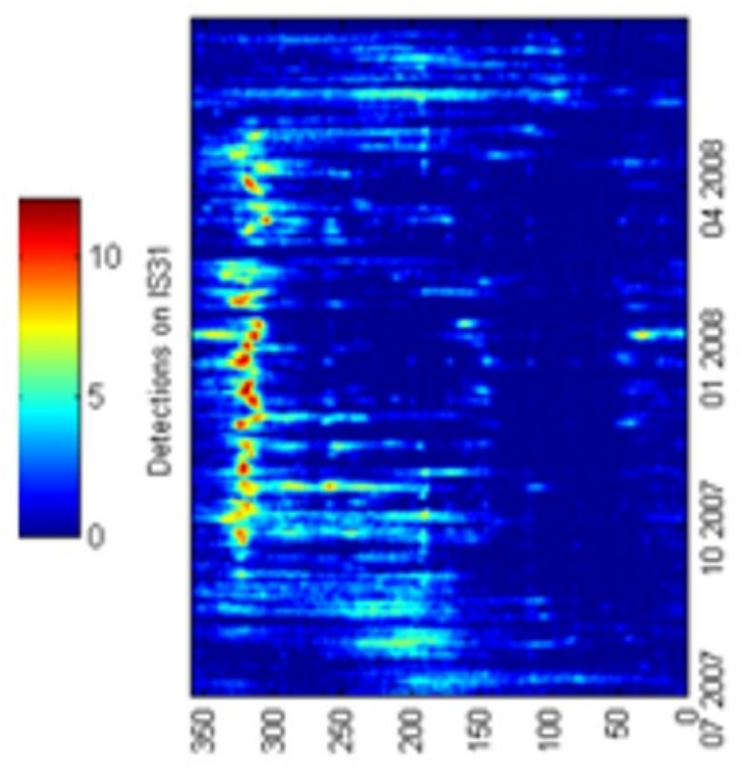

Azimuth, $\left[{ }^{\circ}\right]$

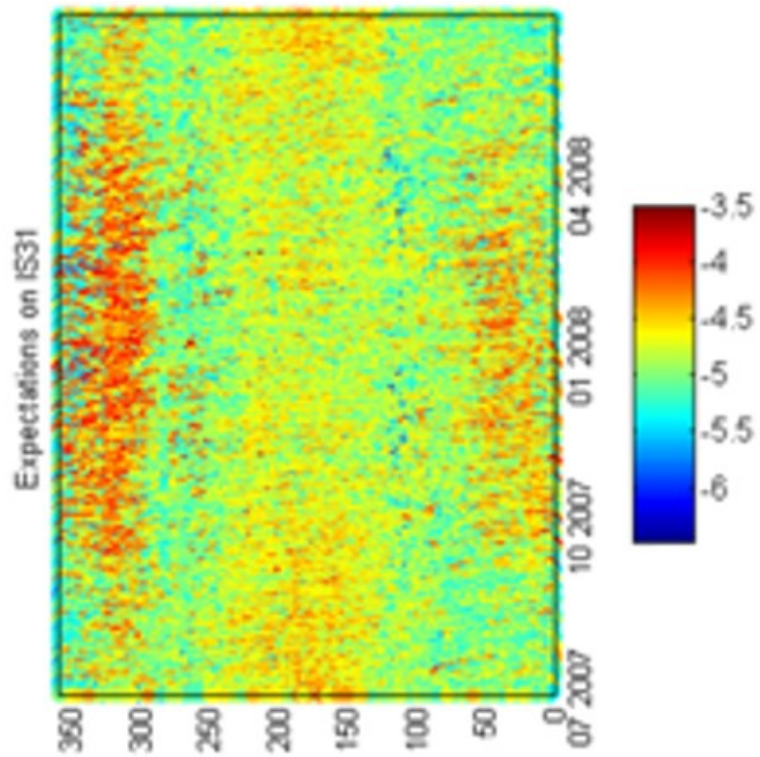

Azimuth, $\left[{ }^{\circ}\right]$

Figure 19. Microbarom signals detected at IS31 infrasound array and predictions 

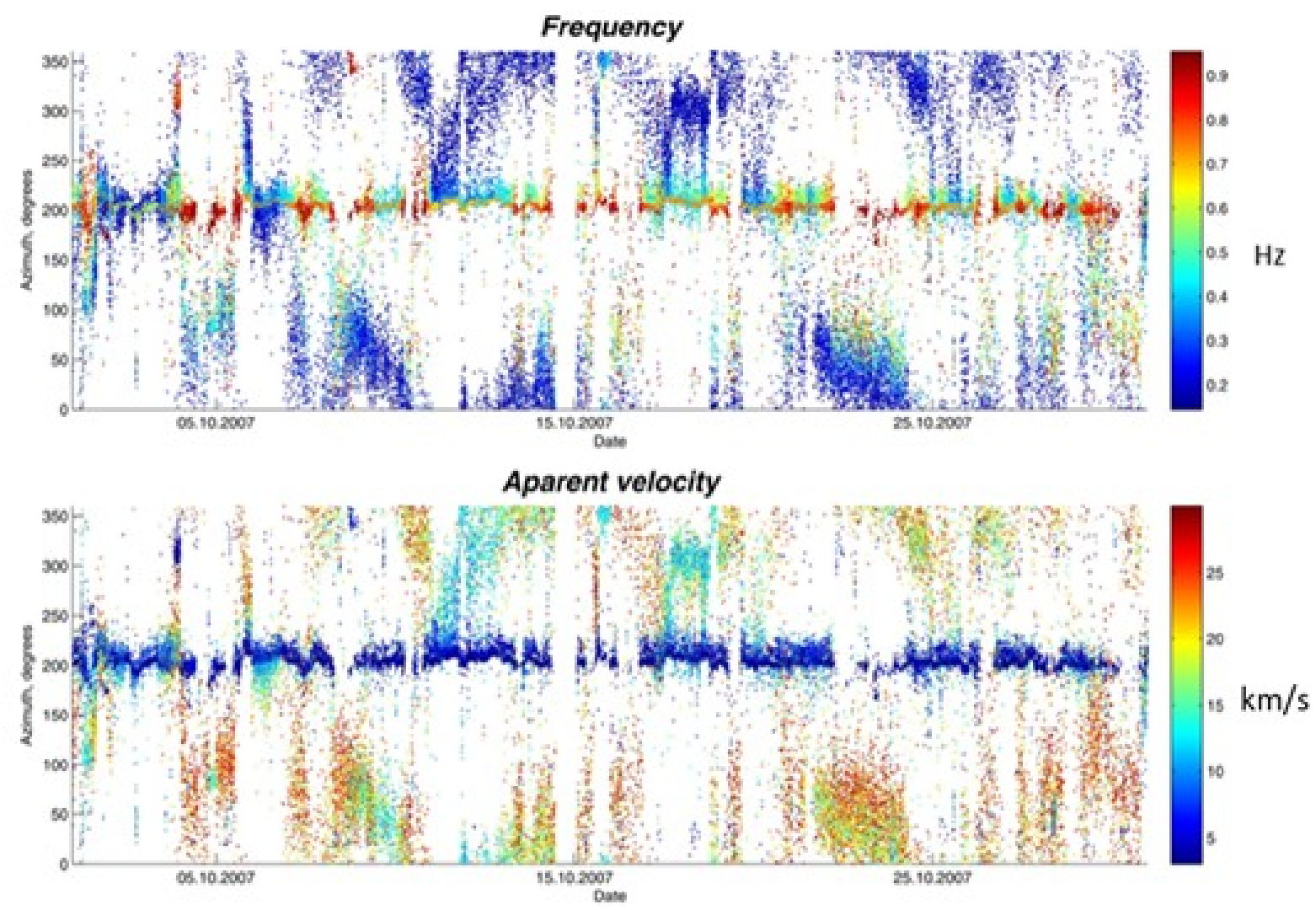

Figure 20. Parameters of PMCC detections made by MKAR in October 2007. Upper panel: azimuth versus time. Color indicates the frequency of the detected signals. Lower panel: azimuth versus time with color indicating the apparent velocity

\subsubsection{Ocean noise recorded at European arrays}

As far as it is suspected that Kazakh arrays record microseisms/microbaroms from North Atlantic we expect the following. European arrays are much closer to the North Atlantic region therefore, they must record microseisms from this region (Figure 21). One month of data (January 2008) of six European arrays was processed using PMCC. Microseisms were predicted with the same technique as was used for Kazakh stations. Figure 22, Figure 23, Figure 24, Figure 25, Figure 26 and Figure 27 show comparison between observations and predictions. There is an overall good agreement for the arrays FINES, ESDC, ARCES and BURAR whereas discrepancies can be noted for NORSAR and EKA. 


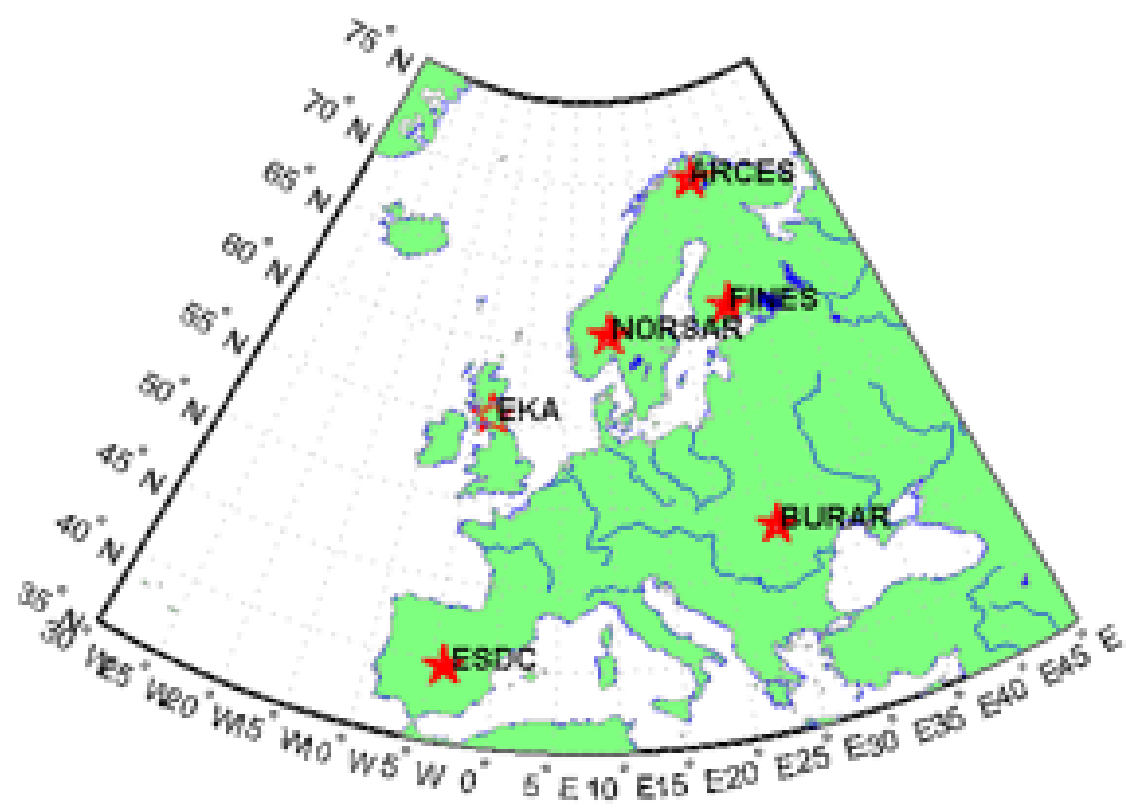

Figure 21. European seismic arrays used to extract microseisms

Detections NORSAR

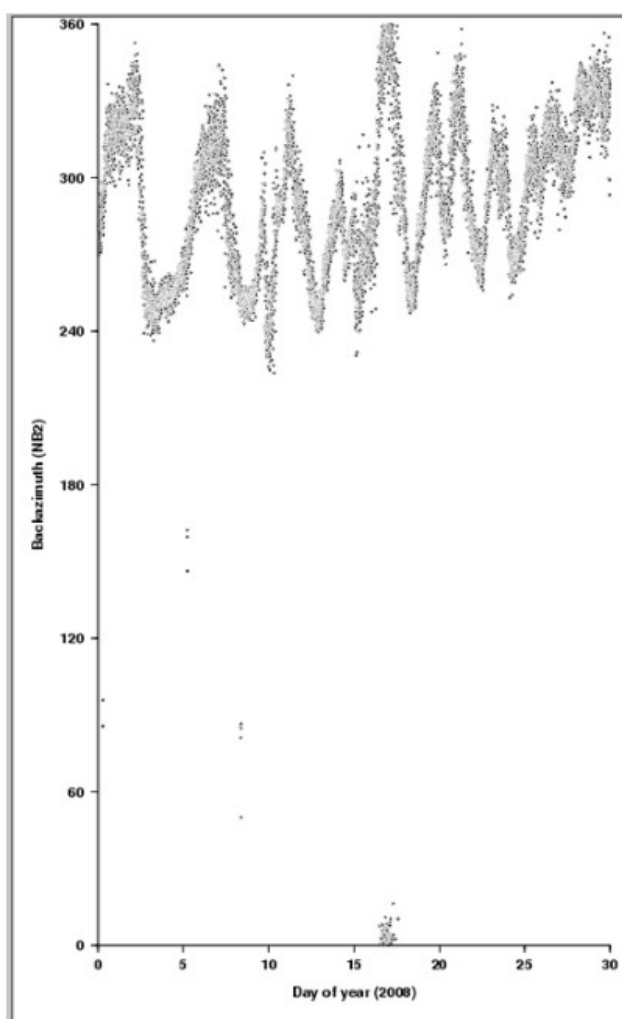

Prediction at NORSAR

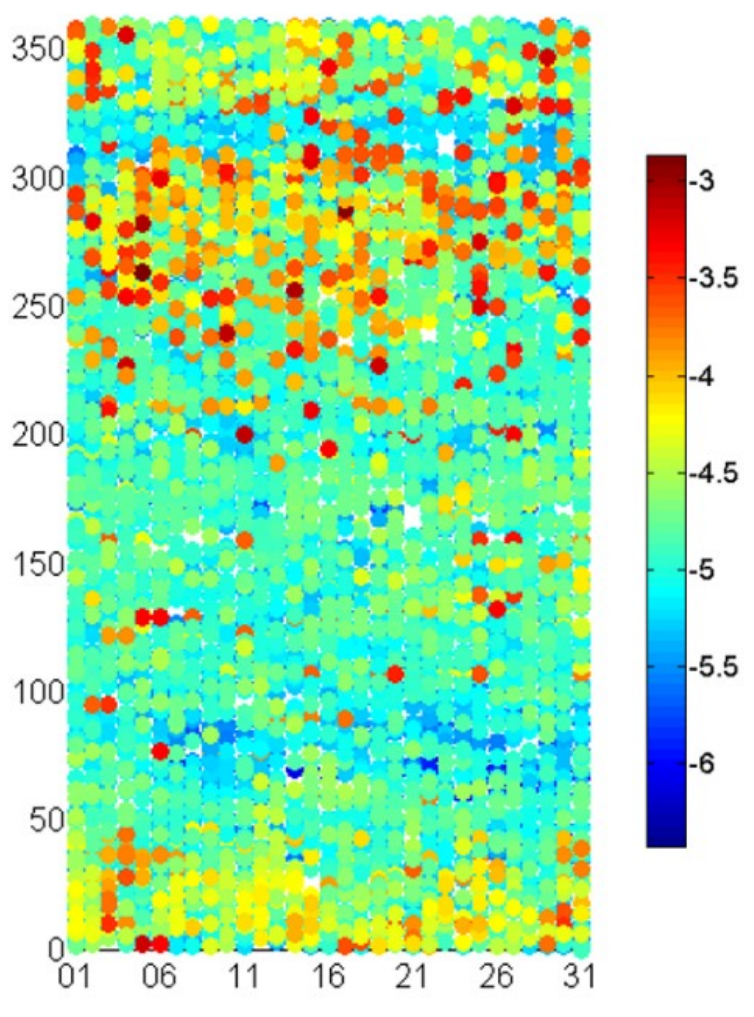

Figure 22. Comparison between microseism detections (left) and predictions (right) for NORSAR. Color of the point in the right panel shows the maximum ratio of the ocean wave energy to the epicentral distance in a given direction. The ratio is growing from blue (small ratio) to red (large ratio) (Here and below) 


\section{Detections EKA}

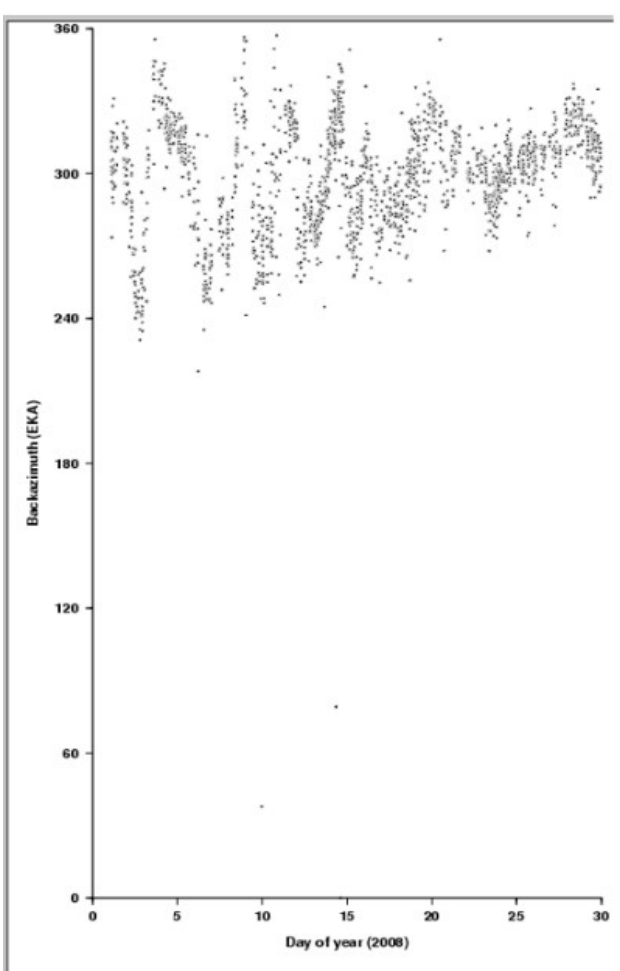

Prediction at EKA

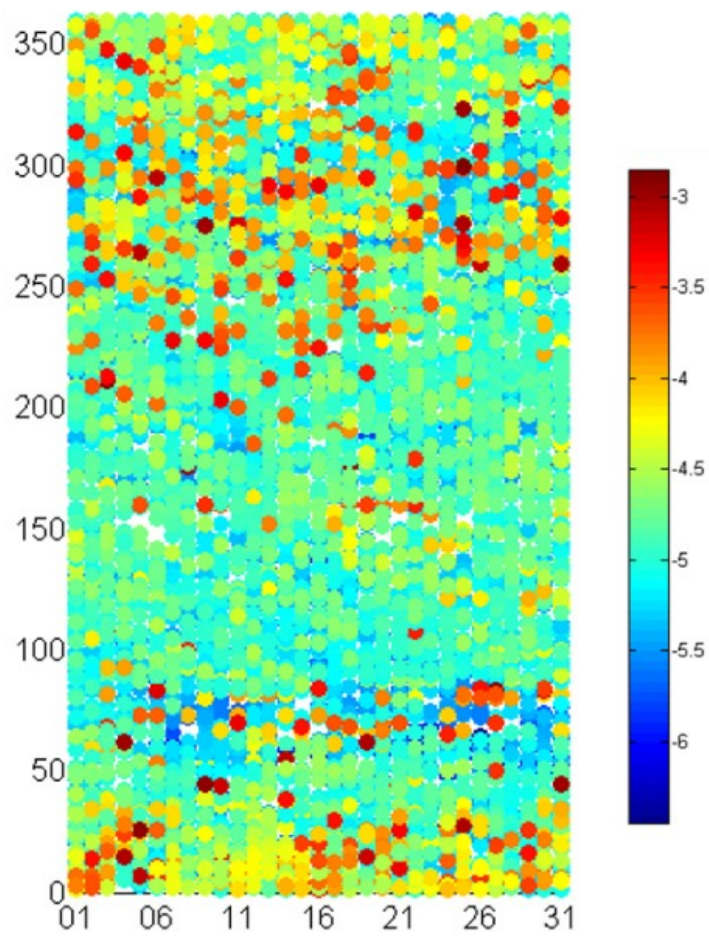

Figure 23. Comparison between microseism detections (left) and predictions (right) for EKA

Detections FINES

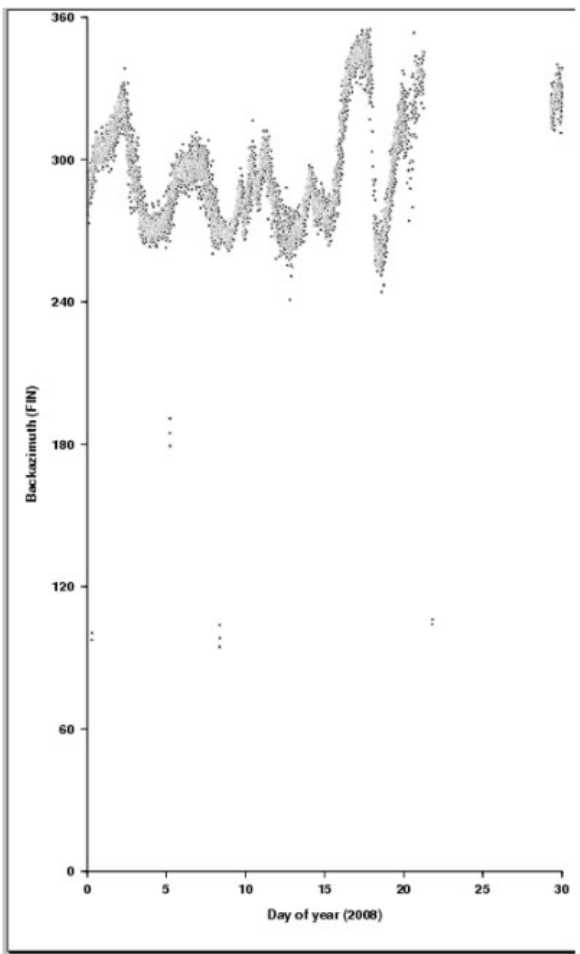

Prediction at FINES

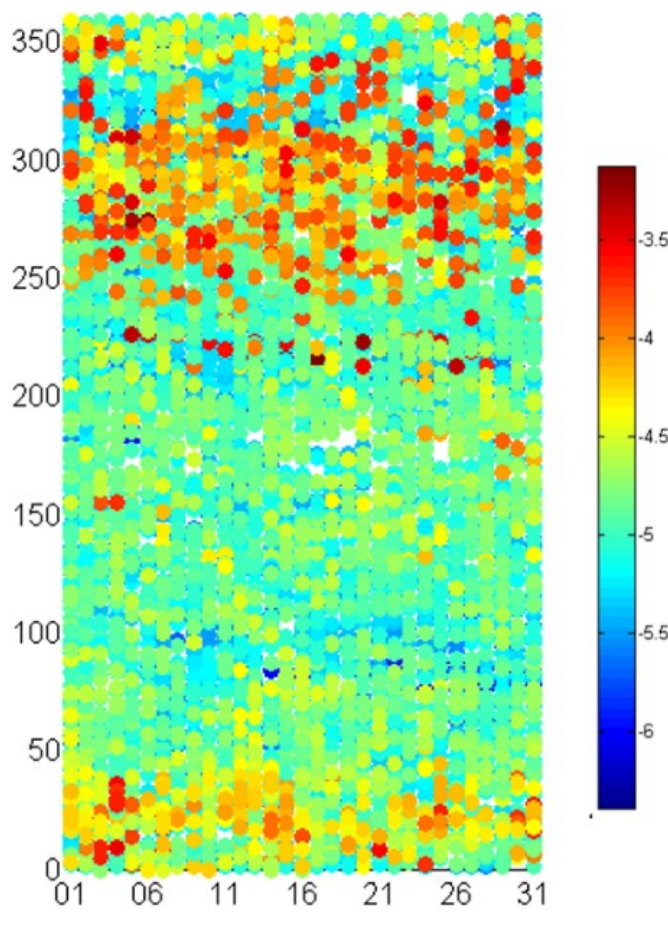

Figure 24. Comparison between microseism detections (left) and predictions (right) for FINES 
Detections ESDC

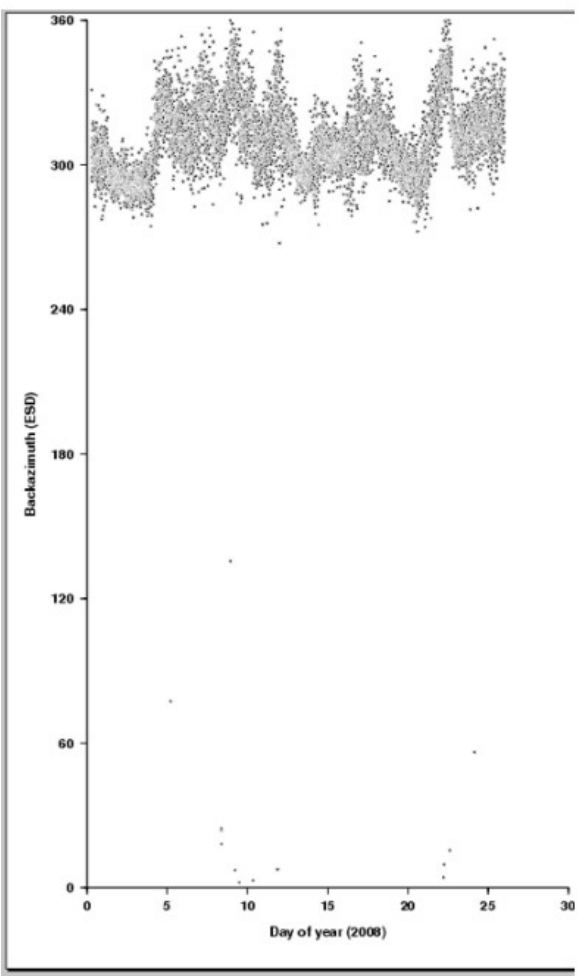

Prediction at ESDC

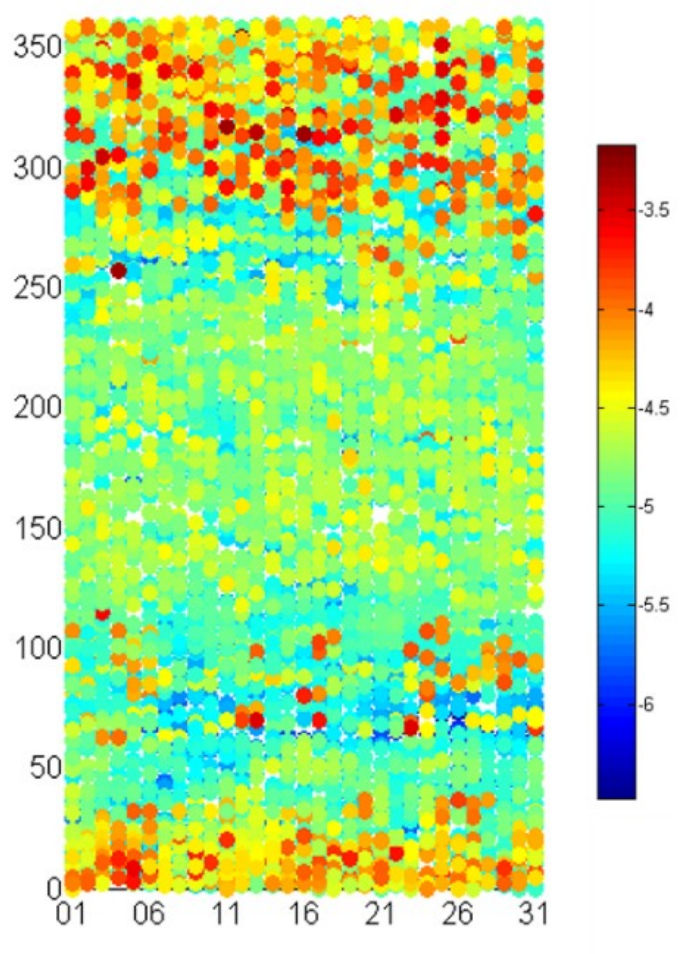

Figure 25. Comparison between microseism detections (left) and predictions (right) for ESDC

Detections ARCES

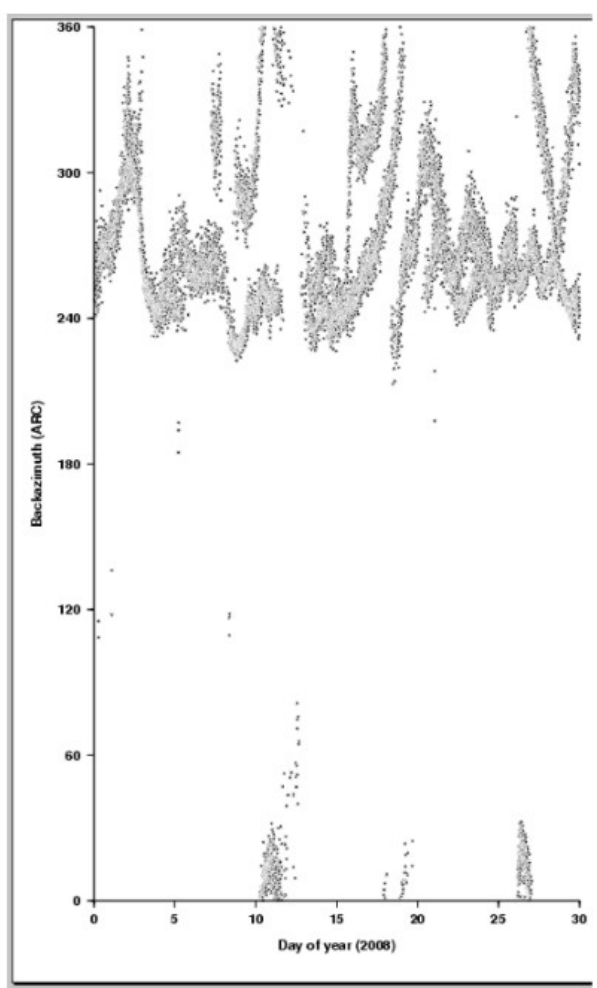

Prediction at ARCES

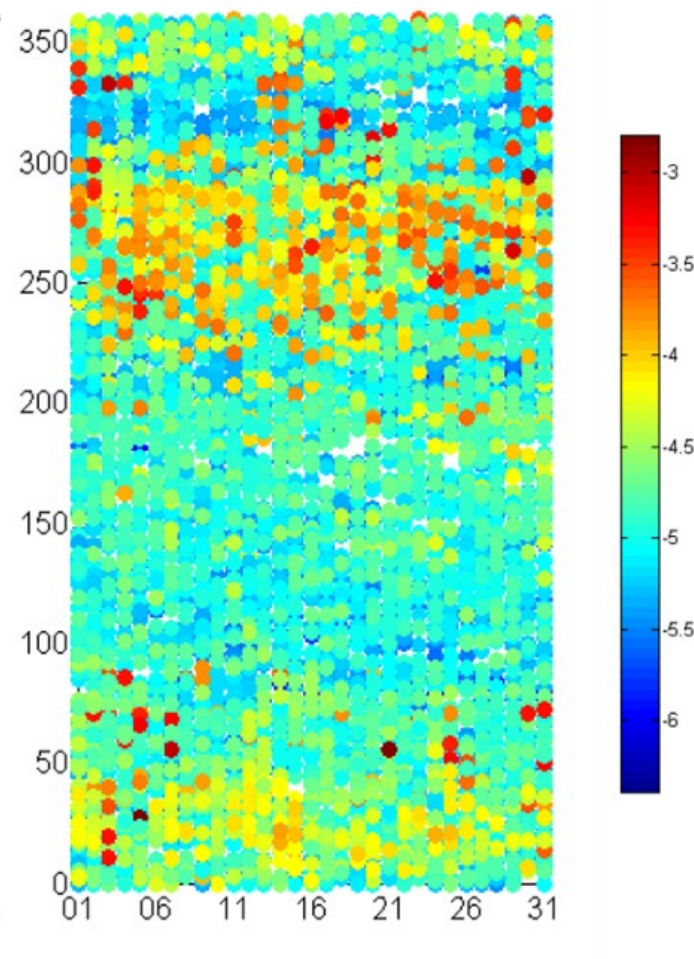

Figure 26. Comparison between microseism detections (left) and predictions (right) for ARCES 
Detections BURAR

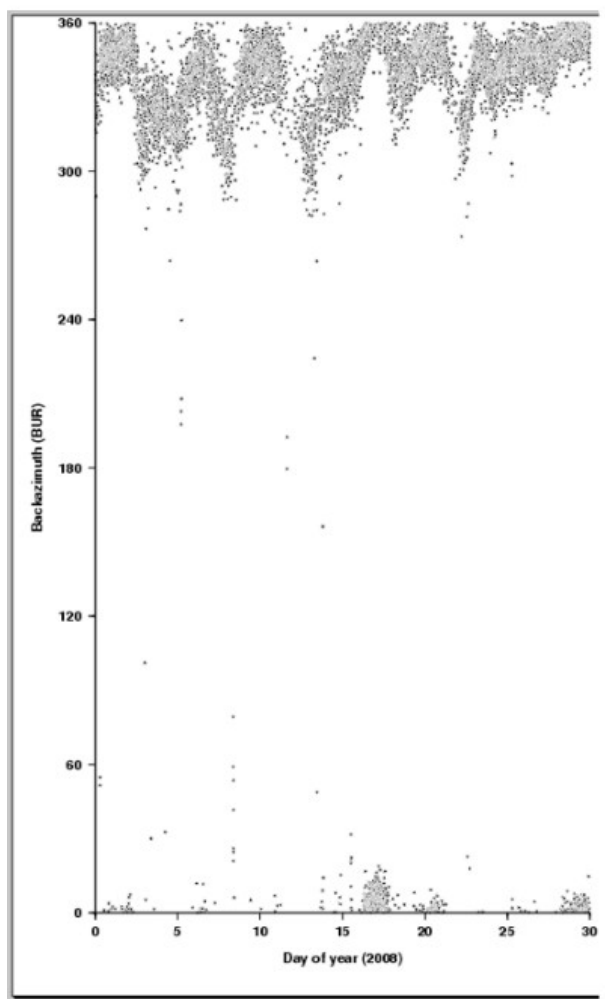

Prediction at BURAR

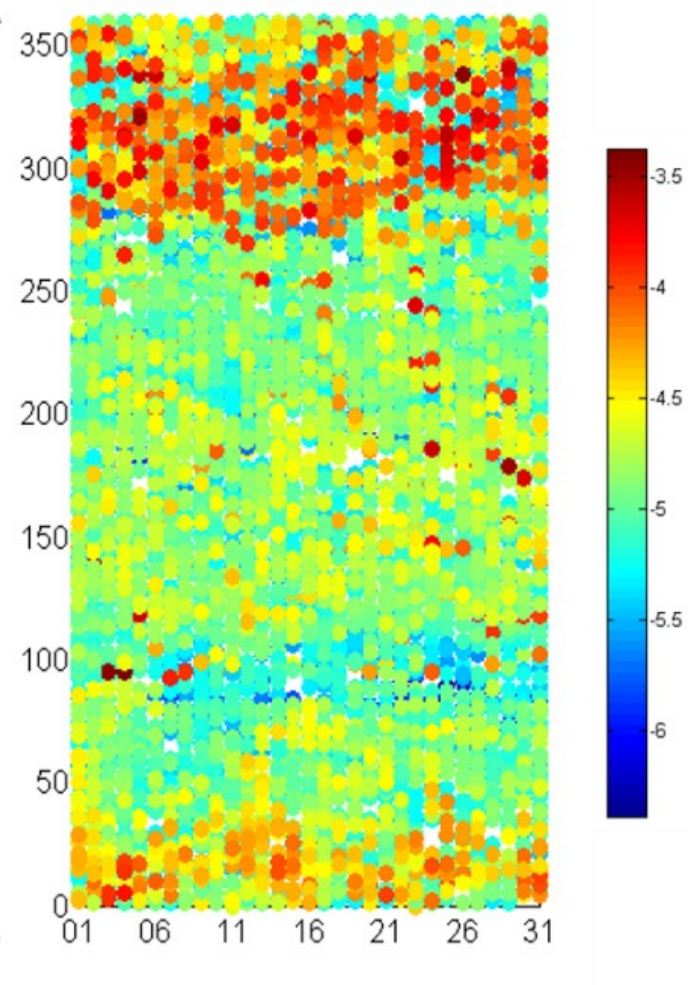

Figure 27. Comparison between microseism detections (left) and predictions (right) for BURAR

\subsection{Assessment of processing methods, propagation of seismic and infrasound waves}

The data processing part of the study consisted of finding the signal parameters from the oceanic storms as recorded in Kazakhstan. Figure 28 shows a processing flowchart, which includes all the procedures applied. The flowchart has two main branches: observations and model. Detection schemes for infrasound and seismic data are similar. The PMCC detector (Cansi, 1995) was used, the only difference in the configuration for different techniques is explained by different apparent velocity and, in turn, the wavelength.

Different approaches were used for the simulation of microseisms and microbaroms. The calculation of the Initial approximation was similar for both techniques.

The numerical wave model WAVEWATCH3 (Ardhuin et al., 2011; Hasselmann, 1963) was also used in the study. For modeling the seismic sources, the bathymetry effect influence has been taken into account (Stutzmann et al., 2012), but the effect does not influence the microbarom source. The attenuation estimation differs depending on the wave types. Geometrical spreading and seismic attenuation for Rayleigh waves were accounted for predicting microseisms (Stutzmann et al., 2012). 
For microbaroms, the acoustic attenuation strongly depends on the propagation directions and the season, therefore the European Center for Medium-range Weather Forecast (ECMWF) 1D atmosphere profiles were used for the effect compensation (Le Pichon et al., 2012).

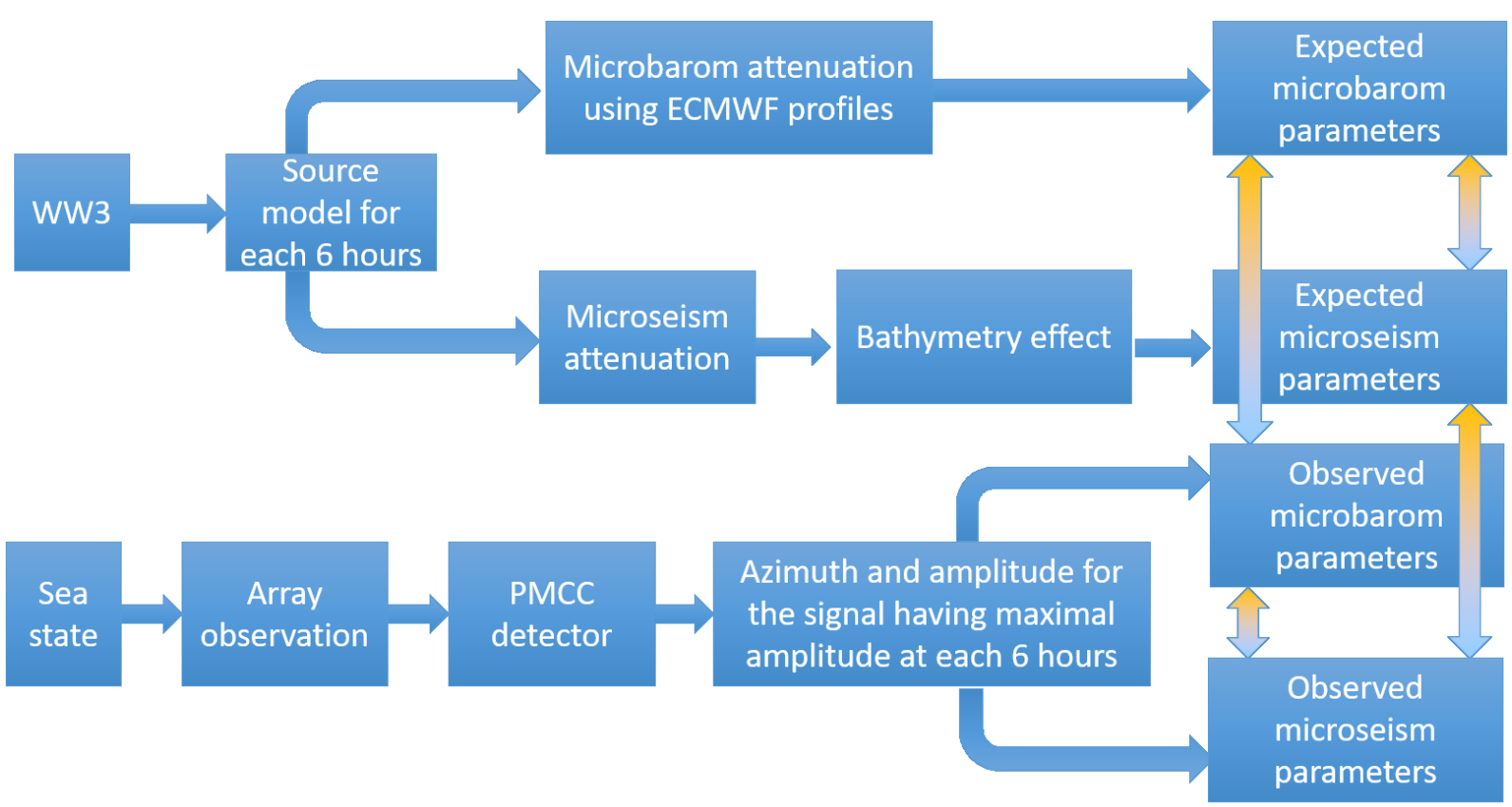

Figure 28. The main processing flowchart 


\subsubsection{Signal detection: the PMCC method}

As mentioned above (Olson and Szuberla, 2005), microseisms, microbaroms are not the impulsive signals but quasi-monochromatic sequences of permanent waves (Figure 29). Therefore, customdesigned detectors shall be used to process these groups of signals. PMCC is such a detector, it is often used for detecting infrasound signals.

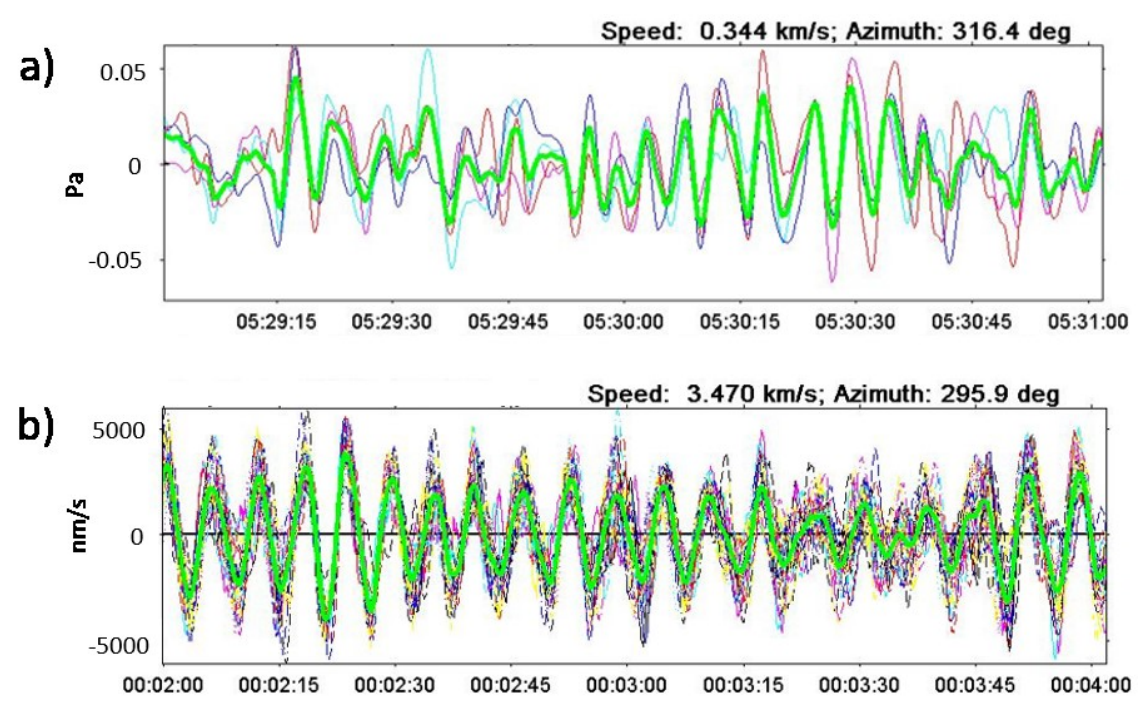

Figure 29. Microbaroms and microseisms registered by Kurchatov infrasound array (panel a) and Kurchatov Cross seismic array (panel b) correspondingly

The operating principle of the PMCC detector is described in Le Pichon and Cansi (2003). In contrast to a set of isolated sensors, a dense array, which aperture is of the order of the wavelengths of the signals of interest, allows similarity measurements of the recordings to avoid uncertainties encountered with individual arrival-time picking. The similarity of the signals can be used to compute arrival time differences and then calculate the propagation parameters with a Husebye's derived method (Cansi and Pichon, 2008).

The conventional method for estimating wave parameters is a systematic search in a specific domain of wave vector using the signals recorded on the sensors. For every discrete wave vector of this regularly discretized domain, the time delay at every sensor is calculated and the delayed signals are summed. When the signals are mainly composed of random background noise, the energy variation of the sum is small over the entire wave vector field. In contrast, the energy is much larger with a wave vector corresponding to the signal wavenumber.

Several methods were proposed to find the wave vector which produces the maximum energy (Capon, 1969). This is not a trivial problem because data are discrete in the space domain. This implies that for each frequency, false results can be obtained due to correlated signals over one or more periods 
(aliasing effect). The PMCC method uses a more flexible approach, less constraining with respect to the propagation model. It is based on conventional signal processing techniques to detect coherent signal on two or more records, partly by relaxing the planar wave model rigidity.

Originally designed for seismic arrays, PMCC proved also to be efficient for analyzing low-amplitude infrasonic coherent waves within non-coherent noise (Cansi, 1995; Cansi and Klinger, 1997). A temporal signal can be represented by its Fourier transform. The background noise is characterized by a rapid variation in both amplitude and phase from one sensor to another, even if they are closer than one wavelength of signal. On the opposite, in case of signal propagating between the sensors, no deformation exists between the two signals. In the case of a planar wave, the only difference is a delay depending on the relative positions of the sensors. Based on these two observations, a signalprocessing tool can be used to detect a signal present on the recordings. The correlation function is used to measure the time delay between two recordings. In case of a wave propagating without distortion, this delay is the same for all frequencies of the signals. This measurement is made in the time domain. Taking into account all frequencies, it measures in a given time window the similarity of the signals shifted in time. The maximum of the correlation function gives the time delay between the signals.

This method enables a decision to be made on whether there is a signal in a set of simultaneous records, independently of any information on previous records. To avoid ambiguity problems when correlating the records from sensors too far apart, the analysis is initialized on the smallest groups of three sensors. The correlation function is used to calculate the propagation time of the wave between sensors $i$ and $j$. For each subnetwork $(i, j, k)$, the sum of time delays $\Delta t_{i j}+\Delta t_{j k}+\Delta t_{k i}$ is computed. In case of a planar wave across the array, the closure relation $\Delta t_{i j}+\Delta t_{j k}+\Delta t_{k i}=0$ should be obtained. In the presence of background noise, the phase is unstable. Therefore, the delays measured in this case are the result of random phase combinations. These delays, independent of the amplitude of each elementary wave, become random, and the closure relation given above is no longer valid. The consistency of the set of delays obtained using all the sensors is then defined as a mean quadratic residual of the closure relations. If this consistency is below a given threshold, a detection is obtained. To minimize errors in the calculation of the wave parameters, distant sensors are progressively added using a criterion based on a comparison between their distance to the subnetwork and the computed wavelength.

This progressive use of distant sensors has two main effects: the removal of false detections which could be due to correlated noise at the scale of the starting subarrays, and a better estimation of the wave parameters by increasing the array aperture. After being initialized with a small subnetwork of 
three sensors, in order to avoid ambiguity problems inherent in the correlation of signals from distant sensors, the wave parameters calculated on the initial subnetworks is used when adding other sensors Figure 30 presents an example of selected subnetworks at the I26DE station.

For that, a propagation of a planar wavefront is assumed. The new measured time delay is given by the maximum of the correlation function, which is the closest to the one that has been estimated. Each elementary detection is therefore defined by several parameters such as the consistency value, the number of sensors participating to the detection, the frequency, the horizontal trace velocity and the backazimuth.

As long as the closure relation is valid, the use of sensors increasingly further apart gives more precise wave parameters since the aperture of the network increases with each new sensor. The final solution is given by the biggest subnetwork.

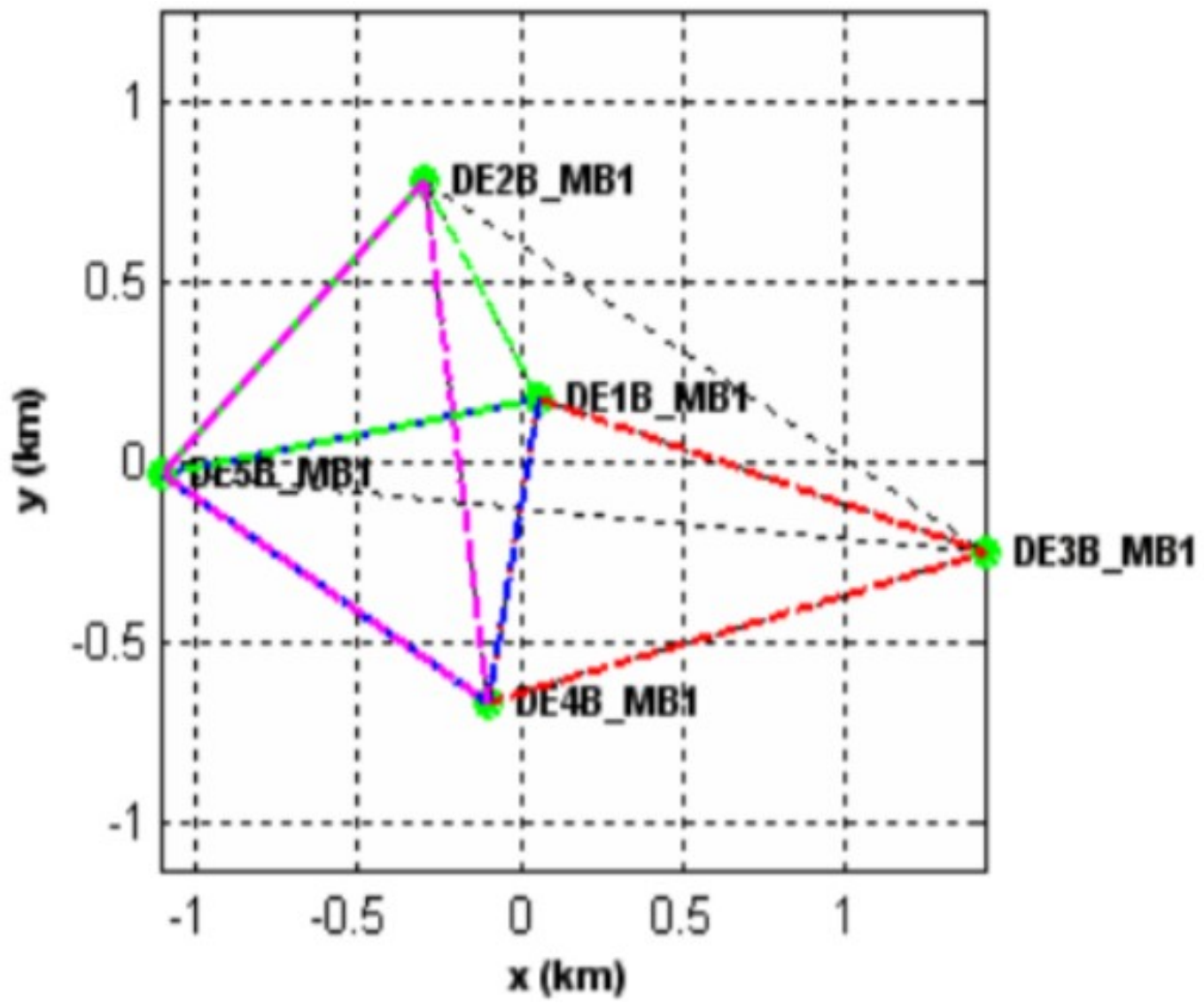

Figure 30. Selection of 4 initial subnetworks of the IMS I26DE infrasound station

To avoid wrong results due to the lack of data in the recordings, an automatic procedure checks the data quality. If the initial subnetworks contain sensors with consecutive zeros in the recordings, this procedure looks for other set of three sensors belonging to the array. Among all possible combinations calculated from the remaining sensors, the best subnetworks are selected. The principle is to sort 
them according to symmetry and size criteria. Equilateral triangle of small aperture is the best configuration. The maximum number of new eligible subnetworks corresponds to the number of subnetworks defined in the configuration file.

The processing is performed consecutively in several frequency bands and in adjacent time windows covering the whole period of analysis. Detections are further classified and outliers removed. A set of several elementary detections in the time-frequency domain is considered to represent one detected wave (corresponding for example to different frequency bands or adjacent windows). Conversely, several waves with different parameters may coexist in the same time window but in different frequency bands. Each wave must be identified separately. To do this, a nearest-neighbor search of elementary detections in the time / frequency / azimuth / velocity domain is used (pixels presented in Figure $31 \mathrm{~A}$ ). The final detection is thus an aggregate of close enough points in this domain. Finally, a weighted Euclidian distance is used to connect close-enough points (Figure $31 \mathrm{~B}$, the final detection is outlined by the red lines. Individual pixels which not connected to this family are removed).
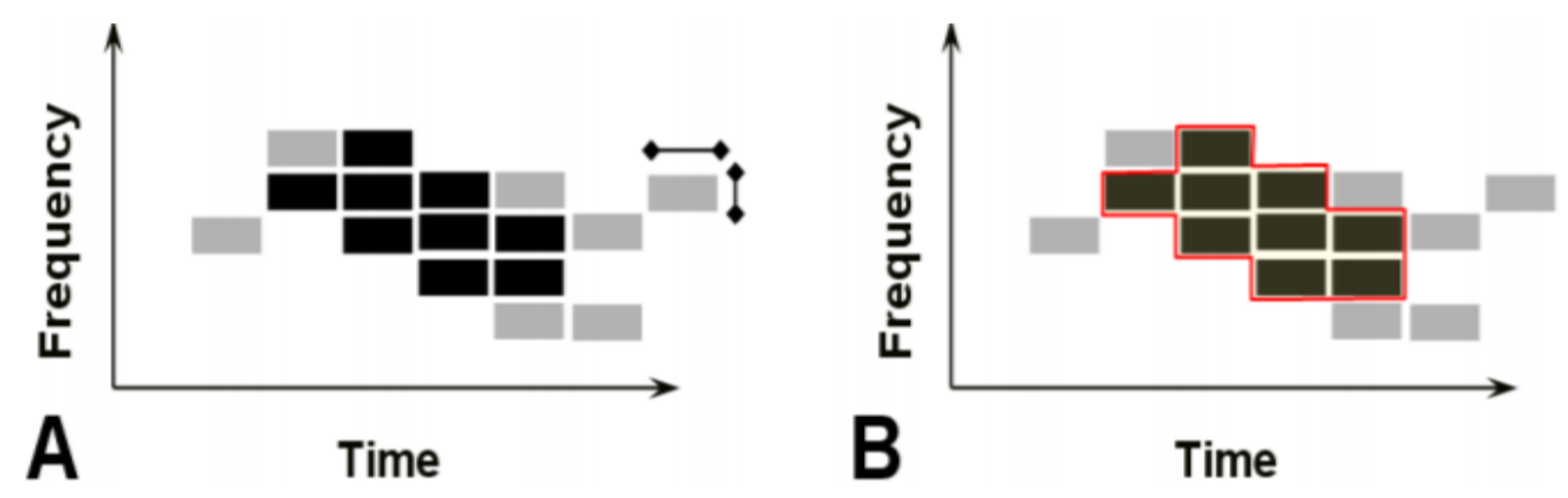

Figure 31. PMCC post processing: connection of close-enough pixels into a family

Figure 32 presents a schematic view of the PMCC flowchart. 


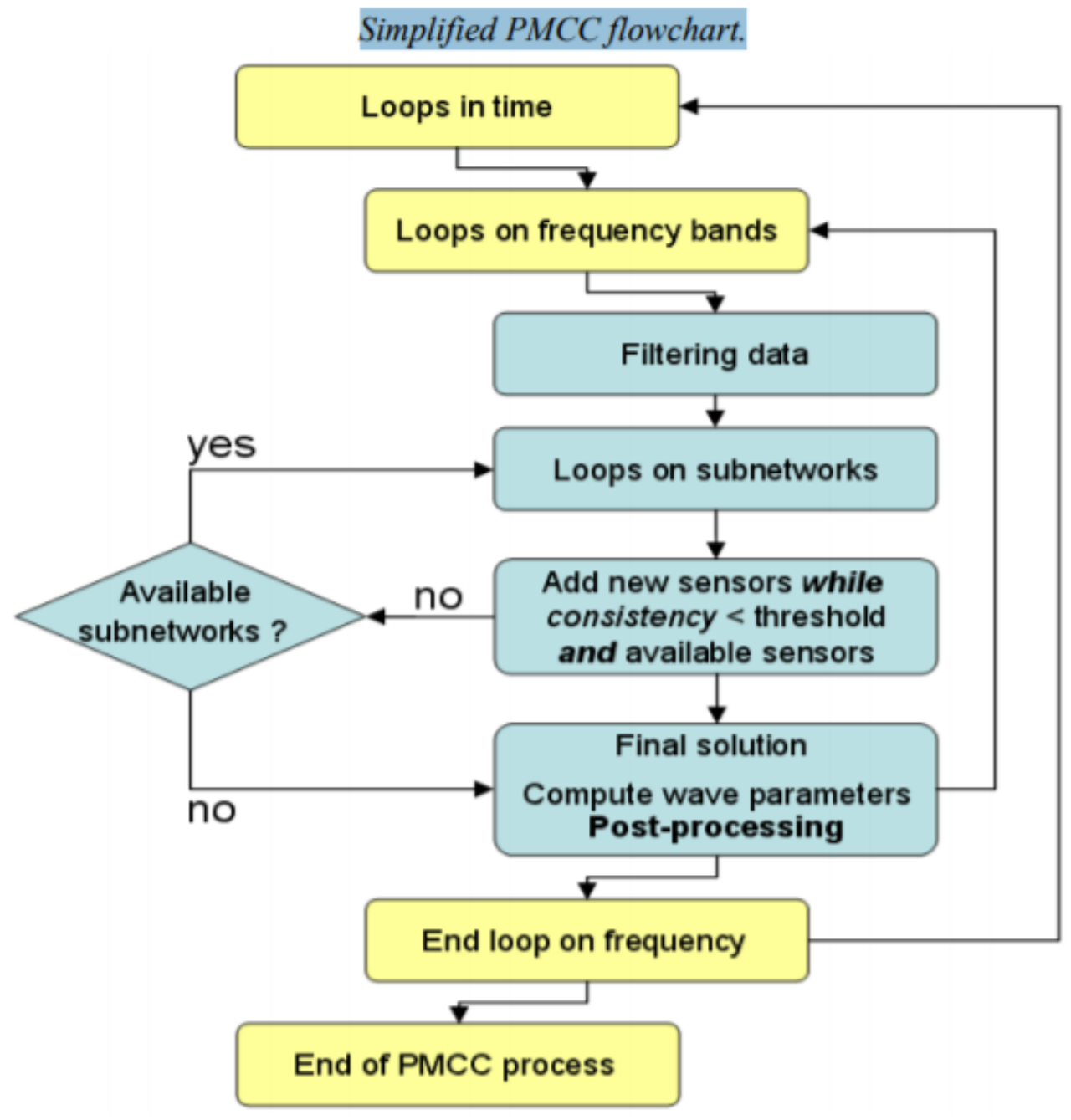

Figure 32. Simplified PMCC flowchart

Figure 33 presents the final results of PMCC calculation. Under favorable upper-wind conditions, multiple phases can be detected. In this example, several phases are detected. These are two fast stratosphere phases Is $1 \mathrm{f}$ and Is $2 \mathrm{f}$, one troposphere phase Iw and one stratosphere phase Is. The PMCC results (horizontal trace velocity and azimuth) are presented in time / frequency diagrams. The results are presented from 0.05 to $4 \mathrm{~Hz}$ in 15 logarithmically spaced frequency bands. Azimuths are given clockwise from North. 


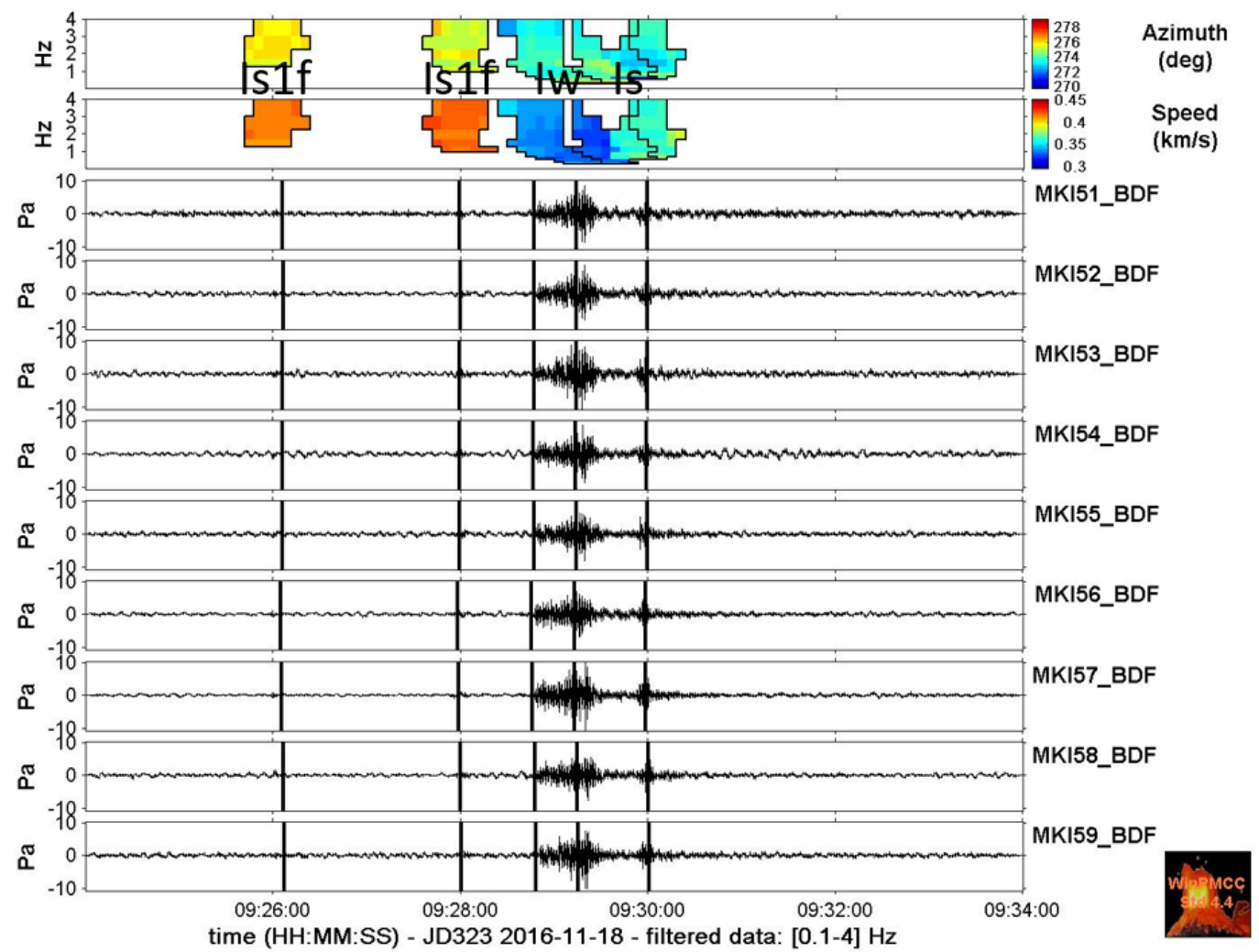

Figure 33. Results of PMCC analysis on typical recordings from the quarry blast at Akbastau quarry, Central Kazakhstan, recorded at MKIAR infrasound array

Starting from the fourth generation of the detector (Brachet et al., 2010) the detector is able to detect the signals from the infrasound arrays using different window length for various frequency bands. Thus, there is no need to calculate the high-frequency and low-frequency bulletins in two consequent runs (Figure 34).
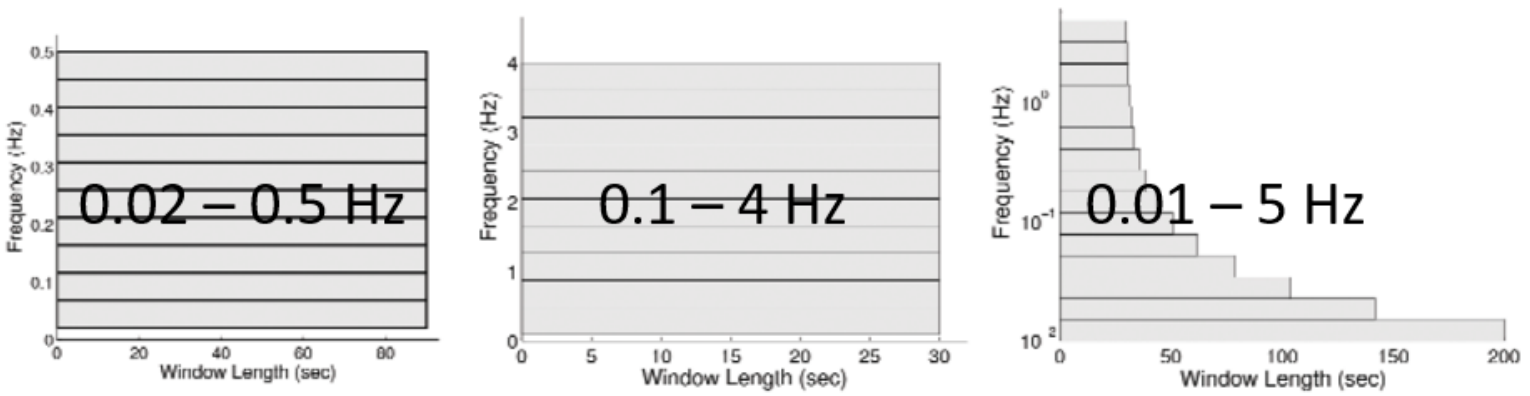

Figure 34. Examples of two 10-band standard configurations for low- and high-frequency processing (0.02-0.5 Hz and $0.1-4 \mathrm{~Hz}$, left and middle respectively), replaced by a single configuration consisting of 15 bands with log-spaced filter parameters $(0.01-5 \mathrm{~Hz})$ and a variable window length 


\subsubsection{Assessment of source models and their validity}

\subsubsection{Microbaroms and microseism source modeling}

We are using the microseism source model (IFREMER, 2018) referred to as 'p2l' that is calculated from the wave-action WaveWatch III model (WW3) developed by the National Oceanic and Atmospheric Administration (NOAA). While the bathymetry strongly affects the source intensity in microseism modelling (Ardhuin et al., 2011; Ardhuin and Herbers, 2013a; Kedar et al., 2008), a recently modelling study by De Carlo (2020) suggests that bathymetry has negligible impact on microbarom source strength in contrast to predictions from the model by Waxler (2007). In this study, the source term for microseisms ('p2l') which does not include coupling with the bathymetry is taken as a proxy to model microbaroms. While microseisms propagate through the static structure of the solid Earth, long-range microbarom propagation is controlled by the strong spatio-temporal variability of the temperature and wind structure of the atmosphere. Therefore, the geometrical spreading and seismic attenuation are the main effects to account for microseism modelling (e.g. Kanamori and Given, 1981; Stutzmann et al., 2012), while the dynamical properties of the middle atmosphere should be taken into account for microbarom modelling. Figure 35 shows example of the source power distribution.

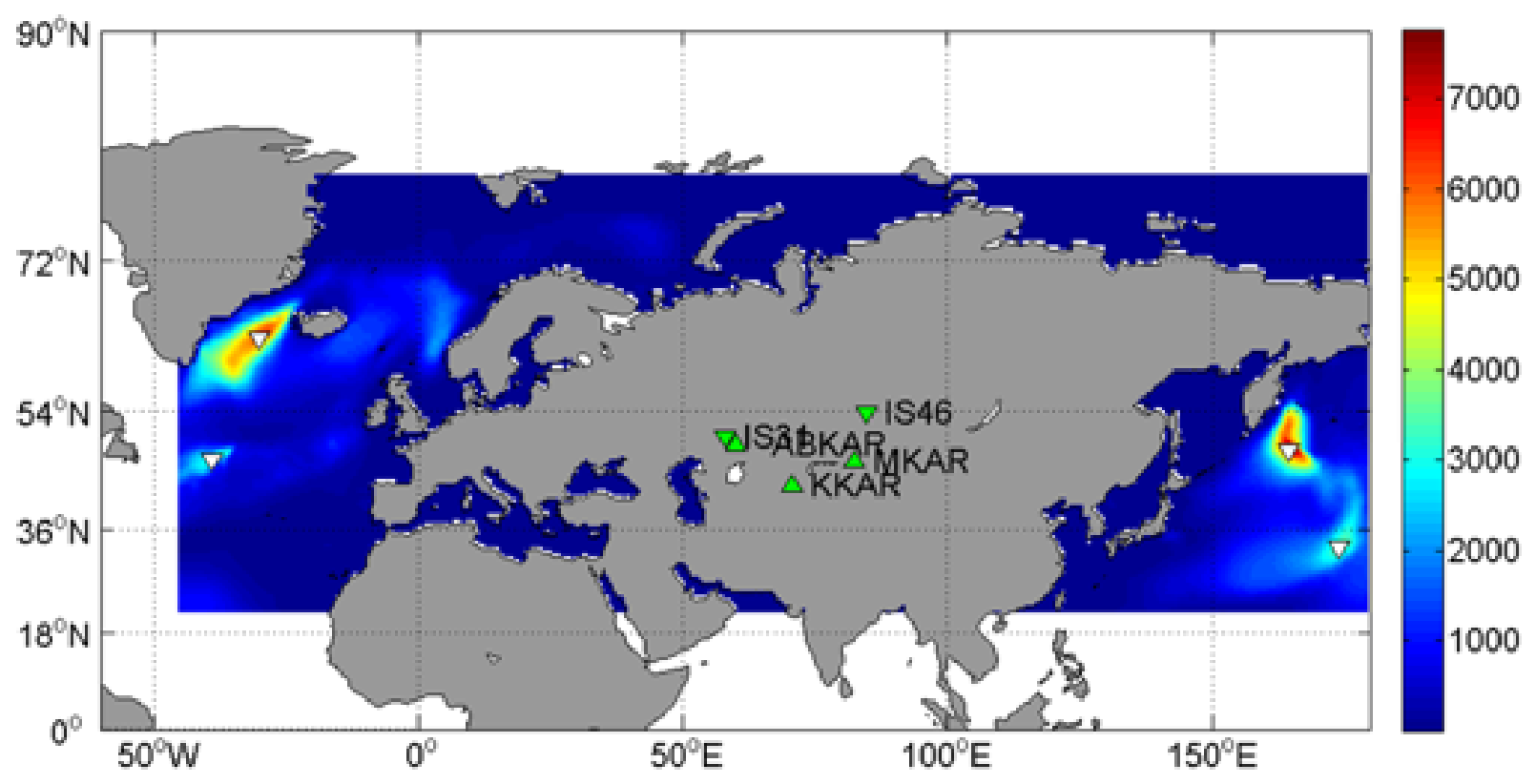

Figure 35. Example of the source energy distribution. The map shows the energy distribution averaged for the entire day February 2, 2017 in the frequency range $0.1-0.3 \mathrm{~Hz}$. Data about the ocean wave energy are provided by the IFREMER (Ardhuin et al., 2011)

The source power map is the average for the entire day February 2, 2017 in the frequency range 0.1$0.3 \mathrm{~Hz}$. Areas west and south of the region are not taken into account as the probability to get any signal from there at that time of the year in Kazakhstan is rather small. 


\subsubsection{Source modelling for microbaroms}

As previously stated, both microseisms and microbaroms originate from second order non-linear wave interactions. Their source term can be written as a function of the second-order equivalent surface pressure $F_{p}\left(f_{2}=2 f\right)$ (Hasselmann, 1963, Ardhuin et al. 2011):

$$
F_{p}\left(f_{2}=2 f\right)=\frac{1}{2} \rho_{w}^{2} g f_{2} H(f)
$$

where $\rho_{w}$ is the water density, $g$ is the gravitational acceleration, $f_{2}$ is the microseisms and microbarom frequency.

The Hasselmann integral $H(f)=\int_{0}^{2 \pi} E(f, \theta) E(f, \theta+\pi) d \theta$ (Hasselmann, 1963) represents the amount of opposite propagative wave interactions, with $E(f, \theta)$ the directional spectrum of waves. The IFREMER's distribution of the wave action model WAVEWATCH III ${ }^{\circledR}$ (WAVEWATCH III ${ }^{\circledR}, 2016$ ) includes the calculation of $F_{p}\left(f_{2}=2 f\right)$ with a $0.5^{\circ} \times 0.5^{\circ}$ spatial resolution and $3 \mathrm{~h}$ temporal resolution. Longuet-Higgins (1950) showed that these pressure fluctuations in the water do not attenuated with depth but are transmitted to the ocean bottom as acoustic waves. Depending on the ratio between the wavelength of the acoustic waves and the ocean depth, resonance effects can occur leading to a modulation of the pressure fluctuations at the sea floor (Stutzmann et al., 2012). Therefore, microseisms are strongly affected by the bathymetry (Ardhuin et al., 2011; Ardhuin and Herbers, 2013a; Kedar et al., 2008). The corresponding seismic source power spectral density at the ocean bottom is (Longuet-Higgins, 1950; Eq. 184):

$$
S_{D F}\left(f_{s}=f_{2}\right)=\frac{2 \pi f_{s}}{\rho_{s}^{2} \beta^{5}}\left[\sum_{m=1}^{m=N} c_{m}^{2}\right] F_{p}\left(f_{2}=2 f\right)
$$

where $S_{D F}$ is in $\mathrm{m} / \mathrm{Hz}, \rho_{\mathrm{s}}$ and $B$ are respectively the density and S-wave velocity in the crust, and coefficients $c_{m}$ correspond to the compressible ocean amplification factor. $c_{m}$ is non-dimensional number varying between 0 and 1 as a function of the ratio $2 \pi f 2 h / B$, where $h$ is the water depth. In this study, the crustal density $\rho_{\mathrm{s}}=2600 \mathrm{~kg} \mathrm{~m}^{-3}$ and the S-wave velocity $B=2800 \mathrm{~m} / \mathrm{s}$. The microbarom source term developed by De Carlo (2020) is essentially a scaled version of the second-order equivalent surface pressure $F_{p}\left(f_{2}=2 f\right)$, which serves as proxy of microbarom source term.

\subsubsection{Signal attenuation for infrasound}

While microseisms propagate through the static structure of the solid Earth, long-range microbarom propagation is affected by the strong spatio-temporal variability of the temperature and wind structure of the atmosphere. As the temperature typically decreases with altitude in the lower atmosphere, infrasonic waves produced close to the ground propagate upwards. They can then be 
refracted back to the ground if the effective sound speed becomes larger than its surface value (Evers and Haak, 2010). This always happens in the thermosphere because of the strong temperature gradient but also commonly occurs at lower altitudes. In the troposphere, temperature inversion or jet streams near the tropopause can lead to relatively high effective sound velocities. Infrasound waveguides are also commonly formed between the stratosphere and ground because of the solar radiative heating of stratospheric ozone combined with strong seasonal stratospheric winds. Because of their relatively small attenuation, infrasonic waves can be detected at great distances from the source (Marty, 2019). Figure 36 shows all three options - tropospheric, stratospheric, and thermospheric paths. It is clearly seen in the picture that a stratospheric waveguide exists in the direction of wave propagation that coincides with wind direction in the stratosphere. In its turn, this wind direction changes in winter and summer: eastward during (local) winter, westward during (local) summer.
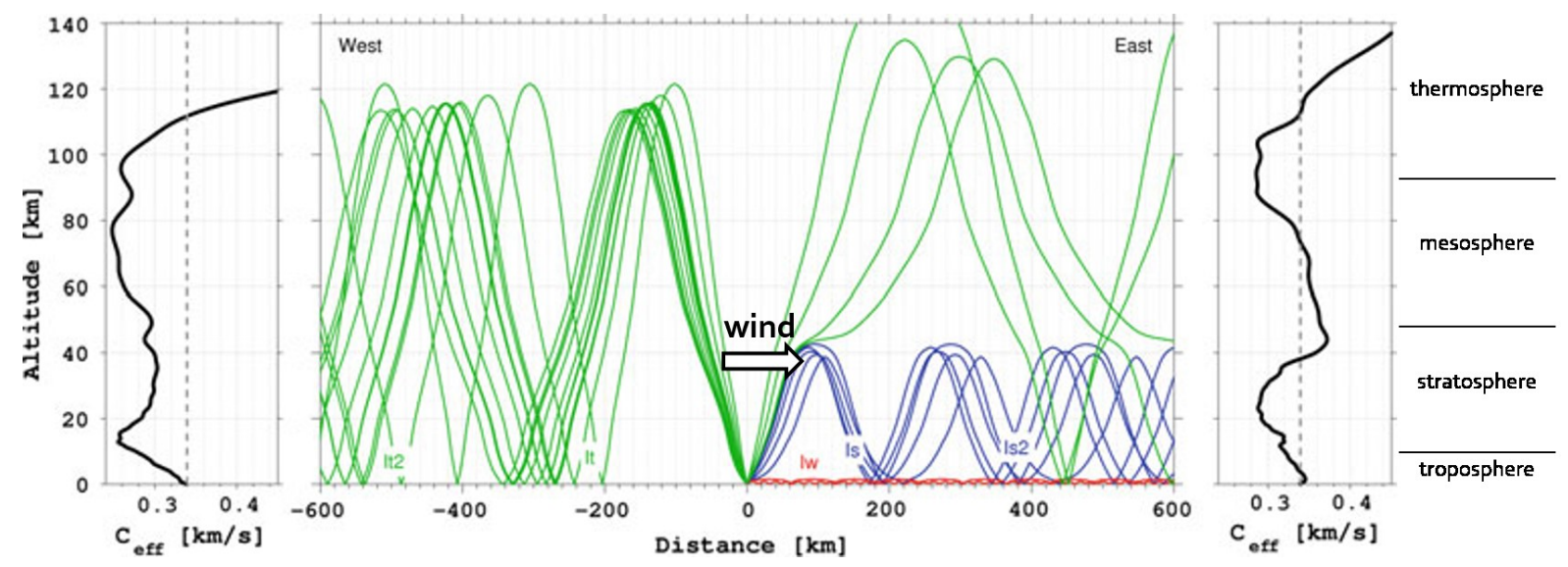

Figure 36. Simulation of the infrasound wave propagation. The red, blue, and green paths are tropospheric, stratospheric and thermospheric phases respectively (Modified from Marty, 2019)

Therefore, the dynamical properties of the middle atmosphere should be taken into account for estimation of the attenuation of microbaroms arriving at the infrasound stations. To do so, we use a semi-empirical frequency dependent attenuation relation (Le Pichon et al., 2012). The equation was based on numerous Parabolic Equations simulations of infrasound through simple range-independent atmosphere models, varying frequency and ratios of effective sound speed. The attenuation coefficient (dimensionless) from a point situated $1 \mathrm{~km}$ from the source is given by (4):

$$
A_{t t}=\frac{10^{\frac{\alpha(f) R}{20}}}{R}+\frac{R^{\beta\left(f, V_{e f f-r a t i o}\right)}}{1+10^{\frac{\delta-R}{\sigma(f)}}}
$$

where $\alpha$ (in $\mathrm{km}^{-1}$ ), $\beta, \delta$ (in $\mathrm{km}$ ), $\sigma$ (in $\mathrm{km}$ ) are parameters tabulated in (Le Pichon et al., 2010), Veff-ratio is the dimensionless ratio of the effective sound speed within the stratosphere to that at ground level, $f$ is the signal frequency (in $\mathrm{Hz}$ ) and $R$ is the distance from the source (in $\mathrm{km}$ ). The pressure amplitude is: $A(f, R, V$ eff-ratio $)=$ 
$\mathrm{A}_{1 \mathrm{~km}}{ }^{*} A_{\mathrm{tt}}$. Figure 37 shows how signal attenuation depends on signal down and up the wind propagation. When propagating up the wind, Veff-ratio is below 1 . In this case, waves may return to the ground only being refracted at thermosphere height (Figure 36). Thermosphere phases attenuate strongly because air at these heights is rarefied causing the signals to propagate no further than some first tens of kilometers. The situation is quite opposite when wind direction and signal propagation coincide. In this case, a stratospheric waveguide is formed, where acoustic energy may propagate to very long distances with no essential losses.

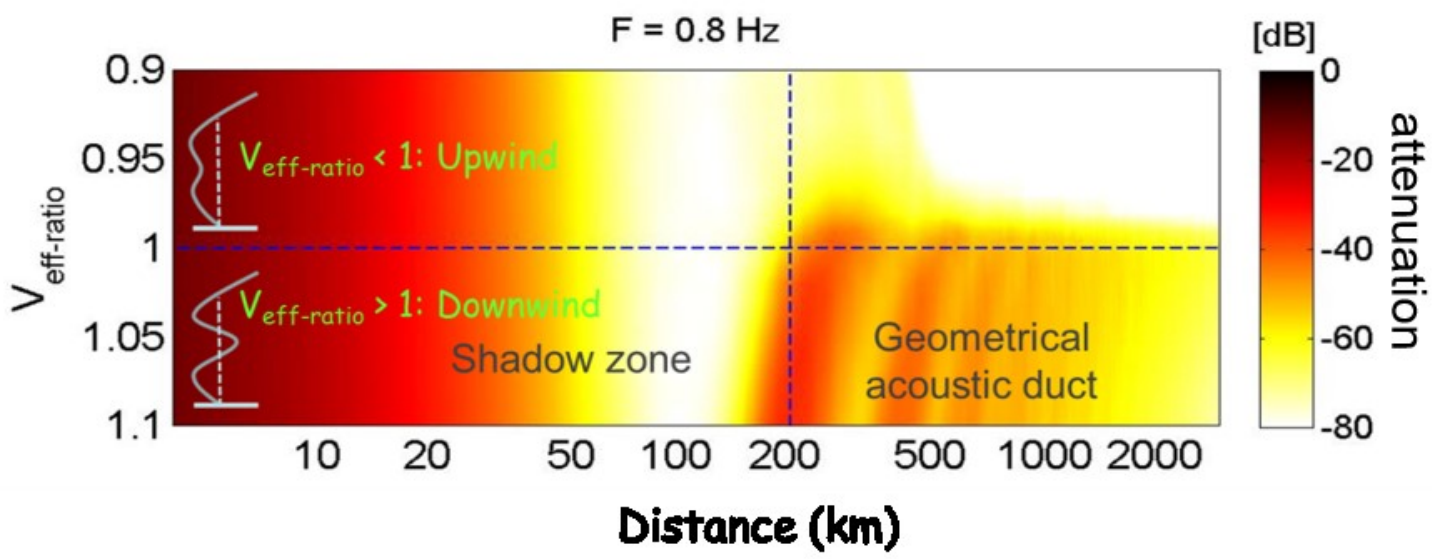

Figure 37. An example of calculating infrasound signals attenuation with PE simulations. The relation incorporates the effects of the source frequency, the effective sound speed ratio in the stratosphere covering realistic down- and counter-wind scenarios, and fine-scale atmospheric structures (modified from Le Pichon 2012)

As this equation was developed for a range-independent atmosphere, a strong assumption is made by choosing a uniform Veff-ratio. Atmospheric specifications are extracted at the station from the high-resolution forecast (HRES) that is part of ECMWF's Integrated Forecast System (IFS) cycle 38r2 (http://www.ecmwf.int). These specifications are assumed to be constant along the propagation path. This approach has been successfully used for microbaroms generated in the northern hemisphere by De Carlo et al. (2018) and Hupe et al. (2018) (in a range of $\sim 10^{\circ}$ for the back-azimuths). However, when calculating an attenuation of signals propagating from another hemisphere, this approach should have serious errors as after crossing the equator, the direction of a zonal component of prevailing stratospheric winds changes, and the range-independent wind model cannot be considered accurate anymore.

\subsubsection{Modeling of the seismic source, bathymetry effect, and attenuation term}

Figure 38 shows the $C_{1}$ component of the ocean amplification factor due to bathymetry for seismic wave with frequencies 0.2 and $0.4 \mathrm{~Hz}$ in accordance with (3). Upper panel in the Figure 38 is the map of the topography used for to construct the $\mathrm{C}_{1}$ distribution maps. The ocean depth map with the 30second spatial resolution was created using data of the ETOPO5 model (Lindquist, 2014). Values of the 
C coefficients are tabulated in Longuet-Higgins (1950). It is possible to get precise values of the coefficients after oversampling using spline interpolation as shown in Figure 39.
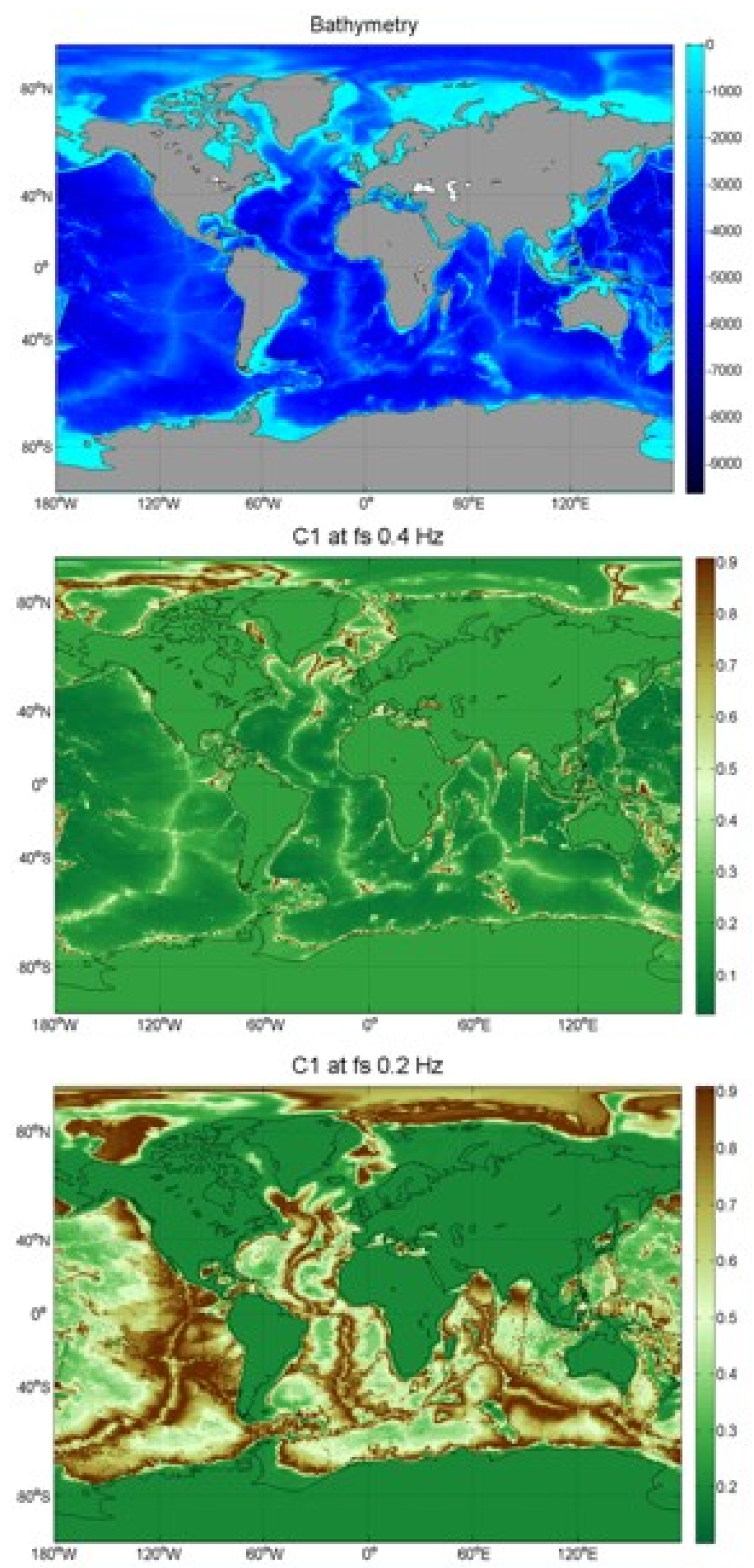

Figure 38. Top panel: topography map. Middle and bottom panels: amplification factor for the seismic waves at 0.2 and $0.4 \mathrm{~Hz}$, respectively 


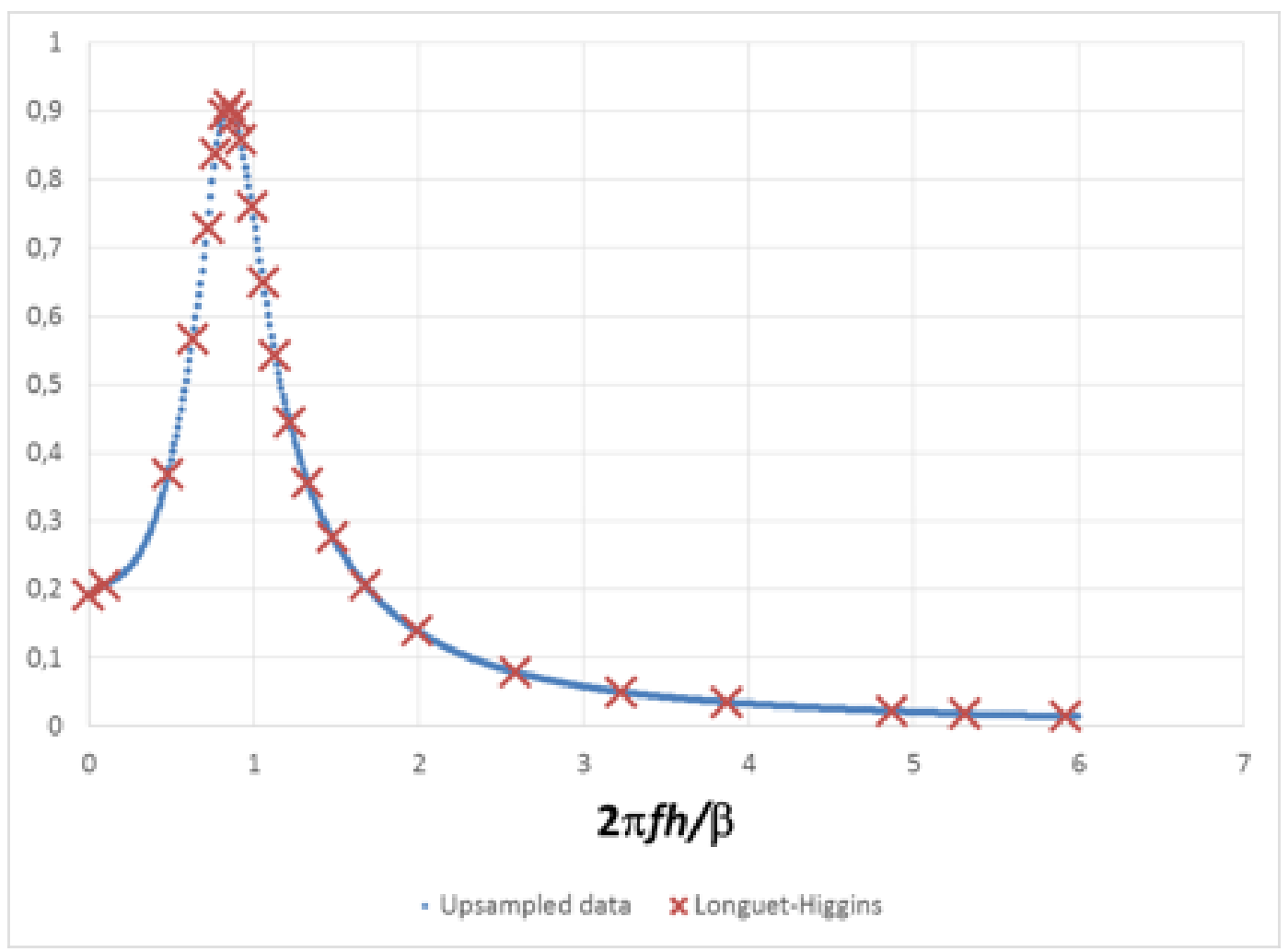

Figure 39. Values of the $C_{1}$ coefficients (red crosses) as it presented in Longuet-Higgins (1950), and after oversampling (blue circles)

\subsubsection{Azimuth corrections from seismicity catalogs (ISC)}

Smirnov et al. (2010) studied static corrections of azimuth for signals arriving from North Atlantic to Kazakh seismic arrays. These corrections were obtained to update locations of the low-frequency signal sources in the North Atlantic. Static errors for defined azimuths at seismic arrays are known to be associated with geological heterogeneities of various scales along the travel path of seismic energy, thus the value of corrections depends on the epicentral distance and the back-azimuth, (Sinyova, 2005). The method described below is used for evaluation of the static correction. Five strong earthquakes with magnitudes larger than 5 that occurred in the North Atlantic since 2006 were selected in the bulletin of International Seismological Center (ISC website, 2020). Using coordinates of the epicenters from the ISC bulletin, the true azimuths were calculated. At the same time, the observed azimuths to the epicenters were found by applying F-K analysis to the waveforms of Akbulak, Borovoe, Karatau, and Makanchy seismic arrays. Differences between the true and observed azimuths were applied as static corrections.

As seen in Table 3, the calculated corrections differ significantly from one station to another in sign and in absolute value. Smirnov et al. (2010) state that statistical corrections were used to adjust the observed azimuths. Observed results were compared to the directions where the highest ocean waves 
in the North Atlantic were recorded. For Borovoe, Karatau, and Makanchy seismic arrays, the observed and forecast azimuths are comparable. For Akbulak array, a systematic error persists at about $10^{\circ}$, Figure 14.

As a systematic error is not explained for ABKAR and Kurchatov Cross, the same analysis was repeated with new earthquake data. The events considered are listed in Table 4. The list contains the largest earthquakes that occurred in the North Atlantic mid-ocean ridge area in accordance with the ISC bulletin (ISC website, 2020), (Figure 40). Several strong events occurred in the next 10 years.

Not only the Ground Truth event set was renewed but also the method of the static correction evaluation. Kolínský and Bokelmann (2019) showed that corrections for the Rayleigh waves strongly depend on arrival azimuth using the Alp array. In the strict sense, their investigation describes the evaluation of the mismatches for isolated events and widely distributed receiving networks composed of the elements of the large Alp array. However, in accordance with the reciprocity principle, the same picture has to take place in case of a distributed set of earthquakes and isolated stations. In particular, Kolínský and Bokelmann (2019) demonstrated that the deviations relative to the respective greatcircle directions for the Mexico earthquake 2017-09-08 recorded by the Alp array vary from $-15^{\circ}$ to $+10^{\circ}$. For this reason, the deviations were evaluated not as an average of the set of events but as a function of the arrival azimuth.

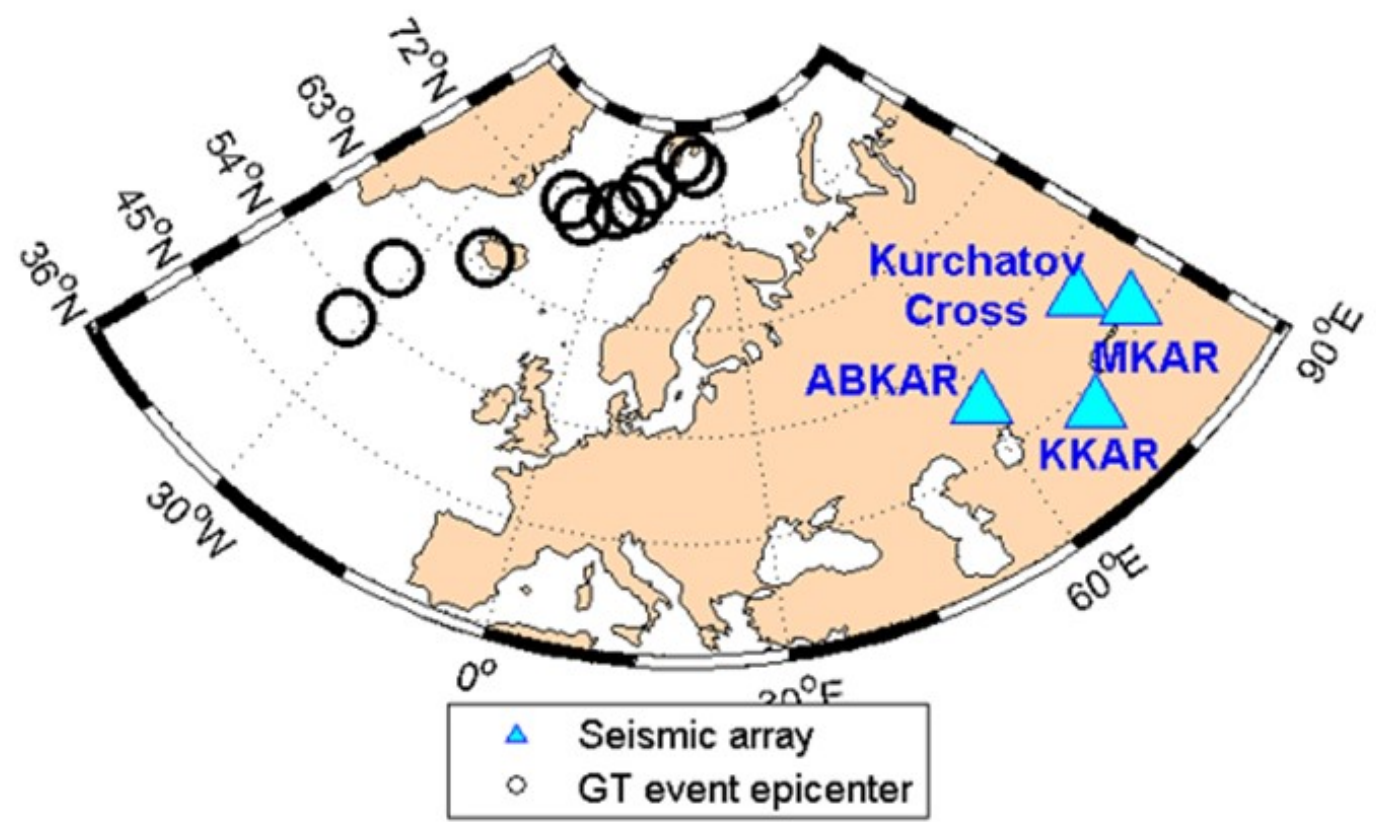

Figure 40. Largest events occurring along the mid-ocean ridge in North Atlantic from 2003 till 2019 and seismic arrays of the Kazakh seismo-acoustic network 
Table 4. Parameters of the strong earthquakes that used as the GT events according to the ISC bulletin (ISC website, 2020). The events occurred in North Atlantic from 2003 to 2019

\begin{tabular}{|c|c|c|c|c|}
\hline Date & Time & Latitude, $\left[^{\circ}\right]$ & Longitude, $\left[^{\circ}\right]$ & Magnitude, Ms \\
\hline $10-03-19$ & $18: 04: 59$ & 58,35 & $-31,95$ & 5,8 \\
\hline $29-05-08$ & $15: 46: 00$ & 63,95 & $-21,08$ & 6,2 \\
\hline $04-07-03$ & $7: 16: 46$ & 76,32 & 23,29 & 5,2 \\
\hline $21-02-08$ & $2: 46: 18$ & 77,08 & 18,80 & 6 \\
\hline $20-08-09$ & $6: 35: 05$ & 72,19 & 0,91 & 5,8 \\
\hline $29-01-11$ & $6: 55: 26$ & 70,87 & $-6,91$ & 6 \\
\hline $24-05-12$ & $22: 47: 46$ & 73,03 & 5,51 & 6,1 \\
\hline $07-08-18$ & $13: 57: 10$ & 74,65 & 8,45 & 5,5 \\
\hline $09-11-18$ & $1: 49: 40$ & 71,63 & $-11,24$ & 6,4 \\
\hline $13-02-15$ & $12: 13: 58$ & 52,51 & $-32,02$ & 7 \\
\hline
\end{tabular}

The PMCC detector was used for the signal parameters evaluation, the configuration was exactly the same as the one used for the microseism detection. All the detections with apparent velocity not exceeding $6 \mathrm{~km} / \mathrm{s}$ were selected as candidates. As a rule, the number of such phases is more than one, moreover, the backazimuths of these phases of one and the same event could differ by $50^{\circ}$ and even more. A possible explanation of this huge variation is the effect described by Labonne et al. (2017). Using the detections of regional seismic events at Kazakh seismic arrays, it was shown that the Lg wavefield provides wide ranges of back azimuths, even in the opposite back azimuth of the epicenter area. Thus, it is critical to choose the proper phases from this set, as using wrong selection method could dramatically change the resulting value of the correction. The phases having the largest RMS amplitudes were chosen.

The same selection principle was used for the microseism phase selection (Section 4). After that, dependencies of the difference between the true and observed azimuths were constructed and finally smoothed with third-degree polynomials. Figure 41 shows an example of deviation vs. true azimuth to source for ABKAR array. 


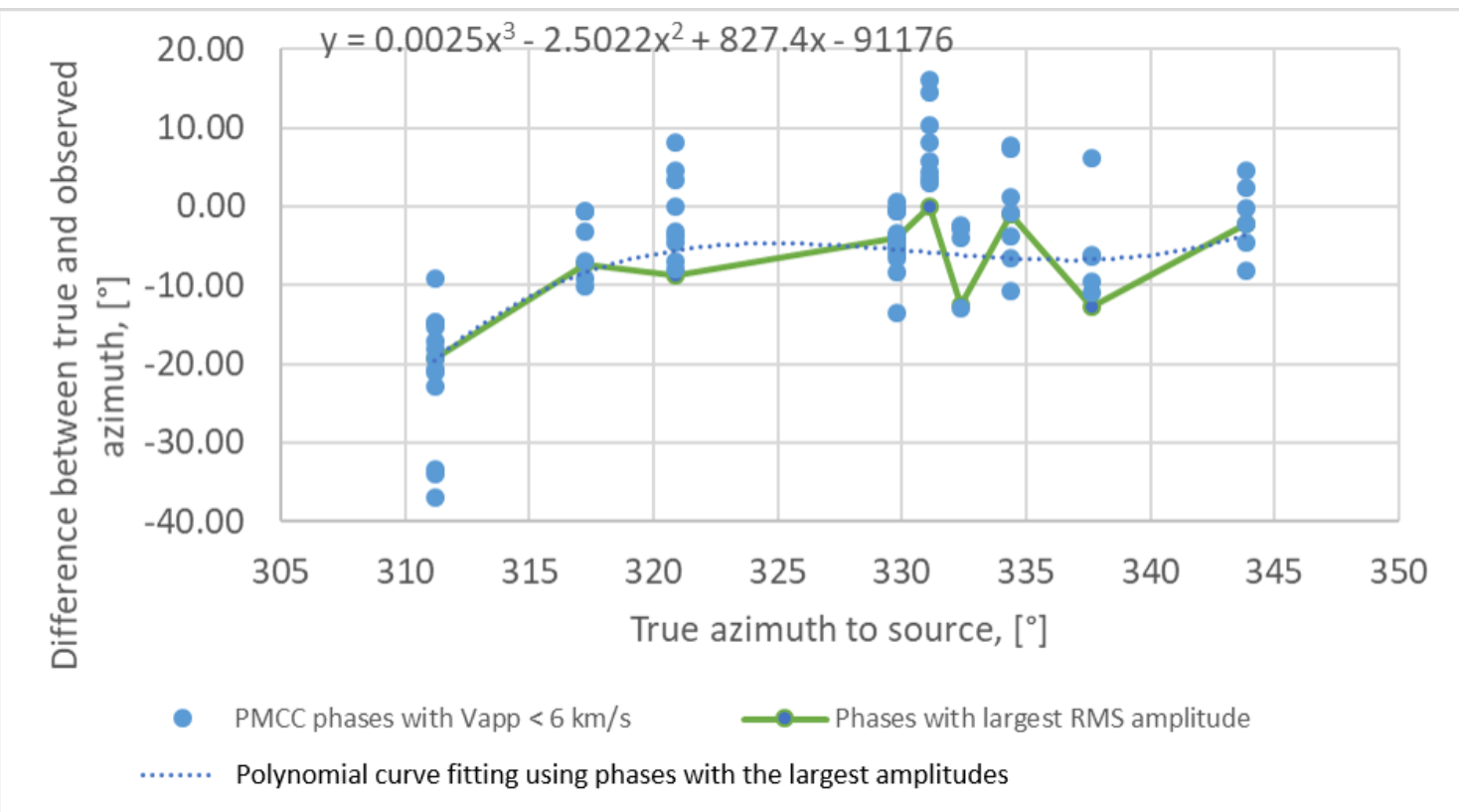

Figure 41. Example of true vs. observed backazimuths for the surface waves for ABKAR array. Dotted line is a result of the $3^{\text {rd }}$ degree polynomial smoothing, the equation of the curve is on the panel

Figure 42 shows the deviation that was found this way for all 4 arrays.

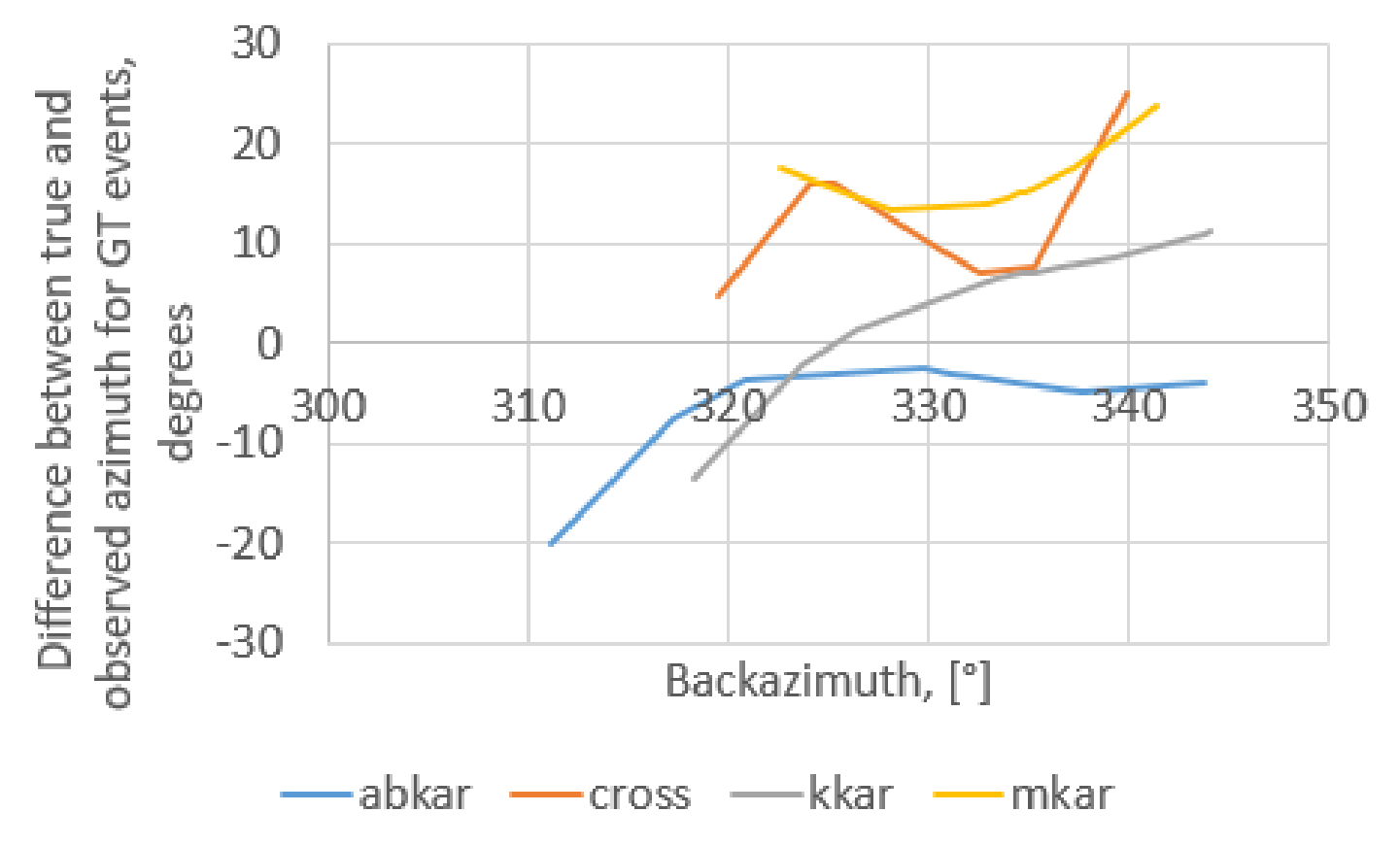

Figure 42. Azimuthal deviations for surface phases as recorded by the Kazakh seismic arrays for the earthquakes in North Atlantic. Blue curve is for ABKAR, orange curve is for Kurchatov Cross, grey curve is for KKAR, and yellow curve is for MKAR 


\subsection{Reprocessing historical infrasound records}

\subsubsection{PMCC processing configuration for infrasound data}

Long-term microbarom observations for the Central Eurasia area were kindly provided by the CEA. These contain four years of PMCC detection results at IS31 (Figure 43) and IS46 (Figure 44) in a frequency range $0.01-4 \mathrm{~Hz}$. Only detections in the 0.1-0.3 Hz band were selected. Azimuths to the predicted source regions are shown by black circles. Data of MKIAR and KURIS infrasound arrays were processed using exactly the same parameters as the ones used by the CEA for IS31 and IS46.

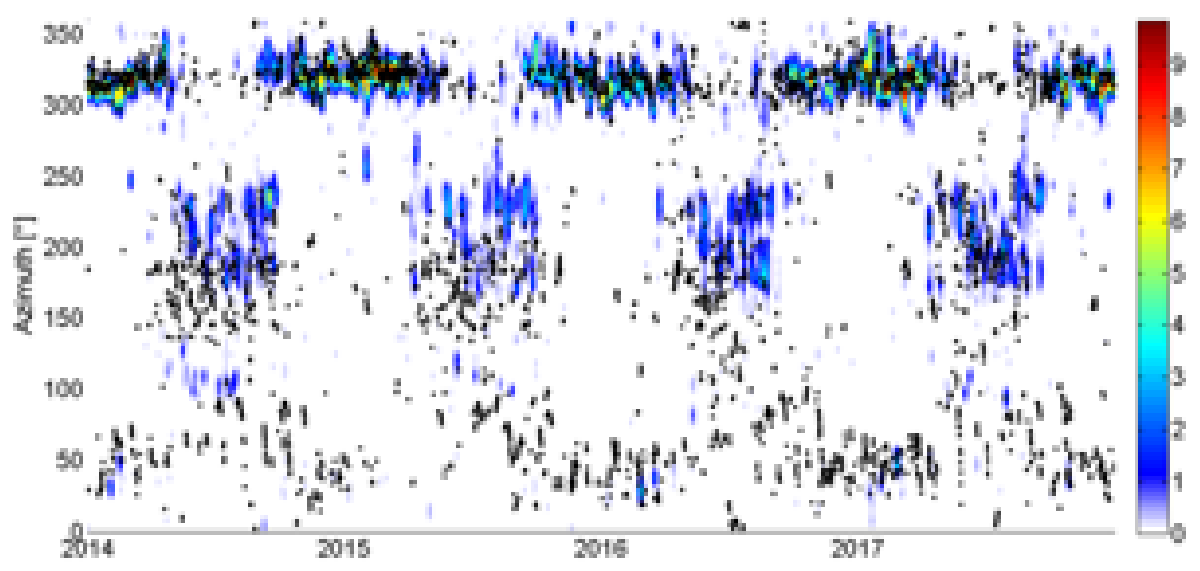

Figure 43. Four years of the PMCC detections at IS31 in the frequency range $0.1-0.3 \mathrm{~Hz}$. Black circles are the predicted backazimuths. The color bar codes the logarithm of the number of detections

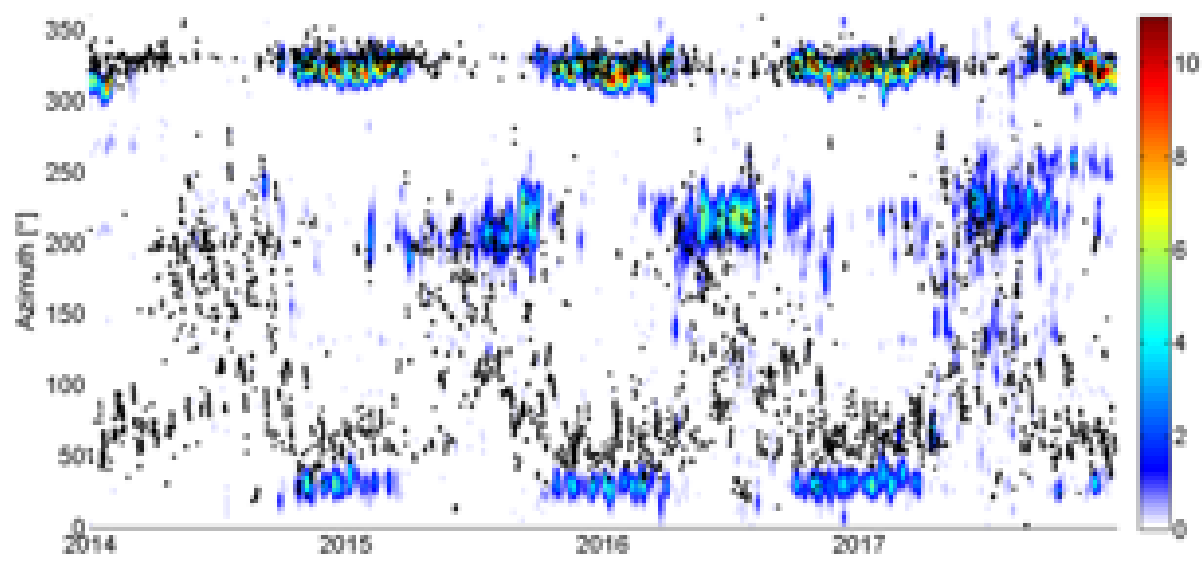

Figure 44. Four years of the PMCC detections at IS46 in the frequency range 0.1-0.3 Hz. Black circles are the predicted backazimuths to source. The color bar codes the logarithm of the number of detections 


\subsubsection{PMCC processing configuration for seismic data}

Microbaroms are detected using the Progressive Multichannel Correlation Method (PMCC) (Cansi, 1995; Cansi and Klinger, 1997; Smirnov et al., 2011) in 10 linearly spaced frequency bands between 0.01 and $4 \mathrm{~Hz}$ using fifteen logarithmically scaled sub-bands, and time window length varying from 30 s to $200 \mathrm{~s}$ (Matoza et al., 2013). Only detections with a mean frequency ranging in the $0.1-0.4 \mathrm{~Hz}$ microbarom band are considered.

Microseisms are detected using PMCC in 10 linearly spaced frequency bands between 0.05 and 0.4 $\mathrm{Hz}$. A fixed time window length of $200 \mathrm{~s}$ is used for each sub-band.

Data from Kazakh arrays are not processed routinely using PMCC detector, therefore processing of ABKAR, KKAR, MKAR and Kurchatov cross data for the period from 2014 through 2017 was completed in 2019 using IPGP's computational resources, namely S-CAPAD DELL cluster. This cluster includes:

- $\quad 100$ CPU intensive nodes (cnode001 to cnode100),

- 28 data intensive nodes with SSD disks (dnode01 to dnode28),

- 4 GPU nodes (gpu01 to gpu04),

- 1 SMP node with 64 cores and 128 GB RAM (smp01),

- 1 GPFS parallel file system with 699 effective TB,

all connected by an Infiniband Fat-tree network QDR 100\% non-blocking.

It shall be noted that even with such large computational resources involved, calculations required several weeks of computed machine time.

The comparisons of microseism observations and simulation results during two-month period show similar pictures when using seismic data. Figure 45, Figure 46, Figure 47 and Figure 48 show observations and simulations at ABKAR, KKAR, MKAR and Kurchatov cross respectively. The PMCC detection distributions look similar at all stations. Most detections have backazimuth distribution nearly $300-350^{\circ}$ that match with the directions to the North Atlantic region. Spreading of azimuth values is roughly $30^{\circ}$ and this value is also almost the same for all stations. Almost all detections have apparent velocities near $6 \mathrm{~km} / \mathrm{s}$. But at some periods the apparent velocity rises up to $16 \mathrm{~km} / \mathrm{s}$. At the same period, the measured backazimuths shift clockwise up $100^{\circ}$ from the average value at some stations. This effect is not observed at ABKAR (Figure 45). 


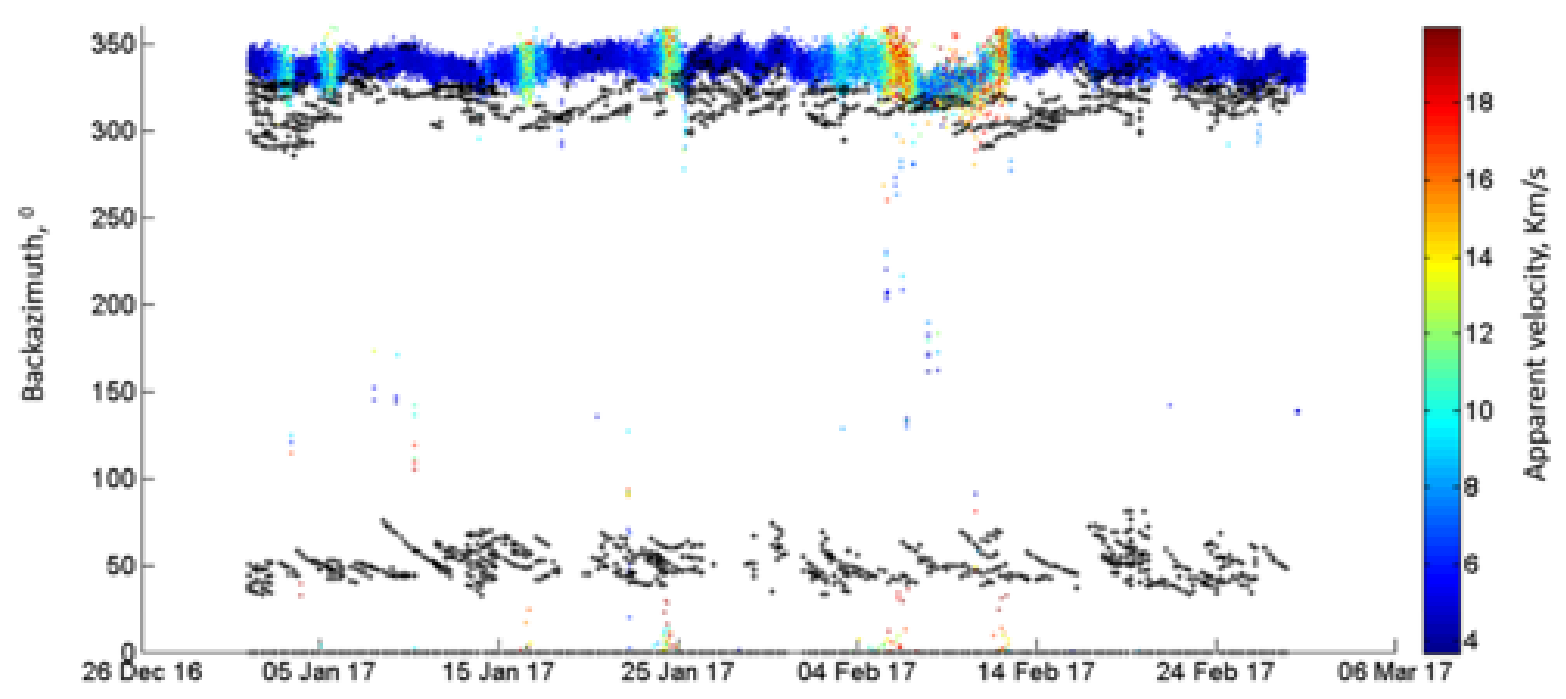

Figure 45. Predicted and observed backazimuths at ABKAR seismic array. Color represents the apparent velocity of the detected microseisms. Black crosses indicate the direction to the main and local maxima of the energy in the simulated source regions

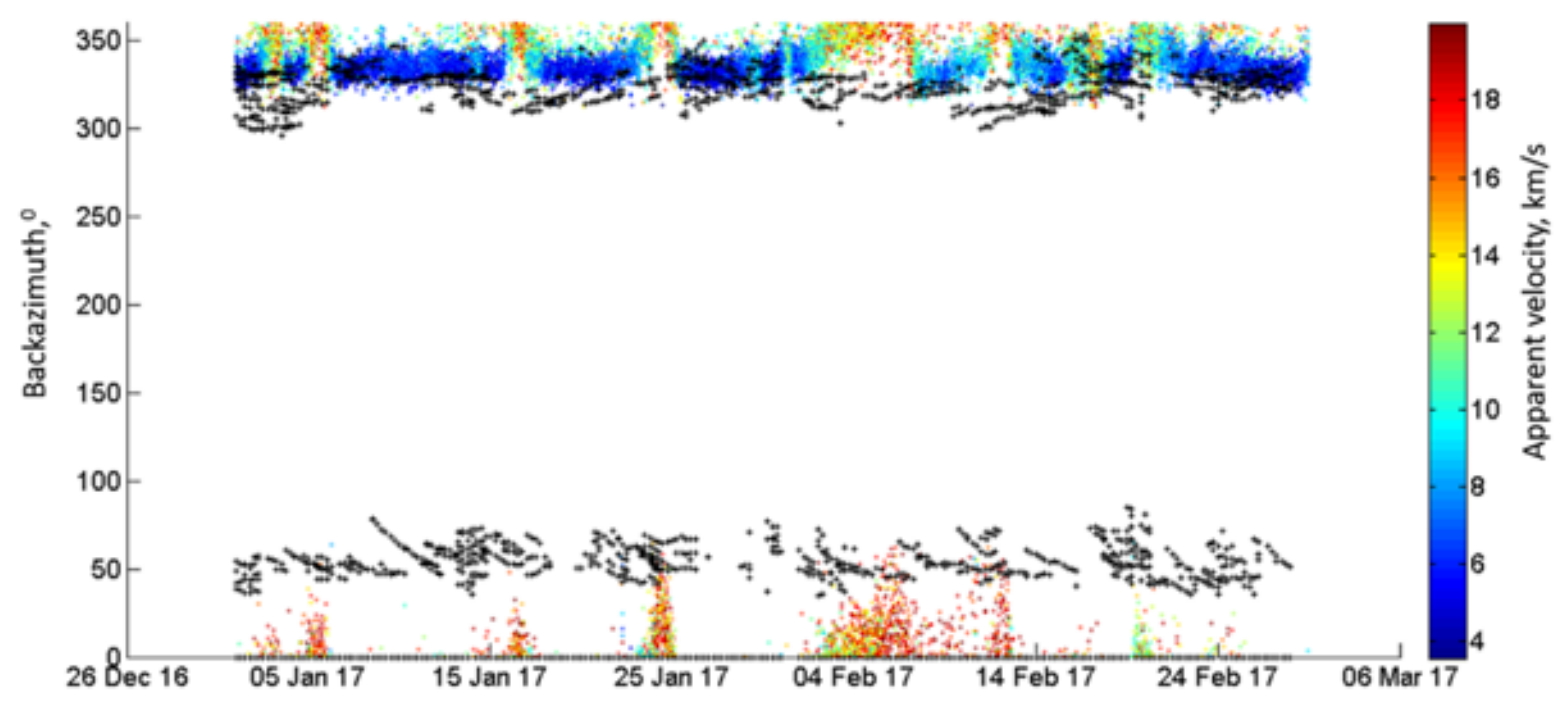

Figure 46. Predicted and observed backazimuths at KKAR seismic array. Color represents the apparent velocity of the detected microseisms. Black crosses indicate direction to the main and local maxima of the energy in the simulated source regions 


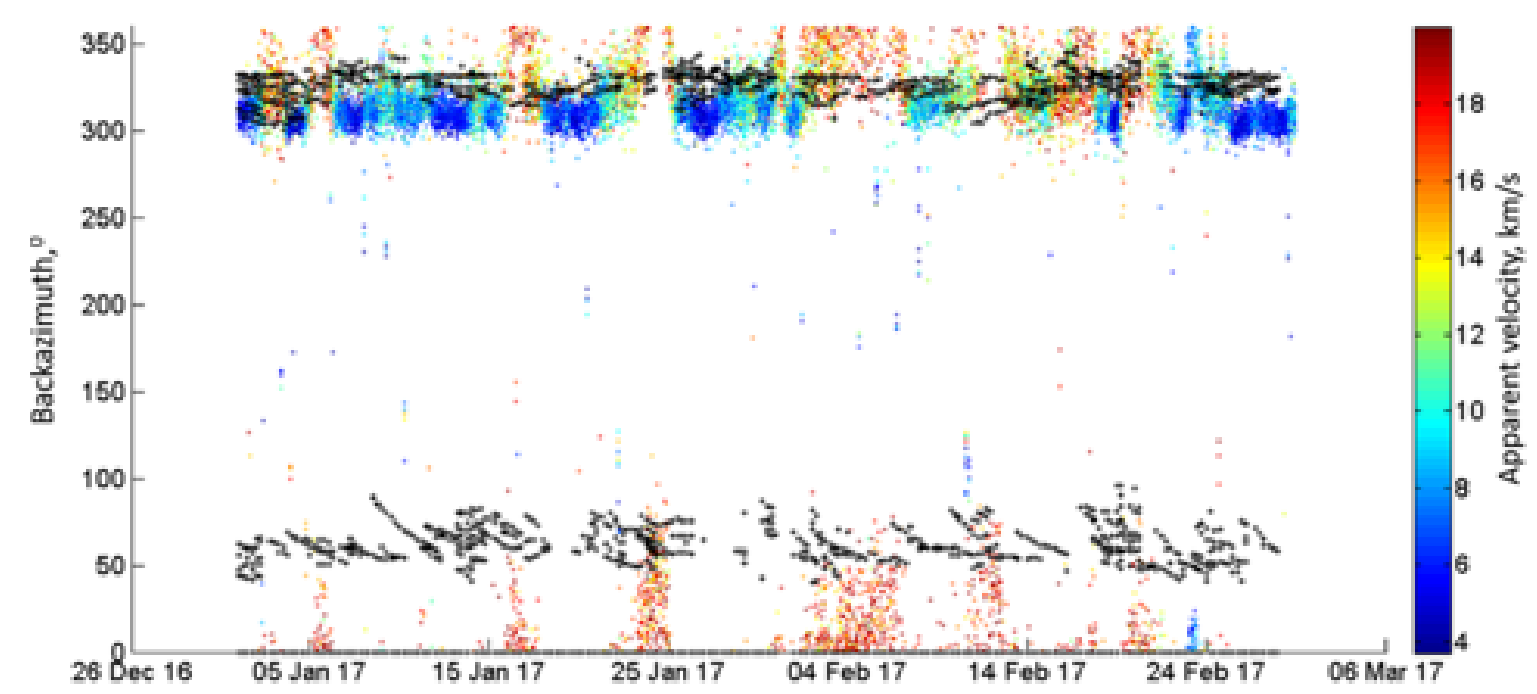

Figure 47. Predicted and observed backazimuths at MKAR seismic array. Color represents the apparent velocity of the detected microseisms. Black crosses indicate the direction to the main and local maxima of the energy in the simulated source regions

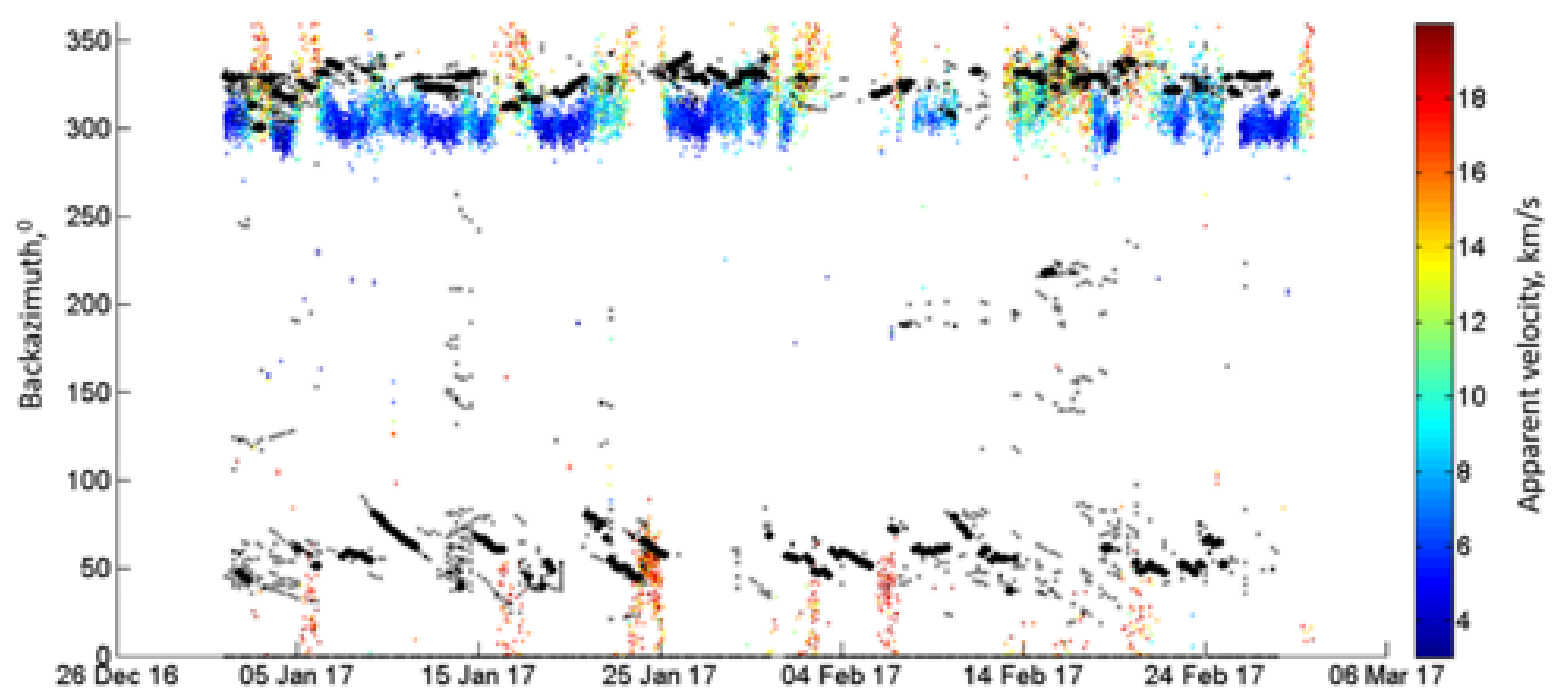

Figure 48. Predicted and observed backazimuths at Kurchatov Cross seismic array. Color represents the apparent velocity of the detected microseisms. Black circles indicate the direction to the main maxima of the energy in the simulated source regions, black crosses point to the local maxima

\subsection{Comparison between observations and predictions}

The good agreement between the detected backazimuths of microbarom and microseisms and predictions demonstrate that the detection parameters were well chosen. Synchronism of the backazimuths deviations from one station to another in the network also confirmed this choice. 


\subsubsection{Comparison for infrasound arrays}

For both IS31 and IS46 there is a good match between observations and modeling results in the range $300^{\circ}-350^{\circ}$ that corresponds to signals originating from the North Atlantic. There are predictions of signals from the Southern direction with poorer correlation. At IS46 there are corresponding observations which are shifted in azimuth by approximately $25^{\circ}$. All these results show that it is needed to take into account atmospheric effects on long range propagation. The lack of detections from the North Pacific at IS31 also suggests that it is needed to incorporate wind effects for wave attenuation calculation.

\subsubsection{Comparison for seismic arrays}

There is a good consistency between observations and modeling results at all stations. Despite some systematic errors, there are stable records of North Atlantic microbaroms. Mean apparent velocity of microbarom detections is close to $7 \mathrm{~km} / \mathrm{s}$. However, at some time intervals, apparent velocity rises up to $16 \mathrm{~km} / \mathrm{s}$. At the same periods, backazimuths vary up to $60^{\circ}$ (Figure 49). This effect is not observed at ABKAR, it is weaker at KKAR and stronger at MKAR and Kurchatov Cross arrays. This seems to be a real effect and cannot be explained by the lack of resolution due to the small aperture of the arrays. Figure 50 shows the predicted errors in velocity and backazimuth for the KKAR and Kurchatov cross arrays (Szuberla and Olson, 2004). It is obvious that for KKAR with $3 \mathrm{~km}$ aperture, the errors should be large (Figure $50 \mathrm{a}$ and $\mathrm{c}$ ). For Kurchatov Cross the errors are much smaller (Figure $50 \mathrm{c}$ and d). This means that the array aperture does not affect the accuracy here. Some systematic offset between the observed and predicted backazimuths appear at all stations. This offset is approximately $10-20^{\circ}$ clockwise for observations at ABKAR and KKAR and almost the same range but counter clockwise at Kurchatov Cross and MKAR.

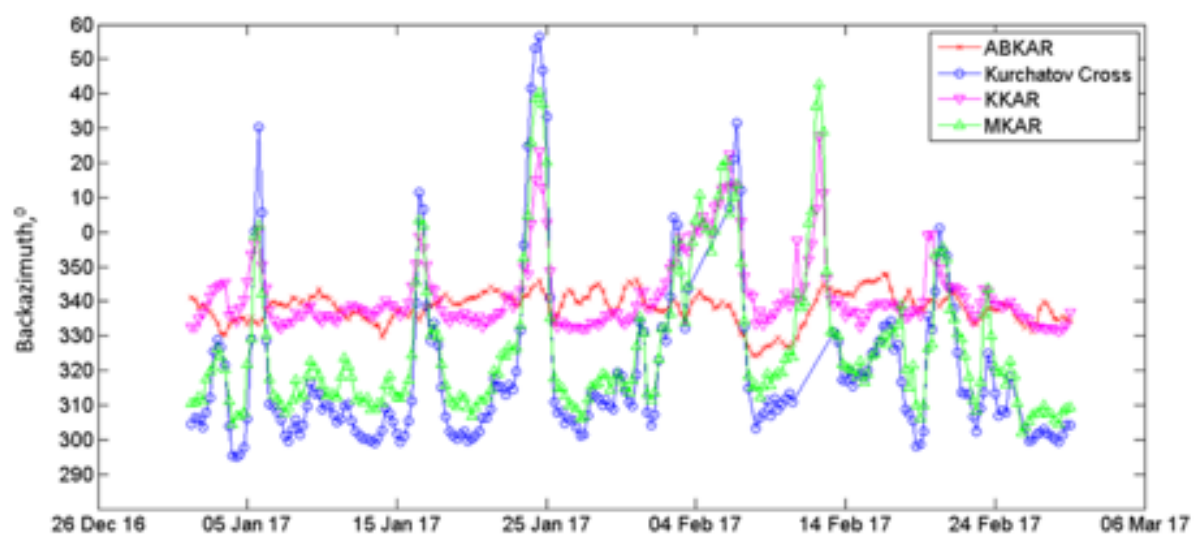

Figure 49. Comparison of the observed backazimuths at four seismic arrays. Detections correspond to the period between January and February 2017. Each point represents and averaged value of the measures over a $6 \mathrm{~h}$ time window 

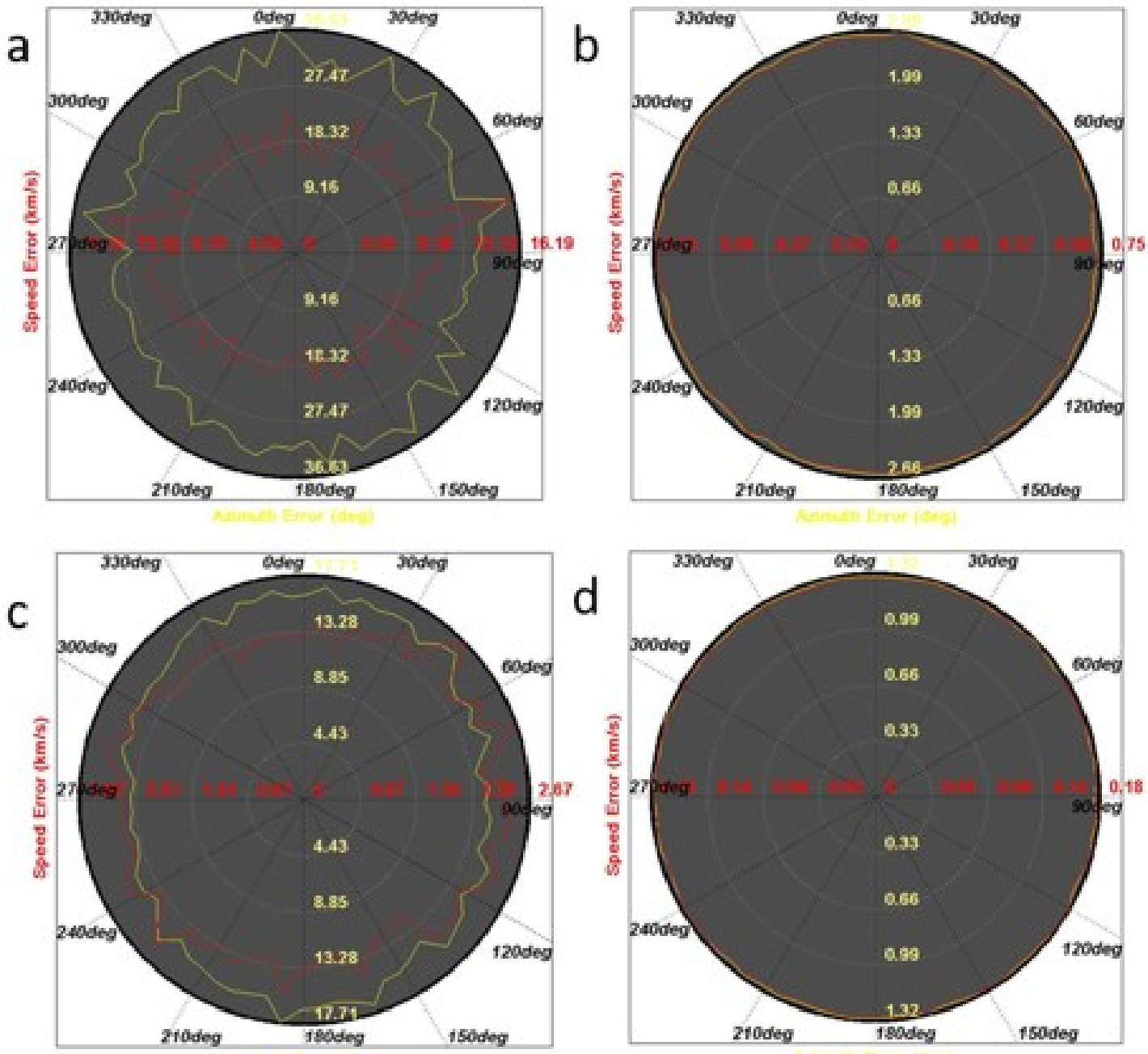

Figure 50. Predicted azimuthal and velocity errors at KKAR ( $a$ and $c$ ) and Kurchatov Cross arrays ( $b$ and d). The error estimation is calculated for a wave speed of $16 \mathrm{~km} / \mathrm{s}$ ( $a$ and $b$ ) and $8 \mathrm{~km} / \mathrm{s}$ (c and d)

\subsubsection{Metrics to compare observations with predictions}

The correlation coefficient between the observed and predicted seasonal patterns is calculated following metrics elaborated by Landès et al. (2014). There are two different metrics: (i) Scorr_Az which defines the correlation between the observed ( $\left.\mathrm{N}_{\text {obs }}\right)$ and predicted $\left(\mathrm{N}_{\text {pred }}\right)$ marginal detection number in the direction $\theta_{\text {Amax }}$ versus time $(t)$ :

$$
S_{\text {corr_Az }}=C_{\text {corr }}\left[N_{\text {obs }}\left(\theta_{\text {Amax }}, t\right), N_{\text {pred }}\left(\theta_{\text {Amax }}, t\right)\right]
$$

and (ii) $\mathrm{S}_{\text {corr_Amp }}$ for the correlation between the predicted and observed amplitude $A_{\max }$.

$$
S_{\text {corr_Amp }}=C_{\text {corr }}\left[N_{\text {obs }}\left(A_{\max }, t\right), N_{\text {pred }}\left(A_{\text {max }}, t\right)\right]
$$




\section{Results}

This section includes findings of signal detections in data acquired over a four-year observation period, from 2014 through 2017. Data from three (3) infrasound arrays - IS31, KURIS, and MKIAR, and four (4) seismic arrays - ABKAR, KKAR, Kurchatov Cross, and MKAR, were processed. For the same period, source parameters were simulated and expected signal parameters for every station were estimated. Findings of this survey are presented on charts, which show measured azimuths and amplitudes and expected signal parameters. The charts presented cover the whole observation period in general and four winter months of the season 2016-2017 in detail. This section only includes a brief description of the findings, which are discussed explicitly in Section 4 - Discussions.

\subsection{Microbarom detections as recorded by infrasound subnetwork and simulation results}

Records of the Kazakh national infrasound arrays were reprocessed using the PMCC detector. Results are presented for the detected azimuths and amplitudes. Results for IS31 are also presented although their bulletins were kindly provided by CEA.

Signals from the ocean waves are successfully extracted from the records at all IGR infrasound and seismic arrays. Diagrams in this section show the backazimuths of the signals as a function of time. Distributions of the maximum amplitudes as a function of time are included as well. The amplitude maxima are found in the PMCC bulletins each 6 hours of the entire investigation period of 2014-2017. Figure 51 shows results for IS31 infrasound array. 
a)

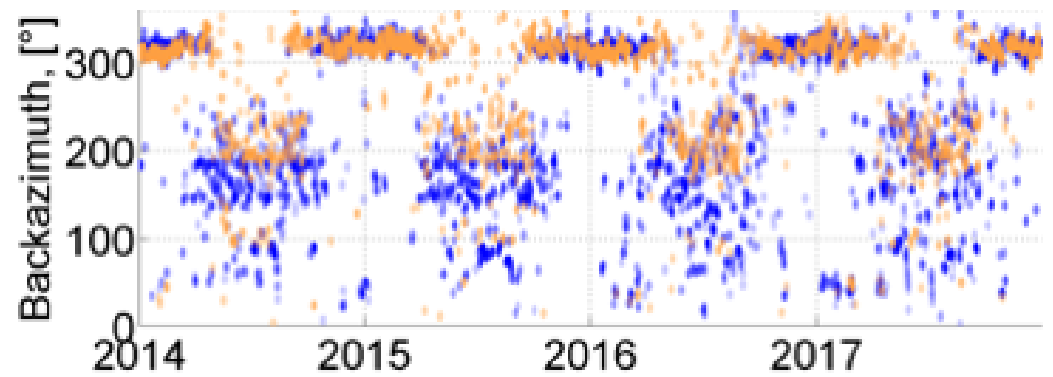

b)

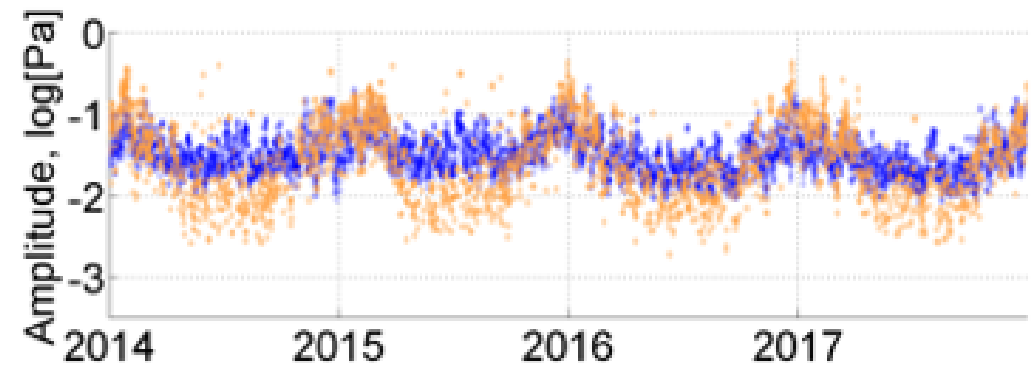

c)

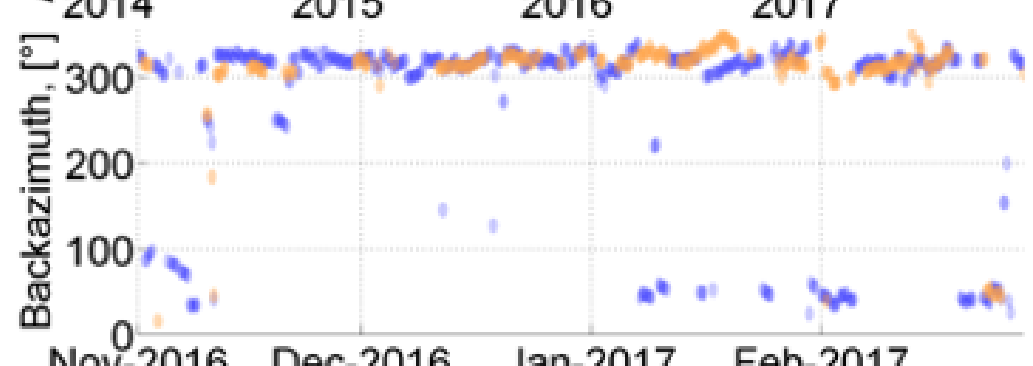

d)

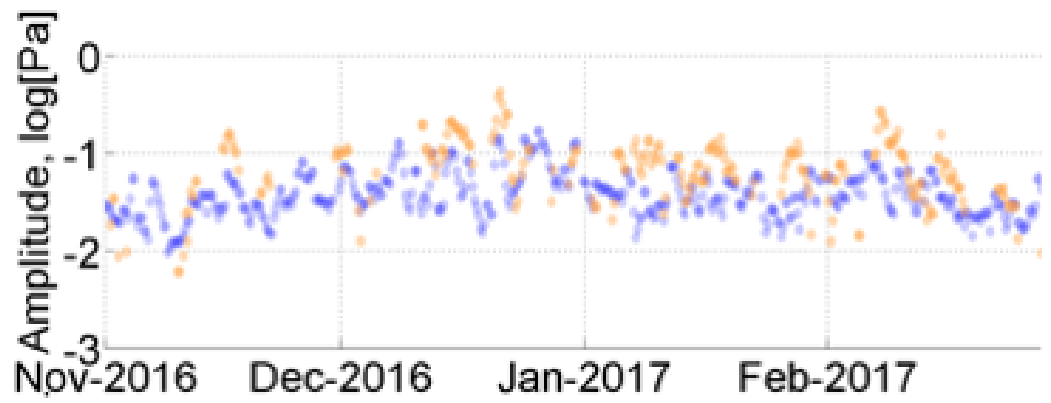

Figure 51. Dominant back-azimuth (a) and amplitude (b) of infrasound signals at IS31 from January 1, 2014 to December 31, 2017. Simulated values of these parameters are marked with blue circles. Figures (c) and (d) show details from November 1, 2016 to February 28, 2017

In addition to the observations, the diagrams represent the simulated microbarom parameters. The graphs show seasonal trends in back-azimuth and amplitude temporal variations. Amplitudes are the highest in winter where detections with back-azimuths of $320 \pm 20^{\circ}$ prevail. During summer months, signals with back-azimuths of $210 \pm 50^{\circ}$ dominate. A small amount of signals with $35 \pm 15^{\circ}$ is observed in winter. The amplitudes range from $\sim 0.001$ to $~ 0.5$ Pa varying from the largest values in winter to minimum values in summer.

Figure 52 shows the results for KURIS. 
a)

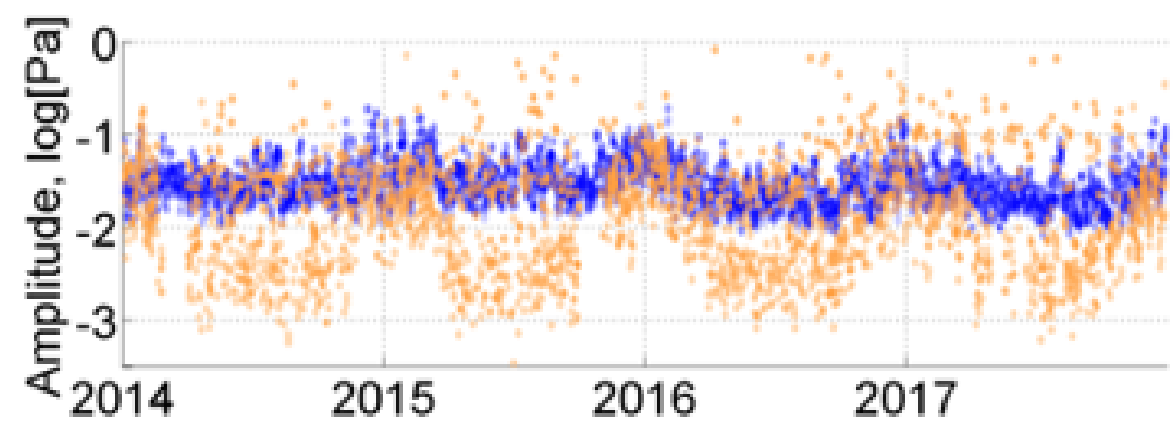

b) $\pi 0$

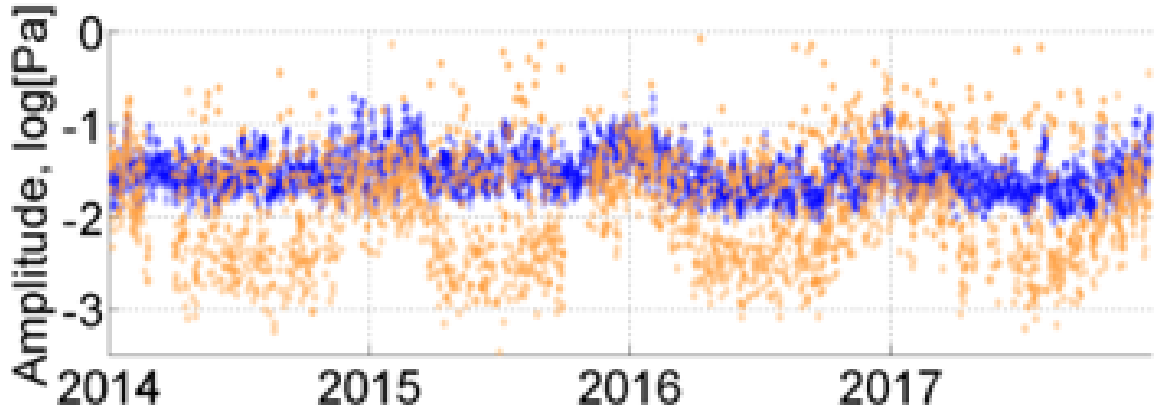

c)

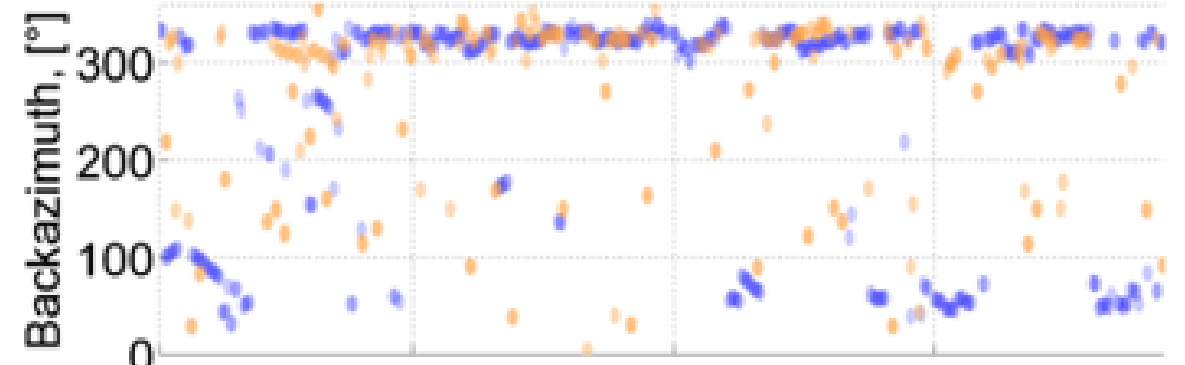

d)
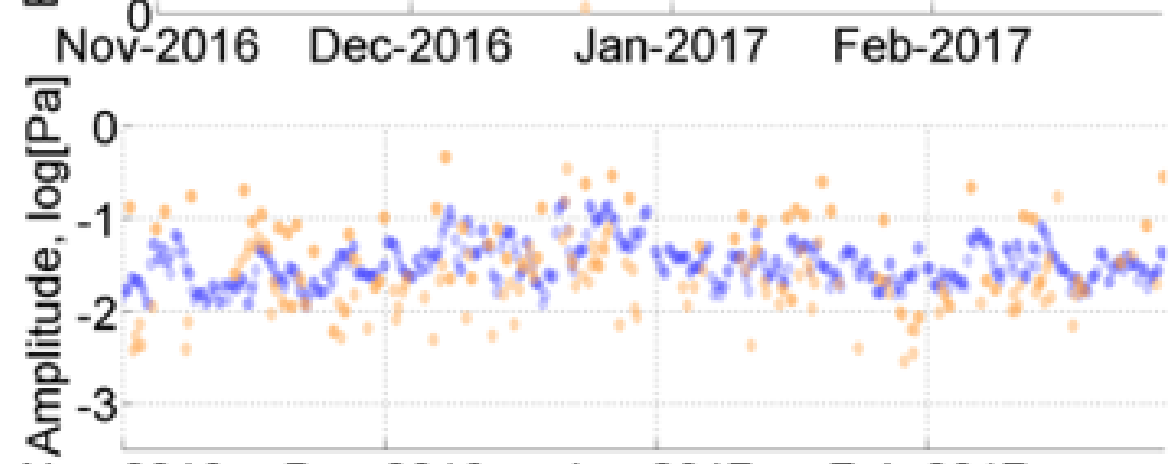

Nov-2016 Dec-2016 Jan-2017 Feb-2017

Figure 52. Dominant back-azimuth (a) and amplitude (b) of infrasound signals at KURIS from January 1, 2014 to December 31, 2017. Simulated values of these parameters are marked with blue circles. Figures (c) and (d) show details from November 1, 2016 to February 28, 2017

Parameters of microbaroms detected at KURIS are pretty similar to those detected at IS31. The averaged backazimuth in winter is about $5^{\circ}$ larger. In winter, back-azimuths peaked at $325 \pm 15^{\circ}$. There are two detection clusters during the summer months at $230 \pm 30^{\circ}$ and $130 \pm 30^{\circ}$. Some sporadic detections with back-azimuth near $50^{\circ}$ are observed in winter. Short-time variations of amplitudes are similar to those at IS31. Amplitudes reach their maximum in winter and minimum in summer, ranging from 0.001 to $0.5 \mathrm{~Pa}$. 
Figure 53 shows results at MKIAR. MKIAR is a new array. It started recording infrasound signals in August 2016. As for IS31 and KURIS, the available observations allow extracting seasonal features. One cluster of detections at $330 \pm 10^{\circ}$ is observed in winter while in summer there are clusters in summer at $230 \pm 25^{\circ}$ and $110 \pm 25^{\circ}$. The seasonal amplitude variation is $0.001-0.5 \mathrm{~Pa}$.

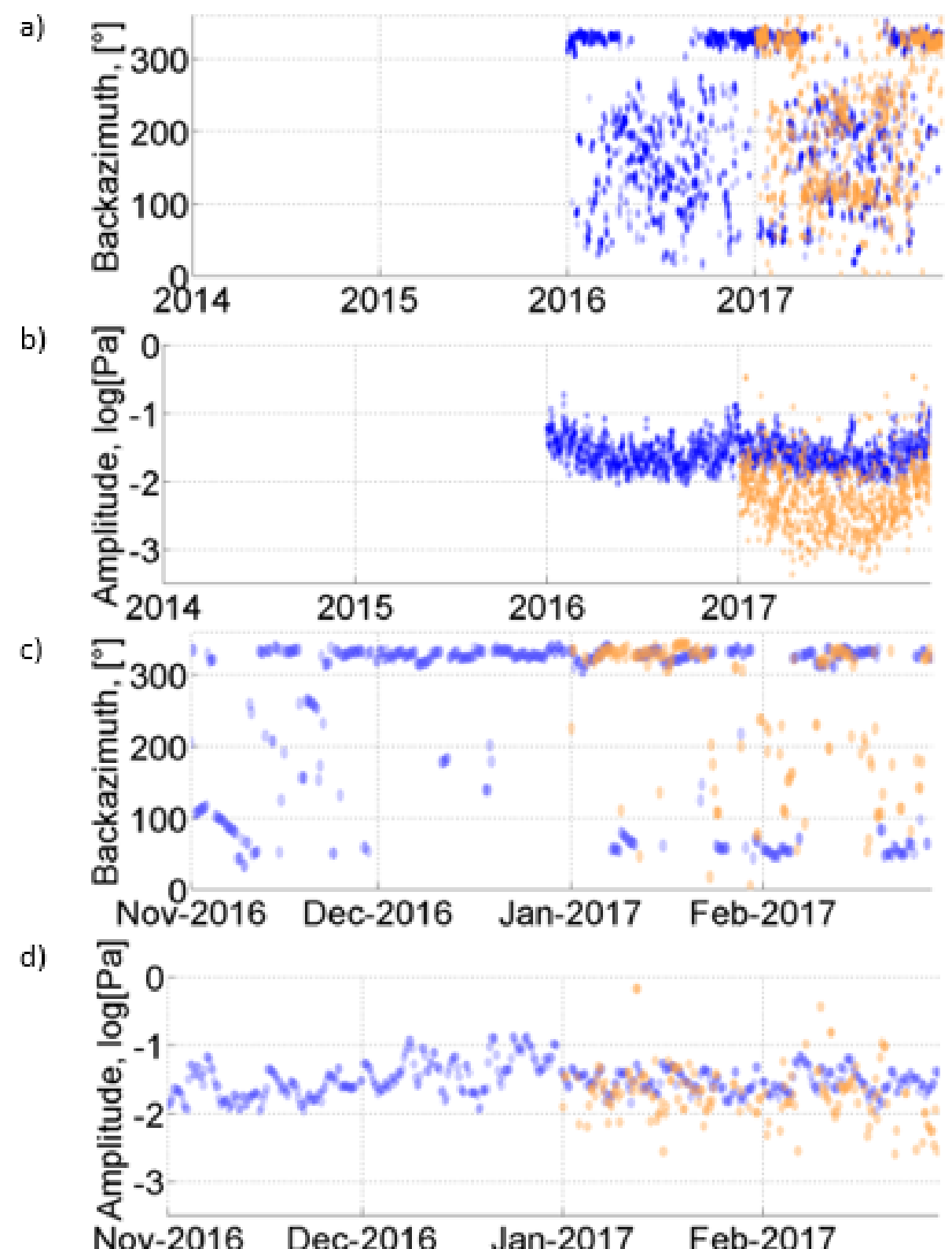

Figure 53. Dominant back-azimuth (a) and amplitude (b) of infrasound signals at MKIAR from January 1, 2017 to December 31, 2017. Simulated values of these parameters are marked with blue circles. Figures (c) and (d) show details from November 1 (January 1 for observed values), 2016 to February 28, 2017 


\subsection{Microseism detections as recorded by seismic sub-network and simulation results}

It is not correct to declare that the seismic records were reprocessed. Actually KNDC doesn't provide routine processing for seismic data using the PMCC detector. Thus in many senses the results presented here is the first experience of the massive processing of seismic records with the PMCC detector, at least at the KNDC. As for microbaroms, historical seismic records were analyzed to study microseisms. Microseism signals are detected in the 0.1-0.4 Hz frequency band.

The main results of the processing are presented for the detected azimuths and amplitudes. Comparisons of the observed and predicted parameters for microbarom focal source areas are based on infrasound data that have been previously analyzed by Smirnov et al. (2020, under review). Signals from the ocean storms are successfully extracted from the records at all IGR seismic arrays. Diagrams in this section show the backazimuths of the signals as a function of time. Distributions of the maximum amplitudes are included as well. The amplitude maxima are found in the PMCC bulletins each 6 hours of the entire investigation period of 2014-2017.

Figure 54 shows results at ABKAR seismic array. 
a)

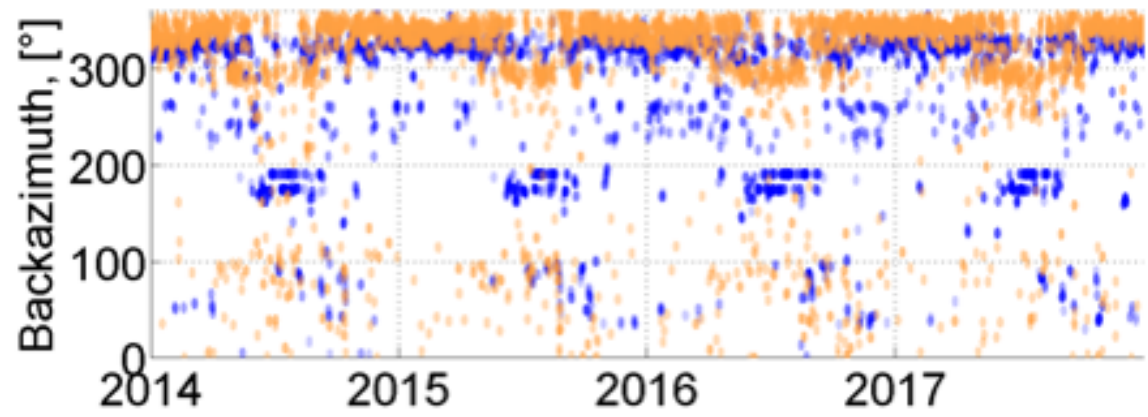

b)

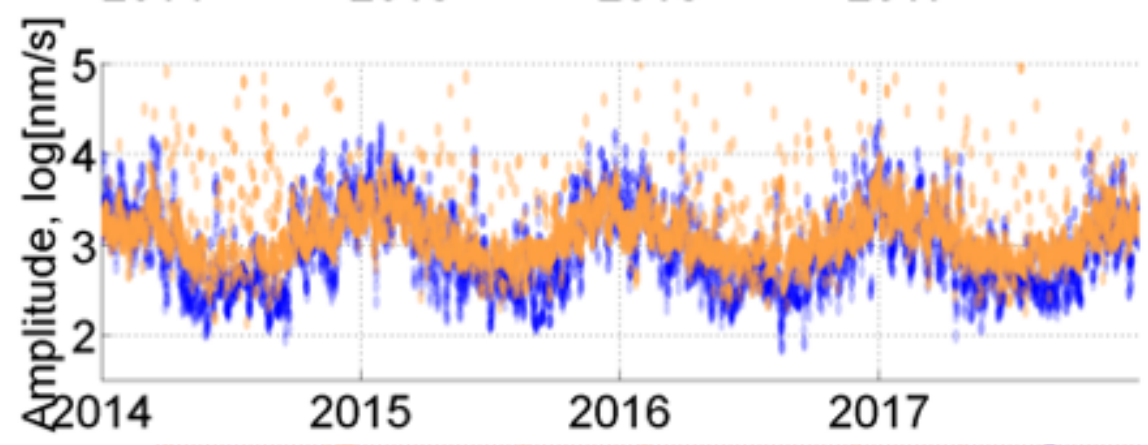

c)

d)

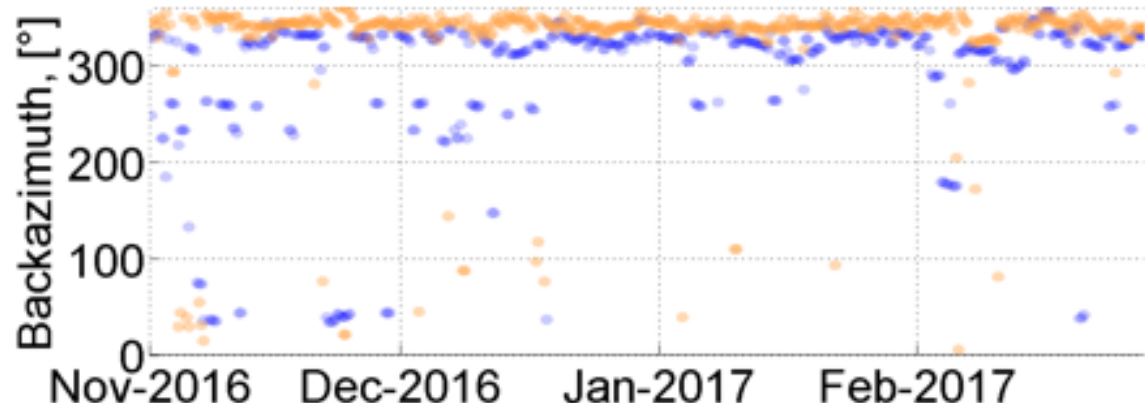

5

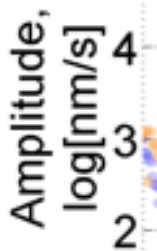

\section{Nov-2016 Dec-2016 Jan-2017 Feb-2017}

Figure 54. Dominant amplitude and backazimuth of microseisms at ABKAR every 6 hours from January 1, 2014 to December 31, 2017. Simulated values of these parameters are marked with blue circles. Figures (c) and (d) show details from November 1, 2016 to February 28, 2017

In addition to the observations, the diagrams represent the simulated microseism parameters. The procedures for calculating the predicted back-azimuth and amplitude of microseisms differed from the method applied for defining such parameters of microbaroms. The effect of seismic amplitude resonance enhancement was applied for specific ocean areas where the water depth is within the defined limits (Longuet-Higgins, 1950). The bathymetry effect was considered similar to the method described by Stutzmann (Stutzmann et al., 2012). The graphs show seasonal trends in back-azimuth 
and amplitude temporal variations. Amplitudes are the highest in winter where detections with backazimuths of $340 \pm 20^{\circ}$ prevail. During summer months, signals with back-azimuths of $290 \pm 20^{\circ}$ dominate. The amplitudes range from $\sim 250$ to $\sim 10000 \mathrm{~nm} / \mathrm{s}$ varying from the largest values in winter to minimum values in summer.

Figure 55 shows the results at Kurchatov Cross.

a)

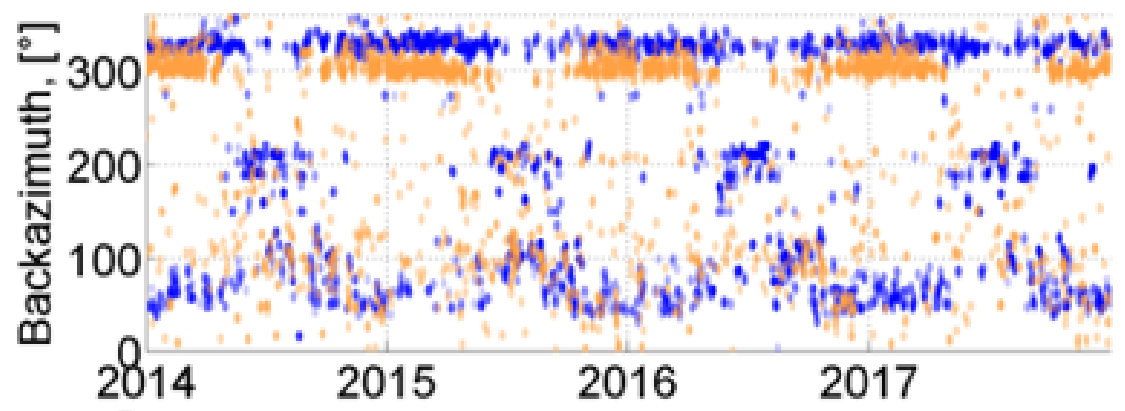

b)

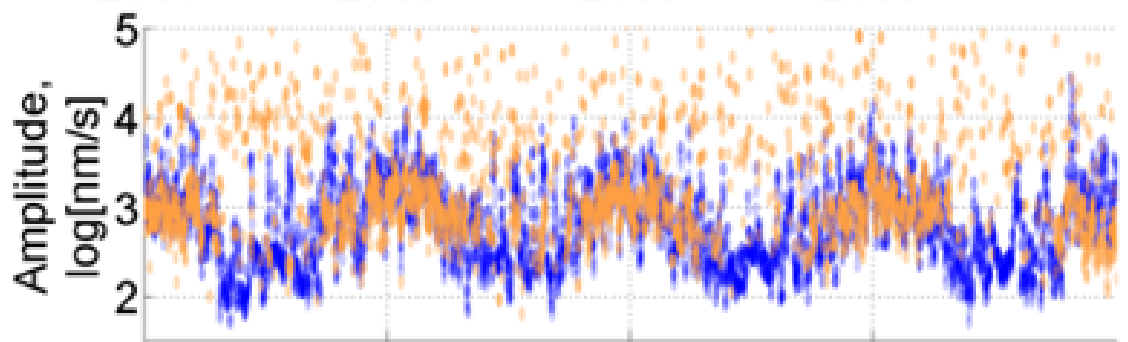

c)

d)
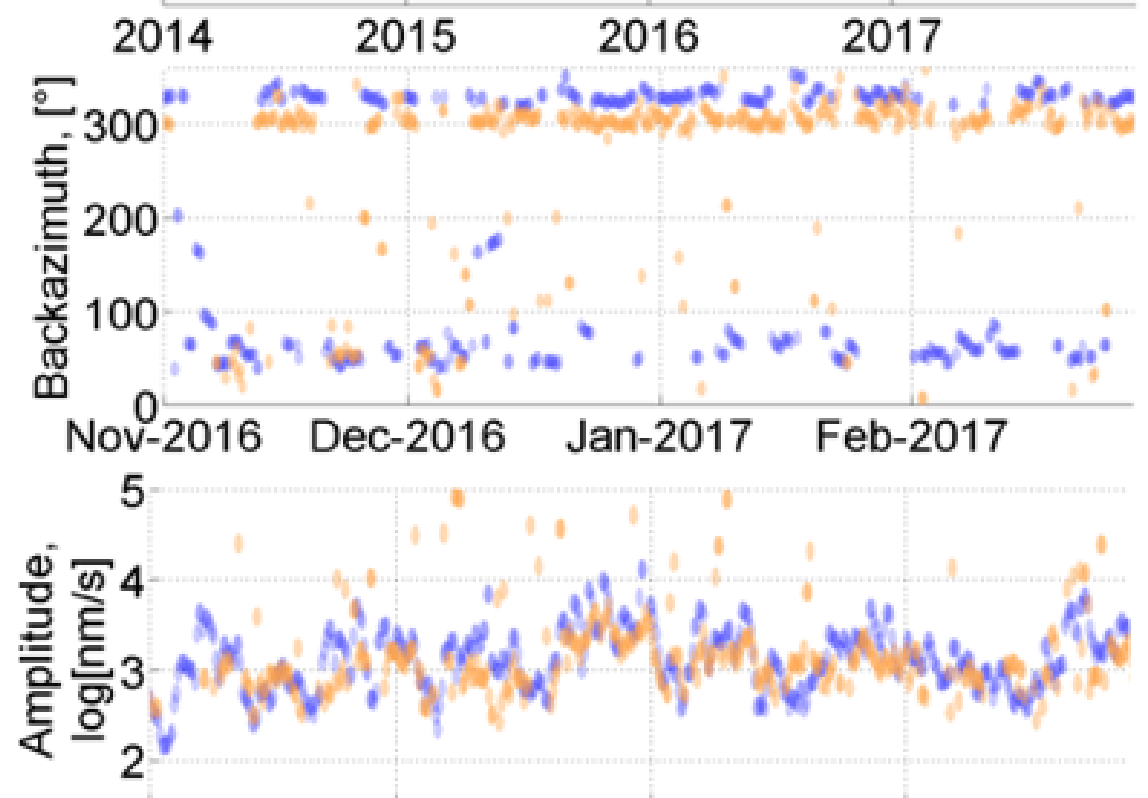

\section{Nov-2016 Dec-2016 Jan-2017 Feb-2017}

Figure 55. Dominant amplitude and backazimuth of microseisms at Kurchatov Cross from January 1, 2014 to December 31, 2017. Simulated values of these parameters are marked with blue circles. Figures (c) and (d) show details from November 1, 2016 to February 28, 2017

Parameters of microseisms detected at Kurchatov Cross are not similar to those detected by ABKAR. In winter, back-azimuths of microseisms are $300 \pm 20^{\circ}$. A small amount of signals with $50 \pm 50^{\circ}$ is 
observed in summer. Amplitudes reach their maximum in winter and minimum in summer, ranging from 250 to $5000 \mathrm{~nm} / \mathrm{s}$.

Figure 56 shows results at KKAR. Two clusters of detections at $330 \pm 20^{\circ}$ and $5 \pm 5^{\circ}$ are observed in winter while in summer there are clusters at $160 \pm 20^{\circ}$ and $190 \pm 15^{\circ}$. The seasonal amplitude variation is 250 to $\sim 9000 \mathrm{~nm} / \mathrm{s}$.

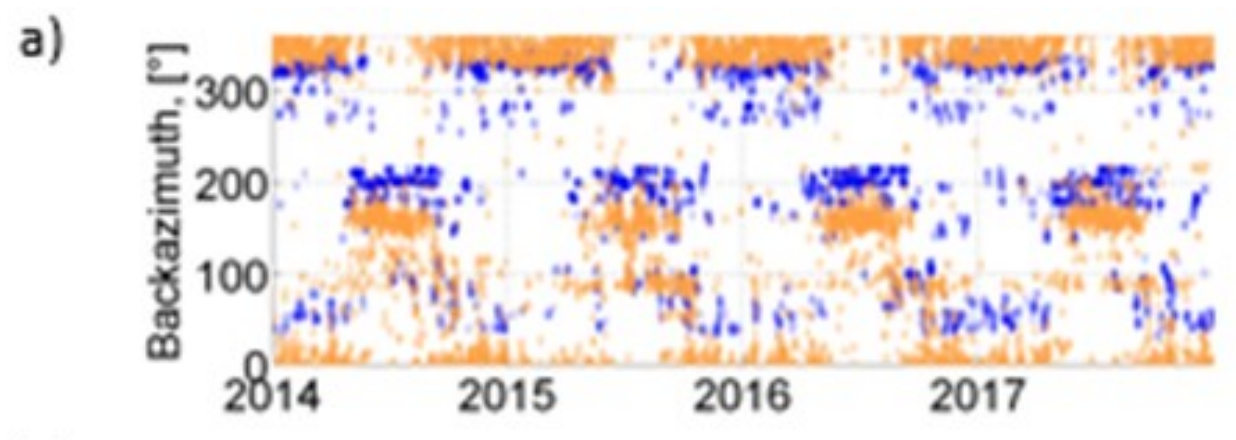

b)

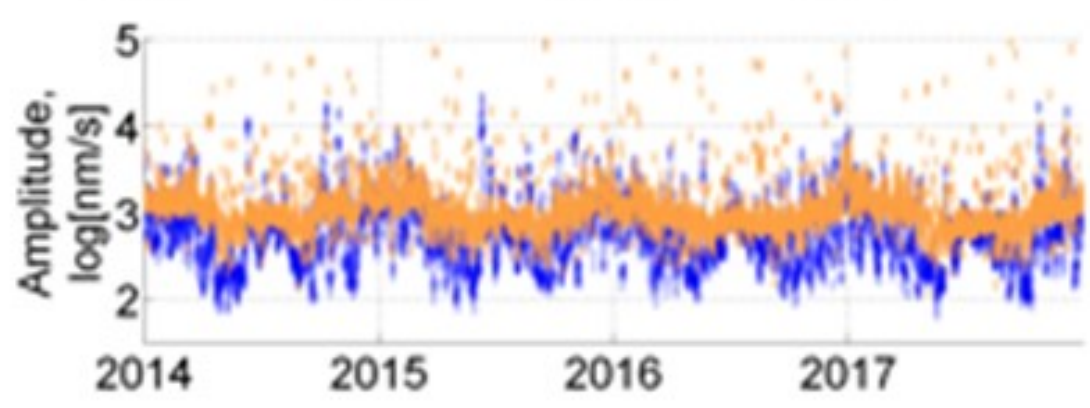

c)

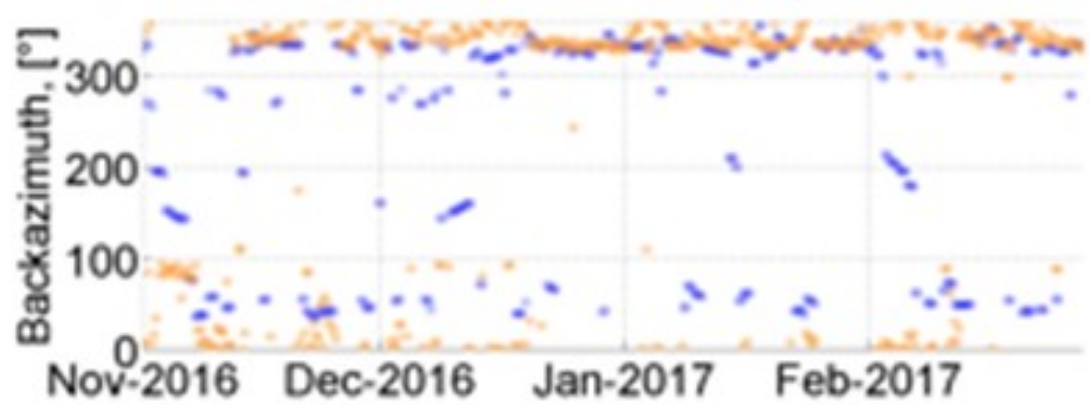

d)

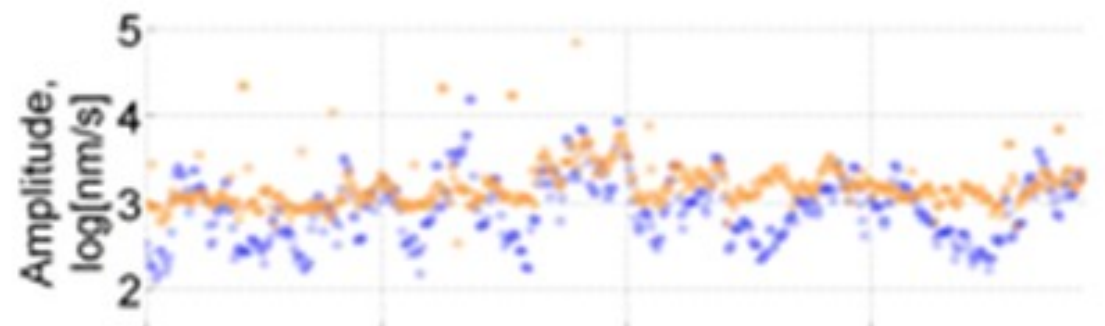

\section{Nov-2016 Dec-2016 Jan-2017 Feb-2017}

Figure 56. Dominant amplitude and backazimuth of microseisms at KKAR from January 1, 2014 to December 31, 2017. Simulated values of these parameters are marked with blue circles. Figures (c) and (d) show details from November 1, 2016 to February 28, 2017. 
Figure 57 shows results at MKAR. Two clusters of detections at $310 \pm 20^{\circ}$ and $5 \pm 5^{\circ}$ are observed in winter while in summer there are clusters at $130 \pm 10^{\circ}$ and $180 \pm 10^{\circ}$. The seasonal amplitude variation is $\sim 250$ to $\sim 3000 \mathrm{~nm} / \mathrm{s}$.

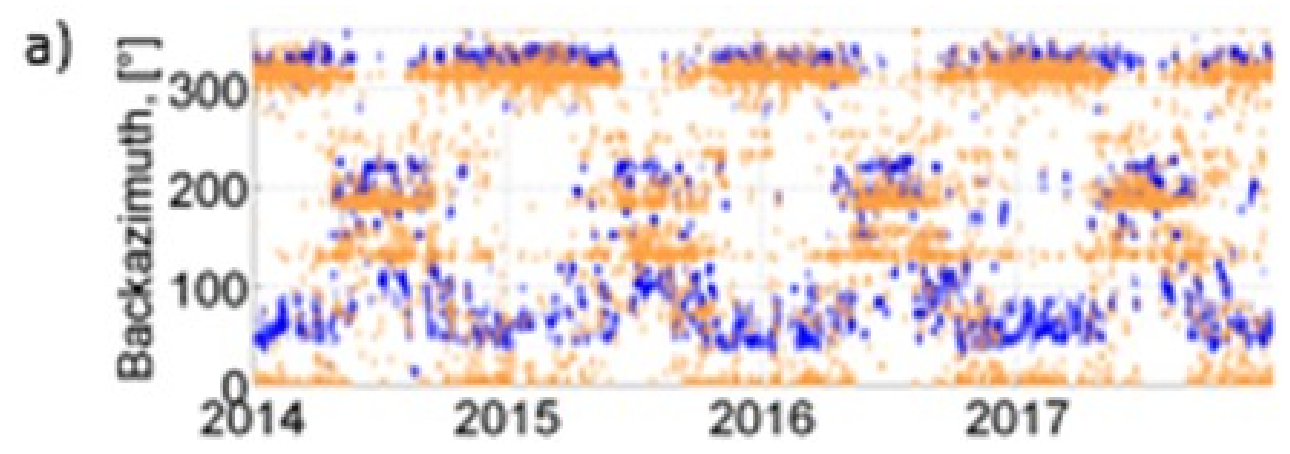

b)

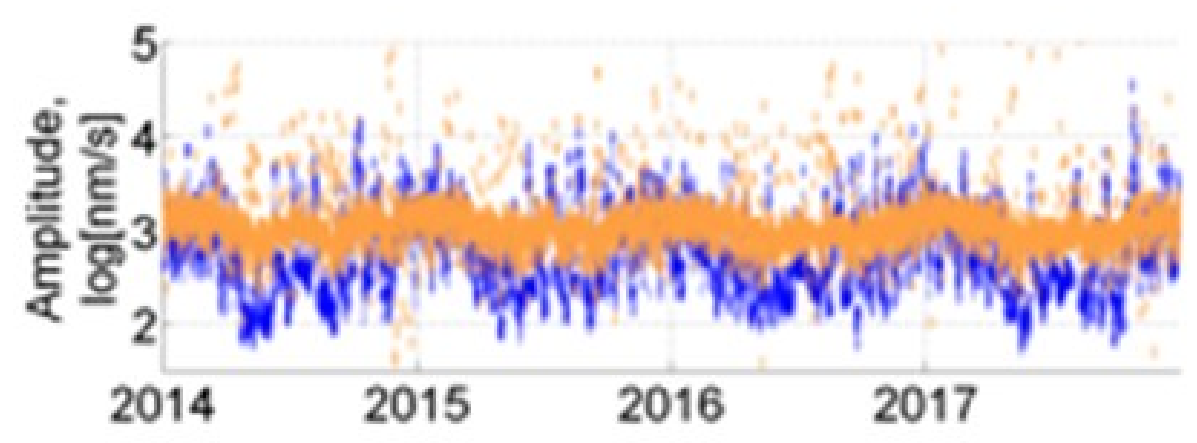

c)

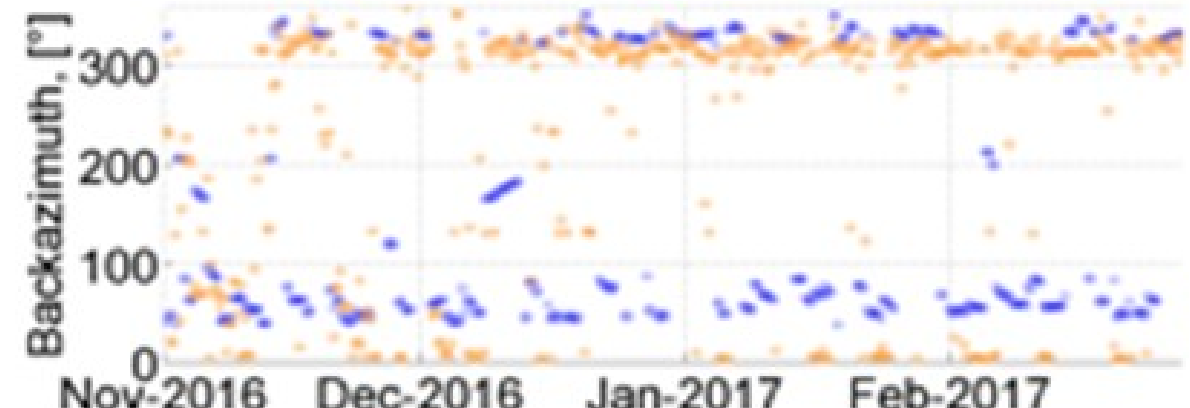

d)

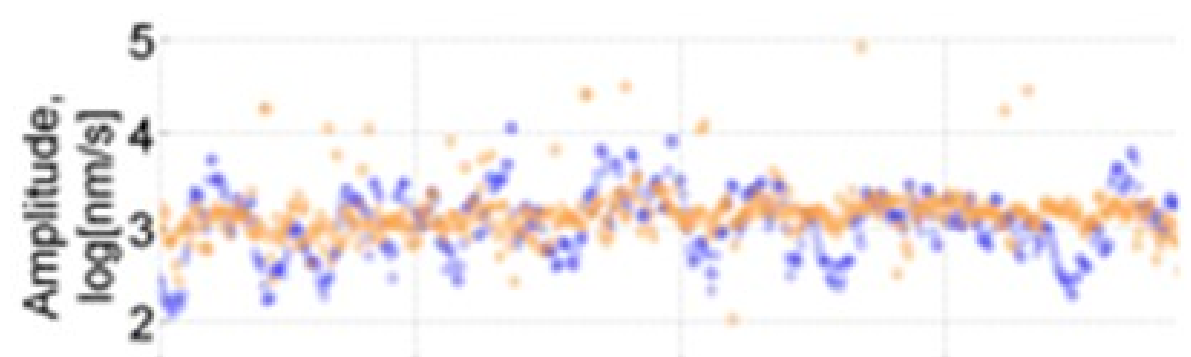

\section{Nov-2016 Dec-2016 Jan-2017 Feb-2017}

Figure 57. Dominant amplitude and backazimuth of microseisms at MKAR from January 1, 2014 to December 31, 2017. Simulated values of these parameters are marked with blue circles. Figures (c) and (d) show details from November 1, 2016 to February 28, 2017 


\section{Discussions}

A distinctive feature of this study is that it reviews observation results of a seismic-acoustic network, instead of a single array. This approach helped to define microbaroms and microseisms common observations for the whole of Kazakhstan and to track consistent patterns of their parameters changing over this vast territory. The section starts with a discussion of the joint analysis of signal detections and the simulation results. Signal arrival directions common both for the infrasound and seismic sub-networks are presented in this study. We also show the evolution of these common direction with the stations. The observed microbarom backazimuths have much better agreement with simulation results compared to microseisms backazimuths, at the same time no doubts arise that in winter months all arrays of the network register signals from the common source. The excellent similarity of multi-year and seasonal fluctuations of microseisms amplitudes and microbarom backazimuths at seismic and infrasound arrays correspondingly expressly supports the hypothesis of the common source. Further in the section, we review the influence of SSW on infrasound distribution. We show that only during SSW events, the infrasound sub-network registers microbaroms from the North Pacific. One of the facts which could not be explained completely during this study is a significant non-agreement between the observed and simulated backazimuths of microseisms. Similar to the previous study (Smirnov et al., 2010), errors in backazimuths detections were analyzed for signals from accurately localized strong earthquakes to explain this mismatch. This section describes the tailored technique for the calculation of corrections and an example of similar observations during the study of signals from strong teleseismic events using Alp Array data (Kolinsky and Bokelmann, 2019). Also, this Section includes a simulation of the velocity heterogeneities influence on Rayleigh wave distribution (Kolinsky and Bokelmann, 2019). Finally, the results obtained after the application of these corrections show that though these corrections cannot fully explain non-agreement, they decrease its absolute value considerably. Besides, this section demonstrates the results of observation data comparison for collocated seismic and infrasound arrays. The observed similarity of amplitudes and backazimuths behavior also confirms the above thesis that both microbaroms and microseisms source for Kazakhstan arrays is one and the same, at least in winter months. We will be able to confirm or disprove this theory for summer months only after adequate correction of SSSC influence on microseisms backazimuths and localization of the source epicenter with cross-bearing. Further in this Section, findings of such localization for microbaroms are presented. As expected for winter months, microbaroms sources are localized in the North Atlantic based on infrasound observations. Besides, in the summer period, according to the Kazakhstan infrasound sub-network, microbaroms sources are located in the southern hemisphere. As to our knowledge, such observation is the first-ever. However, 
it shall be noted that the more relevant range-dependent atmosphere model shall be used for more precise localization. This section also includes know-how for application of microbarom backazimuths observation and simulation findings to develop the database of GT events. We show that sometimes measured microbarom backazimuths agree well with the expected ones. We suggest using such known expected source locations as GT event epicenters. On the other hand, cases of non-agreement between the observed and expected backazimuths are evidently corresponding to situations when an ocean waves model is not absolutely relevant, and they may be used as a reference for improving the model. Further in this Section, we review a theoretical possibility for using ocean storm signals to study the atmospheric structure. At the end of the section, we discuss that infrasound propagation expectedly depends on the direction and force of the winds in the atmosphere. The proof thereof is based on a comparison of the effective sound speed profiles and long-term observations.

\subsection{Joint analysis of the detection results}

\subsubsection{Dominant direction of microbaroms}

In contrast to the single station studies performed by De Carlo et al. (2018) and Hupe et al. (2018), microbarom signals recorded by a dense seismo-acoustic network are here analyzed. Analyzing this set of data allows highlighting regional features of both microbaroms and microseisms.

\subsubsection{Common microbarom/microseism backazimuths throughout network}

Figure 58 shows the histograms of backazimuth distribution of microbarom detections. 
a)
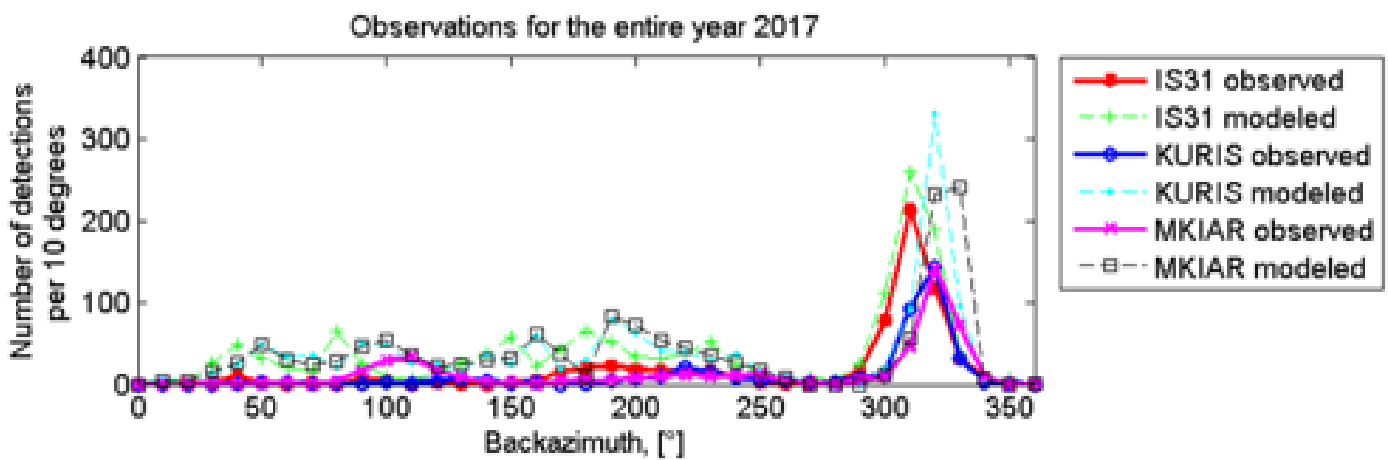

b)
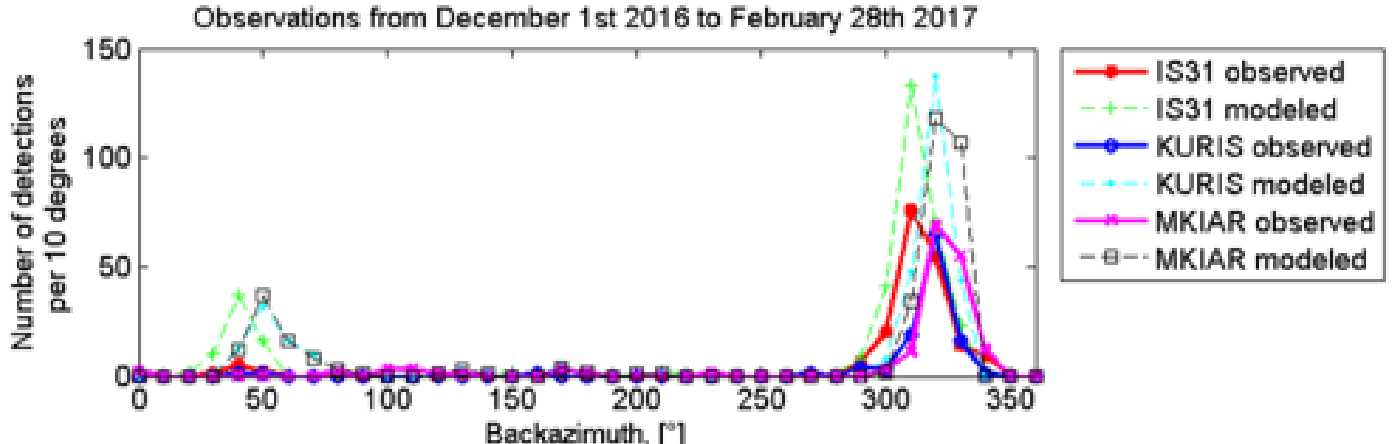

c)

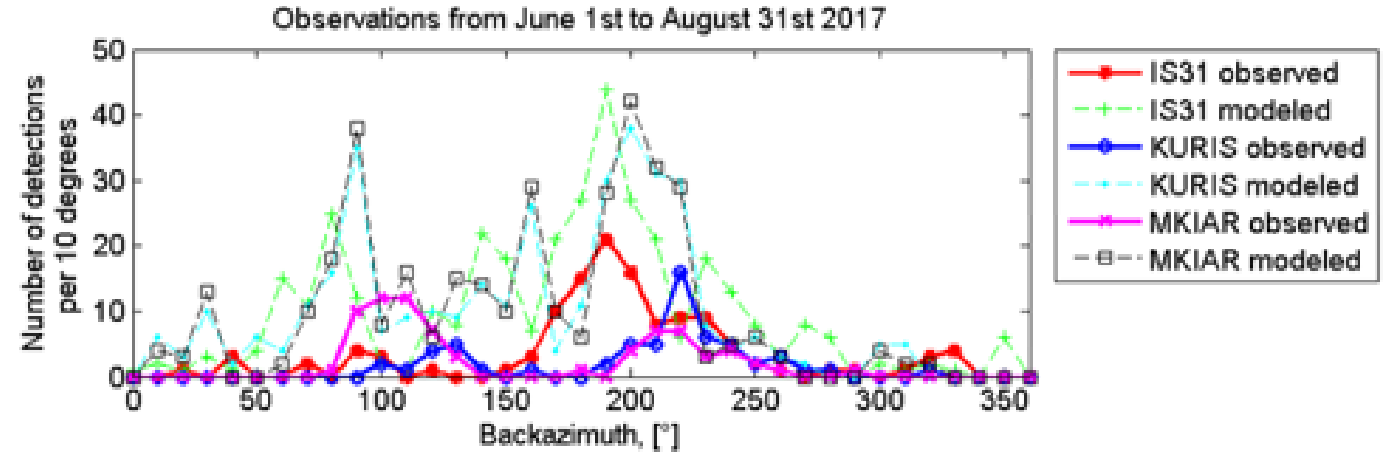

Figure 58. Histograms of azimuthal distribution of microbaroms: (a) entire year of 2017. (b) . from December 1, 2016 to February 28, 2017. (c) from June 1 to August 31, 2017. Detections with maximum amplitudes are selected every 6 hours

Figure 59 shows similar histograms for seismic detections. 


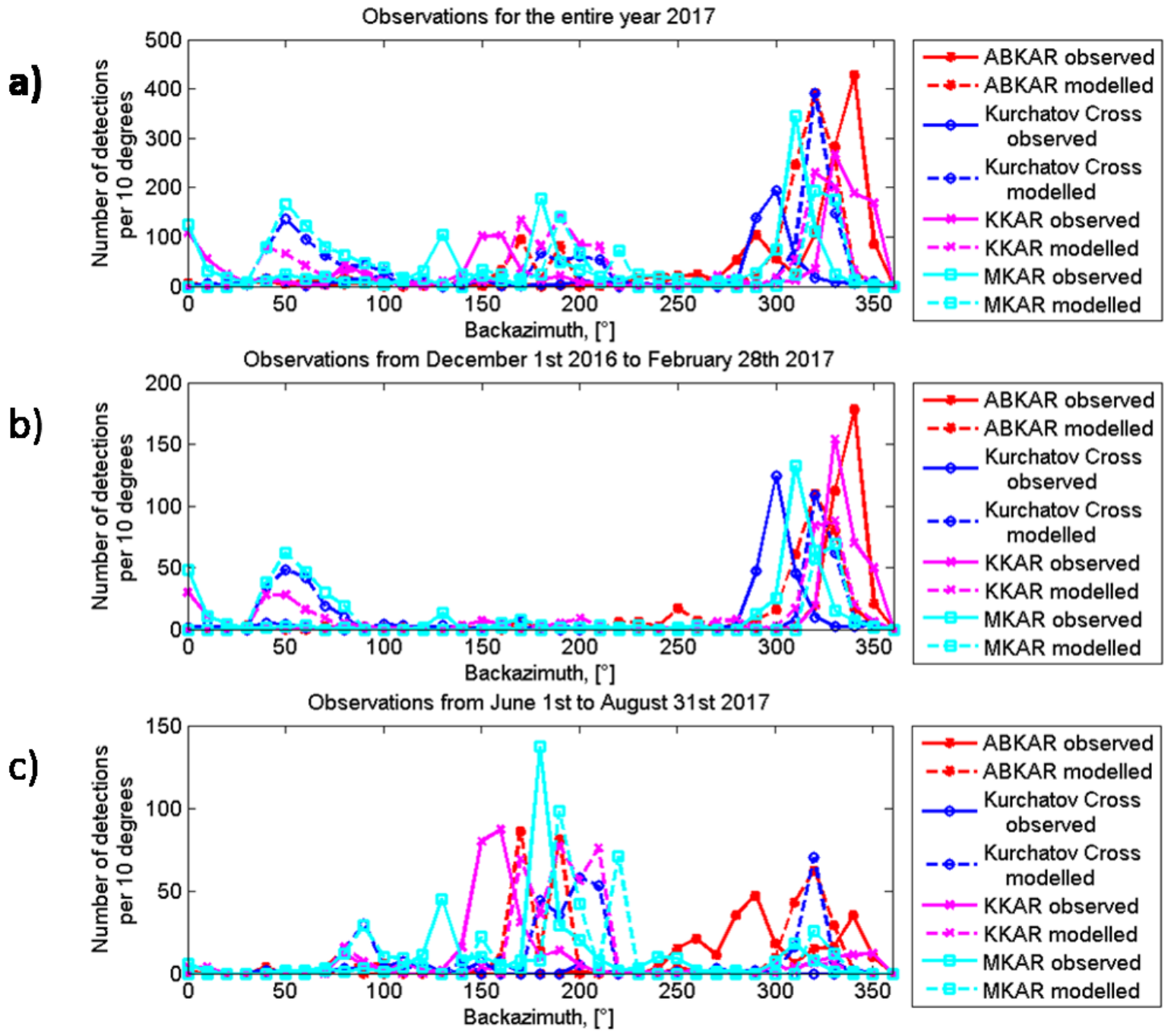

Figure 59. Dominant backazimuths of seismic signals in the $0.1-0.4 \mathrm{~Hz}$ band detected at seismic arrays: (a) entire year of 2017, (b) from December 1, 2016 to February 28, 2017, (c) from June 1 to August 31, 2017

Similar features are observed for both infrasound and seismic detections. Microbaroms and microseisms originate from north and northwest in winter (Figure 58 b and Figure 59 b). Signals dominate from southeast, south and southwest in summer (Figure $58 \mathrm{c}$ and Figure 59 c). ABKAR, KKAR and MKAR detect signals from northwest, which dominate at ABKAR.

The use of the dense seismo-acoustic Kazakh network allows extracting common microbarom and microseism observed in the entire network. Backazimuths could vary from one station to another depending on location of the main source regions with respect to the stations. The observations and predictions of the source areas indicate that their locations are seasonally dependent. Stutzmann et 
al. (2009) showed that in Northern and Sothern hemispheres noise amplitude is larger during local winter. Similar direction of arrivals is clearly visible in the azimuthal distributions during winter months (Figure $58 \mathrm{~b}$ ). The dominant directions of arrival at all stations range between $270^{\circ}$ and $350^{\circ}$. The predicted back-azimuths during winter months coincide with the observations (Figure 51 c, Figure 52, Figure 52 c, Figure 53, Figure 53 c, Figure 58 b). In winter, microseisms exhibit similar trends with some differences (Figure 54 c, Figure 55 c, Figure 56 c, Figure 57 c, Figure 59 b). The dominant directions are comparable with a larger spreading: from $250^{\circ}$ to $360^{\circ}$ and from $0^{\circ}$ to $20^{\circ}$. At KKAR and MKAR, two peaks are seen in the histograms, with a second peak at $0-20^{\circ}$. These peaks are apparently explained by registration of the North Pacific microseisms. Dominant directions of microbaroms from $180^{\circ}$ to $200^{\circ}$ are modelled. Only observations at IS31 and MKAR match these predictions. At KURIS and MKIAR the nearest peaks are shifted $\sim 50^{\circ}$ northward. A dominant cluster predicted near $90^{\circ}$ is observed at $\operatorname{MKIAR}\left(\sim 100^{\circ}\right)$.

Dominant amplitudes of low-frequency detections for the entire observation period from January 1 , 2014 through December 31, 2017 are presented in Figure 60 for the four seismic arrays.

a)

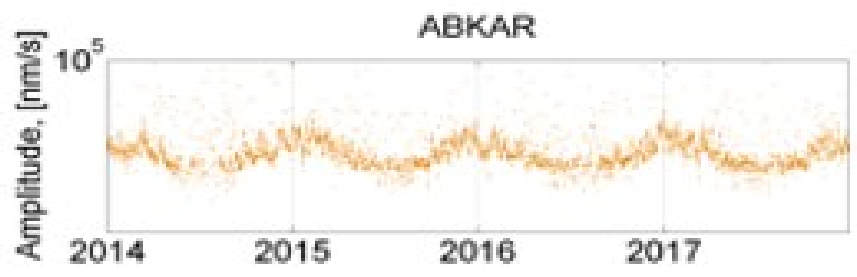

b)

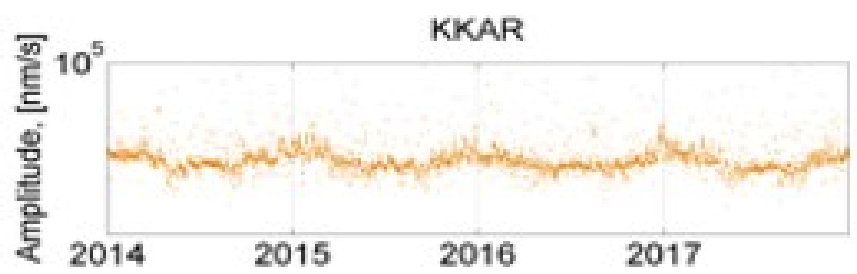

c)

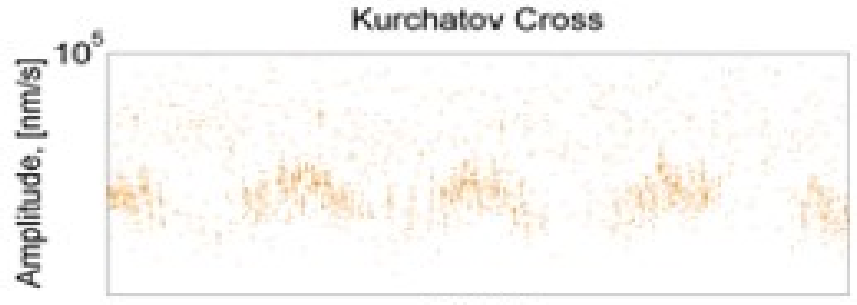

d)

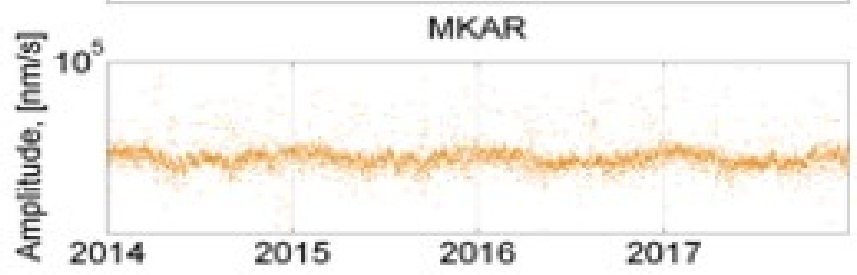

Figure 60. Dominant amplitudes of seismic signals in the $0.1-0.4 \mathrm{~Hz}$ band detected at ABKAR (a), KKAR (b), Kurchatov Cross array (c) and MKAR (d) arrays from January, 12014 to December 31, 2017 
In winter, amplitudes of microseisms behave similarly from station to another. Maximum amplitudes are observed in winter and the minimum ones in summer. Amplitudes of microbarom detected by MKAR and KKAR show some rise in summer, peaking in mid-summer. No similar rise is detected at ABKAR. Kurchatov Cross array detects relatively small amount of low-frequency signals in summer. There is also a good consistency from one station to another station on monthly time scale compared to the seasonal variations (Figure 61).

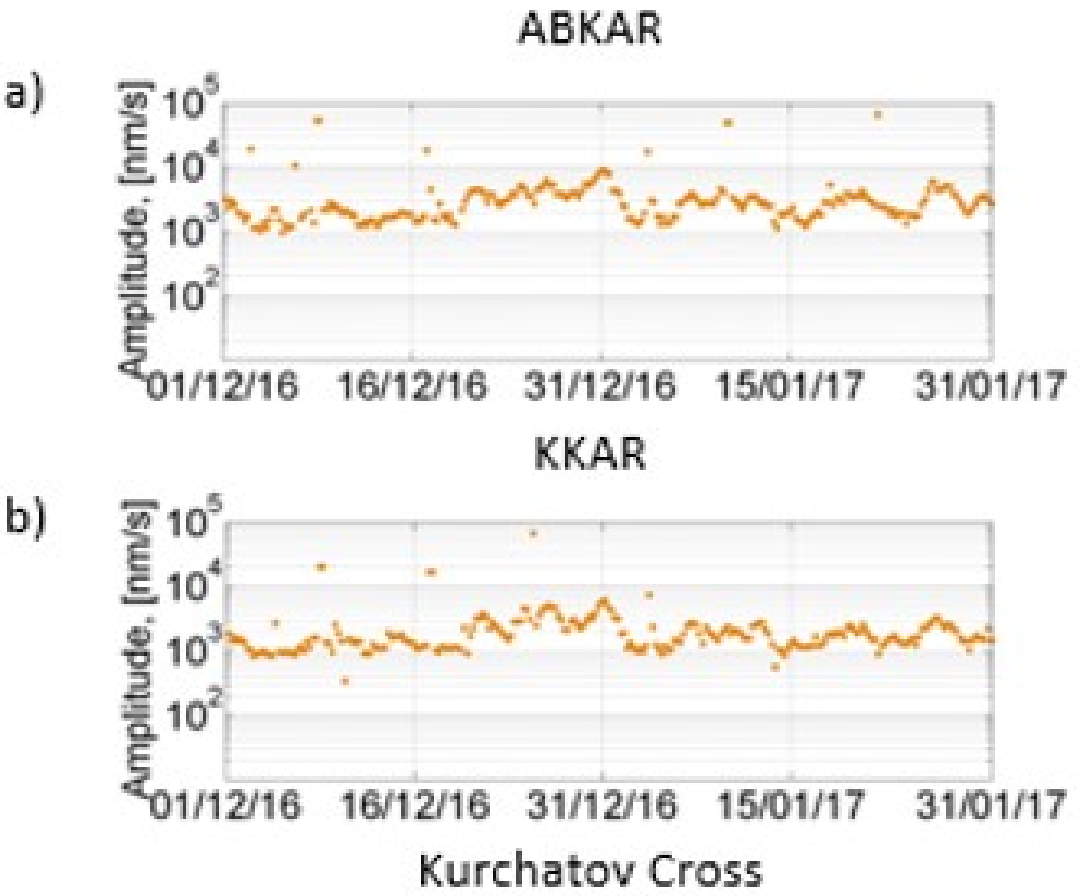

c)

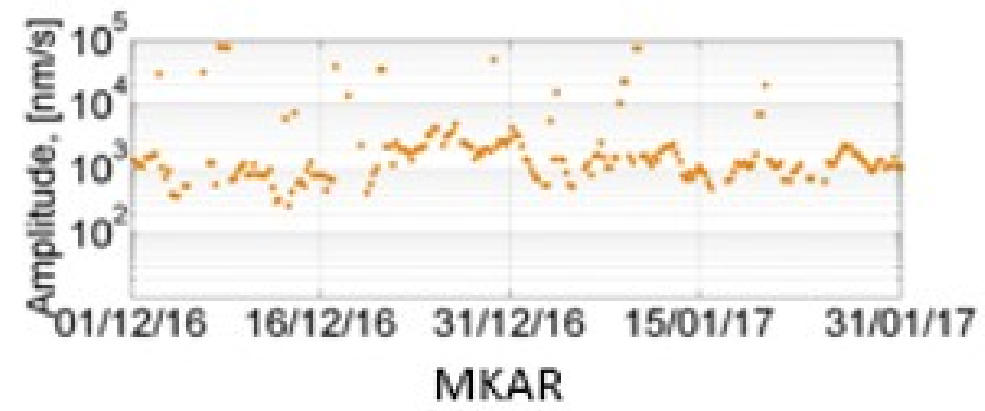

d)

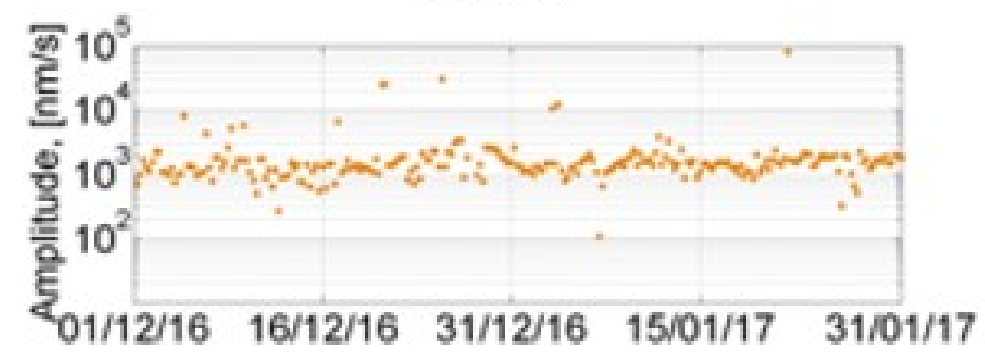

Figure 61. Dominant amplitude of seismic signals in the 0.1-0.4 Hz band detected at ABKAR (a), KKAR (b), Kurchatov Cross array (c) and MKAR (d) arrays from December 1, 2016 to January 31, 2017 
Detections at ABKAR, KKAR and Kurchatov Cross array are comparable (Figure 61). The effect is less pronounced at MKAR compare with the other stations.

To summarize, signals from North Atlantic storms dominate amongst detections at all stations during winter months as confirmed by the microbarom and microseism simulations. More complicated picture is observed during summer months. Some stations detect signals from regions along the periAntarctic belt while simulations predict microbaroms with larger amplitude in summer. Other stations detect signals from the south, but the detected backazimuths disagree with the predictions. For these regions, the use of the simplified attenuation simulation is not relevant, more especially when sources and receivers are located in different hemispheres.

These analyses allow studying the spatio-temporal variation of microbaroms resulting from both the temporal fluctuations of microbarom source regions where the strongest storms occur, and the temporal variability of the structure of the middle atmosphere. There is an overall good seasonal correlation between the observed and simulated microbarom and microseism backazimuths and the amplitude (Figure 51 and Figure 57). In addition, the amplitude of microseisms is varying simultaneously at all the stations at a multiannual and sub-seasonal scale (Figure 60 and Figure 61). Microbaroms exhibit similar features (Figure 62). 

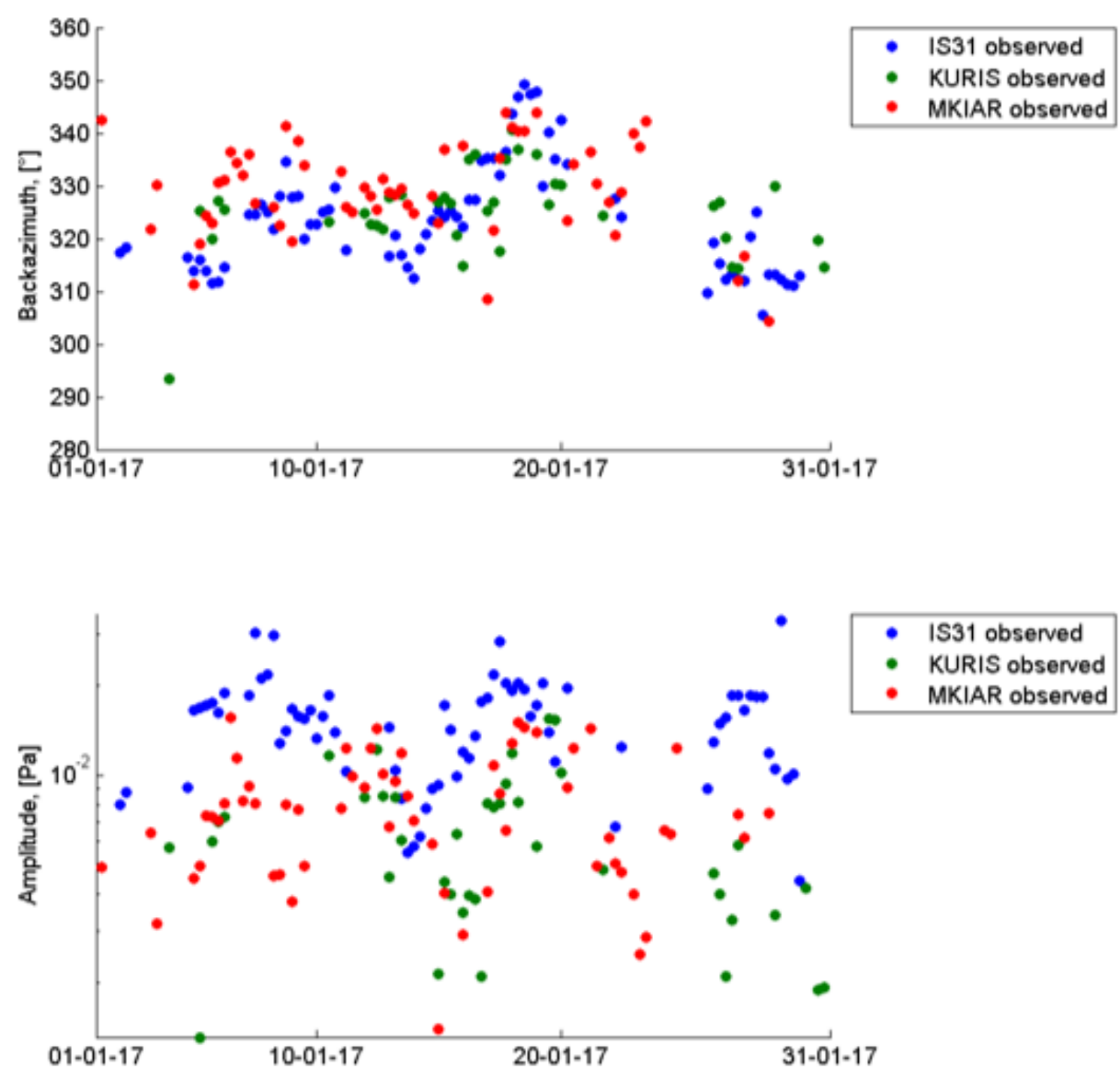

Figure 62. Spatial-temporal variability of microbaroms detected by IS31, KURIS and MKIAR in January 2017. Top panel: backazimuth. Bottom panel: amplitude

\subsection{Spatio-temporal variability of microbarom signals}

Using historical IGR datasets, the spatiotemporal variability of microbarom signals due to changes in the source location and the structure of the atmospheric waveguides can be studied.

\subsubsection{Sudden stratospheric warming}

As already shown by Evers and Siegmund (2009) and Smets and Evers (2014), life cycle of SSW events can be inferred from the observed spatio-temporal variations of microbarom parameters. Such observations are noted at IS31 where microbaroms in early and late February 2017 shifted to easterly directions $\left(\sim 40^{\circ}\right)$ consistent with the simulated source regions in the Northern Pacific (Figure 51). As noted at IS31, KURIS also recorded signals with azimuths of $\sim 40^{\circ}$ in late January 2017 (Figure 52). 
Similarly, signals from $\sim 100^{\circ}$ were also recorded during 2017 SSW event at MKIAR. However, the observed azimuths differ from those expected $\left(\sim 60^{\circ}\right)$. It is likely that this station recorded signals from other regions over the Pacific Ocean not described by the ocean wave model, or inaccuracy in the used ECMWF products (Blanc et al., 2018).

These findings are consistent with comparisons between the observed and modeled microbarom signals carried out by Landès (Landès et al., 2014a) at IS31. This study shows that modeling well describes microbarom sources in North Atlantic in winter and poorly explains signals in summer. This mismatch can be explained by the interference of permanent natural or anthropogenic sources overlapping microbarom signals in the same frequency band. These sources could be mining explosions (Hagerty et al., 2002), subsonic (Evers, 2005) or supersonic aircrafts (Donn, 1978; Liszka and Waldemark, 1995), as well as auroral infrasound (Wilson, 1971).

\subsubsection{Comparison of the source location results with the IFREMER model}

Figure 59 shows the prevailing observed and predicted microseism back-azimuths at all arrays. The pattern of microseism generally reproduces that of microbarom source area (Smirnov et al., under review) (Figure 59 a). In winter, microseisms are detected from northern and northwestern directions (Figure 59 b). In summer, southern, southwestern and southeastern directions dominate (Figure 59 c). However, signals from northwestern direction are also recorded at ABKAR, KKAR, and MKAR in summer. Azimuths differ from one station to another depending on the strongest microseism source regions relative to the station locations. However, the predicted azimuths differ from the observed values essentially. For example, the direction of the dominant microseism source in winter at all seismic arrays mostly matches expectations, being located at $325 \pm 5^{\circ}$, but prevailing backazimuths of observed microseisms at Kurchatov Cross and MKAR are lower than the predicted values by $25^{\circ}$ and $15^{\circ}$, respectively. On the contrary, the observed backazimuths at KKAR and ABKAR exceed the predicted ones by $5^{\circ}$ and $15^{\circ}$ respectively, while the source of these signals at all stations is the same as evidenced by a high correlation with microseism amplitude in winter (Figure 61).

\subsection{Use of the redefined static corrections}

As it was already mentioned above in Section 4, the predicted and observed microseism backazimuths mismatch essentially. It is clearly seen in Figure 63 where the predicted and observed backazimuths are shown for 4 seismic stations. An observation data is presented for winter months (2016 - 2017). This limited time period allows new detailed comparison.

Despite the fact that trends of backazimuth changes correlate well from one station to another and from simulations to observations there are clear systematic errors. The expected backazimuths shown 
in Figure 63 suggest that in most cases the source regions are common at all stations. The expected spread of the azimuths at each particular time due to the finite size of the observation network does not exceed $10^{\circ}$. However, the spread of the observed backazimuths is much larger. When showing the same datasets as presented in Figure 63, systematic error is peculiar to every station and the errors differ from station to station. Predicted values at KKAR and ABKAR are lower than the observed ones. On the contrary, at Kurchatov Cross and MKAR, they are larger. Similarly in Figure 64, in the middle, a histogram is shown for the predicted backazimuths when taking into account the backazimuth static corrections.

It is obvious that applied application of the corrections partially explains the observed systematic errors in the backazimuth measurements. Both observations and prediction with the static corrections at Kurchatov Cross and MKAR are lower than the true azimuths. The most frequent predicted backazimuth at MKAR is close to the observed one. The predicted value at Kurchatov Cross is still larger than the observed one, but the total difference between the predicted and observed azimuth is twice lower, approximately. At KKAR station, the correction application changes the sign of the total systematic error from negative to positive. However, it is noted that the error at KKAR is small comparing with other stations. The dominant predicted value for ABKAR gets closer to observations, although there is still an error. Once again, the total difference between the predicted and observed azimuths is getting twice lower. Finally, the Figure 65 shows both versions of the backazimuth prediction and the observations. 

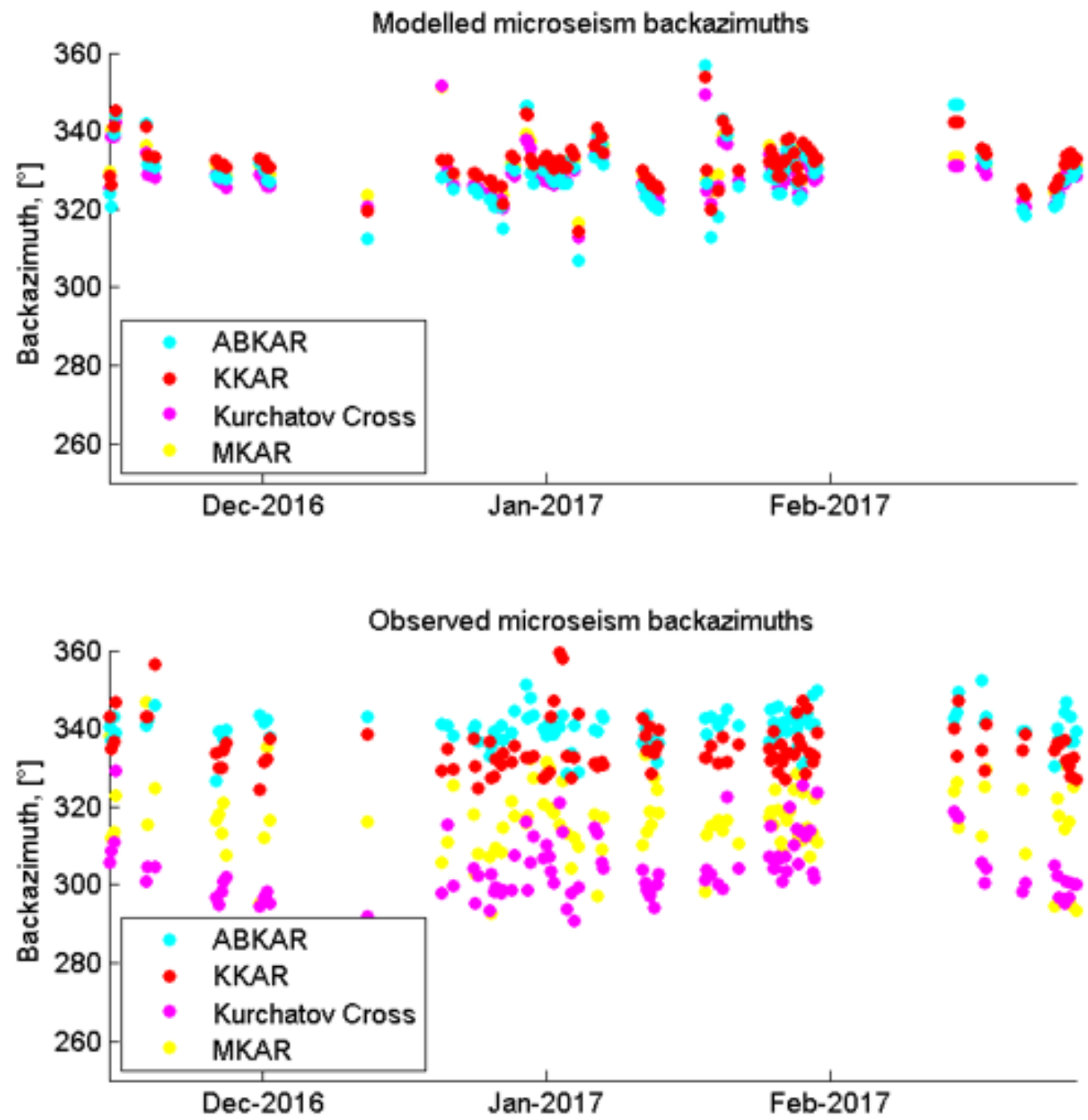

Figure 63. Predicted backazimuths for North-Atlantic microseisms for ABKAR, KKAR, Kurchatov Cross and MKAR seismic stations (upper panel). Observed backazimuths for the same stations (bottom panel) 

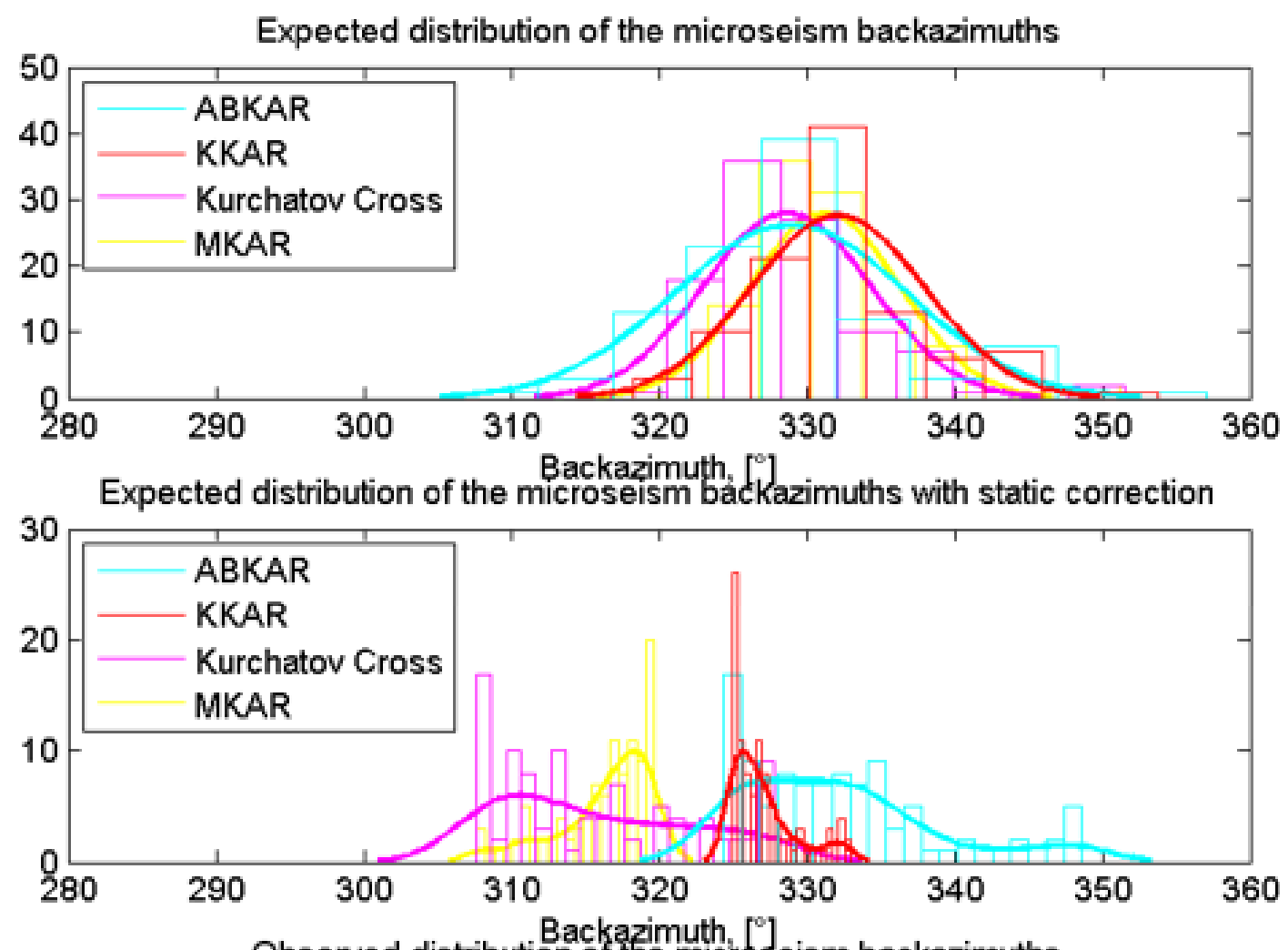

Observed distribution of the microseism backazimuths

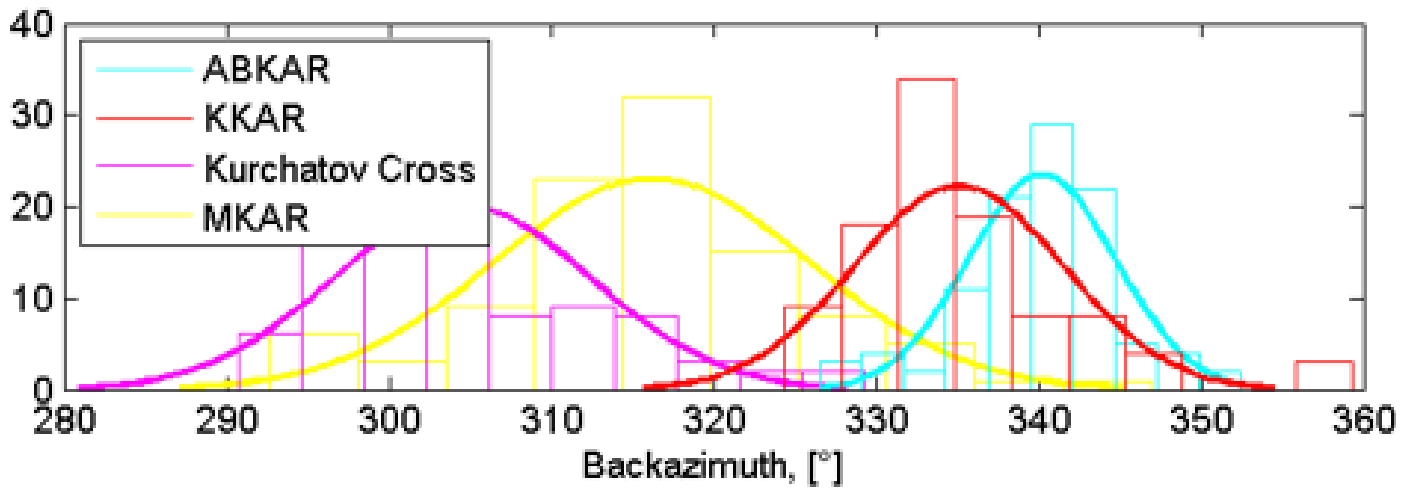

Figure 64. Histogram of the predicted backazimuths for North-Atlantic microseisms at ABKAR, KKAR, Kurchatov Cross and MKAR seismic arrays (upper panel). The observation period is from November 1, 2016 till February 28, 2017. The same histogram of the expected backazimuths built by taking into account static correction (middle plot). The static corrections depend on true backazimuth. Histogram of the observed backazimuths (bottom panel)

It is clearly seen that static correction application improves the quality of a simulation although the prediction remains not fully satisfactory. Application of the correction provides a systematic shift of the backazimuths relative to the true backazimuths at each station in the same direction where the observed azimuths are shifted. The only exception is KKAR but in this case the deviations are relatively small. The question of why the static does not fully explain the observed deviations is still open. Additional investigations are required considering the following issues: 
- To estimate the influence of the finite size of the source area. In this study, a point source is assumed but the nature of the source suggests that it could cover a large area affected by the storms. Thus, the location where the conditions for microseism generation exist could rapidly change within this area. This may drive to additional deviations of the observed backazimuths.

- $\quad$ To study static corrections for the seismic arrays that are closer to the source area using records of smaller magnitude earthquakes compared with those used in this study. In accordance with the Richter - Guttenberg law, such earthquakes are more numerous. In this case, better statistics would improve the accuracy of corrections.

\section{Modelled microseism backazimuths}

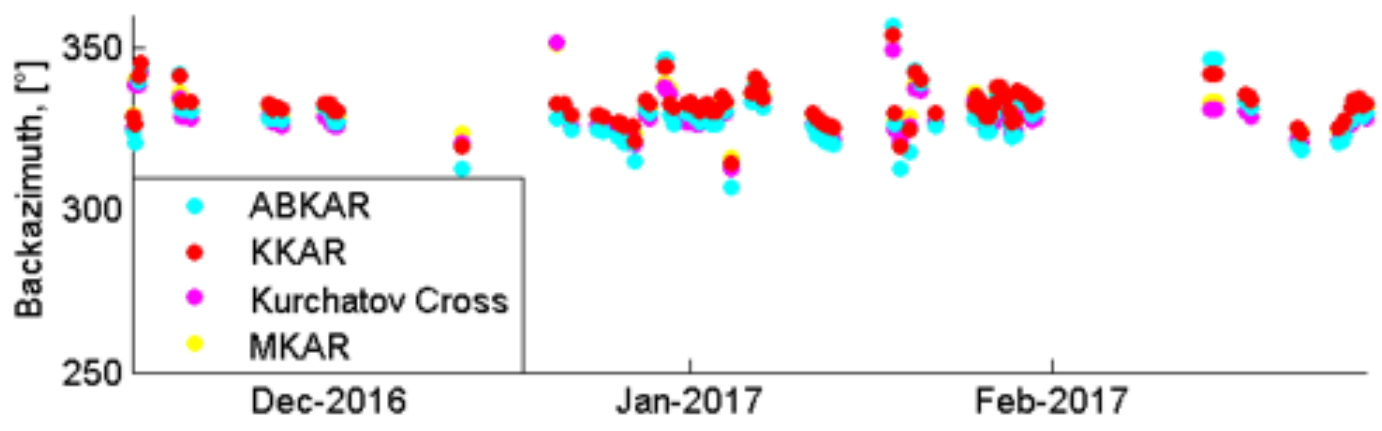

Modelled microseism backazimuths with static correction

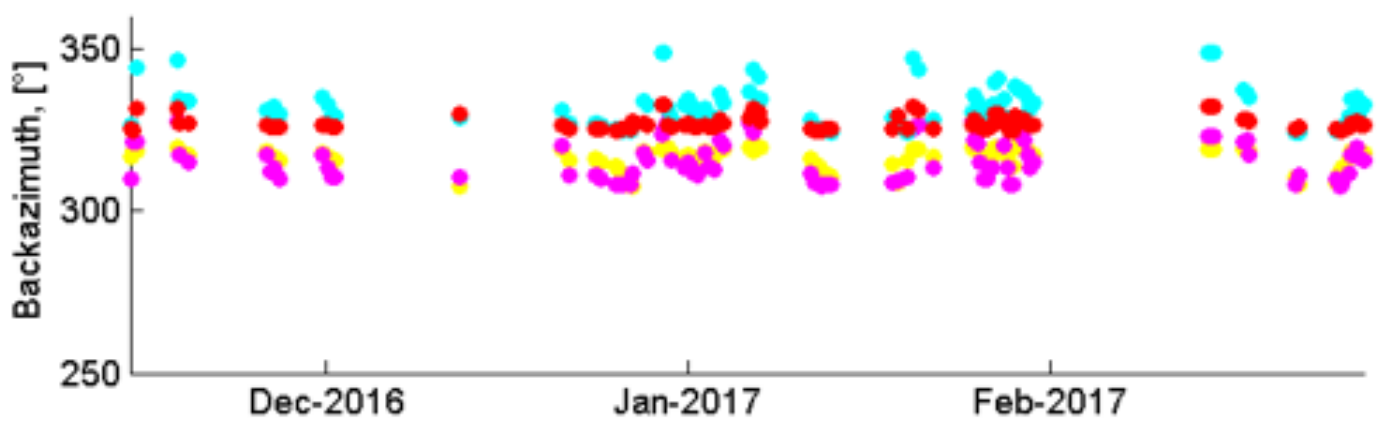

\section{Observed microseism backazimuths}

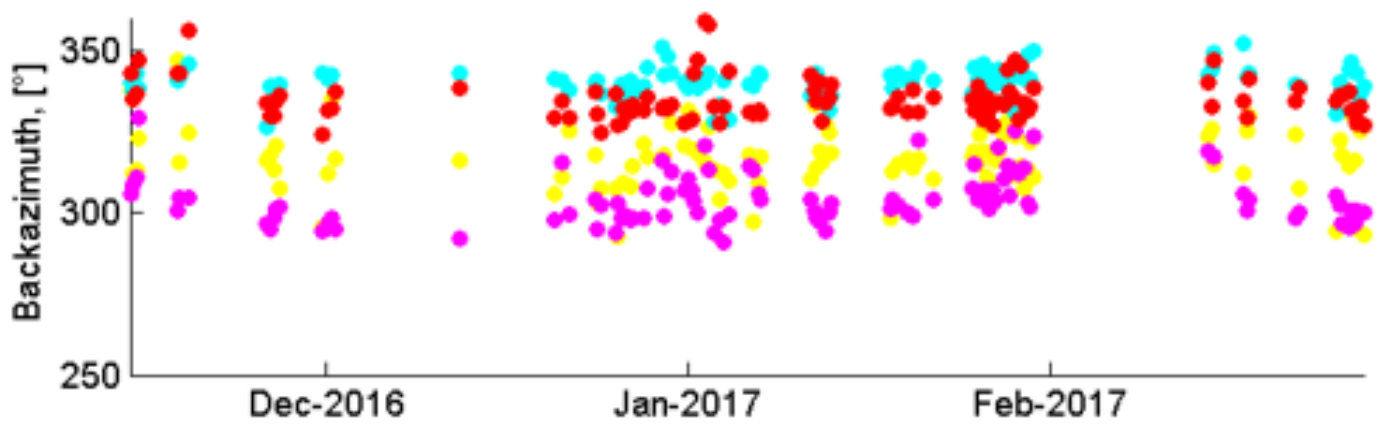

Figure 65. Predicted backazimuths of North-Atlantic microseisms at ABKAR, KKAR, Kurchatov Cross, and MKAR (upper panel). Predicted azimuths with the azimuth static corrections (middle panel). Observed values (bottom panel) 


\subsubsection{Explanation of the nature of the deviations in backazimuths for the Rayleigh waves}

What is the nature of the deviations that were found for the Rayleigh wave? Figure 66 shows the spatial distribution of the deviations at ABKAR array. The map is built as follows: for each 6-hour interval of the period from November 1, 2016 till February 28, 2017, the difference between the predicted and observed backazimuths was calculated.

As multiple detections were observed and predicted during most of the 6-hour intervals, it was needed to choose the most representative ones. The criterion for selecting such phase was the maximum RMS amplitude. The accurate localization of the microseism epicenter using this observation network is not realistic. Therefore, the epicenter of the predicted microseism source was set as a true location. In some points, microseism epicenters were predicted more than once. In this case, the deviations were averaged.

Predicted epicenters are distributed non-uniformly. The natural neighbor interpolation method was applied. As shown by Figure 66, the deviations do not depend on the epicentral distance but strongly change with backazimuths. The deviation values change with backazimuths from $-40^{\circ}$ to $+5^{\circ}$. The deviations that were found using the predicted and observed microseism backazimuths were compared to the backazimuth deviation of the Ground Truth (GT) event. The GT events are strong earthquakes that occurred in North Atlantic from 2003 till 2019 as presented by the ISC catalog (ISC website, 2020).

All strong events that occurred during the period when the Kazakh seismo-acoustic network was in operation were examined. Table 4 describes the event parameters. True backazimuths for the GT events were evaluated using the epicenter locations from ISC catalog. The observed parameters were estimated using PMCC detector. The configuration for the PMCC was the same as the one used for the microseism detection. All the detections with an apparent velocity smaller than $6 \mathrm{~km} / \mathrm{s}$ were selected.

Figure 67 shows the deviations for the microseisms and the GT events at ABKAR. The panel shows the deviations on the true backazimuths. The microseism deviations are selected at the predicted epicenters being nearest to the GT event location. For all GT events, more than one candidate detection was found (magenta dots). The solid turquoise line connects backazimuth values that correspond to the phase with the maximum RMS amplitude. The microseism deviations are shown with a red line. 


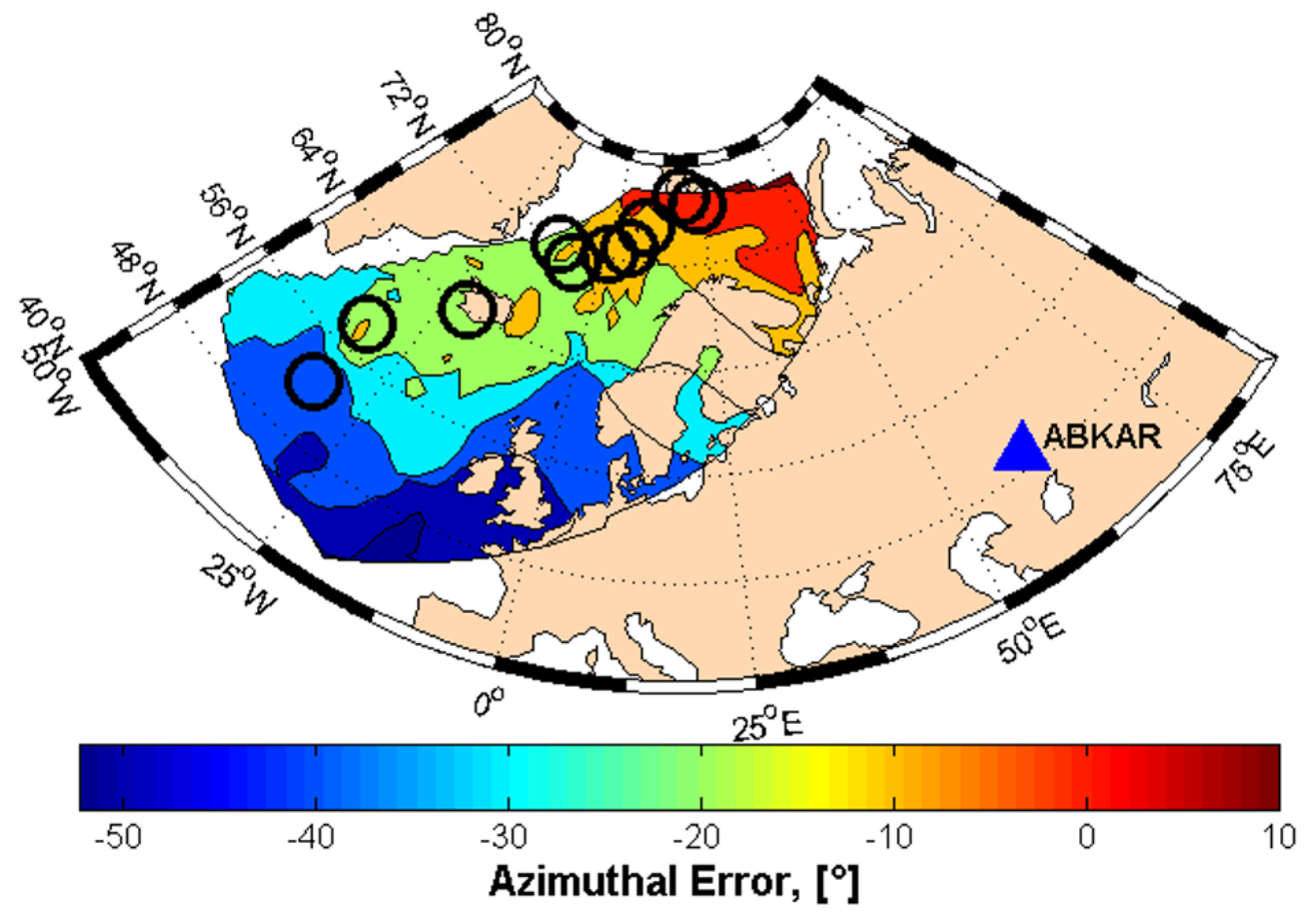

Figure 66. A map of spatial distribution of deviations in the surface wave backazimuths at ABKAR. A period from November 1, 2016 till February 28, 2017 is covered. The deviations are calculated as the difference between the predicted and observed values of the backazimuths. The phase with maximum RMS amplitude is chosen for each 6-hour interval. The deviation positions on the map correspond to the epicenters of the predicted sources. Black circles are the epicenters of the strong earthquakes chosen from the ISC catalog as the GT events

Figure 67 shows that a range of measured backazimuth deviation for some of the events is large, in some cases it exceeds $30^{\circ}$. Evidently, it is critically important to select the proper phase amongst phases of every event correctly. In general, the deviation behavior is similar in both cases of the microseisms and the earthquakes. However, there is a systematical error of $\sim 10^{\circ}$ between them. The picture of the spatial distribution is similar at KKAR (Figure 68). The same is true for the earthquake and microseisms deviations dependence for the true azimuth.

Figure 70 shows spatial distribution of the deviations for Kurchatov Cross array. Figure 71 shows the dependence of the deviations on azimuths. The pictures, in this case, are erratic in comparison to the other stations. However, it should be noted that this station is less sensitive in comparison to the others. The point is that the aperture of Kurchatov Cross is about $20 \mathrm{~km}$ that is roughly 4 times larger than the apertures of ABKAR, KKAR, and MKAR. Due to this fact, the correlation between channels is getting weaker. It does not allow to fully detect the microseisms due to the loss of coherence. 


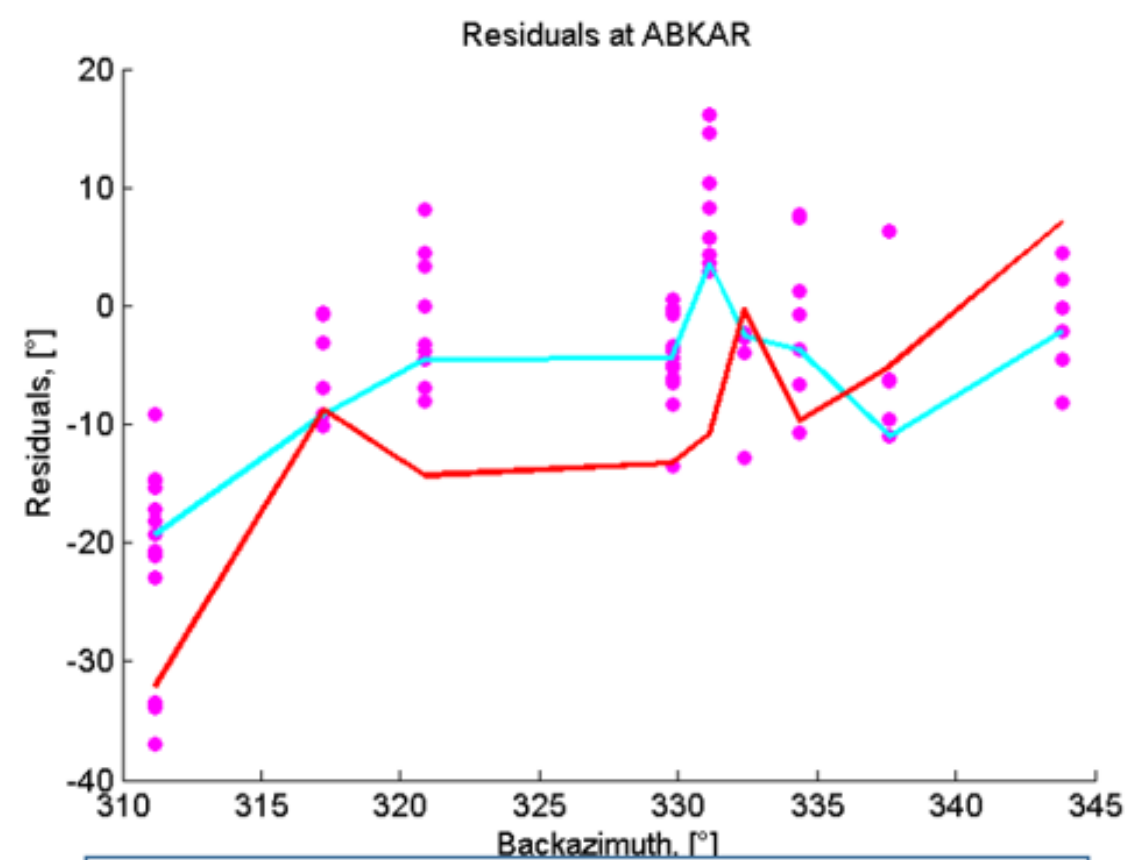

- BAZ residuals for all PMCC detections of the GT events with apparent velocity less than $6 \mathrm{~km} / \mathrm{s}$

BAZ residuals for all PMCC detections of the GT events with maximal RMS amplitude

Difference between predicted and observed BAZ of the microseisms with maximal RMS amplitude

Figure 67. Deviations in backazimuths for the surface waves from the events in North Atlantic as detected by ABKAR

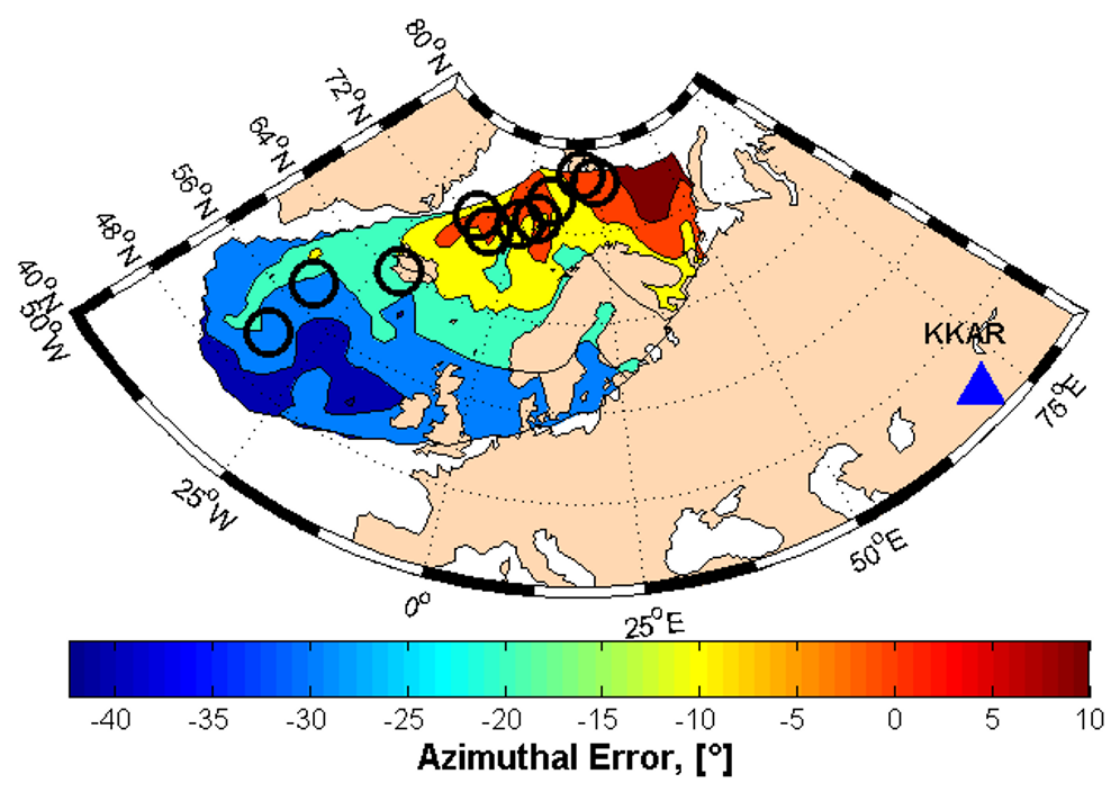

Figure 68. A map of spatial distribution of deviations in the surface wave backazimuths for KKAR 


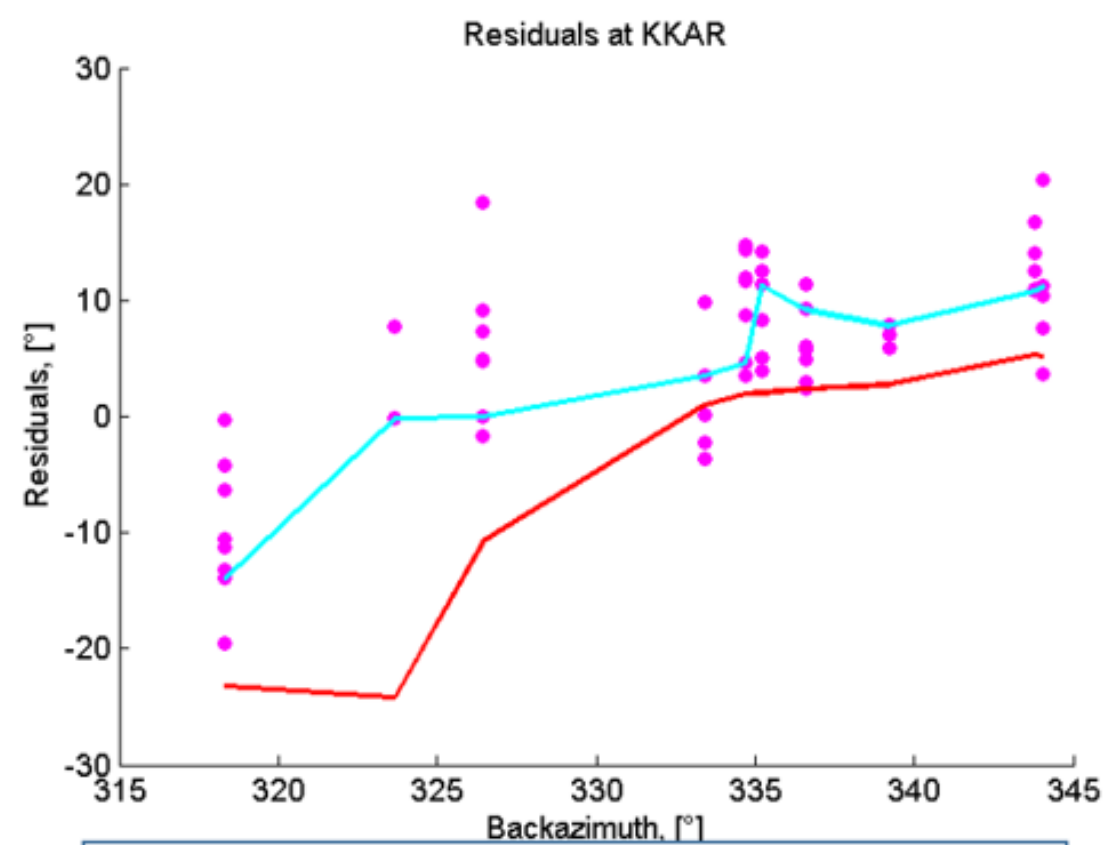

- BAZ residuals for all PMCC detections of the GT events with apparent velocity less than $6 \mathrm{~km} / \mathrm{s}$

BAZ residuals for all PMCC detections of the GT events with maximal RMS amplitude

Difference between predicted and observed BAZ of the microseisms with maximal RMS amplitude

Figure 69. Deviations in backazimuths for the surface waves from the events in North Atlantic as detected by the KKAR

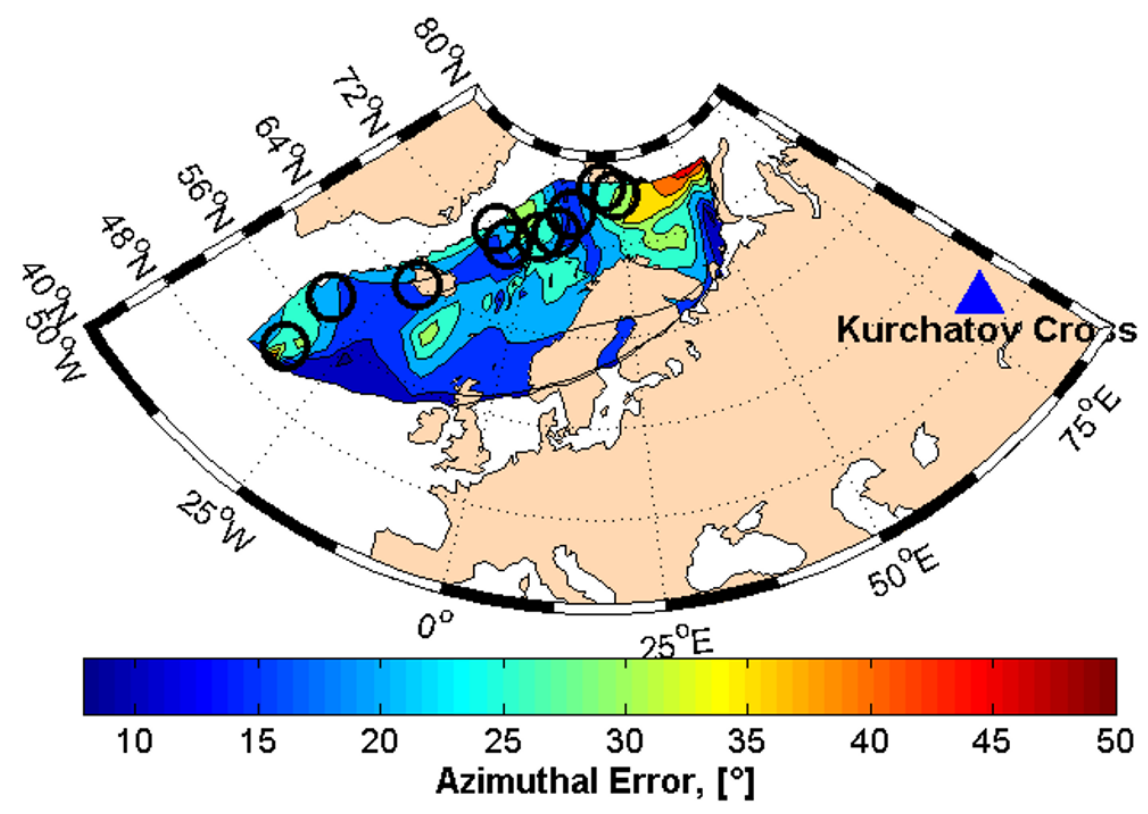

Figure 70. A map of spatial distribution of deviations in the surface wave backazimuths for Kurchatov Cross 
Finally, Figure 72 shows the spatial distribution of the deviation, and Figure 73 shows the dependence of the backazimuth deviations at MKAR. Just as for ABKAR and KKAR, the deviations strongly depend on the backazimuths and do not change with the epicentral distance. The picture at MKAR differs from those for ABKAR and KKAR. The most probable explanation is the smaller range of backazimuths to North Atlantic from MKAR in comparison with ABKAR and KKAR. As seen in Figure 73, diagrams for the backazimuths are quasi-parallel to the X-axis. The mismatch for MKAR between deviation for microseisms and earthquakes is minimal compared to the other stations.

Similar large deviations for the surface waves are described in the literature. Kolinsky and Bokelmann (2019) described the study results of the Rayleigh wave backazimuth deviations for the teleseismic events recorded by the Alp Array. Two methods of the surface wave backazimuth estimation were used. One of these methods is based on the extraction of the set of the smaller subarrays from the large Alp Array. The azimuths were determined at each of these small subarrays. The backazimuth deviations were studied for 20 events situated in the various directions from the Alp Array. One of these events is Mexico earthquake 08.09.2017 (Figure 74).

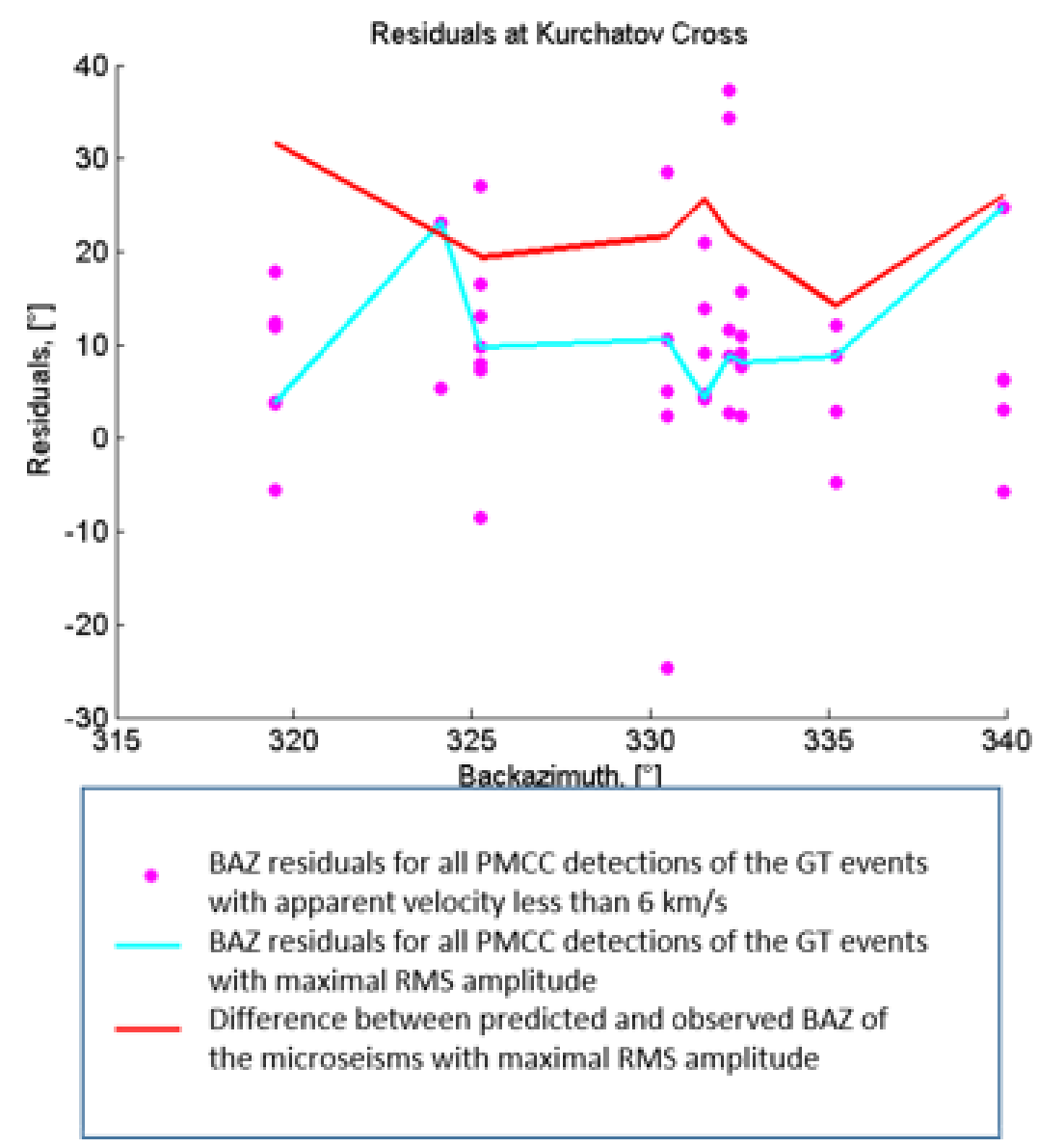

Figure 71. Deviations in backazimuths for the surface waves from the events in North Atlantic as detected by Kurchatov Cross 
In this case, deviations of the Rayleigh wave backazimuths were examined in the different parts of Europe for the Mexico event. It is not the same situation as the one described in our study. According to Kolínský and Bokelmann (2019), the single event is studied using a large amount of arrays. In a recent study, on the contrary, a large amount of sources in North Atlantic is analyzed using only four seismic stations in Kazakhstan.

However, if something is distorting ray traces between North Atlantic and Europe, the resulting picture is at least qualitatively similar in both cases described above. The deviation distribution has negative values on the Northern part and positive ones in the Southern part (0). For all Kazakh stations (except for Kurchatov (ross), the picture is opposite, the deviations in the north are smaller than in the south. Kolinsky and Bokelmann calculated the deviation as a difference between the observed and true values, and in this study, the deviations were calculated as a difference between expected and observed values, i.e. the results are finally identical. The range of the deviations measured by the Alp Array is $\pm 15^{\circ}$. The results of the Kazakh network are of the same order. Therefore, the solutions of the Alp Array and Kazakh network are similar despite the fact that the studied region of the latter investigation is shifted to the East.

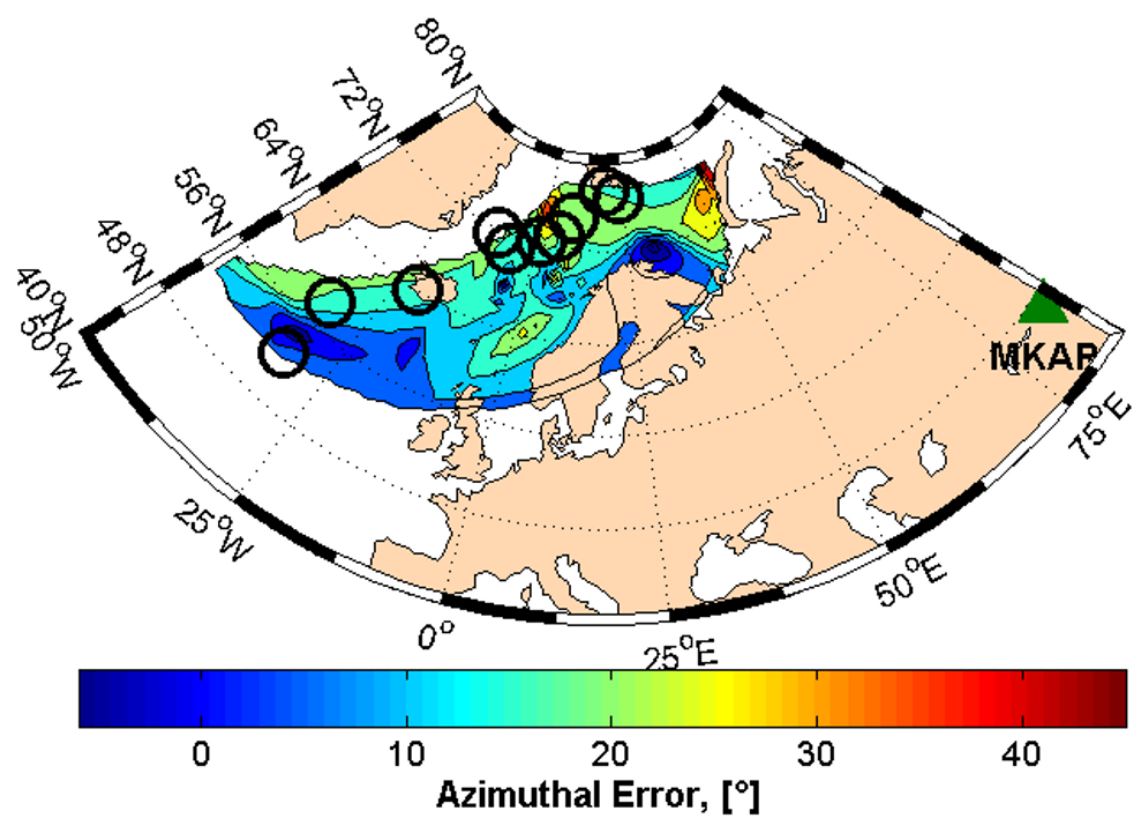

Figure 72. Map of the spatial distribution of the deviations in the surface wave backazimuths at MKAR

Also, Kolinsky and Bokelmann (2019) present an example of the simulation of the azimuth deviation after rectangular anomaly in velocity. A way of modelling of the effect of a heterogeneity along the ray paths has been proposed by Nolet and Dahlen (2000), who gave a simple equation predicting the wavefield of surface waves perturbed by a velocity anomaly in 2-D. They defined $Q$, a function of 
distance $x$ along the ray, the distance $R$ perpendicular to the ray, and the angular frequency $\omega$, as a perturbation to a unit planar wave travelling with a phase velocity $c$, which has the following form:

$$
1+Q(x, R, \omega)=1+\frac{e^{i \omega \tau_{\max }}-1}{\sqrt{\frac{i x \lambda}{\pi L^{2}}+1}} \cdot \exp \left[-\frac{(R / L)^{2}}{1+\frac{i x \lambda}{\pi L^{2}}}\right]
$$

where $\lambda=2 \pi c / \omega$ is the wavelength, $L$ is the half-width of the anomaly and $\tau$ max is the maximum time delay of the initial waveform at $x=0$, referring to the point where the ray leaves the anomaly. The anomaly is a simple box-car anomaly placed in a homogeneous space. Its strength and geometry are controlled by $\tau$ max and $\mathrm{L}$. The phase delay of the perturbed wave with respect to the original wave is then given as the phase of the complex perturbed wave

$$
\omega \tau(x, R, \omega)=\arctan \left[\frac{\operatorname{Im}(1+Q)}{\operatorname{Re}(1+Q)}\right]
$$

where $\tau(x, R, \omega)$ is the resulting phase time delay.

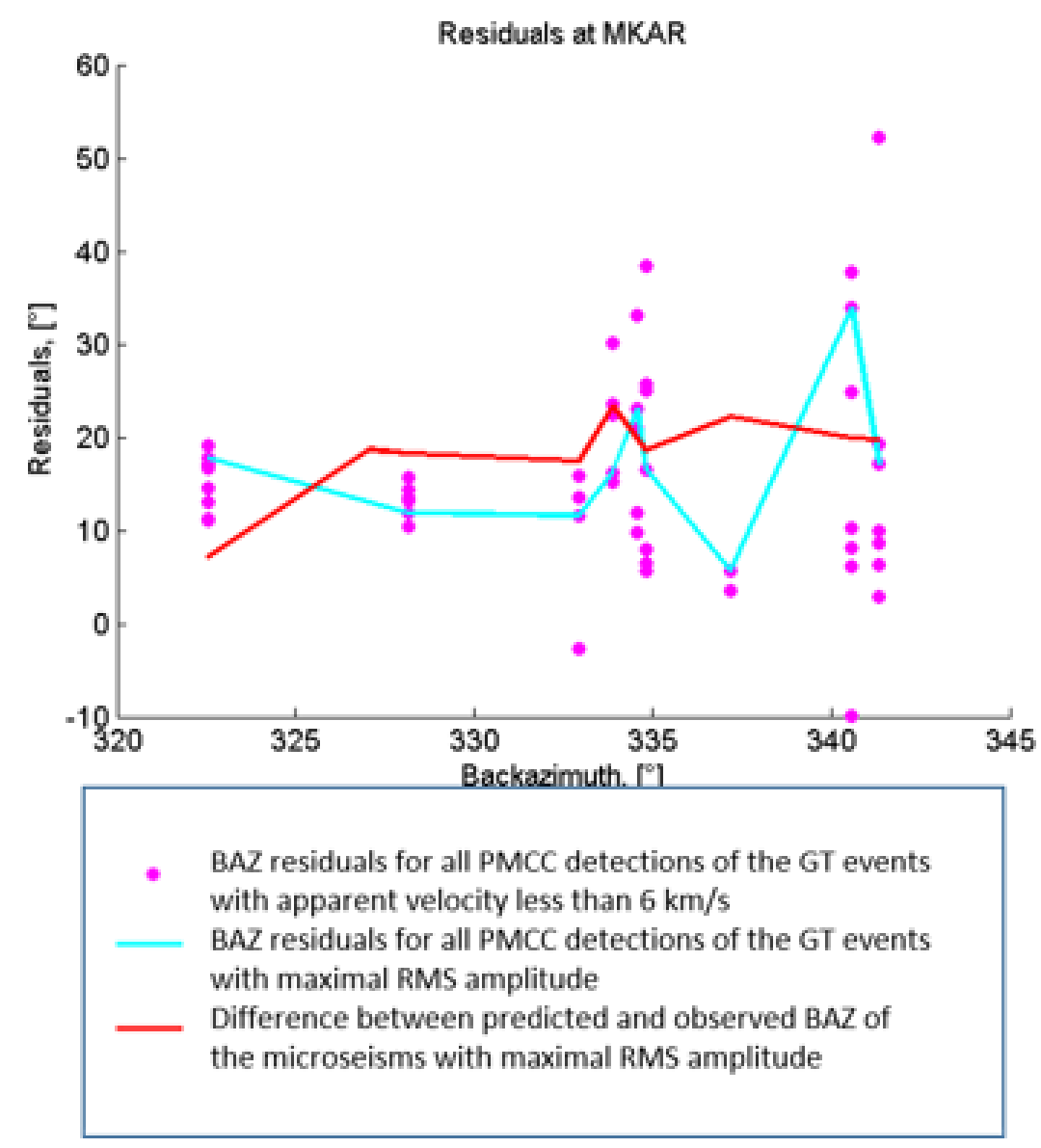

Figure 73. Deviations in backazimuths for the surface waves from the events in North Atlantic as detected by MKAR 
According to Nolet and Dahlen (2000), all results are given in terms of four dimensionless variables: $x / L$ representing the distance along the ray, $R / L$ representing the distance along the wavefronts, $L / \lambda$ controlling the width of the anomaly and $\omega \tau_{\max }$ its strength. Backazimuth deviations can be calculated from the phase time delays $\tau(x, R, \omega)$. First, the time delay was recalculated to wavefront position $w(x, R, \omega)=c \tau(x, R, \omega)$. The position $w(x, R, \omega)$ represents the distance the perturbed wave travelled further or closer with respect to the plane wave. Then, a derivative of the wavefronts $w$ with respect to lateral distance $\mathrm{R}$ was calculated.

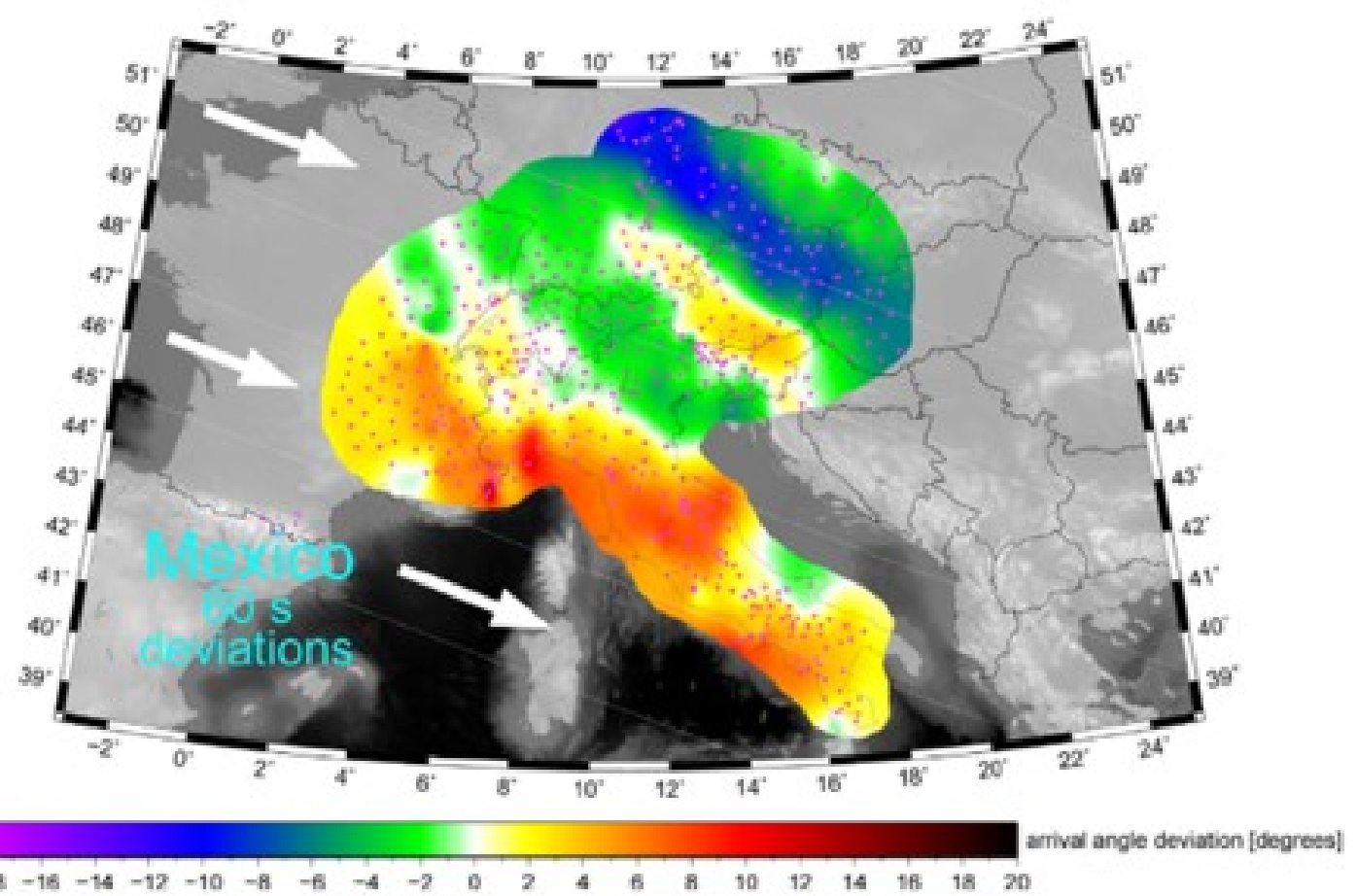

Figure 74. Backazimuth deviations relative to the respective great-circle directions for the Mexico earthquake on 2017-09-08. The measurements were made by the set of the sub-arrays constituting the Alp Array. The stations in the centers of the sub-arrays are marked by magenta triangles. Wave propagation directions are marked with white arrows. Modified from (Kolínský and Bokelmann, 2019).

The backazimuth deviation $\mathrm{A}$ is given by the arctangent of this derivative:

$$
A(x, R, \omega)=\arctan \left[\frac{d w}{d R}\right]=\arctan \left[c \frac{d \tau}{d R}\right]
$$

Hence it is enough to calculate the lateral derivative of the phase time delay. To demonstrate the results in real dimensions, backazimuth deviations were calculated for three hypothetical earthquakes on a global scale (Figure 75). The figure shows that smaller anomaly produces narrower lobes of 
deviations with higher amplitude. The lobes are also tilted with respect to geometrical ray paths. A broader anomaly produces wider lobes with lower amplitude.

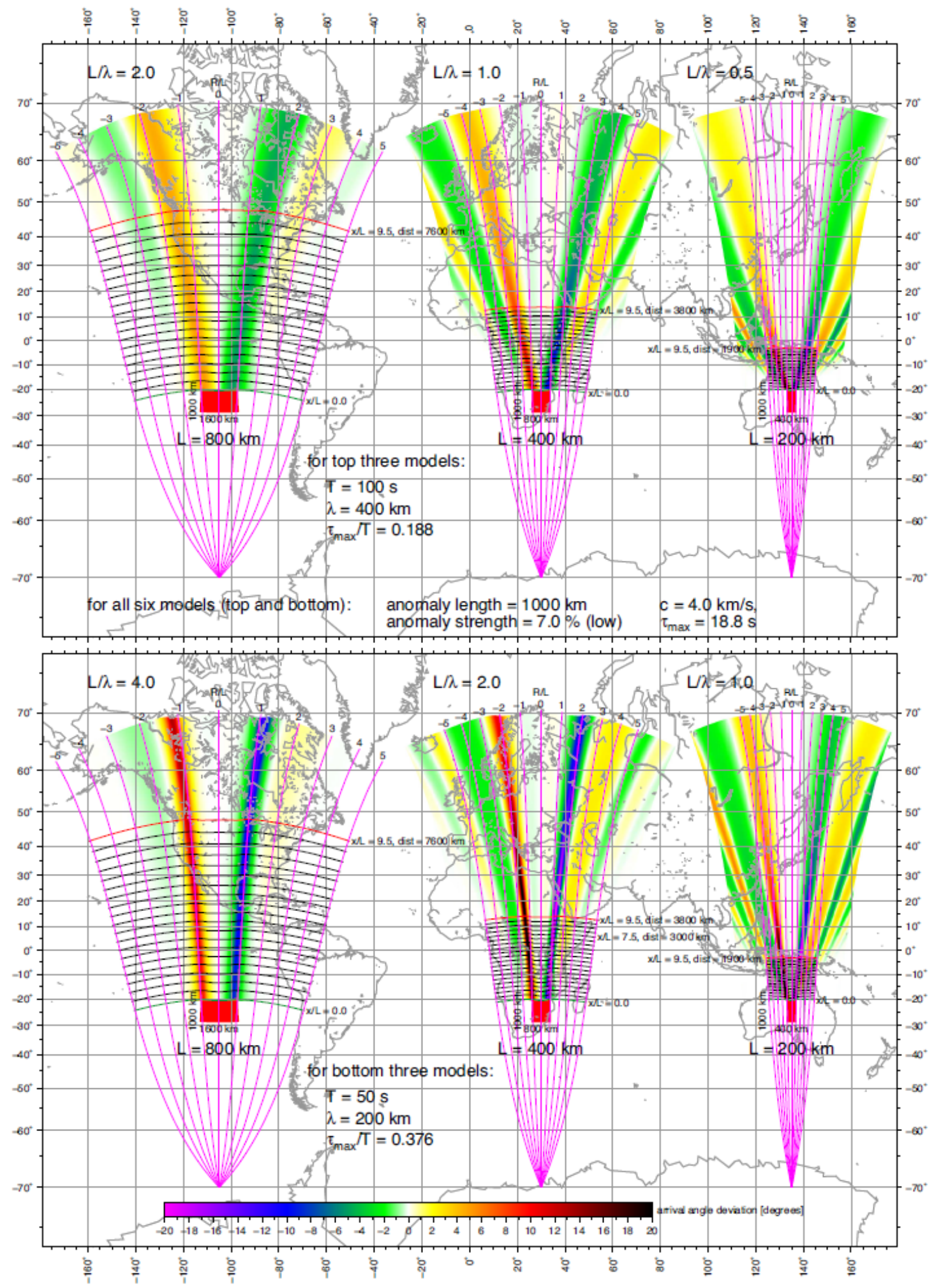

Figure 75. Examples of backazimuth deviations caused by three hypothetical anomalies and three hypothetical earthquakes for a period of $100 \mathrm{~s}$ (top) and $50 \mathrm{~s}$ (bottom). To allow comparison, a rectangular representation (oblique Mercator projection) has been chosen for the Earth's 
surface. Magenta lines show the scaled cross-path distance R/L. From (Kolínský and Bokelmann, 2019).

They persist for longer distance, being more aligned with the geometrical ray paths than those from a narrower anomaly. It is clearly seen, that such anomalies can produce deviation patterns consisting of lobes of changing sign and repeating in space. Exactly the same situation occurs when studying waveforms from the Mexico earthquake of 08.09.2017 and the microseisms. Backazimuth deviations that were found when predicting and observing the microseism parameters match well with the deviations of the Rayleigh wave backazimuths for the earthquakes recorded by Alp Array. The simulation of the deviations that explains the findings matches the microseism cases well.

\subsection{Joint analysis of the infrasound and seismic detections bulletins for IMS and national stations}

Seismic and infrasound array bulletins were compared based on backazimuths and amplitudes at sites were stations are collocated. The locations of the Kazakh seismic and infrasound arrays are shown in Figure 4. Figure 76, Figure 77 and Figure 78 are snapshots of detections at seismic and infrasound arrays. Figure 76 presents backazimuths and signal amplitudes from 1 January 2014 through 31 December 2017 captured by ABKAR and IS31 seismic arrays. These arrays are $230 \mathrm{~km}$ apart. Figure 77 shows the detections results for Kurchatov Cross seismic array and KURIS infrasound station. These two stations are collocated. Figure 78 depicts the backazimuths and amplitudes at MKAR seismic and MKIAR infrasound arrays. These two arrays are collocated as well. 
a)

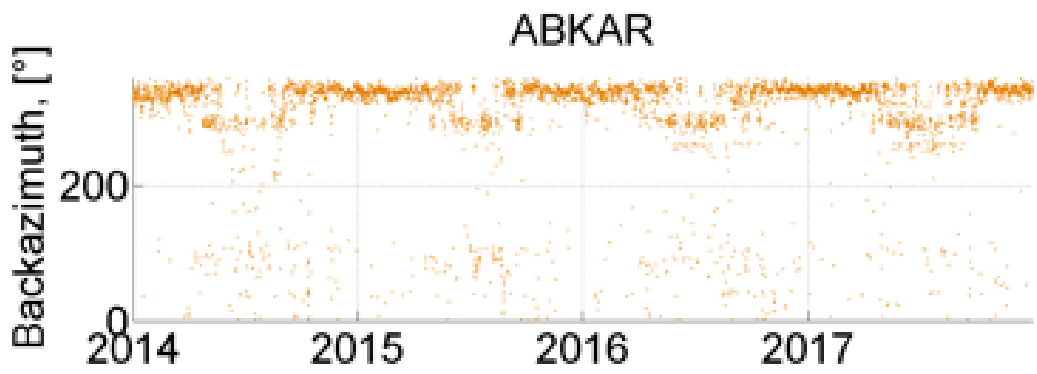

b)

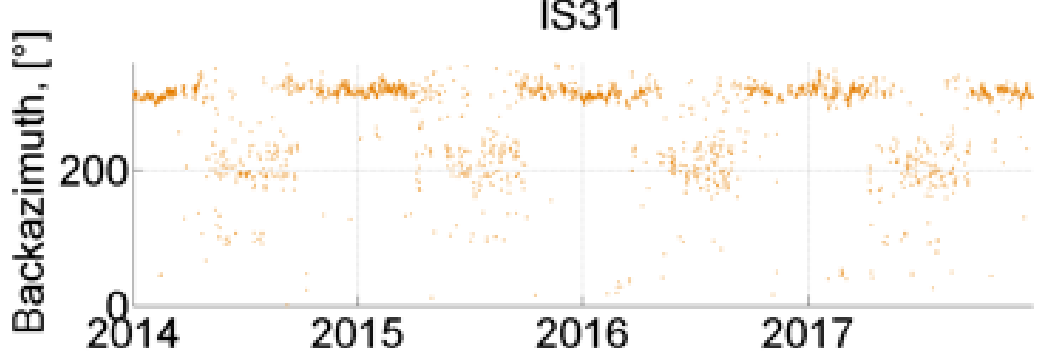

c)

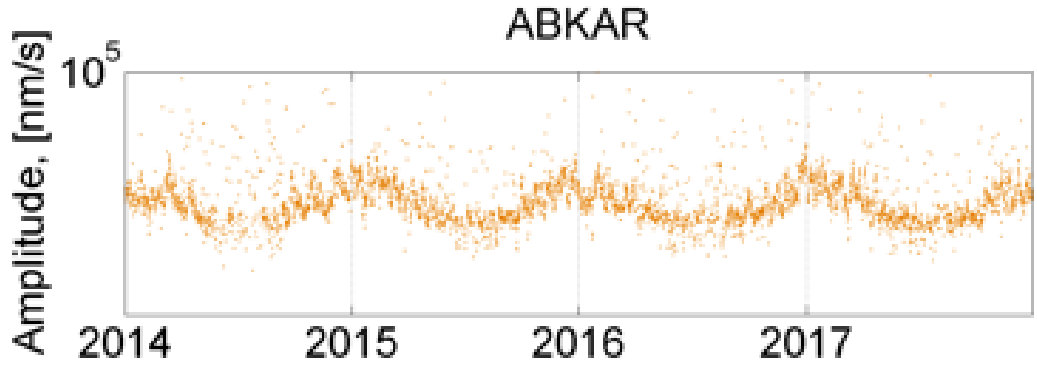

d)

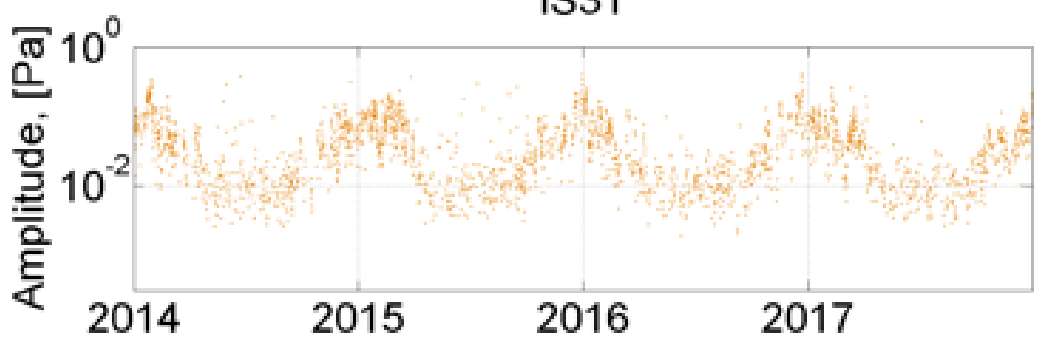

Figure 76. Backazimuths ( $a$ and $b$ ) and amplitudes ( $c$ and $d$ ) of signals recorded from 1 January 2014 through 31 December 2017 by ABKAR seismic ( $a$ and c) and IS31 infrasound (b and d) arrays

The comparison of the bulletins in Figure 76, Figure 77 and Figure 78 shows similar series of seasonal patterns. This comparison illustrates for all pairs of infrasound and seismic arrays the similarity of seismic and infrasound bulletins. 
a)

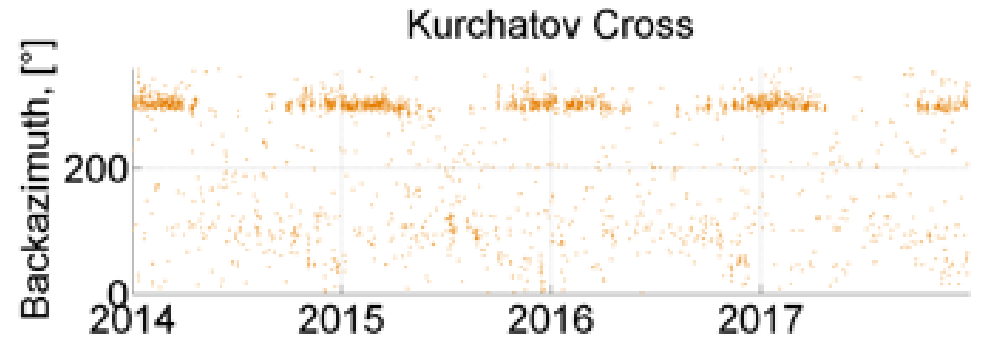

b)

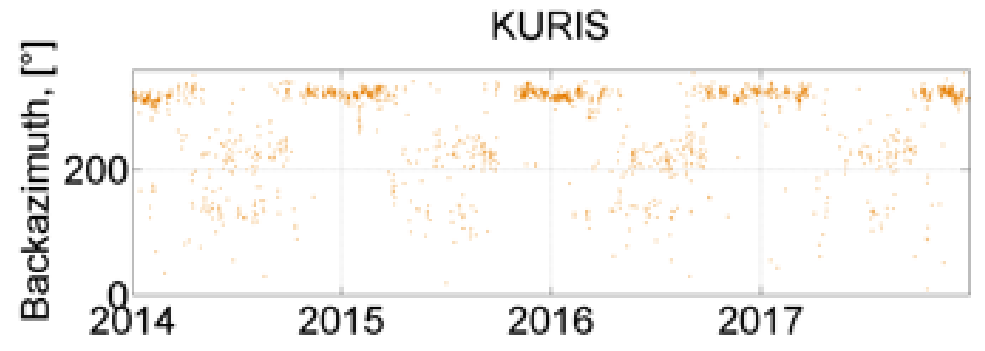

c)

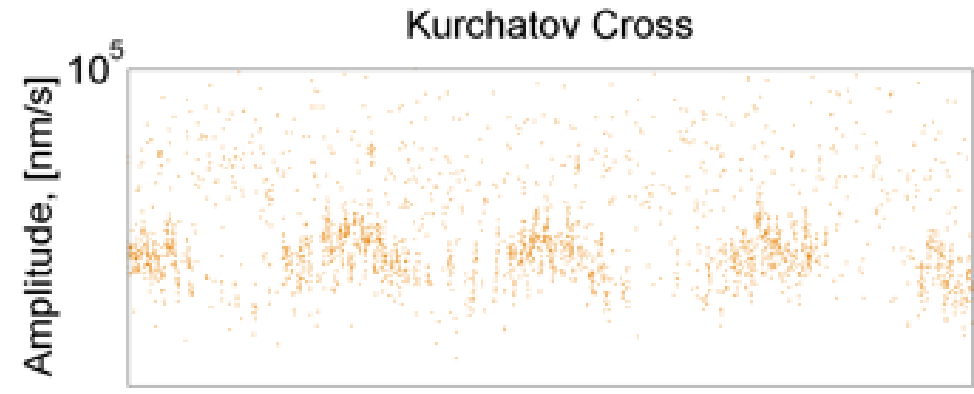

d)

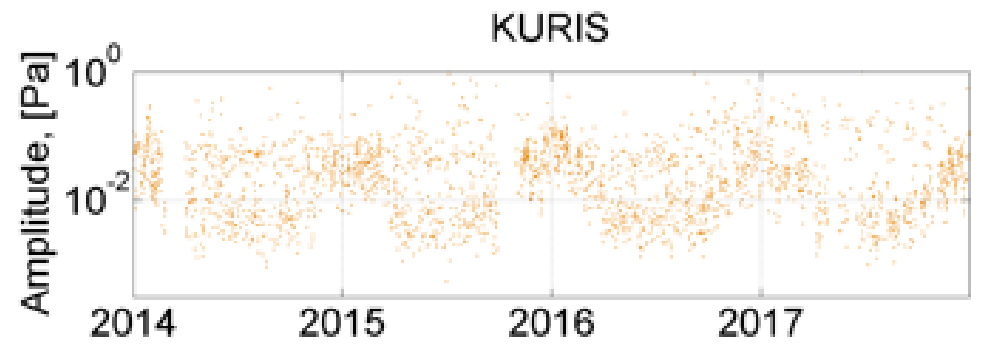

Figure 77. Backazimuths ( $a$ and $b$ ) and amplitudes ( $c$ and $d$ ) of signals recorded from 1 January 2014 through 31 December 2017 by Kurchatov Cross seismic (a and c) and KURIS infrasound (b and d) arrays 
a)

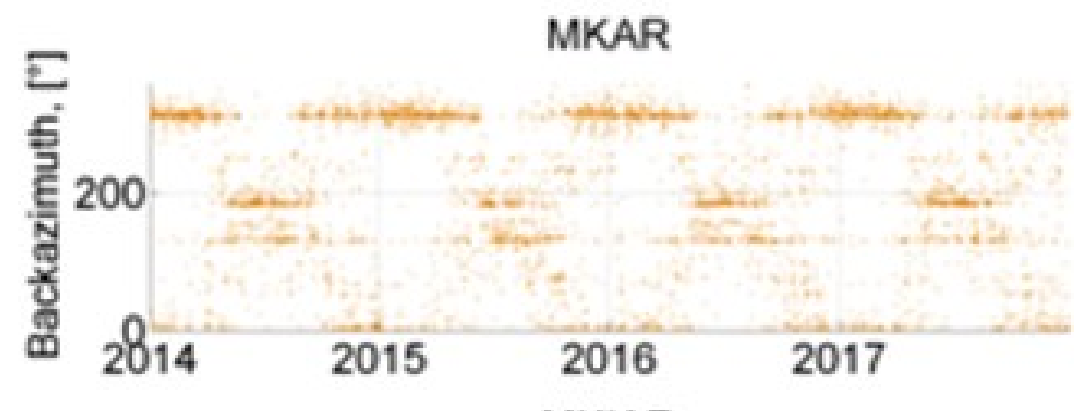

b)

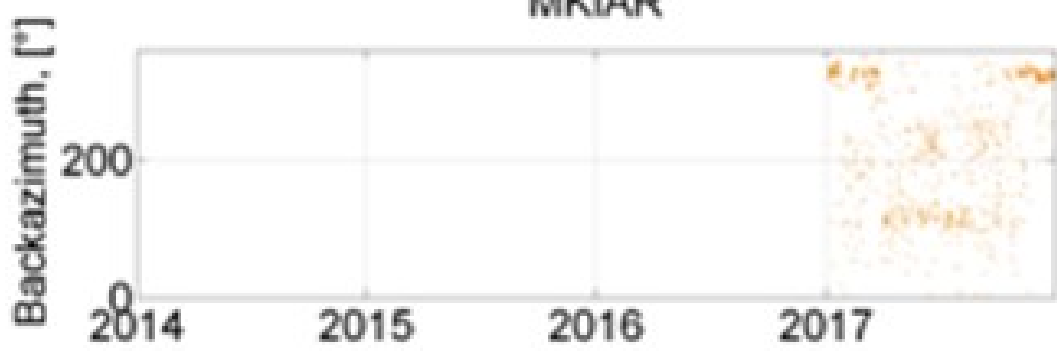

c)

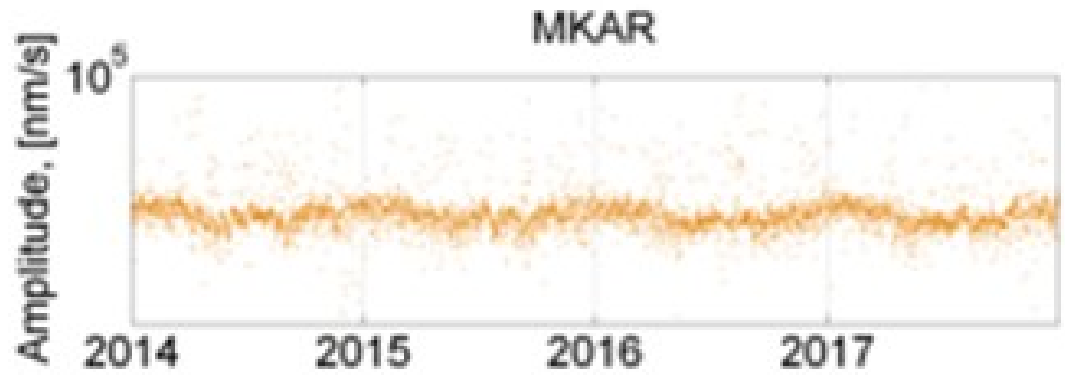

d)

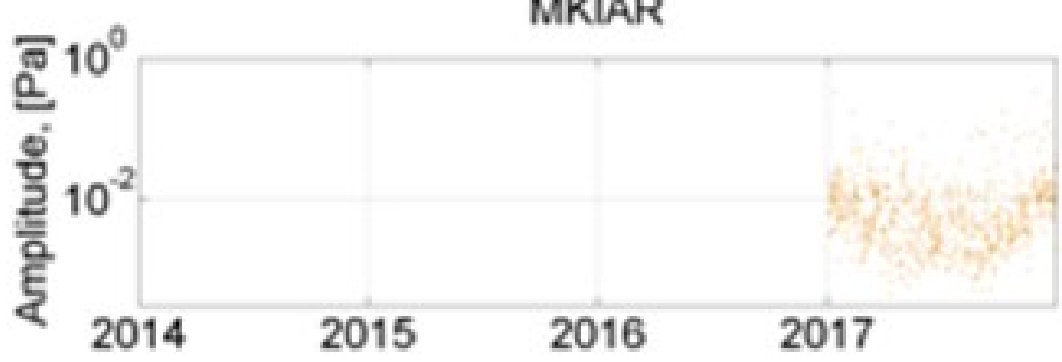

Figure 78. Backazimuths ( $a$ and $b$ ) and amplitudes ( $c$ and $d$ ) of signals recorded from 1 January 2014 through 31 December 2017 by MKAR seismic ( $a$ and $c$ ) and MKIAR infrasound arrays ( $b$ and $d$ )

The main observations are:

- North Atlantic microseisms and microbaroms prevail in winter months. Backazimuths of approximately $300-360^{\circ}$ are clearly visible in Figure 76 a and b, Figure 77 a and b, Figure 78 a and $b$.

- Amplitudes of North Atlantic microbaroms and microseisms exceed significantly amplitude of signals registered during summer months as shown by Figure $76 \mathrm{c}$ and d, Figure $77 \mathrm{c}$ and d, Figure $78 \mathrm{c}$ and $\mathrm{d}$. 
At the same time, the following regular distinctions in seismic and acoustic bulletins were identified for a number of criteria:

- Arrays record North Atlantic microseisms more steadily than microbaroms from that region. Figure $76 \mathrm{a}$ and b, Figure $77 \mathrm{a}$ and b, Figure $78 \mathrm{a}$ and b clearly show that the quantity of recorded microseisms exceeds microbaroms significantly.

- The range of backazimuths for North Atlantic microseisms is significantly more extensive than the range for North Atlantic microbaroms at ABKAR and MKAR (Figure 76 a and b, Figure 77 $a$ and $b$, Figure 78 a and b). However, this distinction is not evident for Kurchatov Cross and KURIS arrays, Figure $77 \mathrm{a}$ and $\mathrm{b}$.

- For all infrasound arrays, backazimuths of North Atlantic microbaroms are larger (320-330 $)$, as shown in Figure 76 b, Figure 77 b, Figure 78 b. For all seismic arrays, backazimuths differ not only from one station to another, but from microbarom backazimuths. The range of backazimuths is about $330-350^{\circ}$ for ABKAR (Figure 76 a), 290-310 for Kurchatov Cross (Figure 77 a), and $310-320^{\circ}$ and $0-10^{\circ}$ (two sets of detections) for MKAR (Figure 78 a).

- During summer months, no correlation is found in the prevailing directions of microseism and microbarom arrivals for respective collocated arrays (Figure 76 a and b, Figure $77 \mathrm{a}$ and b, Figure $78 \mathrm{a}$ and $\mathrm{b})$.

\subsection{Localization of the source region}

As microbaroms and microseisms are recorded by the IGR network, it is possible to localize the source region. Figure 79 shows the first approach of such localization. 


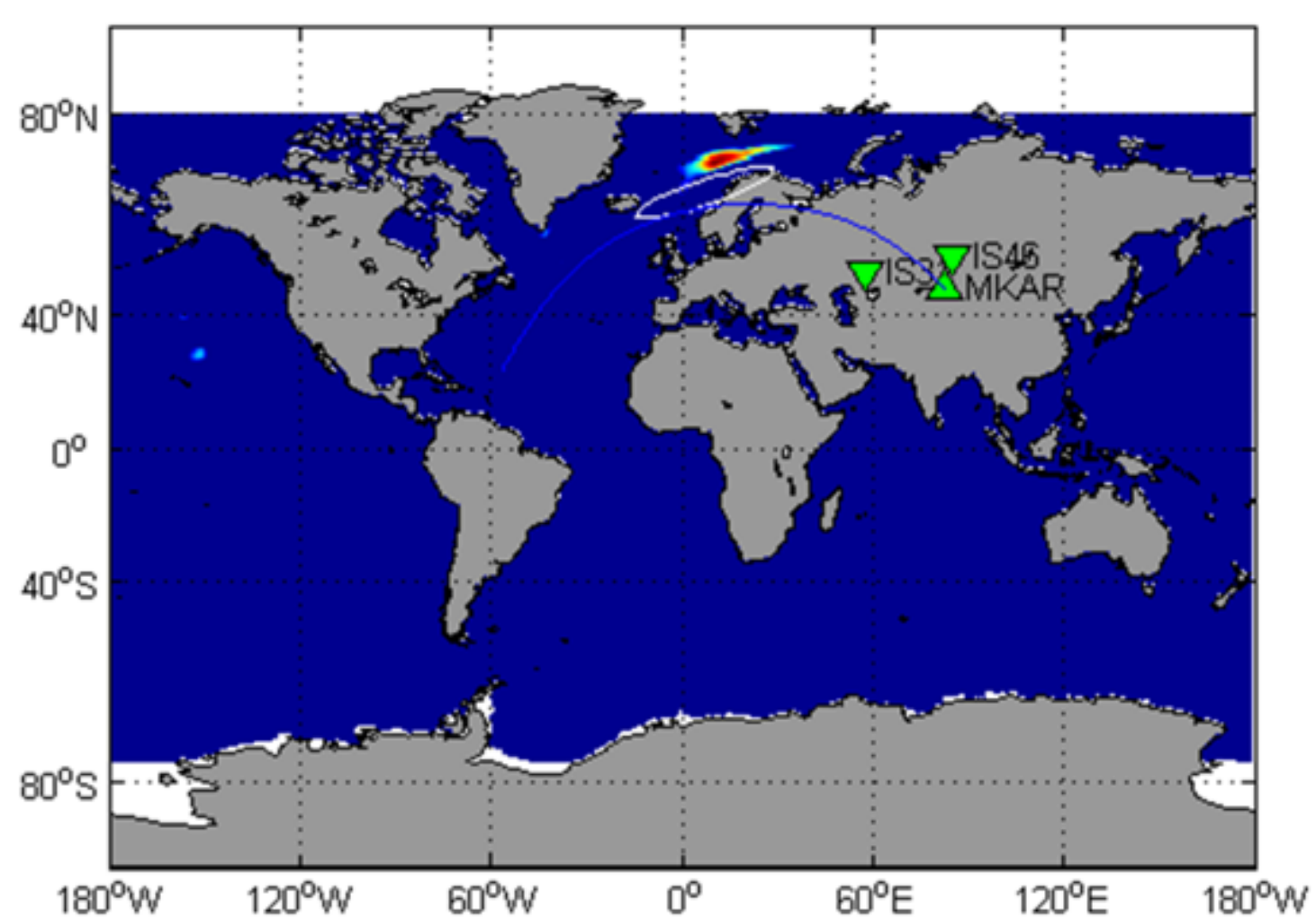

Figure 79. Localization of the microbaroms source regions averaged in January 2017. The map shows the simulation results of microbarom intensity. White line represents the $90 \%$ error ellipse for the locations determined using cross bearing with detections at IS31 and IS46. The blue line indicates the backazimuth calculated at MKAR

Cross-bearing locations use detections at IS31 and IS46. The bearings were averaged for each 6 hours of observations. Error ellipse of the solutions is compared with the intensity distribution of the source region, shown in color on Figure 79. The signal attenuation calculated for effective point placed in between IS31 and IS46 was taken into account when the source strength was calculated.

A simplified formulation of the semi-empirical attenuation relation (9) considering only the combined effects of geometrical spreading:

$$
A=R^{-0.95}
$$

where $\mathrm{R}$ is the radius of the Earth.

Figure 80 presents similar results on February 2017. These results show first order agreement between observations and modeling results in North Atlantic region, although some systematic errors are visible. These errors could likely be reduced by accounting for atmospheric effects on long-range infrasound propagation. 
In contrast to the single station studies performed by Hupe et al. (2018) and De Carlo et al. (2018), microbarom signals recorded by a dense seismo-acoustic network are here analyzed. Analyzing this set of data allows highlighting regional features of both microbaroms and microseisms.

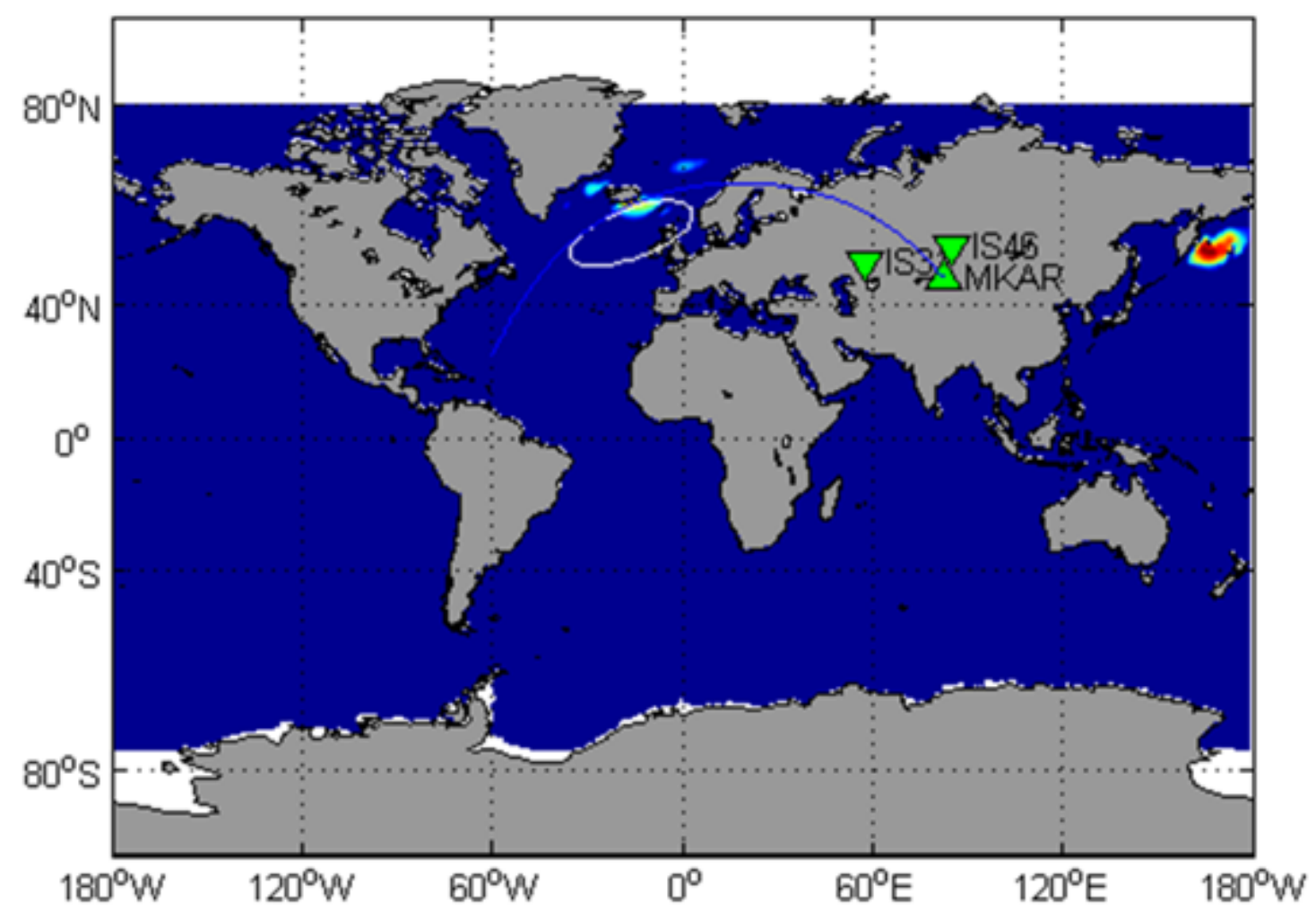

Figure 80. Localization of the microbaroms source regions averaged in February 2017. The map shows the simulation results of microbarom intensity. White line represents the $90 \%$ error ellipse for the locations determined using cross bearing with detections at IS31 and IS46. The blue line indicates the backazimuth calculated at MKAR

Figure 81 shows the averaged distribution of the expected microbarom amplitude over the globe at summertime. The calculation was carried out for two summer months. White isolines map the density of the microbarom source distribution. The sources were located via cross-bearing for the following station pairs: IS31-KURIS, IS31-MKIAR and KURIS-MKIAR. 


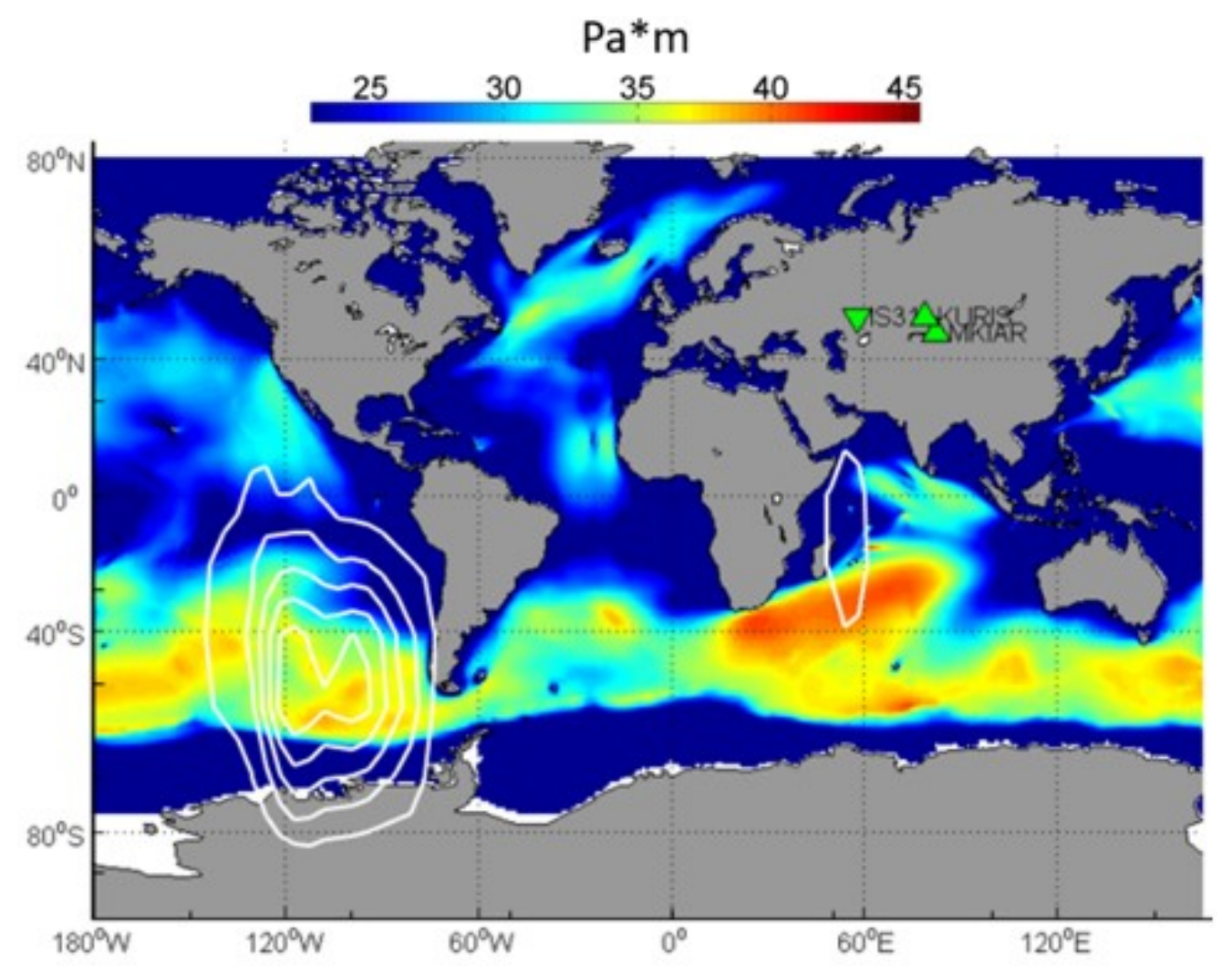

Figure 81. The distribution of the epicenters of the expected microbarom sources in July August 2017 for the IS31 infrasound array. White contours represent the density of the microbarom source locations. The locations were obtained via cross-bearing for pairs IS31-KURIS, IS31-MKIAR, and KURIS-MKIAR for the same time period

\subsection{Catalog of oceanic sources for the reconstruction of atmospheric model}

Technically, the geometry of the Kazakh seismic and acoustic network is not suitable for localizing the sources of the North Atlantic microbaroms and microseisms without source simulation data as both seismic and acoustic stations are close compared with the distance to the source region. True backazimuths to sources from different network arrays practically coincide. Backazimuths measured on infrasound data are disturbed by transversal wind effects along the travel path. The situation with backazimuths measured using seismic data is worse: as detailed in Section 3, average errors may reach $25^{\circ}$ (Kurchatov Cross), that is why the sources could not be localized based on observation data applying cross-bearing technique as the epicentral error may be very large. Besides, with observation data only, epicentral distances may not be easily determined based on a difference in arrival of various seismic phases.

Results of the joint analysis of observation and simulation data prove that the accuracy of predicted microseism and microbarom parameters in many cases is rather high (Figure 82). As presented in the 
enlarged portion of the picture, the difference between the observed and expected data is some degrees, but variations in observed and predicted values are regularly uniform.

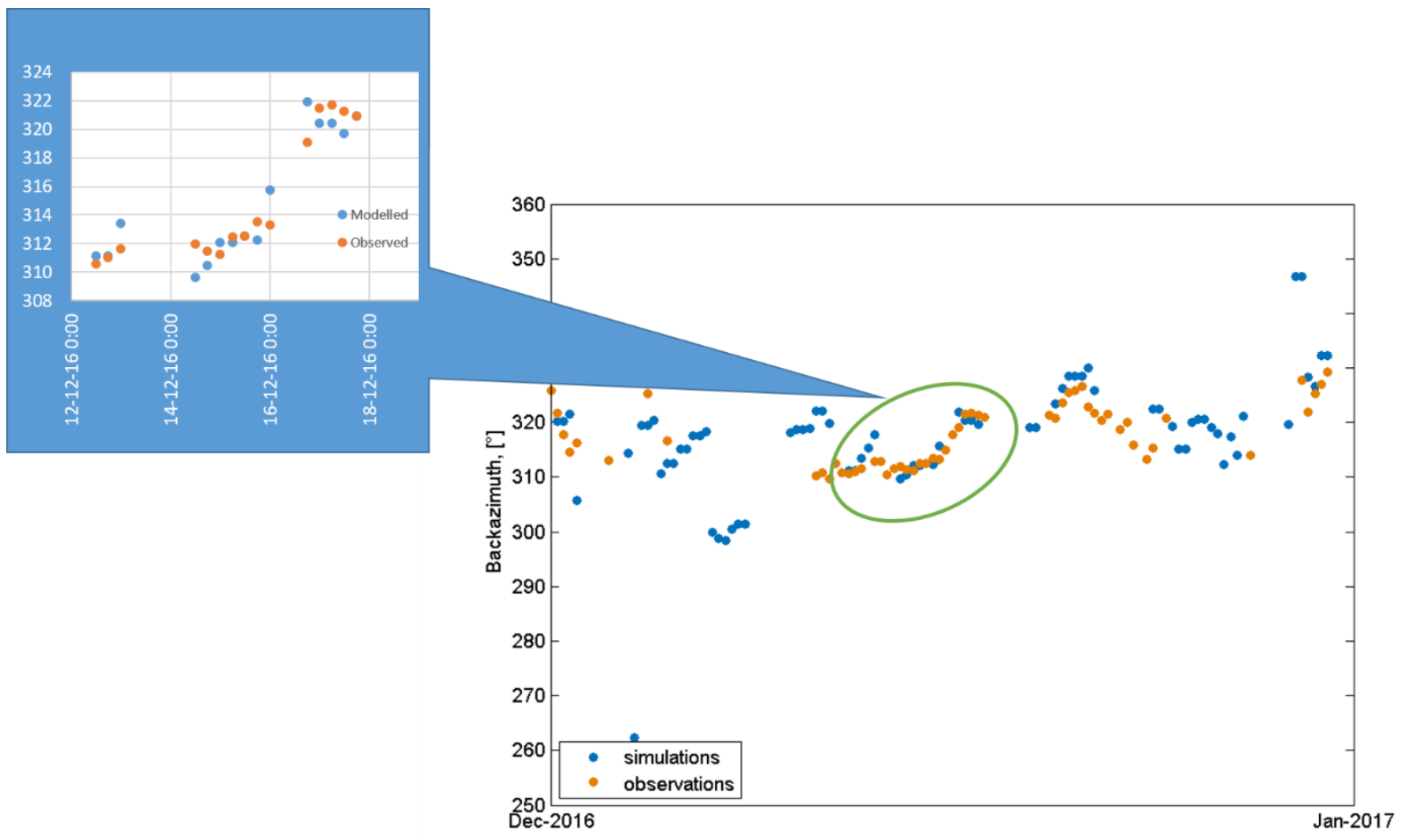

Figure 82. Observed and expected North Atlantic microbarom backazimuths at IS31 array in December 2016

High accuracy of predicted locations of the source is supported with the fact that the observed signal amplitudes in many cases correlate well with predicted values (Figure $55 \mathrm{~d}$ ). Therefore, it may be stated that locations of the source epicenters may be determined to a high degree of accuracy based on simulation data. In some cases, the observed and predicted parameters differ significantly which evidently may be associated with inaccuracies in the ocean wave model used. To substantiate this assumption, additional investigations are required.

An example of practical application of the above technique for developing a microbarom source catalogue is presented in Table 5. The table of the microbarom source catalog was compiled for a measurement area where the observed and predicted parameters are of good correlation (Figure 82). Table 5 details signal arrival times at the station. To determine origin times, signal propagation time must be considered. The spatial accuracy of the microbarom source catalog depends on the ocean wave model, and in our case it equals $0.5^{\circ}$. 
Table 5. Sample catalogue of microbarom sources based on simulated source regions.

\begin{tabular}{|c|c|c|c|c|}
\hline Date and time at station & $\begin{array}{l}\text { Observed } \\
\text { azimuth, }{ }^{\circ} \text { ] }\end{array}$ & $\begin{array}{l}\text { Expected } \\
\text { azimuth, }\left[^{\circ}\right]\end{array}$ & Longitude, ${ }^{\circ}$ ] & Latitude, ${ }^{\circ}$ ] \\
\hline $12-12-1612: 00$ & 310.6 & 311.1 & -32.5 & 52.5 \\
\hline $12-12-1618: 00$ & 311.0 & 311.1 & -32.5 & 52.5 \\
\hline $13-12-160: 00$ & 311.7 & 313.4 & -33 & 54.5 \\
\hline $14-12-1612: 00$ & 312.0 & 309.7 & -31.5 & 51.5 \\
\hline $14-12-1618: 00$ & 311.5 & 310.4 & -28.5 & 53.5 \\
\hline $15-12-160: 00$ & 311.2 & 312.1 & -27 & 55.5 \\
\hline $15-12-166: 00$ & 312.5 & 312.1 & -27 & 55.5 \\
\hline $15-12-1612: 00$ & 312.6 & 312.5 & -25 & 56.5 \\
\hline $15-12-1618: 00$ & 313.5 & 312.3 & -22.5 & 57 \\
\hline $16-12-160: 00$ & 313.3 & 315.8 & -23.5 & 59.5 \\
\hline $16-12-1618: 00$ & 319.1 & 321.9 & -54.5 & 53 \\
\hline $17-12-160: 00$ & 321.5 & 320.4 & -53 & 52 \\
\hline $17-12-166: 00$ & 321.7 & 320.4 & -53 & 52 \\
\hline $17-12-1612: 00$ & 321.3 & 319.7 & -50 & 53 \\
\hline $17-12-1618: 00$ & 320.9 & 320.9 & -49 & 55 \\
\hline
\end{tabular}

\subsection{Direct and inverse problem solution}

A number of studies describe Passive Atmospheric Remote Sensing (PARS) (e.g. Drob et al., 2010). Correctly applied infrasound measurements may (independently or jointly with other atmosphere testing techniques) provide information on the upper atmosphere for scientific studies or for numerical weather forecast. Researches in this area were made by Donn and Rind (1971 and 1972), Rind (1978), Rind and Donn (1975) and Rind et al. (1973). For a stand-alone station in Palisades, New York, they could find a dependency of time-domain amplitude changes of North Atlantic microbaroms with seasonal and daily patterns of stratosphere and lower atmosphere.

Later on, Garcés (2004) and Le Pichon et al. (2005 a,b and 2006) revealed new perspectives of this method to be applied to infrasound signals from volcanos and ocean waves. They demonstrated, in a similar way to other studies, the presence of obvious seasonal and minor time-dependent variations of infrasound distribution. In particular, they described how variations of backazimuths and celerities correlate directly with atmospheric changes. Le Pichon et al. (2005b) advance their studies and determined corrections to ground-to-space profiles (G2S), which is required to align theoretical concept and measured backazimuths of infrasound signals (Drob et al., 2010). Thereby, infrasound 
observations may serve as a diagnostic tool to validate existing atmospheric models. Furthermore, infrasound signals from the known sources may be used independently for sounding the atmosphere. Besides, good perspectives exist for using North Atlantic microbaroms and infrasound component of the monitoring network for PARS. Predictions of sources match the observations findings (Smirnov et al., under review). Expected azimuths to the sources were calculated with by considering of atmospheric attenuation with an empirical formula of Le Pichon et al. (2012) which applies $V_{\text {eff }- \text { ratio }}$ calculated with ECMWF atmospheric profiles. It is evidenced of the fact that the ECMWF profiles could be used as a good initial model for the tomography. Therefore, these dataset is ready to be used as a good basis for PARS when observed and predicted backazimuths of microbaroms correlate well. On the other hand, a lack of a good correlation between the observed and predicted azimuths is most likely associated with an inaccurate ocean wave model. The correlation between the observations and predictions, if applied as a diagnostic feature, would help improving the ocean wave model. And later, after the improvement of the oceanic wave model and obtaining the previously unavailable locations of the source areas, PARS would be possible for such time-domain intervals too.

\subsection{Comparison between PMCC detections and effective sound speed ratio}

Strong atmospheric winds are the determinant factors of infrasound propagation (e. g. Green et al., 2011). Le Pichon et al. (2008) identified that the most frequent type of arrival at distances greater than $200 \mathrm{~km}$ from the source are signals propagating within the ground-to stratosphere waveguide, which is consistent with numerous other data studies (e.g. Balachandran et al., 1971; Whitaker and Mutschlecner, 2008). It has been repeatedly shown that stratospheric winds play a dominant role in controlling the ability of this waveguide to efficiently propagate low-frequency acoustic waves ( e.g. Antier et al., 2007; Garcés et al., 1998; Reed, 1969; Whitaker and Mutschlecner, 2008). The effect of stratospheric wind is illustrated by the altitude-dependent effective sound speed, $v(z)$, defined as:

$$
v(z)=c(z)+w^{\prime}(z)
$$

where $c(z)$ is the sound speed, and $w^{\prime}(z)$ is the horizontal wind speed component in the propagation direction (Hagerty et al., 2002). The effective vertical sound speed is an approximation that represents the combined effects on infrasound of refraction due to sound speed gradients and advection due to wind. Sound will return to the ground surface if the effective sound speed at any height exceeds the acoustic speed at the surface, or

$$
V_{\text {eff-ratio }}>1
$$

Where: 


$$
V_{\text {eff-ratio }}=\frac{c+V_{z}(z) \sin \theta+V_{m} \cos \theta}{c_{0}}
$$

$c$ - wind speed,

$V_{z}$ - zonal wind speed component,

$V_{m}$ - meridional wind speed component,

$\theta$ - wind direction,

$c_{0}$ - sound speed on the day surface.

Therefore, when the acoustic propagation is in the downwind direction, the increased effective sound speed acts to increase the likelihood that infrasound will be refracted back towards the ground surface. In contrast, when acoustic propagation occurs in the upwind direction, the decreased effective sound speed reduces the angle through which the sound is refracted, increasing the likelihood that a ground-to-stratosphere acoustic waveguide will be disrupted and that the sound will propagate upwards towards the thermosphere and will scatter (Sutherland and Bass, 2004).

Therefore, the accurate parametrization of the wind speed with altitude is essential for predicting both where infrasound arrivals will be observed from a particular event, and the structure of the resulting waveform. The influence of the horizontal wind structure on low-frequency acoustic propagation acts over a wide variety of time and length scales, and early work recognized the strong seasonal influence of oscillating zonal stratospheric winds ( e.g. Reed, 1969).

In the northern hemisphere, the stratospheric zonal wind is oriented eastwards in winter and westwards in summer with periods of lower wind speeds in between. In the Southern hemisphere, the directions reverse. This oscillation, clearly captured in climatological models of the wind structure (Drob et al., 2008), controls to first order where infrasound is expected to be detected from any particular location due to the preferential detection capability downwind (Le Pichon et al., 2009).

Comparison between the observed and predicted backazimuth of microbaroms with a ratio of $V_{\text {eff-ratio }}$ over a seasonal time scale is illustrated in Figure 83 . Figure 83 shows data for three arrays, IS31, KURIS and MKIAR. Values of $V_{\text {eff-ratio }}$ have been calculated for two spots based on altitude-dependent wind speed profiles (ECMWF). The observed and expected backazimuth values at IS31 are compared with ECMWF profiles extracted for the station. The measured and calculated backazimuths at KURIS and MKIAR are compared with wind profile data at IS46 as it is the closest location for which altitudedependent wind speed profile could be obtained. 
It shall be noted that $V_{\text {eff-ratio }}$ was calculated without regard to lateral wind speed variation. As shown in Figure 1, such assumption can be used for sources in the northern hemisphere, however it is absolutely unfeasible for the Southern hemisphere as winds spin counterclockwise there. Accordingly, such comparisons would be accurate for backazimuths of approximately $280-360^{\circ}$ and $0-80^{\circ}$ as they show a good correlation between the expected and observed microbarom backazimuths and atmospheric profiles.

IS31
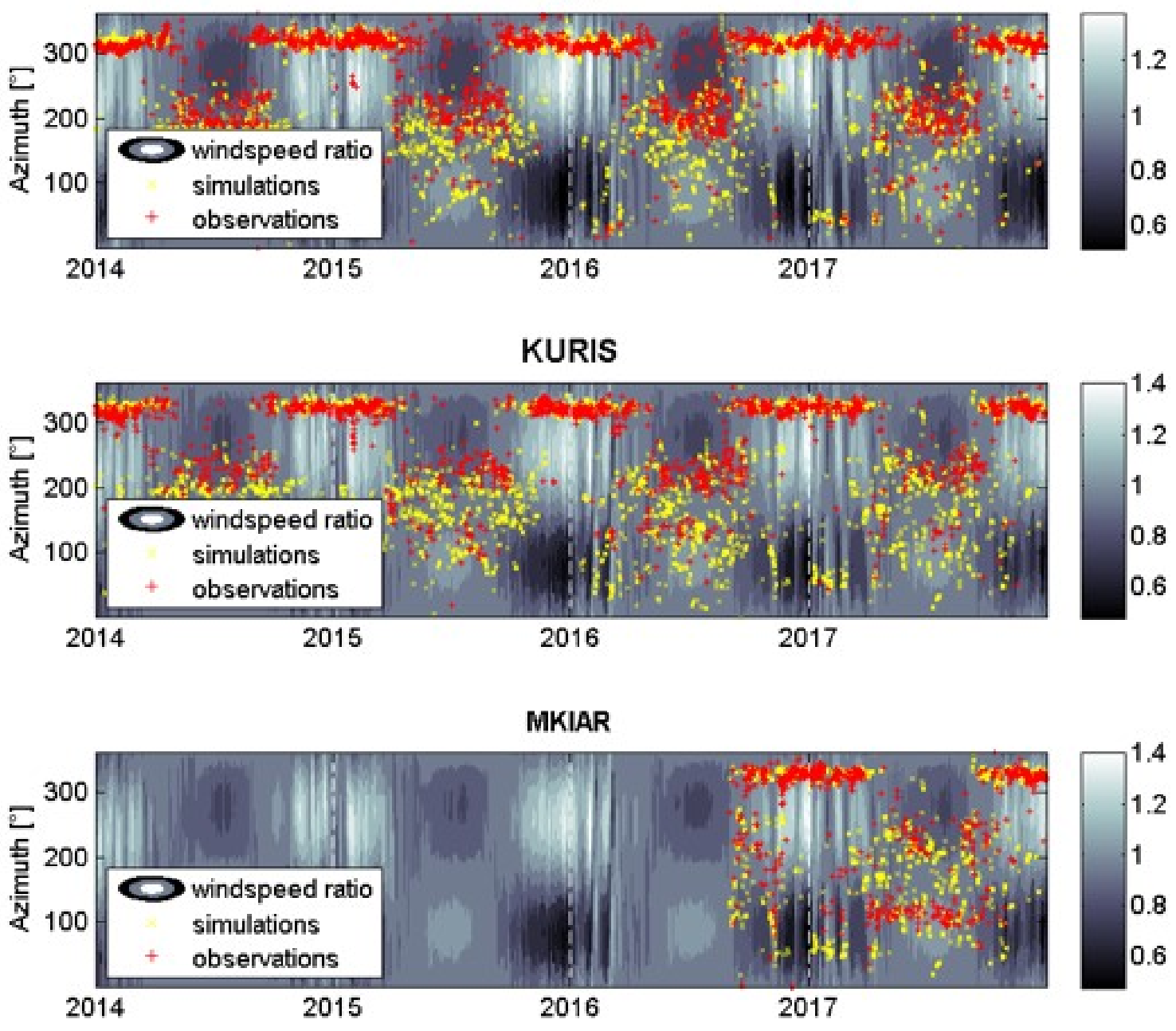

Figure 83. Comparison between the observed and predicted microbarom backazimuth from 2014 to 2018 together with the wind speed ratio. From top downward: IS31, KURIS and MKIAR

As anticipated, signals are registered in winter with backazimuths of $300-330^{\circ}$ and are not registered in summer. This assumption is correct for all three stations. Values of $V_{\text {eff-ratio }}$ for this period and within this back-azimuth range exceeds 1 (light background color). It may be further noted that though this approach cannot be used for the Southern hemisphere predictions, it is not of a serious concern as no prevailing direction of arrivals therefrom has been registered: different stations do not detect 
signals from the common prevailing source, and significant sources are unique for every array. This assumes that signals from regional sources are specific for every station in the summer months (Figure 58, Figure 83).

Variations in the wind speed, not captured by climatological models, can greatly enhance or degrade the efficiency of infrasound propagation over long distances in a given direction. Drob et al. (2003) provided evidence that predicted propagation paths simulated based on meteorological profiles captured several hours apart and over length scales exceeding $750 \mathrm{~km}$ differ significantly from those imaged with climatological models. It is well illustrated in Figure 84. It presents comparison of the observed and expected backazimuth values for arrays IS31, KURIS and MKIAR and $V_{\text {eff-ratio }}$ in a detailed time scale, for a limited period of four month observations. According to the climatological model, most acoustics from ocean storms are expected and registered from the north-west.

However, in several cases acoustic arrivals have been predicted from the north-east. For example, at the end of March and in early February 2017, acoustics with backazimuths of approximately $45^{\circ}$ have been predicted, and at stations IS31 and MKIAR such predictions have been confirmed with observations. As shown in Figure 84, according to climatological model, acoustics from the north-west are normally expected during winter months (light background color in the picture), but in late February and early March the actual scene reverses, with light background for azimuths $0-100^{\circ}$ and dark for $300-360^{\circ}$. This is an illustration of the effect of SSW on infrasound propagation (period of stratospheric wind reversal allowing microbarom sources for North Pacific region to be detected). 


\section{IS31}

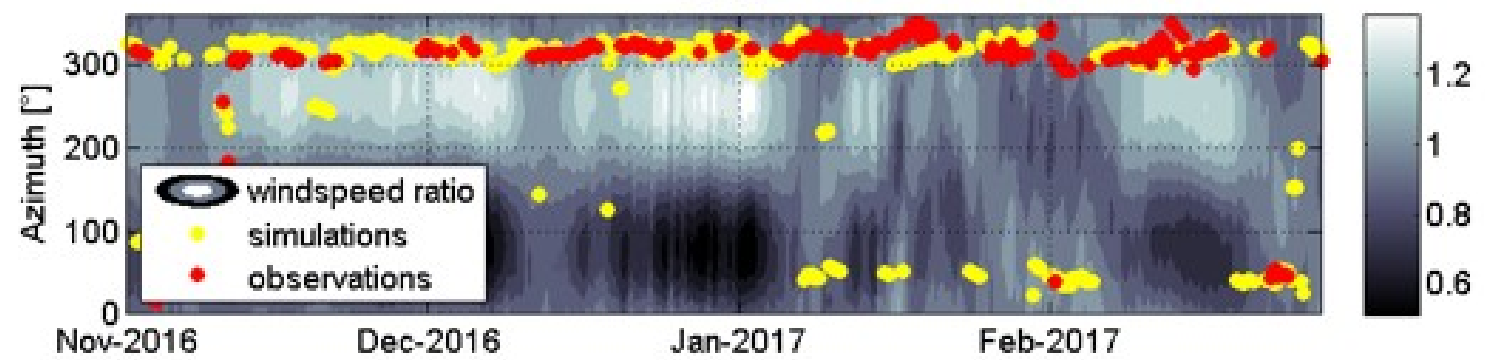

\section{KURIS}

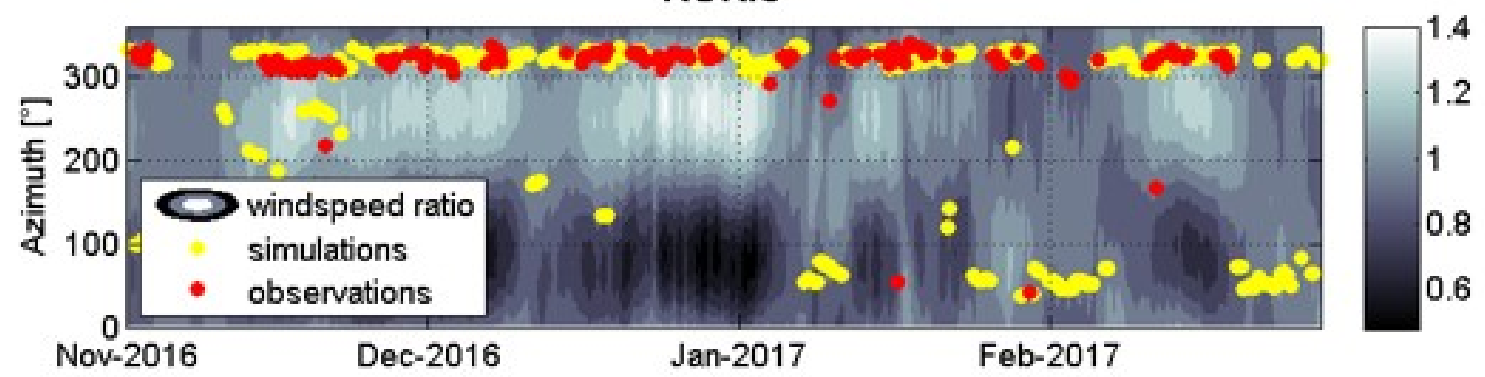

MKIAR

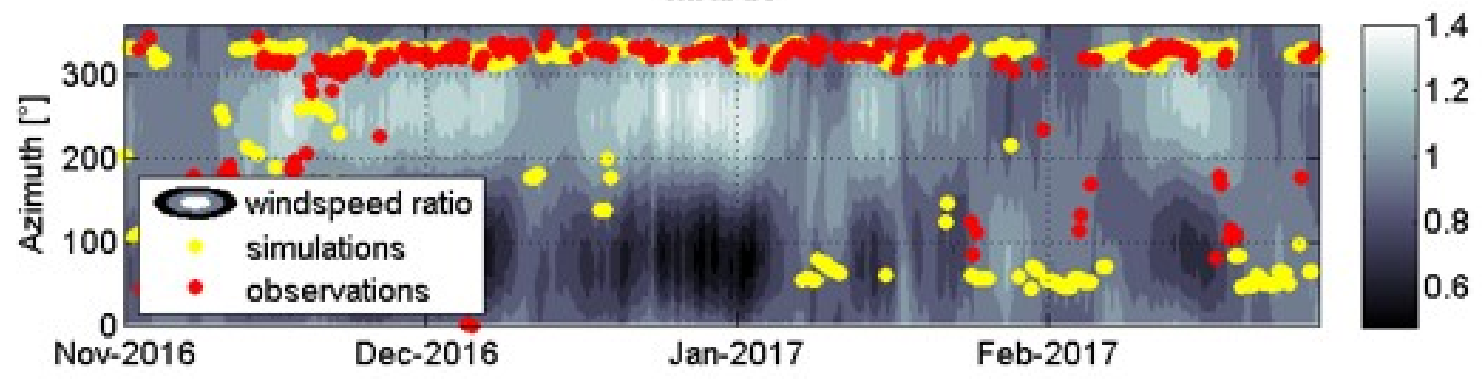

Figure 84. Comparison between the observed and predicted backazimuth values at IS31, KURIS and MKIAR and $V_{\text {eff-ratio }}$ from 1 November 2016 through 28 February 2017 


\section{Conclusions}

The first microseism and microbarom study for the Kazakh seismic and infrasound arrays was made in 2010, and even at that time findings for three Kazakh seismic arrays, namely Akbulak (ABKAR), Borovoe (BVAR), and Karatau (KKAR), and I31KZ Aktyubinsk infrasound array showed a quite good match between the observed backazimuths of low frequency seismic and infrasound signals and the directions towards areas of severe storms over the oceans. Continuous measurements of the direction of arrival of microseisms at six European seismic arrays support the hypothesis that microseisms and microbaroms recorded in Kazakhstan are generated by the same source regions in the North Atlantic Ocean as those observed in Europe. Microseisms and microbaroms generated in the North Pacific do not appear to be observed on the stations in Central Asia.

Infrasonic noise at $131 \mathrm{KZ}$ originates from two main directions. Microbaroms from northwest are dominated by low frequencies (never exceeding $1 \mathrm{~Hz}$ ). Continuous noise from the south $\left(\sim 185^{\circ}\right)$ is generated by gas flares in the Zhanazhol oil fields and is dominated by higher frequencies (between 1.5 and $4.0 \mathrm{~Hz})$.

The low-frequency background seismic and infrasonic noise recorded at the arrays in the north of Kazakhstan indicate dominant sources in the North Atlantic. KKAR array and the Makanchy arrays (MKAR) - both in the south of Kazakhstan - also recorded persistent noise (at somewhat higher frequencies) from different directions: from the south of MKAR and from the east of KKAR. These signals are not consistent with the regions of oceanic microseism generation and are likely the result of icequakes activity in the Tien Shan glaciers.

Over the last few years, Kazakh monitoring network was improved significantly: two new infrasound arrays were installed, thereby the study could cover the infrasound network. This study includes findings of microseism detections using Kurchatov Cross data. Processing of data registered by this station as an array is impossible for regional events due to its relatively large aperture, however processing of teleseismic events, such as microbaroms, were completed with promising results.

A great progress was achieved in recent years by building a model of ocean waves, which is used for simulating a global microseism and microbarom source, thus the quality of studying all aspects of the ocean noise based on Kazakh monitoring network data could be increased significantly.

The IGR seismo-acoustic network is much denser than the global IMS infrasound network. Therefore, analyzing multi-year archives of continuous recordings yields additional information about the spatial and temporal variability of the ambient noise originating from two hemispheres. In winter, the most 
intense oceanic storms are modelled in the Northern Atlantic, and their signature prevails on infrasound and seismic records.

When SSW events occur, abrupt changes in the stratospheric wind direction allow signals from the North Pacific to be detected by infrasound stations. Simulated and observed microbarom parameters are consistent, as shown by high correlation coefficients. The largest amplitudes of both microbaroms and microseisms are found for sources in the Northern Atlantic. Exploiting the synergy between seismic and infrasound ambient noise observations is thus valuable to: (i) better constrain the source location as azimuthal errors at the seismic ABKAR, KKAR and MKAR arrays that are approximately 10 times larger than at IS31, and MKIAR due to shorter wavelength; (ii) improve the detectability of ocean-wave interaction, and location accuracy as microbarom wave parameters are less affected by heterogeneities in the propagation medium, and; (iii) improve the physical description of seismoacoustic energy partitioning at the ocean-atmosphere interface.

Analysis of the bathymetry effect did not explain the actual deviation of the observed backazimuth from the expected parameters of microseisms. In 2010, a first attempt was made to explain such deviations with the influence of the local geological conditions at array locations: predicted and observed azimuths of arriving signals from earthquakes in the North Atlantic were compared for the Kazakh seismic arrays.

The deviation study was repeated in this work. A significant number of the strong earthquakes in the North Atlantic were recorded by the Kazakh network for the time elapsed since 2010. It helped to get not just averaged deviation value for the entire North-Atlantic region, but to build the maps of the distribution of the deviations in the region. It turned out that the deviation values strongly depend on the part of the ocean where the source is. The effect is observed regularly by all the stations of the network. The same effect was found not only for signals from well-localized earthquakes but also for the microseisms. Simulated positions of the highest amplitude sources were taken for the epicenters to estimate the deviations in this case. The dependencies of the deviation on true backazimuths are similar for the earthquakes and microseisms, but there are some systematic errors. Additional investigations are needed to explain this mismatch.

Even a short literature review confirmed that it is not the first time that the effect was found for the strong earthquakes. Kolínský and Bokelmann (2019) described this effect for the Alp Array records. Amongst others, they presented similar deviations of the Rayleigh wave backazimuth pathing through partially coinciding traces from the 2017-09-08 Mexico earthquake to Europe. They also showed the results of the simulation of the backazimuth deviation after the wavefront distortions due to the rectangular velocity anomaly. The simulations match well with their findings. In summer, the 
microbarom and microseism sources which dominate in the Southern hemisphere more especially along the peri-Antarctic belt are likely at the origin of the weak signals observed south of the IGR network. For such long propagation ranges, numerical simulation using range dependent atmosphere models could reduce the difference between the observed and modelled amplitude. Including additional data from other seismo-acoustic network in the Southern hemisphere would help validating long-range propagation modelling, better characterize station-specific ambient noise signatures, and enhance discrimination methods at a regional scale.

Compared observation data of the collocated seismic and infrasound arrays have a series of common features and discrepancies. During winter months, North-Atlantic microbaroms and microseisms prevail both in seismic and infrasound records and their amplitudes are significantly higher than amplitudes registered during summer months. At the same time, registration of microseisms is more stable than for microbaroms. As for the seismic arrays, the spread in the azimuth values is wider than for infrasound arrays, and errors in microseism backazimuths determination are much higher than for microbaroms. No common dominant source has been found in summer for the network, as every station registers data from specific regional sources.

Kazakh monitoring network is located on one side and at a large distance from the source area, therefore source epicenters cannot be localized precisely. However, if the ocean wave model accuracy is sufficient to predict source azimuth and amplitude, such predicted values may be used as source epicenters. Within this assumption, a catalog of the ocean sources was created. This catalog may be used for ARISE (WW3 Development Group, 2016). The Project goals, inter alia, include better description of the atmosphere and an improved accuracy in short- and medium-range weather forecasts and, in the long term, monitoring of the middle atmosphere climate, its long-term mean trends and changes in extreme events. 


\section{Perspectives}

The study of the oceanic noise using a fusion of the seismic and acoustic methods opens new perspectives. The investigations where the only seismic or acoustic method is involved are relatively well developed, although these investigations have not exhausted its potential. This kind of exploration is based on the comparison of the observed data and theoretical model for them. These relations are shown as green arrows by the symbolic scheme in Figure 85 .

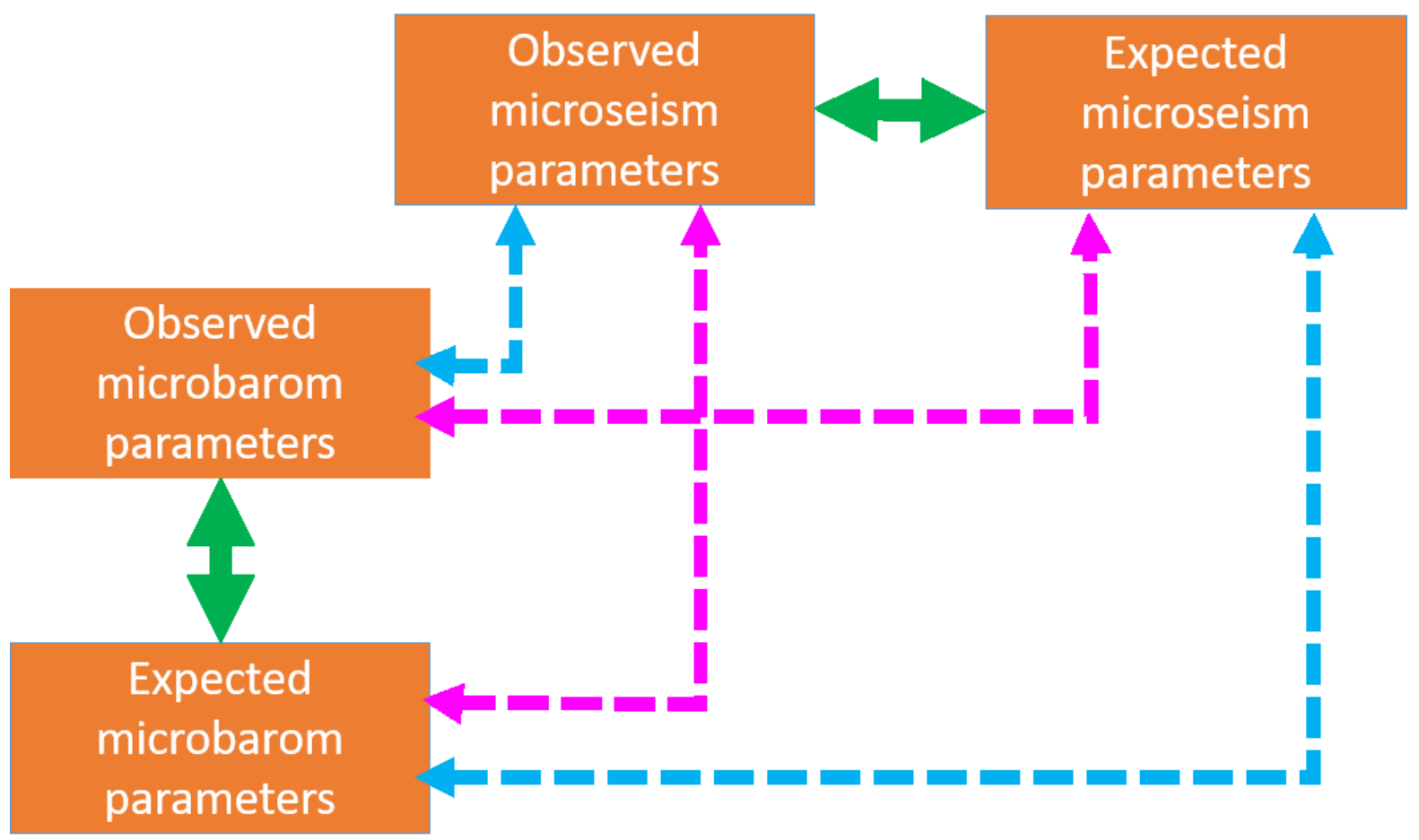

Figure 85. The relations that are under analysis when studying noise from the oceanic waves. Usually, the predicted and observed data are compared for just a single technique, these relations are shown by green arrows. Relations between the predicted parameters of the signals for seismic and acoustic techniques are shown by blue arrows. Relations between observation results for seismic and infrasound techniques are also shown by blue arrows. And, finally, relations between the predicted parameters of signals for one technique and observations for other technique are shown with the magenta arrows

A joint use of the acoustic and seismic methods allows analyzing relations between seismic and infrasound observations and between seismic and infrasound predicted signal parameters. This kind of relations is shown in Figure 85 with blue arrows. Moreover, some new information could be obtained even comparing the predicted infrasound and observed seismic and vice versa. These relations are shown by the magenta arrows in Figure 85 . 
Joint application of the seismic and infrasound techniques has a series of explicit advantages compared to the use of every method individually. Several exploration directions may be proposed:

1. Improvement of signal detection and propagation methods. Observation and simulation data received from the dense seismo-acoustic networks is the powerful input for creating the reach GT database. Unlike conventional events such as precisely localized explosions and earthquakes, this database will comprise a selection of ocean waves generated seismic and acoustic events. The information in GT database is collected much faster and more often compared to the number and frequency of events of another type. Epicenters of the GT events are located within the ocean water areas with extensive non-seismic regions free from mining activity; the frequency and density of such events is much higher than of the conventional sources, therefore this database would enable improving signal detection methods and predicting signal propagations ways at a totally new level.

2. Seismic tomography. Use of seismo-acoustic GT database will ease challenges of the seismic tomography as such source density and accessibility of new areas was never available before. High accuracy of back azimuths determined using the acoustic approach will benefit to exact measurements of backazimuth deviation for seismic events. Calculated deviations may be used as input information for the seismic tomography. For the moment, clear perspective is for the tomography on surface waves. Perhaps the same is applicable for other seismic phases, but additional investigations are required. Ocean waves are the permanent seismic acoustic energy source, and signals generated by ocean waves may be used for tomographic monitoring.

3. Atmospheric tomography. The dynamics of the middle atmosphere may be studied for climatology and environmental scientific purposes. Use of the state-of-the-art ocean models from IFREMER for the accurate source modeling allows the building of the highly reliable temperature and wind profiles for the altitudes from the ground to the stratopause region along the infrasound propagation path. Data on dynamic properties of the source derived using the seismic technique would secure totally new results in this sphere as well. Similar to seismic method, signals from ocean waves may be used for the long-term tomographic monitoring of the atmosphere.

\section{Important issues to improve operational monitoring}

4.1. Improvement of localization accuracy. Seismic tomography performance may be helpful for improving the SSSC mapping. Findings of the atmospheric tomography will be useful for precise determination of Bayesian priors for backazimuths and celerities. The above examples show, but not limit by no means, the possible alternative options for application of the 
combined technology to improve localization accuracy of epicenters of seismic and acoustic events.

4.2. Characterization of the source. Advantages of accurate measurements of the dynamic parameters of the source using seismic data may be used for the source model validation for the microbarom studies. Comparison of the infrasound and seismic observations allows selecting seasons when the oceanic noise prevails in the background noise at each particular territory.

4.3. Discrimination of the source nature. The detailed description of the source behavior and characteristics of the seismic and acoustic signals generated by the ocean storms shall be used to recognize the source nature within the ocean area and differentiate between microseisms, microbaroms and other signals.

5. Recommendations to upgrade seismo-acoustic network. Further numerical investigations are needed to define the most suitable detection parameters in terms of missed events and false alarm rate, and estimate wave parameter uncertainties accounting for the response functions of all arrays. This information may be used to work out the recommendations to improve the monitoring network, including such aspects as sensor properties, array geometry, network density and many others. 


\section{$7 \quad$ References}

Antier, K., Le Pichon, A., Vergniolle, S., Zielinski, C. and Lardy, M.: Multiyear validation of the NRLG2S wind fields using infrasound from Yasur, J. Geophys. Res., 112(D23), doi:10.1029/2007jd008462, 2007.

Ardhuin, F., Balanche, A., Stutzmann, E. and Obrebski, M.: From seismic noise to ocean wave parameters: General methods and validation, J. Geophys. Res. Ocean., 117(C5), doi:10.1029/2011jc007449, 2012.

Ardhuin, F. and Herbers, T. H. C.: Noise generation in the solid Earth, oceans and atmosphere, from nonlinear interacting surface gravity waves in finite depth, J. Fluid Mech., 716, 316-348, doi:10.1017/jfm.2012.548, 2013.

Ardhuin, F., Collard, F., Chapron, B., Girard-Ardhuin, F., Guitton, G., Mouche, A. and Stopa, J. E.: Estimates of ocean wave heights and attenuation in sea ice using the SAR wave mode on Sentinel1A, Geophys. Res. Lett., 42(7), 2317-2325, doi:10.1002/2014gI062940, 2015.

Ardhuin, F., Stutzmann, E., Schimmel, M. and Mangeney, A.: Ocean wave sources of seismic noise, J. Geophys. Res., 116(C9), doi:10.1029/2011jc006952, 2011.

Balachandran, N. K., Donn, W. L. and Kaschak, G.: On the Propagation of Infrasound from Rockets: Effects of Winds, J. Acoust. Soc. Am., 50(2A), 397-404, doi:10.1121/1.1912649, 1971.

Bass, H., Gilbert, K., Garces, M., Hedlin, M., Berger, J., Olson, J., Wilson, C. W. and Osborne, D.: Studies of microbaroms using multiple infrasound arrays, in 23rd Seismic Research Review: Worldwide Monitoring of Nuclear Explosions, October 2-5, pp. 73-80, Jackson Hole, Wyoming., 2001.

Belyashov, A., Dontsov, V., Dubrovin, V., Kunakov, V. and Smirnov, A.: New infrasound array "Kurchatov," NNC RK Bull., (2), 24-30, 2013.

Benioff, H. and Gutenberg, B.: Waves and Currents Recorded by Electromagnetic Barographs, Bull. Am. Meteorol. Soc., 20(10), 421-428, doi:10.1175/1520-0477-20.10.421, 1939.

Blanc, E., Pol, K., Le Pichon, A., Hauchecorne, A., Keckhut, P., Baumgarten, G., Hildebrand, J., Höffner, J., Stober, G., Hibbins, R., Espy, P., Rapp, M., Kaifler, B., Ceranna, L., Hupe, P., Hagen, J., Rüfenacht, R., Kämpfer, N. and Smets, P.: Middle Atmosphere Variability and Model Uncertainties as Investigated in the Framework of the ARISE Project, Infrasound Monit. Atmos. Stud., 845-887, doi:10.1007/978-3-319-75140-5_28, 2018.

Bowman, J. R.: Ambient infrasound noise, Geophys. Res. Lett., 32(9), doi:10.1029/2005gl022486, 2005.

Brachet, N., Brown, D., Le Bras, R., Cansi, Y., Mialle, P. and Coyne, J.: Monitoring the Earth's atmosphere with the global IMS infrasound network, in Infrasound Monitoring for Atmospheric Studies, pp. 77-118, Springer., 2010.

Cansi, Y.: An automatic seismic event processing for detection and location: The P.M.C.C. Method, Geophys. Res. Lett., 22(9), 1021-1024, doi:10.1029/95gl00468, 1995.

Cansi, Y. and Klinger, Y.: An Automated Data Processing Method for Mini-Arrays, Newsl. Eur. Seismol. Cent., 1021-1024, 1997.

Cansi, Y. and Pichon, A. Le: Infrasound Event Detection Using the Progressive Multi-Channel Correlation Algorithm, Handb. Signal Process. Acoust., 1425-1435, doi:10.1007/978-0-387-304410_77, 2008.

Capon, J.: High-resolution frequency-wavenumber spectrum analysis, in Proceedings of the IEEE, vol. 57, no. 8, pp. 1408-1418., 1969. 
Capon, J.: Long-Period Signal Processing Results for LASA, NORSAR and ALPA, Geophys. J. Int., 31(13), 279-296, doi:10.1111/j.1365-246x.1972.tb02370.x, 1972.

De Carlo, M., Le Pichon, A., Ardhuin, F. and Näsholm, S.: Characterizing and modelling ocean ambient noise using infrasound network and middle atmospheric models, NNC RK Bull., (2), 144-151, 2018.

De Carlo, M., Ardhuin, F., Ceranna, L., Hupe, P., Le Pichon, A. and Vergoz, J.: Global comparison between ocean ambient noise modelling and infrasound network observations, , doi:10.5194/egusphere-egu2020-17475, 2020.

Ceranna, L., Matoza, R., Hupe, P., Le Pichon, A. and Landès, M.: Systematic Array Processing of a Decade of Global IMS Infrasound Data, Infrasound Monit. Atmos. Stud., 471-482, doi:10.1007/978-3319-75140-5_13, 2018.

Donn, W. and Rind, D.: Natural infrasound as an atmospheric probe, Geophys J R Astron Soc, 26, 111-133, 1971.

Donn, W. and Rind, D.: Microbaroms and temperature and wind of upper-atmosphere, J Atmos Sci, (29), 56-172, 1972.

Donn, W. L.: Exploring the atmosphere with sonic booms, Am. Sci., 66, 724-733, 1978.

Drob, D. P., Picone, J. M. and Garcés, M.: Global morphology of infrasound propagation, J. Geophys. Res. Atmos., 108(D21), doi:10.1029/2002jd003307, 2003.

Drob, D. P., Emmert, J. T., Crowley, G., Picone, J. M., Shepherd, G. G., Skinner, W., Hays, P., Niciejewski, R. J., Larsen, M., She, C. Y., Meriwether, J. W., Hernandez, G., Jarvis, M. J., Sipler, D. P., Tepley, C. A., O’Brien, M. S., Bowman, J. R., Wu, Q., Murayama, Y., Kawamura, S., Reid, I. M. and Vincent, R. A.: An empirical model of the Earth's horizontal wind fields: HWM07, J. Geophys. Res. Sp. Phys., 113(A12), n/a-n/a, doi:10.1029/2008ja013668, 2008.

Drob, D. P., Meier, R. R., Picone, J. M. and Garcés, M. M.: Infrasound Monitoring for Atmospheric Studies, in Infrasound Monitoring for Atmospheric Studies, edited by A. Le Pichon, E. Blanc, and A. Hauchecorne, pp. 701-731., 2010.

Evers, L. G.: Infrasound monitoring in the Netherlands, J. Netherlands Acoust. Soc. (Nederlands Akoestisch Genoot., 176, 1-11, 2005.

Evers, L. G. and Haak, H. W.: Listening to sounds from an exploding meteor and oceanic waves, Geophys. Res. Lett., 28(1), 41-44, doi:10.1029/2000gl011859, 2001.

Evers, L. G. and Haak, H. W.: The Characteristics of Infrasound, its Propagation and Some Early History, Infrasound Monit. Atmos. Stud., 3-27, doi:10.1007/978-1-4020-9508-5_1, 2009.

Evers, L. G. and Siegmund, P.: Infrasonic signature of the 2009 major sudden stratospheric warming, Geophys. Res. Lett., 36(23), doi:10.1029/2009gl041323, 2009.

Farra, V., Stutzmann, E., Gualtieri, L., Schimmel, M. and Ardhuin, F.: Ray-theoretical modeling of secondary microseism P waves, Geophys. J. Int., 206(3), doi:10.1093/gji/ggw242, 2016.

Garcés, M.: On using ocean swells for continuous infrasonic measurements of winds and temperature in the lower, middle, and upper atmosphere, Geophys. Res. Lett., 31(19), doi:10.1029/2004gl020696, 2004.

Garcés, M. A., Hansen, R. A. and Lindquist, K. G.: Traveltimes for infrasonic waves propagating in a stratified atmosphere, Geophys. J. Int., doi:10.1046/j.1365-246X.1998.00618.x, 1998.

Green, D. N., Vergoz, J., Gibson, R., Le Pichon, A. and Ceranna, L.: Infrasound radiated by the Gerdec and Chelopechene explosions: propagation along unexpected paths, Geophys. J. Int., 185(2), 890910, doi:10.1111/j.1365-246x.2011.04975.x, 2011. 
Gualtieri, L., Stutzmann, E., Capdeville, Y., Ardhuin, F., Schimmel, M., Mangeney, A. and Morelli, A.: Modelling secondary microseismic noise by normal mode summation, Geophys. J. Int., 193(3), 17321745, doi:10.1093/gji/ggt090, 2013.

Hagerty, M. T., Kim, W.-Y. and Martysevich, P.: Infrasound Detection of Large Mining Blasts in Kazakstan, Pure Appl. Geophys., 159(5), 1063-1079, doi:10.1007/s00024-002-8673-3, 2002.

Hasselmann, K.: A statistical analysis of the generation of microseisms, Rev. Geophys., 1(2), 177, doi:10.1029/rg001i002p00177, 1963.

Hasselmann, K.: Feynman diagrams and interaction rules of wave-wave scattering processes, Rev. Geophys., 4(1), 1, doi:10.1029/rg004i001p00001, 1966.

Haubrich, R. A. and McCamy, K.: Microseisms: Coastal and pelagic sources, Rev. Geophys., 7(3), 539, doi:10.1029/rg007i003p00539, 1969.-

Hupe, P., Ceranna, L., Pilger, C., de Carlo, M., Le Pichon, A., Kaifler, B. and Rapp, M.: Assessing middle atmosphere weather models using infrasound detections from microbaroms, Geophys. J. Int., 216(3), 1761-1767, doi:10.1093/gji/ggy520, 2018.

IFREMER: Wave Watch 3, [online] Available from: ftp://ftp.ifremer.fr/ifremer/ww3/ (Accessed 3 October 2018), 2018.

ISC website: ISC Bulletin, ISC Bull., doi:10.31905/d808b830, 2020.

Kanamori, H. and Given, J. W.: Use of long-period surface waves for rapid determination of earthquake-source parameters, Phys. Earth Planet. Inter., 27(1), 8-31, doi:10.1016/00319201(81)90083-2, 1981.

Kedar, S., Longuet-Higgins, M., Webb, F., Graham, N., Clayton, R. and Jones, C.: The origin of deep ocean microseisms in the North Atlantic Ocean, Proc. R. Soc. A Math. Phys. Eng. Sci., 464(2091), 777793, doi:10.1098/rspa.2007.0277, 2008.

KNDC: Observation network of the Institute of Geophysical Researches of the National Nuclear Center of the Republic of Kazakhstan., [online] Available from:

http://www.kndc.kz/index.php?option=com_content\&view=article\&id=45\&Itemid=147\&lang=en (Accessed 3 October 2019), 2019.

Kolínský, P. and Bokelmann, G.: Arrival angles of teleseismic fundamental mode Rayleigh waves across the AlpArray, Geophys. J. Int., 218(1), 115-144, doi:10.1093/gji/ggz081, 2019.

Labonne, C., Sèbe, O., Smirnov, A., Gaffet, S., Cansi, Y. and Mikhailova, N.: Detailed analysis of the far-regional seismic coda in Kazakhstan using array processing, Bull. Seismol. Soc. Am., 107(2), doi:10.1785/0120160015, 2017.

Landès, M., Ceranna, L., Le Pichon, A. and Matoza, R. S.: Localization of microbarom sources using the IMS infrasound network, J. Geophys. Res. Atmos., 117(D6), n/a-n/a, doi:10.1029/2011jd016684, 2012.

Landès, M., Le Pichon, A., Shapiro, N. M., Hillers, G. and Campillo, M.: Explaining global patterns of microbarom observations with wave action models, Geophys. J. Int., 199(3), 1328-1337, doi:10.1093/gji/ggu324, 2014.

Lindquist, R. T.: Review of theNational Oceanic and Atmospheric Administration (NOAA) website(http://www.noaa.gov/), J. Agric. Food Inf., 15(2), 149-150, doi:10.1080/10496505.2014.890004, 2014.

Liszka, L. and Waldemark, K.: High Resolution Observations of Infrasound Generated by the Supersonic Flights of Concorde, J. Low Freq. Noise, Vib. Act. Control, 14(4), 181-192, doi:10.1177/026309239501400403, 1995. 
Longuet-Higgins, M. S.: A Theory of the Origin of Microseisms, Philos. Trans. R. Soc. A Math. Phys. Eng. Sci., 243(857), 1-35, doi:10.1098/rsta.1950.0012, 1950.

Marchetti, E., Ripepe, M., Campus, P., Le Pichon, A., Vergoz, J., Lacanna, G., Mialle, P., Héreil, P. and Husson, P.: Long range infrasound monitoring of Etna volcano, Sci. Rep., 9(1), 18015, doi:10.1038/s41598-019-54468-5, 2019.

Matoza, R. S., Landès, M., Le Pichon, A., Ceranna, L. and Brown, D.: Coherent ambient infrasound recorded by the International Monitoring System, Geophys. Res. Lett., 40(2), 429-433, doi:10.1029/2012gl054329, 2013.

Nolet, G. and Dahlen, F. A.: Wave front healing and the evolution of seismic delay times, J. Geophys. Res. Solid Earth, 105(B8), 19043-19054, doi:10.1029/2000jb900161, 2000.

Olson, J. V and Szuberla, C. A. L.: Distribution of wave packet sizes in microbarom wave trains observed in Alaska, J. Acoust. Soc. Am., 117(3), 1032-1037, doi:10.1121/1.1854651, 2005.

Le Pichon, A.: Infrasound monitoring of volcanoes to probe high-altitude winds, J. Geophys. Res., 110(D13), doi:10.1029/2004jd005587, 2005a.

Le Pichon, A. and Cansi, Y.: Progressive Multi-Channel Correlation: Technical Documentation, Vienna., 2003.

Le Pichon, A., Blanc, E. and Drob, D.: Probing high-altitude winds using infrasound, J. Geophys. Res., 110(D20), doi:10.1029/2005jd006020, 2005b.

Le Pichon, A., Ceranna, L., Garcés, M., Drob, D. and Millet, C.: On using infrasound from interacting ocean swells for global continuous measurements of winds and temperature in the stratosphere, $\mathrm{J}$. Geophys. Res., 111(D11), doi:10.1029/2005jd006690, 2006.

Le Pichon, A., Vergoz, J., Herry, P. and Ceranna, L.: Analyzing the detection capability of infrasound arrays in Central Europe, J. Geophys. Res., 113(D12), doi:10.1029/2007jd009509, 2008.

Le Pichon, A., Vergoz, J., Blanc, E., Guilbert, J., Ceranna, L., Evers, L. and Brachet, N.: Assessing the performance of the International Monitoring System's infrasound network: Geographical coverage and temporal variabilities, J. Geophys. Res., 114(D8), doi:10.1029/2008jd010907, 2009.

Le Pichon, A., Matoza, R., Brachet, N. and Cansi, Y.: Recent enhancements of the PMCC infrasound signal detector, Inframatics, 5-8, 2010.

Le Pichon, A., Ceranna, L. and Vergoz, J.: Incorporating numerical modeling into estimates of the detection capability of the IMS infrasound network, J. Geophys. Res. Atmos., 117(D5), n/a-n/a, doi:10.1029/2011jd016670, 2012.

Le Pichon, A., Assink, J. D., Heinrich, P., Blanc, E., Charlton-Perez, A., Lee, C. F., Keckhut, P., Hauchecorne, A., Rüfenacht, R., Kämpfer, N., Drob, D. P., Smets, P. S. M., Evers, L. G., Ceranna, L., Pilger, C., Ross, O. and Claud, C.: Comparison of co-located independent ground-based middle atmospheric wind and temperature measurements with numerical weather prediction models, J. Geophys. Res. Atmos., 120(16), 8318-8331, doi:10.1002/2015jd023273, 2015.

National Research Council: Research Required to Support Comprehensive Nuclear Test Ban Treaty Monitoring, The National Academies Press, Washington, DC., 1997.

Reed, J. .: Climatology of airblast propagation from Nevada Test Site Nuclear airblasts. Technical Report SC-RR-69-572, Sandia Laboratories, Albuquerque., 1969.

Rind, D.: Investigation of the lower thermosphere results of ten years of continuous observations with natural infrasound, J. Atmos. Terr. Phys., 40(10-11), 1199-1209, doi:10.1016/0021-

9169(78)90069-7, 1978. 
Rind, D. and Donn, W. L.: Further Use of Natural Infrasound as a Continuous Monitor of the Upper Atmosphere, J. Atmos. Sci., 32(9), 1694-1704, 1975.

Rind, D., Donn, W. L. and Dede, E.: Upper Air Wind Speeds Calculated from Observations of Natural Infrasound, J. Atmos. Sci., 30(8), 1726-1729, 1973.

Sinyova, Z., On azimuth and slowness assessment for regional phases according to PS23 Makanchi seismic array data, NNC RK Bull., 2 (25), 46-52, 2005.

Smets, P. S. M. and Evers, L. G.: The life cycle of a sudden stratospheric warming from infrasonic ambient noise observations, J. Geophys. Res. Atmos., 119(21), 12,12-84,99, doi:10.1002/2014jd021905, 2014.

Smets, P. S. M., Evers, L. G., Näsholm, S. P. and Gibbons, S. J.: Probabilistic infrasound propagation using realistic atmospheric perturbations, Geophys. Res. Lett., 42(15), doi:10.1002/2015GL064992, 2015.

Smirnov, A.: Preliminary Results of Localization and Characterization of Steady Infrasound Source as Detected by 131KZ, in 2007 Infrasound Technology Workshop, Tokyo, Japan, 13 - 16 November, Tokyo., 2007.

Smirnov, A.: The Variety Of Infrasound Sources Recorded By Kazakhstani Stations, in CTBT: Science and Technology, Vienna. [online] Available from:

https://www.ctbto.org/fileadmin/user_upload/SnT2015/SnT2015_Posters/T2.3-P20.pdf, 2015.

Smirnov, A., Dubrovin, V., Evers, L. G. and Gibbons, S. J.: Explanation of the nature of coherent lowfrequency signal sources recorded by the monitoring station network of the NNC RK, in CTBT: Science and Technology 2011. [online] Available from:

https://www.ctbto.org/fileadmin/user_upload/SandT_2011/posters/T4-P12 A_Smirnov Explanation of the nature of coherent low-frequency signal sources recorded by the monitoring station.pdf, 2011.

Smirnov, A., de Carlo, M., Le Pichon, A. and Shapiro, N. M.: Signals from severe ocean storms in North Atlantic as it detected in Kazakhstan: observations and modelling, NNC RK Bull., (2), 152-160, 2018.

Smirnov, A., De Carlo, M., Le Pichon, A., Shapiro, N. M., and Kulichkov, S.: Characterizing the oceanic ambient noise as recorded by the dense seismo-acoustic Kazakh network, Solid Earth, 12, 503-520, https://doi.org/10.5194/se-12-503-2021, 2021.

Smirnov, A., Dubrovin, V., Evers, L., Explanation of the nature of coherent low frequency signal sources recorded by monitoring station network of the NNC RK, NNC RK Bull., (3), 76 - 81, 2010.

Stehly, L., Campillo, M. and Shapiro, N. M.: A study of the seismic noise from its long-range correlation properties, J. Geophys. Res., 111(B10), doi:10.1029/2005jb004237, 2006.

Stevens, J. L., Divnov, I. I., Adams, D. A., Murphy, J. R. and Bourchik, V. N.: Constraints on Infrasound Scaling and Attenuation Relations from Soviet Explosion Data, Pure Appl. Geophys., 159(5), 10451062, doi:10.1007/s00024-002-8672-4, 2002.

Stopa, J. E., Cheung, K. F., Garcés, M. A. and Badger, N.: Atmospheric infrasound from nonlinear wave interactions during Hurricanes Felicia and Neki of 2009, J. Geophys. Res. Ocean., 117(C12), n/an/a, doi:10.1029/2012jc008257, 2012.

Stutzmann, E., Schimmel, M., Patau, G. and Maggi, A.: Global climate imprint on seismic noise, Geochemistry, Geophys. Geosystems, 10(11), n/a-n/a, doi:10.1029/2009gc002619, 2009.

Stutzmann, E., Ardhuin, F., Schimmel, M., Mangeney, A. and Patau, G.: Modelling long-term seismic noise in various environments, Geophys. J. Int., 191(2), 707-722, doi:10.1111/j.1365-

246x.2012.05638.x, 2012. 
Sutherland, L. C. and Bass, H. E.: Atmospheric absorption in the atmosphere up to $160 \mathrm{~km}, \mathrm{~J}$. Acoust. Soc. Am., 115(3), 1012-1032, doi:10.1121/1.1631937, 2004.

Szuberla, C. A. L. and Olson, J. V: Uncertainties associated with parameter estimation in atmospheric infrasound arrays, J. Acoust. Soc. Am., 115(1), 253-258, doi:10.1121/1.1635407, 2004.

Tabulevich, V., Ponomarev, E., Sorokin, A., Drennova, N., Standing ocean waves, Physics of atmosphere and ocean, 2, 235-244, 2001.

Tabulevich, V., Complex investigations of the microseismic oscillations, pp. 250-300, Nauka, Novosibirsk, 1986.

Tabulevich, V., Chernykh, E., Potapov, V., Drennova, N., Influence of the storm vibrations to the earthquakes, Priroda, 12-16, 2002.

Toksoz, M. N. and Lacoss, R. T.: Microseisms: Mode Structure and Sources, Science (80-. )., 159(3817), 872-873, doi:10.1126/science.159.3817.872, 1968.

WAVEWATCH III Development Group (2016). User manual and system documentation of WAVEWATCH III version 5.16. NOAA/NWS/NCEP/MMAB Technical Note 329, 326.

Waxler, R. and Gilbert, K. E.: The radiation of atmospheric microbaroms by ocean waves, J. Acoust. Soc. Am., 119(5), 2651-2664, doi:10.1121/1.2191607, 2006.

Waxler, R., Gilbert, K., Talmadge, C., \& Hetzer, C., The effects of finite depth of the ocean on microbarom signals, in 8th International Conference on Theoretical and Computational Acoustics (ICTCA), Crete, Greece, 2007.

Weaver, R. L.: GEOPHYSICS: Information from Seismic Noise, Science (80-. )., 307(5715), 1568-1569, doi:10.1126/science.1109834, 2005.

Whitaker, R. W. and Mutschlecner, J. P.: A comparison of infrasound signals refracted from stratospheric and thermospheric altitudes, J. Geophys. Res., 113(D8), doi:10.1029/2007jd008852, 2008.

Willis, M. C., Garces, M., Hetzer, C. and Businger, S.: Source Modeling Of Microbaroms In The Pacific., in AMS 2004 Annual Meeting., 2004.

Wilson, C. R.: Auroral infrasonic waves and poleward expansions of auroral substorms at Inuvik, N.W.T., Canada, Geophys. J. R. astr. Soc., 26, 179-181, 1971. 
ANNEX A

\section{$8 \quad$ Publications}

The first experience of the microbarom and microseism study in Kazakhstan using seismo-acoustic research complex was implemented in Kazakhstan with the direct participation of doctorant was described in the short note:

The work carried out during this thesis gave rise to participation in two scientific articles:

Smirnov, A., de Carlo, M., Le Pichon, A. and Shapiro, N. M.: Signals from severe ocean storms in North Atlantic as it detected in Kazakhstan: observations and modelling, Bulletin of National Nuclear Center of the Republic of Kazakhstan, -(2), 152-160, 2018.

Smirnov, A., De Carlo, M., Le Pichon, A., Shapiro, N. M., and Kulichkov, S.: Characterizing the oceanic ambient noise as recorded by the dense seismo-acoustic Kazakh network, Solid Earth, 12, 503-520, https://doi.org/10.5194/se-12-503-2021, 2021. 
UDK 534.2

\title{
EXPLANATION OF THE NATURE OF COHERENT LOW-FREQUENCY SIGNAL SOURCES RECORDED BY MONITORING STATION NETWORK OF THE NNC RK
}

\author{
1)A. Smirnov, ${ }^{1)}$ V. Dubrovin, ${ }^{2)}$ L. Evers \\ 1) Institute of Geophysical Research, Kurchatov, Kazakhstan \\ 2) The Royal Netherlands Meteorological Institute (KNMI)
}

The results of secondary representative signals recorded by IS31-Aktyubinsk have been shown. Spectral analysis of these signals (not higher than $0.5 \mathrm{~Hz}$ ), station-to-source azimuth (coinciding with the direction to the North Atlantic) let us suppose that the station may record storm signals from the Barents Sea - microbaroms. Meteorological and seismic data applied to the complex analysis proved this out.

From March 2005 and on, fully automatic search for coherent signals has been running on records of $\mathrm{I} 31 \mathrm{KZ}$ infrasound array. The search algorithm is based on the Progressive Multi-Channel Correlation technique (PMCC) [1]. The main advantage of PMCC is the ability to detect signals registered by several elements of seismic and infrasound arrays, but one, by searching of mutual correlation between seismic and infrasound records. Besides, this method detects signals from permanent sources. PMCC generates an automatic bulletin of infrasonic signals from eight elements of IS31Aktyubinsk array processed daily, with the chronological sequence of parameters of every detection by time, backazimuth, apparent velocity, frequency,

and amplitude. Figure 1 shows azimuthal distribution of signals detected by the station from January 1 to January 31, 2008 .

As follows from Figure 1, there are several directions of coherent signals arrival, i.e. a number of continuing infrasound signals is available which are registered by IS31-Aktyubinsk. Some data on signal studies are shown in [2]. For example, the study of the most representative signals with $180^{\circ}-195^{\circ}$ backazimuth (completed with space photos and observations from a temporary infrasound arrays at Akbulak seismic array) revealed the source of these signals, being a group of flares at Zhanazol gas and oil field [2]. Figure 1 demonstrates a source located north-westward the array, which shows second best representative detections in bulletins. According to findings of the source signals analysis (Figure 2), prevailing frequencies are significantly lower than signals from Zhanazhol field flares.

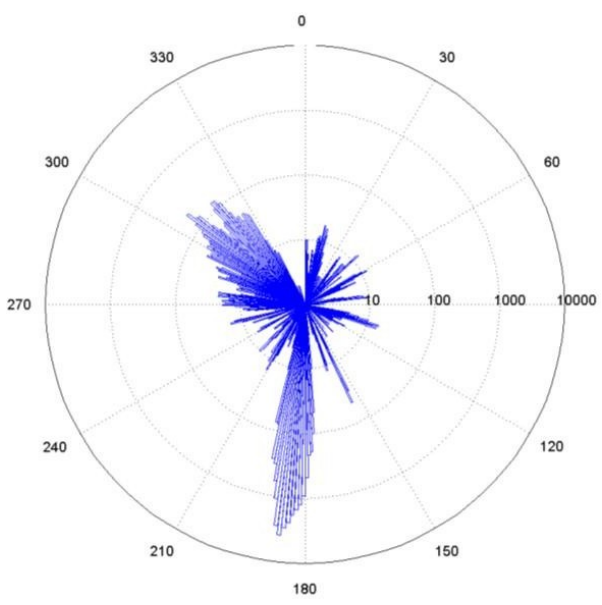

Figure 1. Example of azimuthal distribution of infrasound detections for I31KZ-Aktyubinsk for January 2008

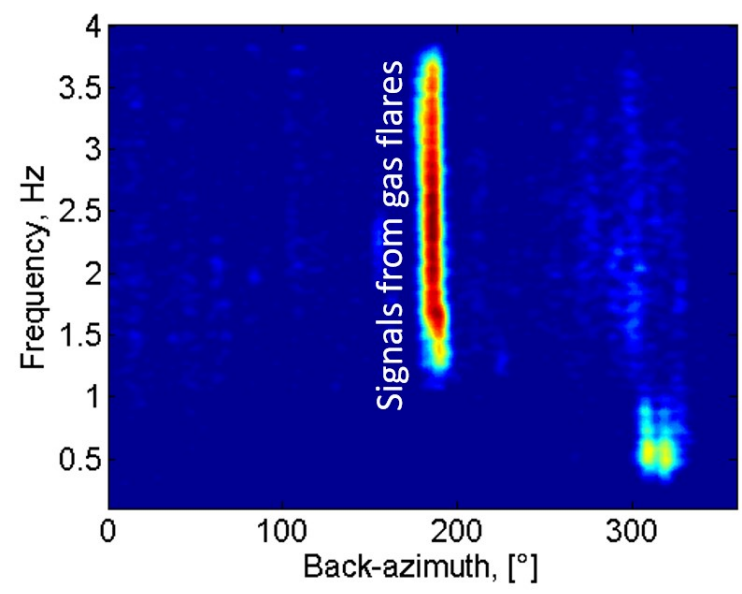

Figure 2. Frequency characteristics of detections with different arrival azimuth in January 2008 at I31KZ 
Prevailing signals, as a rule, do not exceed $0.5 \mathrm{~Hz}$, azimuth from the station towards the signal source agrees with a direction to the North Atlantic, - it speaks to the assumption that this station may register microbaroms which are signals from storms in this region.

Microbaroms were first observed by Benioff and Gutenberg [3] who assumed these signals are generated by low pressure areas. In 1950, Longuet-Higgins [4] formulated the basis of modern notions about the generation mechanism for microbaroms. He assumed, inter alia, that microseisms could be generated from pressure oscillation on the surface in the area where running ocean waves of similar frequency come across [5] and form standing water waves (SWW). SWW area generates pressure changes on the ocean floor which do not attenuate with depth $[4,6]$. These pressure changes are manifested in low-frequency seismic oscillations in the Earth crust referred to as storm microseisms. Standing waves are generated by collision of two oppositely directed running wave systems, or by interaction of the opposing wind with swelling sea. SWW area at the rear side of cyclone (typhoon) is huge and its area may reach hundreds of square kilometers. There are oscillations similar to piston performing reciprocable movements. Moving up "the piston" generates microbaroms, moving down it produces microseisms at the bottom. The oscillations are coherent (cophased). The source mechanism theory was proved experimentally and described in detail by specialists of Lamont Doherty Earth Observatory and other experts [7, 8]. Microseisms from SWW from moving cyclones propagate to large distances. Seismic stations all over the world making continuous registration of signals record them. For example, microseism from Atlantic cyclones are recorded not only by European stations but also by Asian arrays (in Tashkent and Ashkhabad), stations in Siberia (Irkutsks and Novossibirsk) and many others [9].

The integrated analysis of meteorological, seismic and infrasound data was conducted to clarify if IS31Aktyubinsk infrasound array registered target microbaroms from the ocean storms. Considering the idea that in areas of high energy SWW generation microseisms and microbaroms shall be generated together, seismic and infrasound data have been analysed for a period from 1 July 2007 through 30 June 2008. The detector used was PMCC between 0.07 and $0.5 \mathrm{~Hz}$. Analysis was performed for four Kazakh seismic arrays,
Akbulak, Borovoe, Karatau and Makanchy and infrasound array IS31-Aktyubinsk. Figure 3 shows the detections derived over a year of observations represented in a 2D histogram.

There are some features in the azimuthal distribution of low frequency detections that are common at all stations but there are also some individual peculiarities. Akbulak array has the clearest trend. This seismic array recorded target signals mostly with arrival azimuths of $300^{\circ}-360^{\circ}$. As seen on the records of Borovoe array, detections from azimuths of $300^{\circ}-360^{\circ}$ are clear, however, in the summertime, Borovoe station recorded signals from the southward along with seldom signals from the north-west. For Karatau array, distribution of detections by azimuths is similar to Borovoe records in general, but in winter months Karatau array registered an additional source located eastward. Makanchy array recorded signals from a source to the southward almost for the whole the year (except between January and April). From January through April, same as all the above arrays, Makanchy array recorded signals from a source to the north-westward. IS31-Aktyubinsk infrasound array, similar to Akbulak seismic array, registered signals arriving from the Northwest, and from time to time in summer months - from the south. In summary, though the general picture is similar from station to station, all seismic and infrasound arrays registered signals from a north-westward source.

According to meteorological data such as wave height and period maps over the world ocean area, areas of SWW generation were found, where microbaroms and microseisms could be generated as well. The perfect calculation of microseism and microbarom amplitude requires calculation of the wave trend spectrum for every value used for mapping, and determination of the area where ocean waves flow in reversed direction [10]. As this approach requires large computed machine time, an easier method was applied. As SWW are located near high-energy wave spots [11], a value has been calculated for every grid note, which is proportional to the wave energy - squared ratio of water wave height to its period. 


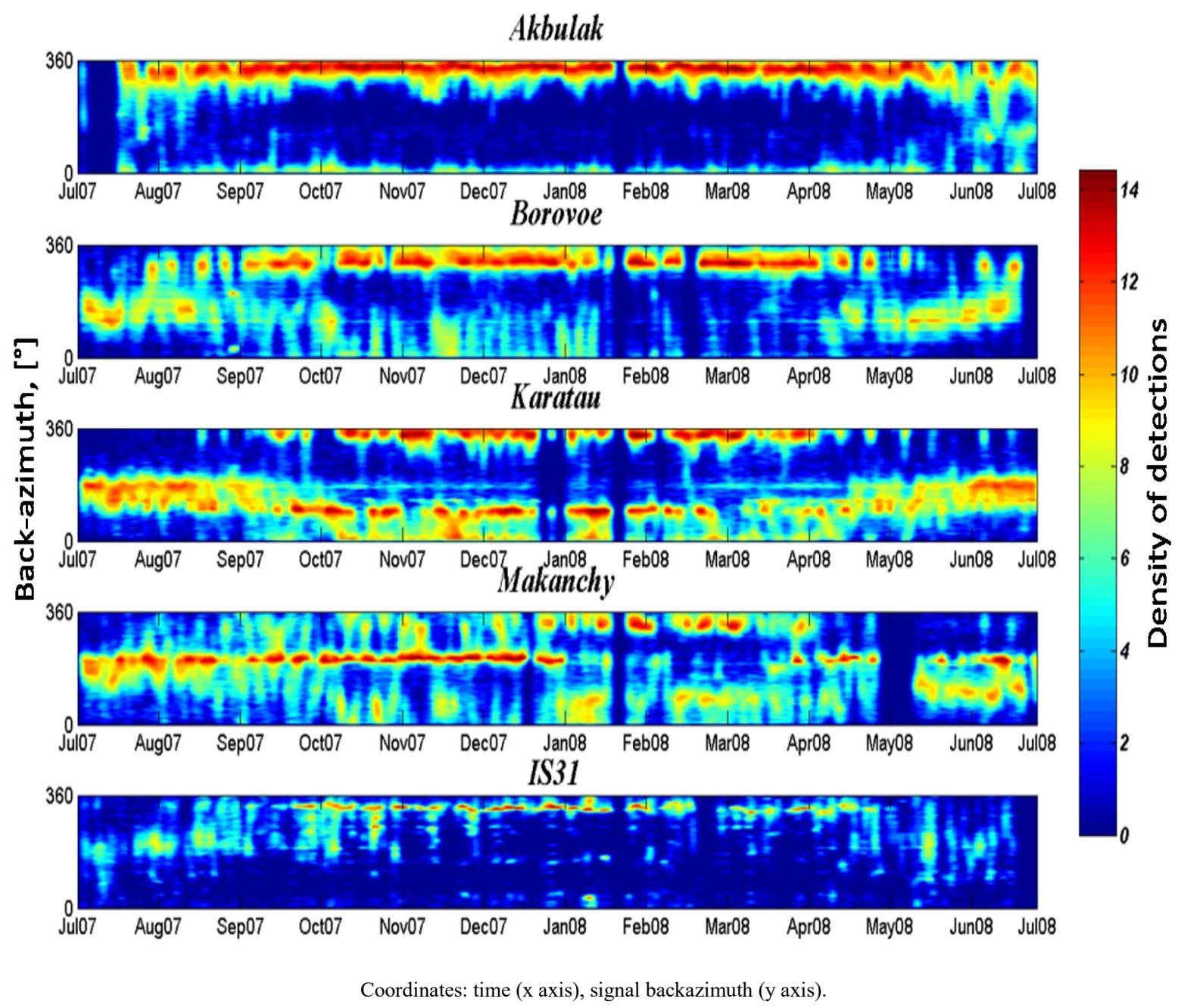

Figure 3. 2D histograms of the number of detections within 0.07-0.5 Hz over the period of 1 July 2007 through 30 June 2008 per seismic arrays and IS31-Aktyubinsk infrasound station

According to the common opinion on formation of microseisms and microbaroms, the energy of microseisms and microbaroms shall be maximum, along with the maximum energy of the water wave. Raw data for calculations - values of wave height and period - were taken from the archives of European Centre for MediumRange Weather Forecasts (ECMWF) for January 2008. Data from the extended archive data processing project were used (ERA interim [12]), which are available for public access in the internet. Data on wave height and period for the world ocean are represented on a regular rectangular grid with $1,5^{\circ}$ spacing on latitude and longitude. For every day of January 2008, two parameters were taken, namely for 00:00 and 12:00 UTC, to be used as the basis for calculation of the squared ratio of water wave height to its period for every grid node. Thereafter, ten maximum values were selected from the derived sets, for the North Atlantic region. Figure 4 shows an example of simulated result of the water waves energy spacial distribution, and ten (10) points where the energy of microseisms and microbaroms shall be maximum, in line with the accepted assumptions. This example describes distribution of water wave energy distribution as of 00:00 of 26 January 2008.

Such highly-energy areas in the world ocean where microseisms and microbaroms could be generated, were found for every day of January 2008. As shown above (Figure 3), low frequency signals arrived regularly to four (4) seismic array and the infrasound station from these areas. 


\section{EXPLANATION O THE NATURE OF COHERENT LOW-FREQUENCY SIGNAL SOURCES RECORDED BY MONITORING STATION NETWORK OF THE NNC RK}

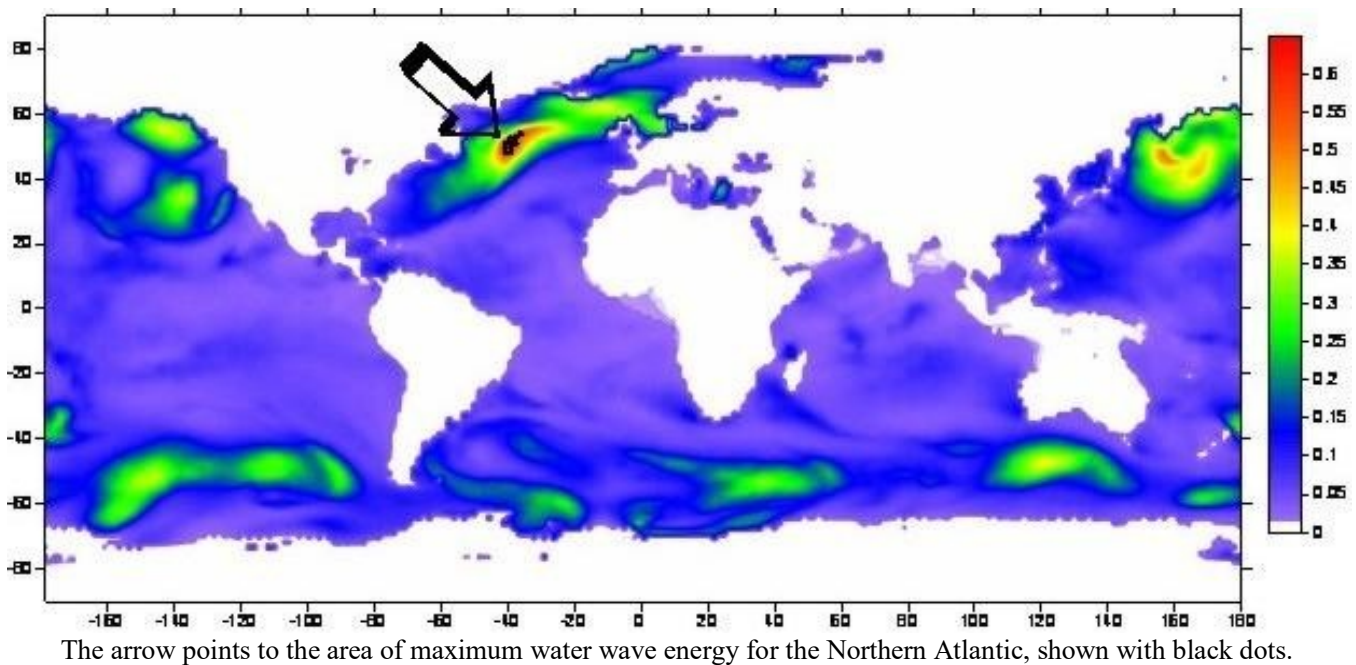

Figure 4. Distribution of the ocean wave energy all over the world calculated by ERA Interim (ECMWF) for January 26, 2008.

Special activities were conducted to mitigate corrections of signal backazimuths before data from these seismic arrays could be used to accurately locate lowfrequency signal sources. It is known that these corrections were caused by geological heterogeneities of different scale at approaches and along seismic energy distribution path towards the arrays, and a value of correction depends on the epicenter distance and wave backazimuth [13]. The following approach is used to calculate corrections. According to the International Seismological Center, ISC, five (5) reference strong earthquakes were selected in the North Atlantic, with magnitude 5 and over, happened in 2006 and later. Coordinates of the earthquakes epicentres were taken from ISC bulletins and azimuths calculated from four (4) seismic arrays to these earthquakes (true azimuth). Then corresponding azimuths to reference earthquakes (experimental azimuths) were found based on wave forms of Akbulak, Borovoe, Karatau and Makanchy seismic records. Differences between the true and experimental azimuth values were used as required corrections (Table 1).

As follows from Table 1, estimated corrections vary significantly from station to station in sign and absolute values. Corrections were used for detection of lowfrequency coherent oscillations registered by four (4) seismic arrays within one (1) observation month. Figure 5 shows a two-dimensional histogram of detections within $0.07-0.5 \mathrm{~Hz}$ for four seismic arrays and infrasound station over the period from 1 through 31 January 2008. For comparison, white lines on histogram are corrected expected SWW azimuths from the maximum energy area.

Table 1. Reference earthquakes and azimuthal corrections for seismic arrays

\begin{tabular}{|c|c|c|c|c|c|c|c|c|c|c|}
\hline \multirow[b]{2}{*}{$\begin{array}{l}\text { Origin Date and Time } \\
\text { (hour, minute, } \\
\text { second) }\end{array}$} & \multirow[b]{2}{*}{$\begin{array}{l}\text { Latitude } \\
\text { Longitude }\end{array}$} & \multirow[b]{2}{*}{ 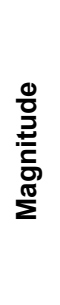 } & \multicolumn{2}{|c|}{ Akbulak } & \multicolumn{2}{|c|}{ Borovoe } & \multicolumn{2}{|c|}{ Karatau } & \multicolumn{2}{|c|}{ Makanchy } \\
\hline & & & 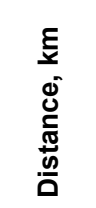 & 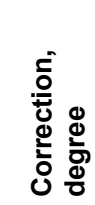 & 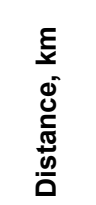 & 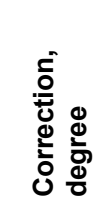 & 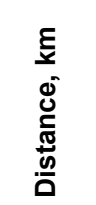 & 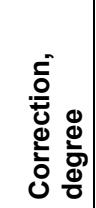 & 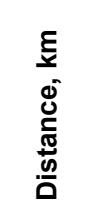 & 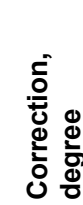 \\
\hline $\begin{array}{c}29.11 .2006 \\
15: 38: 43 \\
\end{array}$ & $\begin{array}{c}53.82 \\
-35.41 \\
\end{array}$ & 5.3 & 6,099 & -6.8 & 6,309 & -5.4 & 7,152 & 15.9 & 7,382 & 4.4 \\
\hline $\begin{array}{c}23.05 .2007 \\
4: 41: 47\end{array}$ & $\begin{array}{l}52.37 \\
-31.76\end{array}$ & 5.5 & 6,001 & -14.7 & 6,254 & -9.0 & 7,059 & 27.5 & 7,337 & 1.6 \\
\hline $\begin{array}{c}06.05 .2008 \\
8: 47: 11\end{array}$ & $\begin{array}{l}53.47 \\
-35.2\end{array}$ & 5.2 & 6,112 & -3.9 & 6,328 & -14.2 & 7,166 & 19.3 & 7,403 & -5.9 \\
\hline $\begin{array}{c}29.05 .2008 \\
15: 45: 57\end{array}$ & $\begin{array}{c}64.02 \\
-21.11\end{array}$ & 6.2 & 4,835 & -5.8 & 4,964 & -9.3 & 5,866 & 20.9 & 6,021 & 10.8 \\
\hline $\begin{array}{c}21.02 .2009 \\
16: 53: 25\end{array}$ & $\begin{array}{r}55.09 \\
-41.63 \\
\end{array}$ & 4.9 & 6,325 & -10.7 & 6,476 & -12.8 & 7,366 & 18.8 & 7,530 & -1.4 \\
\hline $\begin{array}{c}01.01 .2010 \\
9: 37: 10 \\
\end{array}$ & $\begin{array}{c}42.39 \\
-30.54 \\
\end{array}$ & 5.2 & 6,622 & -10.9 & - & - & 7,680 & 29.4 & 8,098 & 7.3 \\
\hline \multicolumn{3}{|c|}{ Average correction, degrees } & \multicolumn{2}{|c|}{-8.8} & \multicolumn{2}{|c|}{-9.3} & \multicolumn{2}{|c|}{20.1} & \multicolumn{2}{|c|}{3.0} \\
\hline
\end{tabular}


For three seismic arrays - Borovoe, Karatau and Makanchy and IS31-Aktyubinsk array, observed and expected azimuths agree rather well. For Akbulak array, expected azimuths to the source agree with the marginal observed values. Findings prove the nature of the source of low-frequency signals registered continuously by the monitoring net stations. Such signals are microseisms and microbaroms.

Therefore, findings of the integrated analysis of meteorological, seismic and infrasound data allowed to determine the nature of the significant part of detected coherent low-frequency signals, i.e. microseisms and microbaroms: most of microseisms and microbaroms registered by Kazakh arrays, are generated in the North Atlantic. Akbulak and Borovoe seismic arrays and IS31Aktyubinsk array are located in Northern Kazakhstan. According to the findings,
North Atlantic microseisms and microbaroms prevail in low-frequency noise detected by these arrays. At Makanchy and Karatau arrays located southward, lowfrequency noise includes other components, with sources located in other regions. Reference document [15] describes one possible source of signals registered by Karatau and Makanchy arrays in microseismic frequency range. It is Tian Shan glacier, which continuously generates weak earthquakes. Central Tian Shan is located eastward of Karatau array and southward of Makanchy array, direction to which agrees well with detected signal sources. However, verification of this hypothesis and study of the nature of other, weaker sources of microseismic noise require additional investigations. The issue of an insignificant mismatch (up to $15^{\circ}$ ) at Akbulak seismic array between the expected and observed directions in SWW area with the strongest energy in the North Atlantic remains unsolved.

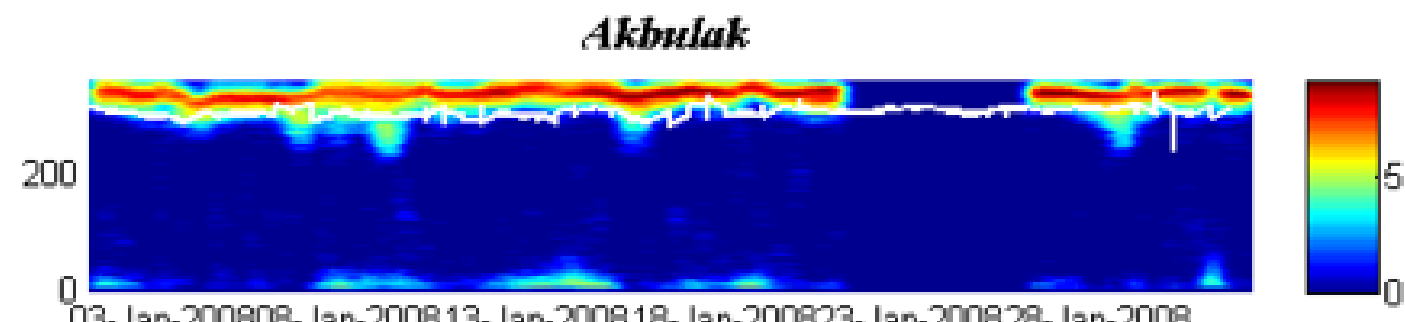

03-Jan-200808-Jan-200813-Jan-200818-Jan-200823-Jan-200828-Jan-2008

Borovoe
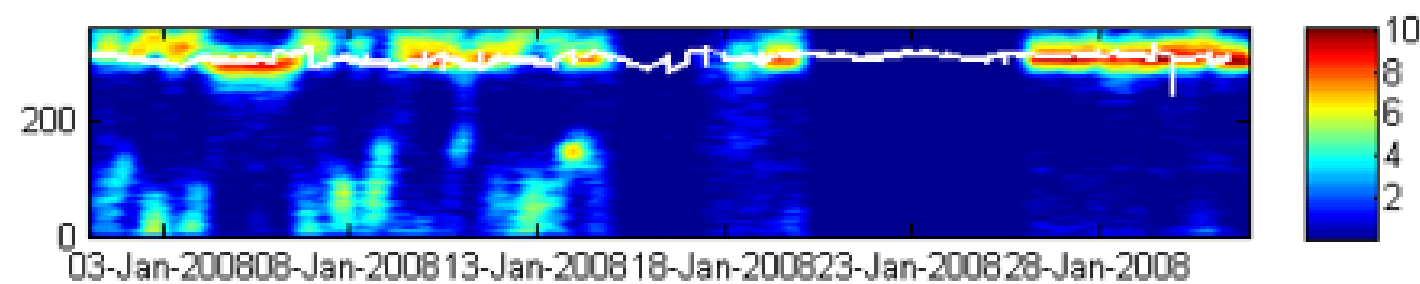

Karatau
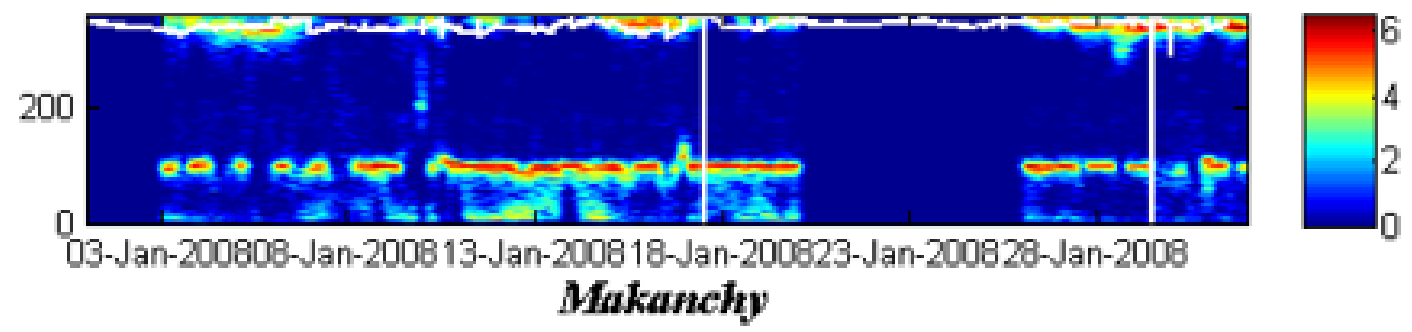

\section{Makanchy}

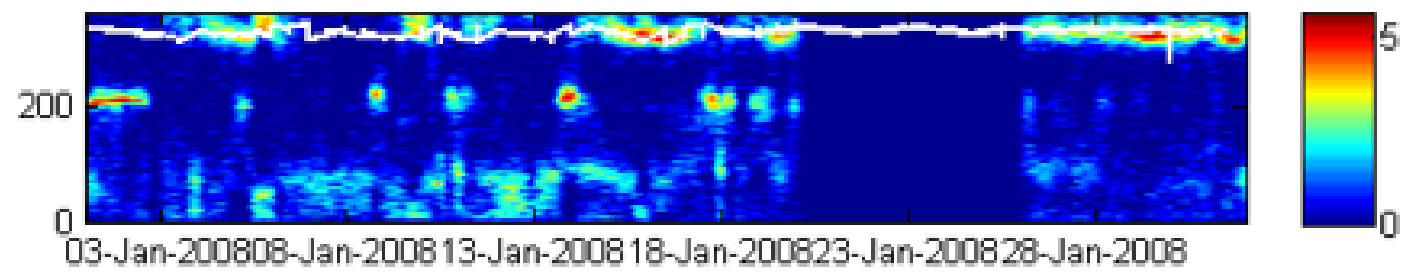

White line stands for corrected expected azimuths in SWW area with maximum energy.

Figure 5. 2D hystogram of detections within 0.07-0.5 Hz

for 1-31 January 2008 of seismic arrays and IS31-Aktyubinsk infrasound station 


\section{REFERENCES}

1. Cansi, Y. An automatic seismic event processing for detection and location: The P.M.C.C. method / Y.Cansi //

2. Smirnov, A. Preliminary Results of Localization and Characterization of Steady Infrasound Source as Detected by I31KZ / A. Smirnov [et al] // Infrasound Technology Workshop Tokyo, Japan, 13 - 16 November, 2007.

3. Benioff, H. and B. Gutenberg, 1939: Waves and currents recorded by electromagnetic barographs. Bull. Am. Met. Soc., 20, 421.

4. Longuet-Higgins, M. S. A theory of the origin of microseisms / M. S.Longuet-Higgins // Phil. Trans. R. Soc. A., 1950. - 243. - P. 1 - 35.

5. Kedar, S. The origin of deep ocean microseisms in the North Atlantic Ocean / S Kedar [et al] // Proc. R. Soc. A, 464. P. 777 - 793.

6. V.N. Tabulevich // Izv. RAS. Atmospheric and Oceanic Physics // V.N. Tabulevich, E.A. Ponomarev, A.G. Sorokin, N.N. Drennova, 2001. No. 2. Pages 235-244.

7. V.N. Tabulevich Integrated studies of microseismic vibrations / V.N. Tabulevich - Novossibirsk, 1986.

8. V.N. Tabulevich Microseismic and Infrasound Waves / V.N. Tabulevich // Heidelberg, 1992.

9. Tabulevich, V., Chernykh, E., Potapov, V., Drennova, N., Influence of the storm vibrations to the earthquakes, Priroda, 12-16, 2002.

10. Willis, Mark C.; Garces, M.; Hetzer, C.; Businger, S. (2004). "P2. 5 Source Modeling Of Microbaroms In The Pacific". AMS 2004 Annual Meeting. Retrieved 2007-11-22.

11. Evers, L. G. Infrasonic. - 36, L23808, doi: 10.1029/2009GL041323.

12. http://data-portal.ecmwf.int/data/d/interim_daily/

13. Z.I. Sinyova, Evaluation of azimuths and slowness for regional phases based on PS23-Makanchy array data / Z.I. Sinyova // Vestnik NNC RoK, 2005. Issue 2 (22), Pages 46-52.

14. http://www.isc.ac.uk/search/bulletin/rectang.html

15. N.N. Mikhailova, Glacial earthquakes of the Central Tian Shan / N.N. Mikhailova, I.I. Komarov // Vestnik NNC RoK, 2009. - Issue 3. Pages 120-126. 


\title{
SIGNALS FROM SEVERE OCEAN STORMS IN NORTH ATLANTIC AS IT DETECTED IN KAZAKHSTAN: OBSERVATION AND MODELLING
}

\author{
${ }^{1)}$ A.A. Smirnov, 2, 3) M. De Carlo, 3) A. Le Pichon, 4) N.M. Shapiro \\ 1) Institute of Geophysical Researches of Ministry of Energy of the Republic Kazakhstan, Kurchatov, Kazakhstan \\ ${ }^{2)}$ University of Western Brittany (UBO), Brest, France \\ ${ }^{3)}$ The Atomic Energy Commission (CEA/DAM/DIF), Arpajon, France \\ ${ }^{4)}$ Institute of Physics of Globe of Paris (IPGP), Paris, France
}

The Kazakh monitoring network consists of four seismic and three infrasound arrays. All the arrays record low frequency signals mostly from North-West. A dominating source region of microbarom/microseism signals is located in North Atlantic [1]. Time dependent simulations of the microbarom/microseism source regions are made using a hydrodynamic model of ocean wave interactions developed by IFREMER. Comparisons between observations at the Kazakh monitoring network and modelling results are carried out.

There are different seismoacoustic sources of various origin. Microbaroms and microseisms are dominant sources of coherent noise detected continuously worldwide. High amplitude background seismic and acoustic noise originates from the non-linear interaction of ocean gravity waves with the sea floor and atmosphere (e.g. [25]. The wave energy is directly proportional to this interaction [6-8]. The coupling with the bathymetry plays an important role $[9,10]$. Source simulation tech- niques are developing rapidly. One way to simulate the source region and its intensity is to apply the Longuet Higgins theory to wave action numerical models [9, 10]. The patterns obtained are usually compared with the excited surface and body waves [11-14]. Seismic and infrasound arrays together with $3 \mathrm{C}$ stations are part of the Kazakhstani monitoring network. The use of array data allows to locate the source region of both microseisms and microbaroms. Microbarom source location procedures have to take into account the spatial and temporal variability of the atmosphere [15-18]. Accurate localization using the data of the seismic network should take into account station specific bias that depend on range and azimuth. The detection and charac- terization of microbarom and microseism signals, location of the source areas and comparison of the results with source simulation are carried out for different objectives: passive seismic probing [19-25]; monitoring of the Earth crust [24, 25], study of climate [12], of atmosphere state $[26,17]$, and monitoring the detection capability of the IMS (International Monitoring System) network [27, 28].

\section{OBSERVATION OF MICROBAROM AND MICROSEISM IN}

\section{KAZAKHSTAN}

Microseism and microbarom observations in Kazakhstan using array techniques started in 2010 [1, 29]. Data of four seismic and one infrasound arrays were used for this preliminary study. The array data were processed with the PMCC detector [30] in the frequency band 0.07$0.5 \mathrm{~Hz}$.

It was shown [1] that all stations record signals from Northwest with back-azimuth $300-360^{\circ}$. Northwest for Kazakhstani stations corresponds to the North Atlantic. Such signals are dominant for the ABKAR station which is the closest station to North Atlantic region (Figure 1).

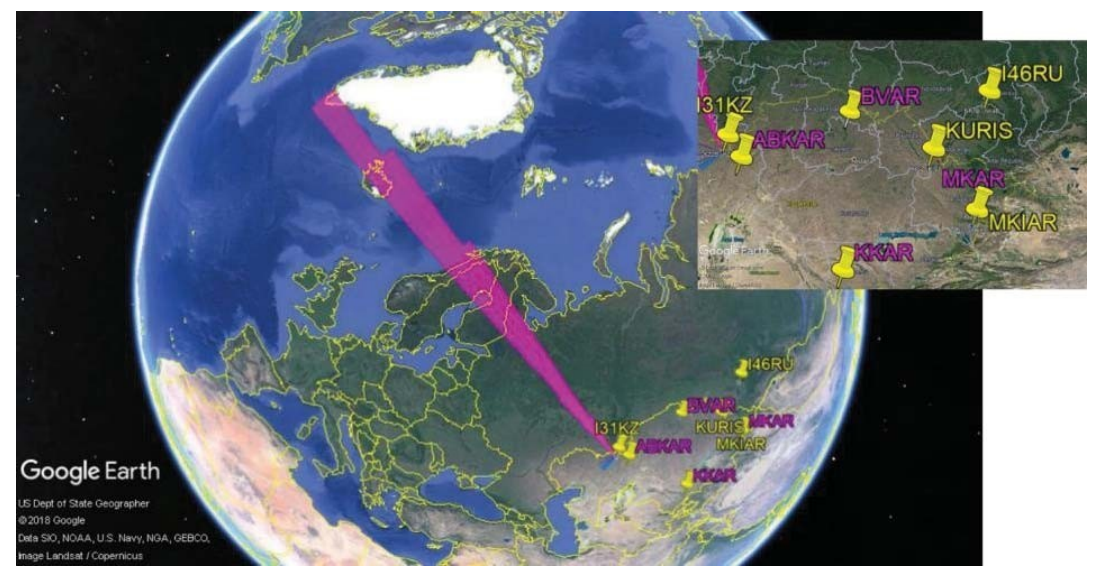

Magenta polar bars indicate the detected directions of signals recorded by IS31 in December 2016. Seismic array names are signed in magenta and infrasound station names in yellow. I46RU is also shown in addition to Kazakhstani station as its data contribute to routine processing at IGR.

Figure 1. Location of the monitoring network of the Institute of Geophysical Researches (IGR) and North Atlantic region 
It was also shown that the other stations also detect these signals including the infrasound array $\mathrm{I} 31 \mathrm{KZ}$. However not only microseisms from the ocean storms but also permanently acting sources of other nature were recorded by the KKAR and MKAR seismic arrays. For example, signals from a source southward from MKAR were detected. The parameters (frequency, velocity of arrival) of the signals differ strongly from that of microseisms. There were also found the huge difference in apparent velocities explained by different types of seismic phases. Later studies found out that the source of the signals at MKAR are likely icequakes at the Inylcheck glacier, Tyan-Shan $[31,32]$. Attempt to predict the location of microbarom and microseism source region was done. The prediction was based on a simplified approach assuming the source regions to be located where ocean wave height reaches its maximum value. The azimuths to those areas were found for each station using water wave heights from ECMWF [33]. Comparison of observation results and the predicted azimuth to the source region were made. Observations and predictions consistent to a first order, although some systematic azimuthal errors were noted for ABKAR.

\section{OBSERVATION SYSTEM}

The observation network of IGR, especially its infrasound part, was improved since this previous study, Figure 2. Two new infrasound arrays have been installed in Kazakhstan. These are infrasound arrays in Kurchatov [34] and in Makanchy. KNDC has also started to use the data of Russian array I46RU.

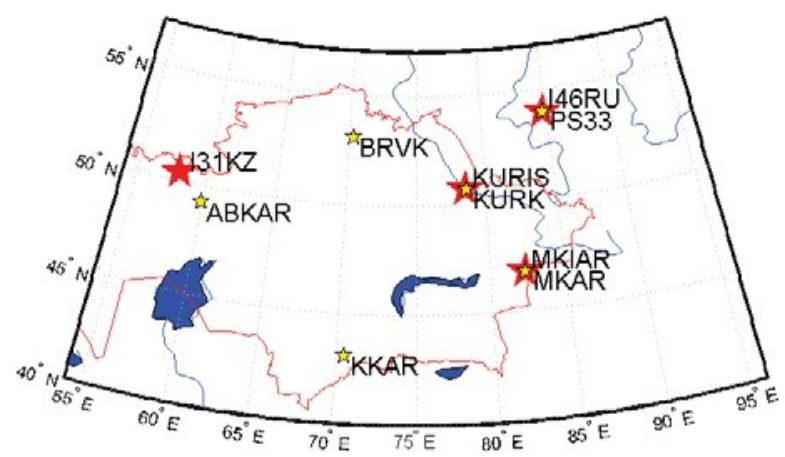

Yellow stars are seismic arrays and red stars are infrasound arrays. Russian infrasound array I46RU and seismic array PS33 are also shown as their data are actively used by KNDC. At three points both seismic and infrasound arrays are collocated. Distance between I31KZ infrasound array and ABKAR seismic array is near $200 \mathrm{~km}$.

\section{Figure 2. Arrays of the monitoring network of the IGR}

Such a development suggests that a new study of microbaroms and microseisms with the data of the Kazakhstani stations will provide additional useful results. These results can also be enhanced by using more accurate method of the source prediction that is described below. Seismic arrays ABKAR, BVAR, KKAR and MKAR are similar in configuration. They consist of nine elements with aperture of about $5 \mathrm{~km}$. The ABKAR array configuration is shown by Figure 3 as an example.

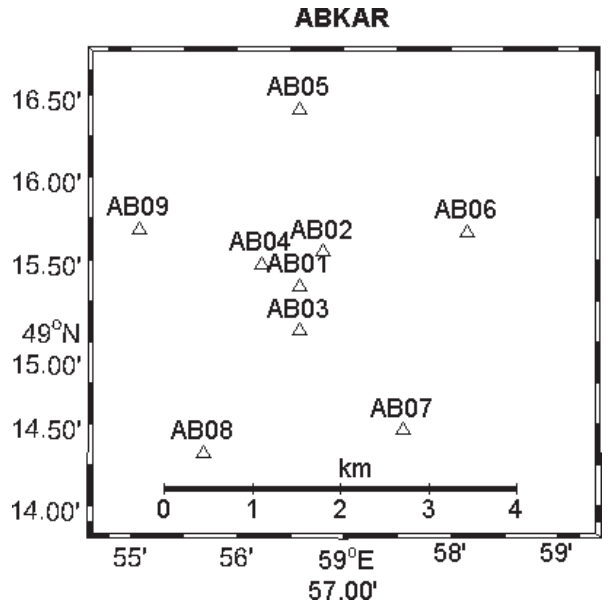

Figure 3. Configuration of the ABKAR seismic array. It consists of 9 elements with a central point, inner circle of three elements and outer circle of five elements.

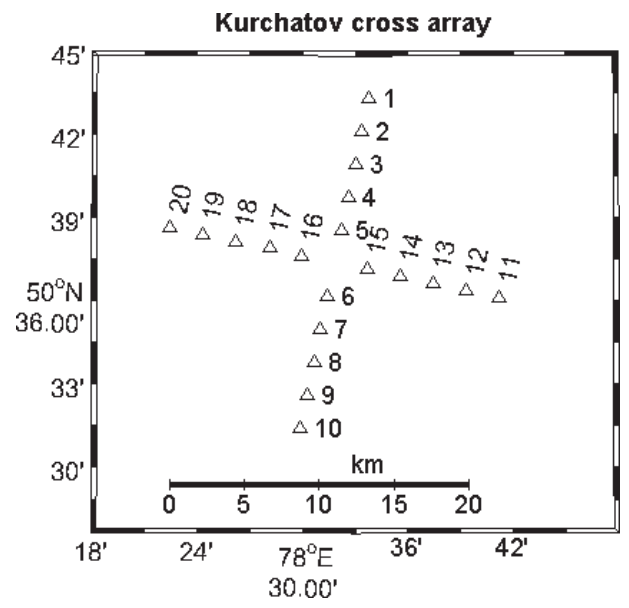

Figure 4. Configuration of the Kurchatov Cross seismic array which consists of 20 short period sensors

The Kurchatov cross array differs from the other seismic stations considering its large aperture of $22 \mathrm{~km}$ and the number of elements Figure 4. There are short period vertical sensors GS21 at ABKAR, BVAR, KKAR and MKAR. Kurchatov Cross consists of CMG- $3 \mathrm{~V}$. Although the frequency band $0.1-0.3 \mathrm{~Hz}$ is at the edge of the frequency response of the sensors, they can record well the microseisms. Figure 5 shows the frequency response of GS-21. The frequency response of CMG-3V is similar.

MKIAR and Kurchatov are two new infrasound arrays Kurchatov is at Northeast and MKIAR at East of Kazakhstan. Their aperture is about of $1 \mathrm{~km}$. MKIAR consist of 9 elements. Kurchatov has only 4. IS31 and IS46 are IMS stations. The first one is located Northwest of Kazakhstan and the second one at Altay, Russia. Their apertures are 2.1 and $2.8 \mathrm{~km}$ respectively [35]. The number of elements at IS31 is 8 and 4 at IS46. Microbarometers MB2000 and MB2005 are used at IS31, IS46 and Kurchatov and Chapparel Physics microbarometers are installed at MKIAR. Figure 6 shows the 
frequency response of the MB2000 microbarometer. The frequency responses of other infrasound sensors used are similar to MB2000 with a flat response be- tween 0.01 and $5.0 \mathrm{~Hz}$.

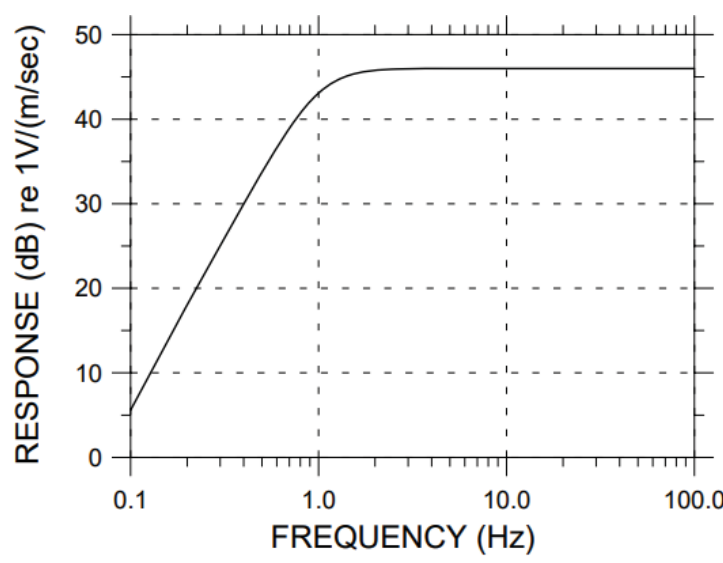

Figure 5. Frequency response of the GS-21 sensor

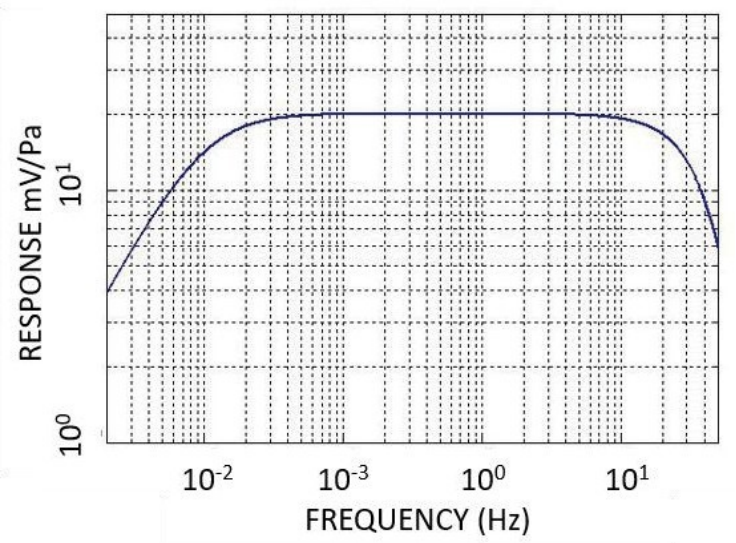

Figure 6. Frequency response of the MB2000 microbarometer

The stations in the network are part of the different global networks such as the IMS, and IRIS. KNDC has been collaborating for several years with the institutions responsible for these networks and leading seismic and infrasound centers. These are Data Center (IDC) of the Comprehensive Nuclear-Test-Ban Treaty Organization (CTBTO, Austria), Air Force Technical Applications Center (AFTAC, USA), Commissariat à l'Energie Atomique (CEA, France) and others.

\section{SIGNAL DETECTION: THE PMCC METHOD}

Microbarom signals are detected using the PMCC method. This algorithm [30] widely used to process infrasound signals. Processing was carried out in $15 \mathrm{log}$ scaled frequency band between 0.01 and $5 \mathrm{~Hz}$ using a standardized configuration $[36,37]$. The windows length varied from $600 \mathrm{~s}$ for the lowest frequency up to $30 \mathrm{~s}$ for the uppermost. In contrast with infrasound, processing seismic data with PMCC still needs dedicated tuning in the frequency band of interest. Thus the con- figuration was specially chosen for this study and proved to be efficient for the detection of microseism signals. The data were processed in the frequency band $0.05-0.3 \mathrm{~Hz}$ in 10 windows of equal length of $200 \mathrm{~s}$. Due to the low frequency composition of microseisms signals, processing was done with decimation. Originally seismic waveforms have sampling frequency of $40 \mathrm{~Hz}$. It was checked that decimation down to $10 \mathrm{~Hz}$ does not affect the processing result at the frequency range $0.1-0.3 \mathrm{~Hz}$ and at the same time significantly re- duce the computational time.

\section{SOURCE MODELLING}

The principles that were used to predict the location of the regions where microseisms and microbaroms are generating are based on classical work of Longuet Higgins [6]. In this paper it is shown how opposing waves and their second order nonlinear interactions can generate propagating acoustic waves in the ocean which produce seismic noise by exciting the ocean floor. Hasselmann $[38,39]$ generalized this phenomenon to random waves and wave-wave interactions. They both show that if we consider two nearly opposing waves interacting, the resulting frequency of interest will double the frequency of water wave.

Ardhuin et al. 2011 [10] developed a numerical model based on Longuet-Higgins-Hasselmann theory for the generation of Rayleigh waves, considering an equivalent pressure source at the undisturbed surface of the ocean. Sources of microseisms are provided by IFREMER [40] -'p2l' - as a composite calculated from the wave-action model WaveWatchIII (WW3 - developed by the NOAA and distributed by IFREMER).

These nonlinear interactions also generate waves propagating in the atmosphere - known as microbaroms. As the source term at the ocean surface is the same as for microseisms - only the amplitude might change due to a resonance term in finite depth ocean $[7,8]$, the same ' $\mathrm{p} 21$ ' model was used to make qualitative comparisons with observations. Figure 7 shows example of the source power distribution. The source intensity was calculated on February 2, 2017 in the 0.1 -

$0.3 \mathrm{~Hz}$ frequency range. Sources in white areas were not taken into account as the probability to get signals from these regions at that time of the year in Kazakhstan is rather small considering both source intensity and propagation range.

\section{COMPARISON OF THE OBSERVATIONS AND PREDICTIONS}

Long term microbarom observations for the Central Eurasia area were kindly provided by CEA. These contains four years of the PMCC detection results at IS31 (Figure 8) and IS46 (Figure 9) in a frequency range 0.01$4 \mathrm{~Hz}$. Only detections in the $0.1-0.3 \mathrm{~Hz}$ band were selected. Azimuths to the predicted source regions are shown by black circles. 


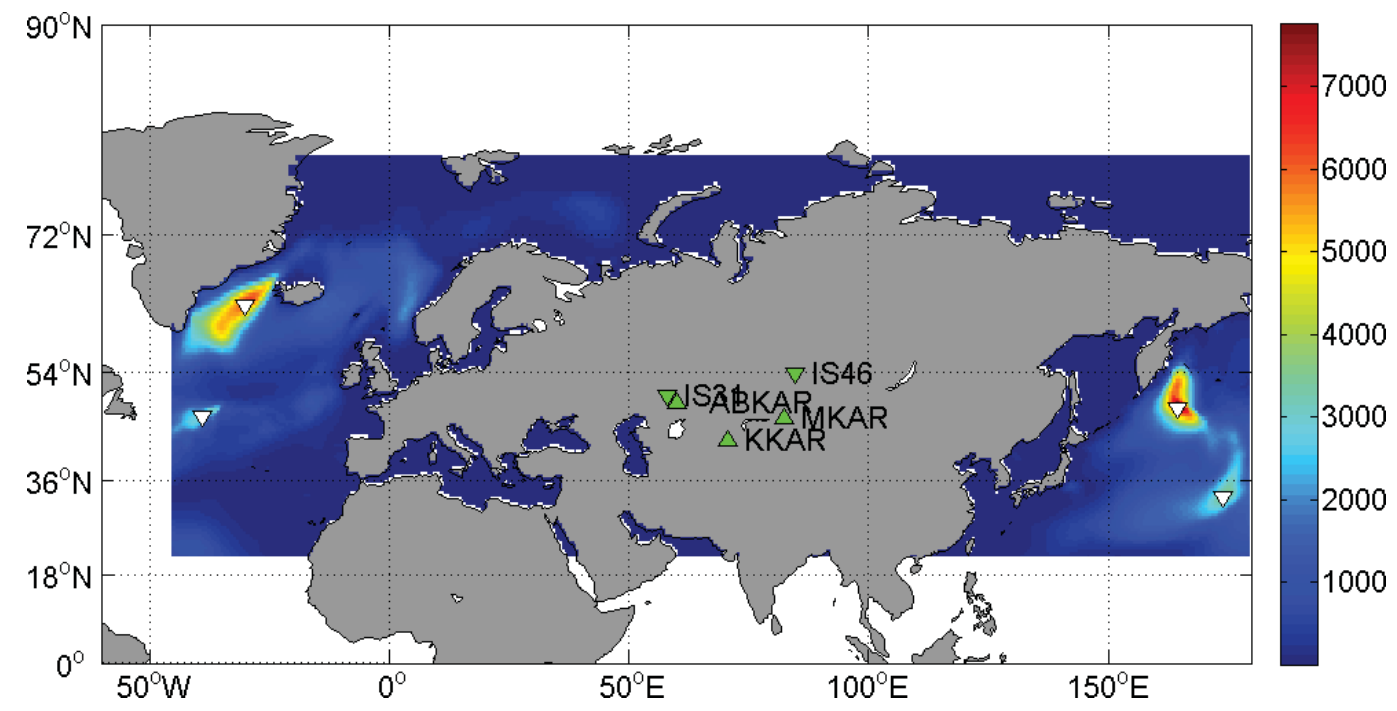

Figure 7. Example of the source energy distribution. The map shows the energy distribution averaged for the entire day of February 2, 2017 in the frequency range 0.1-0.3 Hz. Data about the ocean wave energy are provided by the IFREMER [10].

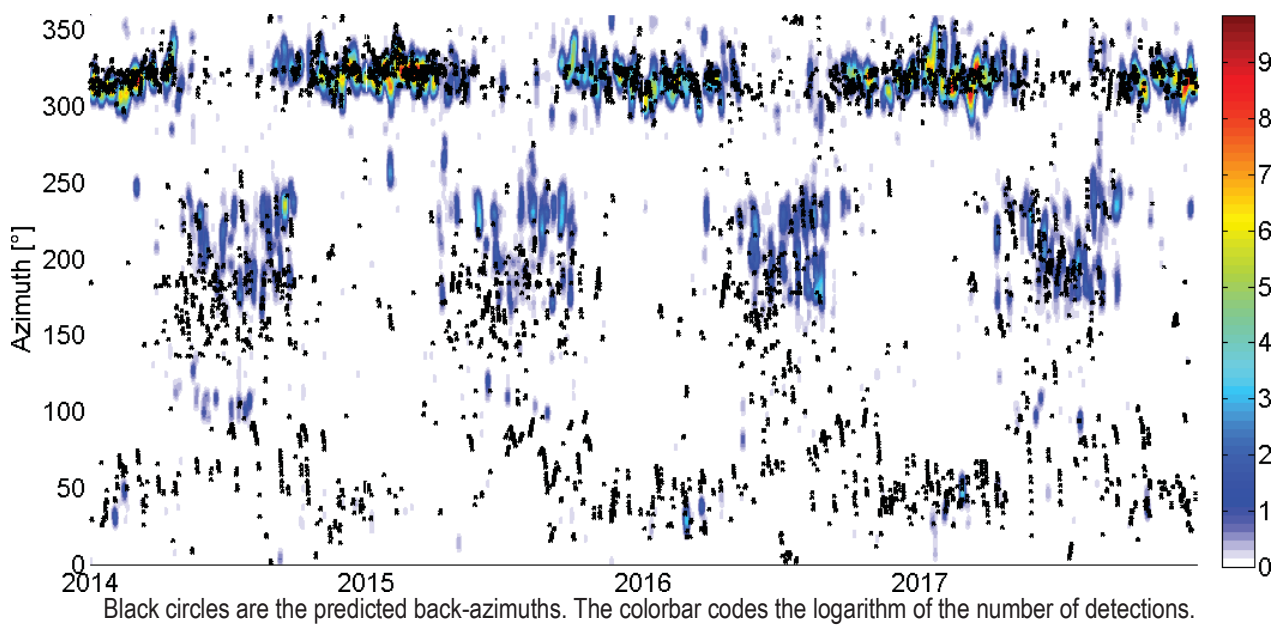

Figure 8. Four years of the PMCC detections at IS31 in the frequency range 0.1-0.3 Hz (the PMCC bulletins are kindly provided by CEA)

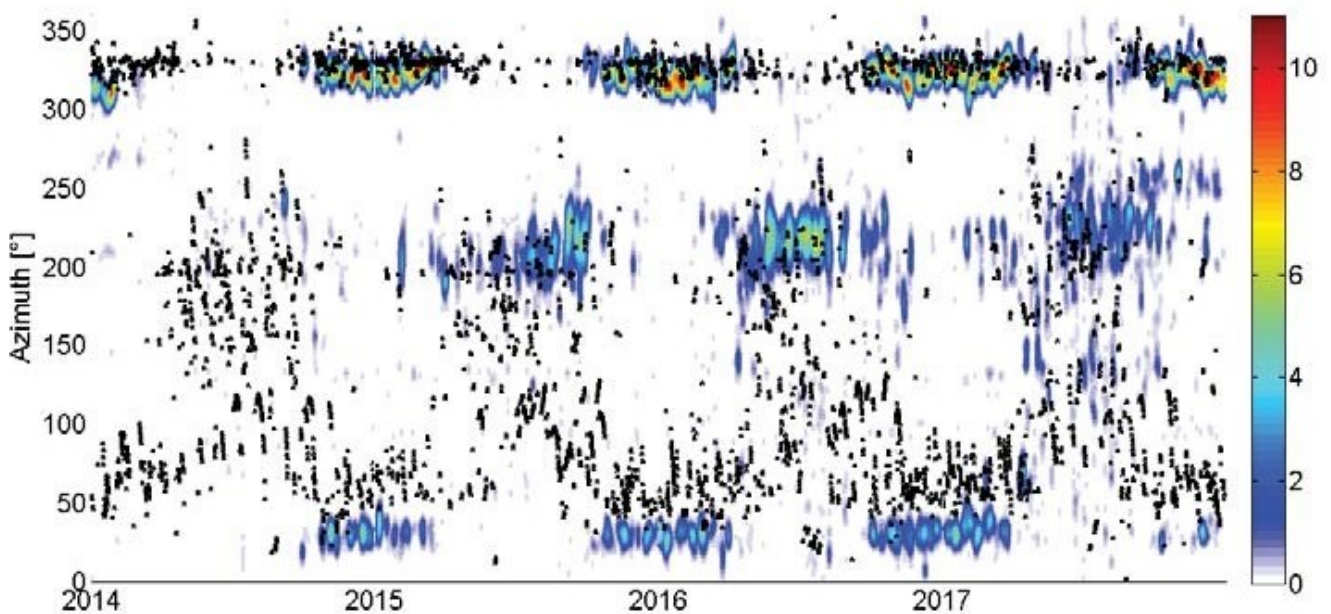

Black circles are the predicted back-azimuths to source. The colorbar codes the logarithm of the number of detections.

Figure 9. Four years of the PMCC detections at IS46 in the frequency range 0.1-0.3 Hz (the PMCC bulletins are kindly provided by CEA) 
For both IS31 and IS46 there is a good match between observations and modelling results in range $300^{\circ}$. $350^{\circ}$ that corresponds to signals originating from North Atlantic. There are predictions of signals from the South with poor correlation with observations. There are also predictions of signals from North Pacific. At IS46 there are corresponding observations which are shifted in azimuth by approximately $25^{\circ}$. All these results show that it is needed to take into account for the atmospheric effects on long range propagation. The lack of detections to North pacific at IS31 also suggests that it is needed to incorporate wind effects on the wave attenuation.

The comparisons of microseism observations and simulation results during two-month period show similar pictures when using seismic data. Figure 10-13 show observations and simulations at ABKAR, KKAR, MKAR and Kurchatov cross respectively.
Figure 11 PMCC detections and source region simulation for KKAR seismic array. Color represents the apparent velocity of the detected microseisms. Black crosses indicate direction to the main and local maxima of the energy in the simulated source regions.

There is a good consistency between observations and modelling results at all stations. Despite of some systematic errors there are stable records of North Atlantic microbaroms. Mean apparent velocity of microbarom detections is close to $7 \mathrm{~km} / \mathrm{s}$. However, at some time intervals, apparent velocity rises up to $16 \mathrm{~km} / \mathrm{s}$. At the same periods, back-azimuths vary up to $80^{\circ}$, Figure 14. This effect is not observed at ABKAR, small at KKAR and large at MKAR and at Kurchatov Cross arrays. Some systematic offset between the observed and predicted back-azimuths appear at all stations. This offset is approximately $10^{\circ}-20^{\circ}$ clockwise for observations at ABKAR and KKAR and almost the same range but counter clockwise at Kurchatov Cross and MKAR.
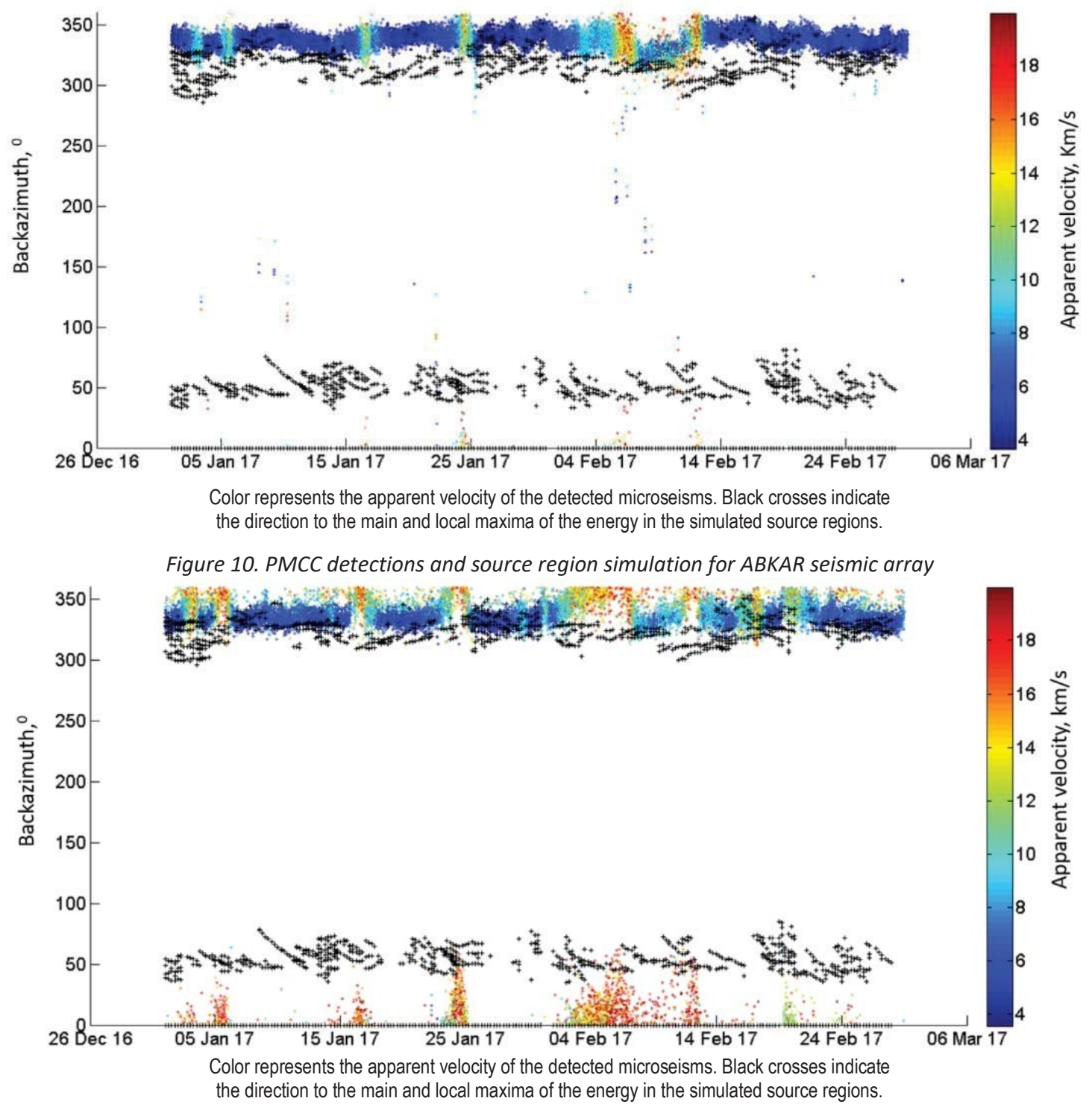

Figure 11. PMCC detections and source region simulation for KKAR seismic array 

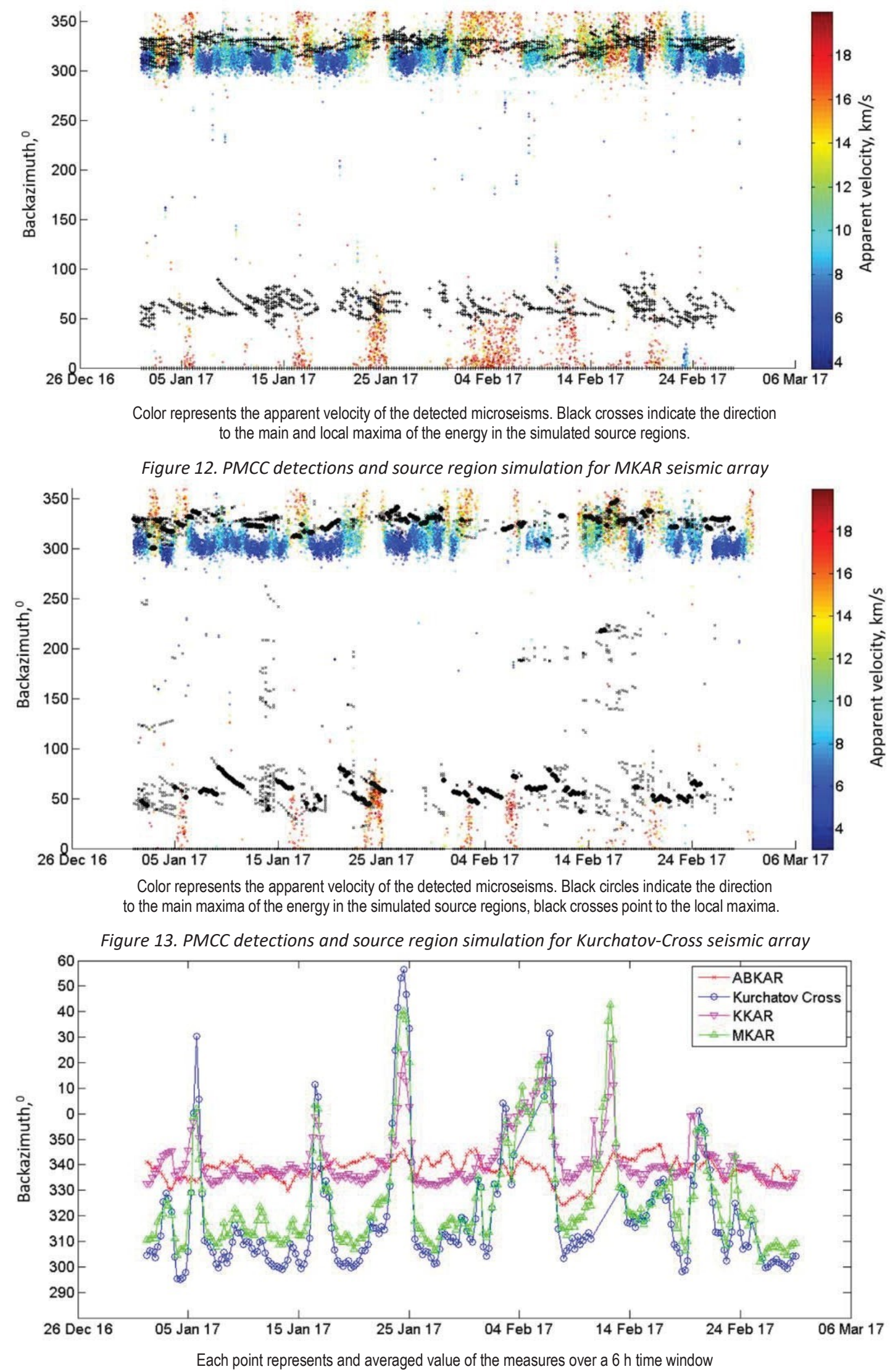

Figure 14. Comparison of the observed back-azimuths at four seismic arrays. Detections correspond to the period between January and February 2017. 


\section{LoCALIZATION OF THE SOURCE REgION}

As microbaroms and microseisms are recorded by the network, it is possible to localize the source region. Figure 15 shows first approach of such localization.

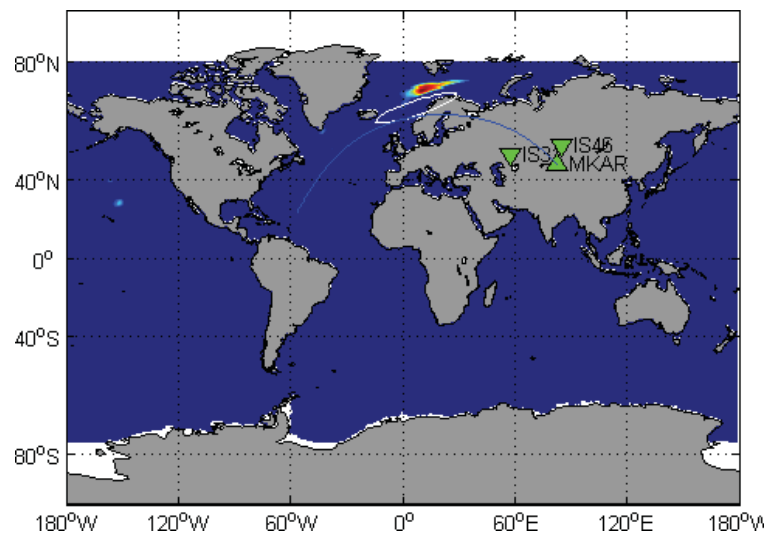

White line represents the $90 \%$ error ellipse for the locations determined using cross bearing with detections at IS31 and IS46. The blue line indicates the backazimuth calculated from MKAR.

Figure 15. Localization of the microbaroms source regions averaged in January 2017. The map shows the simulation results of microbarom intensity.

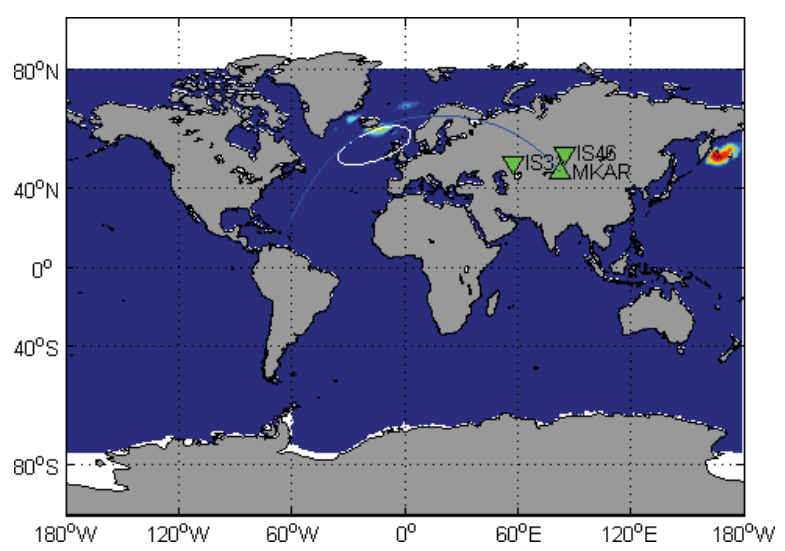

White line represents the $90 \%$ error ellipse for the locations determined using cross bearing with detections at IS31 and IS46. The blue line indicates the backazimuth calculated from MKAR.

Figure 16. Localization of the microbaroms source regions averaged in February 2017. The map shows the simulation results of microbarom intensity.

Cross-bearing locations use detections at IS31 and IS46. The bearings were averaged for each 6 hours of observations. Error ellipse of the solutions is compared with the intensity distribution of the source region, shown in color on the Figure 15. The signal attenuation calculated for effective point placed in between IS31 and IS46 was taken into account when the source strength was calculated. A simplified formulation of the semiempirical attenuation relation considering only the combined effects of geometrical spreading and absorption was used [41] (1):

$$
A_{t t}=\frac{10^{\frac{\alpha(f) R}{20}}}{R}+\frac{R^{\beta\left(f, V_{\text {eff }} \text {-ratio }\right)}}{1+10^{\frac{\delta-R}{\sigma(f)}}}
$$

$$
\mathrm{A}=\mathrm{R}^{(-0.95)} \text {. }
$$

where $\alpha$ (in $\left.\mathrm{km}^{-1}\right), \beta, \delta$ (in $\mathrm{km}$ ), $\sigma$ (in $\mathrm{km}$ ) are parameters tabulated in [41], $\mathrm{V}_{\text {eff-ratio }}$ is the dimensionless ratio of the effective sound speed within the stratosphere to that at ground level, $\mathrm{f}$ is the signal frequency (in $\mathrm{Hz}$ ) and $\mathrm{R}$ is the distance from the source (in $\mathrm{km}$ ).

These results show first order agreement between observations and modelling results in the North Atlantic region, although some systematic errors are visible. These errors could likely be reduced by accounting for atmospheric effects on long-range infrasound propagation.

\section{CONCLUSIONS}

Historical records of the Kazakhstani network have been collected and processed to characterize microseism and microbarom permanently recorded. The existing seismo-acoustic network with collocated stations offers a good opportunity to better understand coupling mechanisms at the ocean-earth-atmosphere interfaces considering the same source. Parameters for the processing using PMCC were tuned to better characterize microseisms and microbaroms. State of the art source simulation method was also chosen. The source area was localized following a cross bearing approach. Comparisons between the localization results and the predicted source regions with the maximum intensity shows satisfactory results over North Atlantic. However, there is systematic error that will hopefully be corrected considering propagation simulations. Comparisons between the observed bearings of seismic data and the source location show systematic errors which vary from one station to another. There are anomalous measured backazimuth deviations up to $80^{\circ}$ at several intervals of time, at least at three seismic stations. Detections during these time intervals exhibit large azimuthal deviations and high apparent velocity values $(15-19 \mathrm{~km} / \mathrm{s})$. The effect appears when using both small and middle aperture seismic arrays 5 and $22 \mathrm{~km}$ respectively. The lack of resolution of the seismic arrays due to their small aperture might contributes to these discrepancies. Array size smaller than the wavelength of the seismic signals (several tens of $\mathrm{km}$ for body waves) could explain an increase of the azimuthal errors. Also, it was shown in

[42] that the azimuth to source measured by Kazakhstani arrays may deviate significantly from the true azimuth to source epicenter due to refraction at Kazakhstan orocline. Presence of relation between this fact and the anomalous azimuth deviations found at this study is issue for future investigations. 


\section{REFERENCES}

1. Smirnov, A., Dubrovin, V., Evers, L., Explanation of the nature of coherent low frequency signal sources recorded by monitoring station network of the NNC RK, NNC RK Bull., (3), 76 - 81, 2010.

2. Donn, W.L. Sea wave origin of microbaroms and microseisms / W.L. Donn, B. Naini // J. Geophys. Res. 1973. - V. 78. P. 4482-4488.

3. Rind, D. Microseisms at Palisades. III-microseisms and microbaroms / D. Rind // J. Geophys. Res., 1980. - 85. - P. $4854-4862$.

4. Hedlin, M.A.H. Listening to the secret sounds of Earth's atmosphere / M.A.H. Hedlin, M. Garces, H. Bass, C. Hayward, G. Herrin, J. V. Olson, C. Wilson //EOS, Trans. Am. Geophys. Un., 2002. - 83 (48). - P. 564-565.

5. Bowman, J.R. Ambient infrasound noise / J.R. Bowman, G.E. Baker, M. Bahavar //Geophys. Res. Lett., 2005. - 32. - 09803, doi:10.1029/2005GL022486.

6. Longuet-Higgins, M.S. A theory of the origin of microseisms / M.S. Longuet-Higgins // R. Soc. Lond. Phil. Trans., 1950.A, 243. - P. 1-35.

7. Waxler, R. The radiation of atmospheric microbaroms by ocean waves / R. Waxler, E.K. Gilbert // J. acoust. Soc. Am., 2006. 119. - P. 2651-2664.

8. Ardhuin, F. Noise generation in the solid Earth, oceans and atmosphere, from nonlinear interacting surface gravity waves in finite depth / F. Ardhuin, T.H.C. Herbers // J. Fluid Mech., 2013. - 716. - P. 316-348.

9. Kedar, S. The origin of deep ocean microseisms in the North Atlantic Ocean / S. Kedar, M. Longuet-Higgins, F. Webb, N. Graham, R. Clayton, C. Jones // R. Soc. Lond. Proc., 2008. - A, 464. - P. 777-793.

10. Ardhuin, F., Ocean wave sources of seismic noise / F. Ardhuin, E. Stutzmann, M. Schimmel, A. Mangeney // J. Geophys. Res. (Oceans), 2011. - P. 116. - 9004. - doi:10.1029/2011JC006952.

11. Stehly, L. A study of the seismic noise from its long-range correlation properties / L. Stehly, M. Campillo, N.M. Shapiro // J. Geophys. Res.: Solid Earth., 2006. - 111 - 10306. - doi:10.1029/2005JB004237.

12. Stutzmann, E. Global climate imprint on seismic noise / E. Stutzmann, M. Schimmel, G. Patau, A. Maggi, // Geochem. Geophys. Geosyst., 2009. - 10. - 11004. - doi:10.1029/2009GC002619.

13. Landes, M. Origin of deep ocean microseisms by using teleseismic body waves / M. Landes, F. Hubans, N.M. Shapiro, A. Paul, M. Campillo // J. Geophys. Res.: Solid Earth, 2010. - 115. - doi:10.1029/2009JB006918.

14. Hillers, G. Global oceanic microseism sources as seen by seismic arrays and predicted by wave action models / G. Hillers, N. Graham, M. Campillo, S. Kedar, M. Landes, N. Shapiro // Geochem., Geophys., Geosyst., 2012. - 13. - 1021. doi:10.1029/2011GC003875.

15. Drob, D.P. Global morphology of infrasound propagation / D.P. Drob, J.M. Picone, M. Garces // J. Geophys. Res. (Atmospheres), 2003. - 108. - 4680, doi:10.1029/2002JD003307.

16. Garces, M., Willis, M., Hetzer, C., Le Pichon, A. \& Drob, D. On using ocean swells for continuous infrasonic measurements of winds and temperature in the lower, middle, and upper atmosphere / M. Garces, M. Willis, C. Hetzer, A. Le Pichon, D. Drob // Geophys. Res. Lett., 2004. - 31. - doi:10.1029/2004GL020696.

17. Le Pichon, A. On using infrasound from interacting ocean swells for global continuous measurements of winds and temperature in the stratosphere / A. Le Pichon, L. Ceranna, M. Garces, D. Drob, C. Millet // J. Geophys. Res. (Atmospheres), 2006. - 111. doi:10.1029/2005JD006690.

18. Brachet, N., Brown, D., Le Bras, R., Cansi, Y., Mialle, P. \& Coyne, J. Monitoring the Earth's atmosphere with the global IMS infrasound network / N. Brachet, D. Brown, R. Le Bras, Y. Cansi, P. Mialle, J. Coyne // Infrasound Monitoring for Atmospheric Studies, 2010. - P. 77-118, eds Le Pichon, A., Blanc, E. Hauchecorne, A. - Springer.

19. Campillo, M. Correlations of Seismic Ambient Noise to Image and to Monitor the Solid Earth / M. Campillo, P. Roux, N. M. Shapiro // Springer. - 2011.

20. Campillo, M. New developments on imaging and monitoring with seismic noise / M. Campillo, H.Sato, N.M. Shapiro, R.D. van der Hilst // C. R. Geoscience, 2011. - 343. - P. 487-495.

21. Shapiro, N.M. 2005. High resolution surface-wave tomography from ambient seismic noise / N.M. Shapiro, M. Campillo, L. Stehly, M.H. Ritzwoller // Science, 2005. - 307. - P. 1615-1618.

22. Ritzwoller, M.H. Ambient noise tomography with a large seismic array / M.H. Ritzwoller, F.-C. Lin, W. Shen // Comp. Rend. Geosci., 2011. - 343(8). - P. 558-570.

23. Mordret, A. Near-surface study at the valhall oil field from ambient noise surface wave tomography / A. Mordret, M. Landes, N.M. Shapiro, S.C. Singh, P. Roux, O.I. Barkved // Geophys. J. Int., 2013. - 193(3) - P. 1627-1643.

24. Brenguier, F. Postseismic relaxation along the San Andreas fault at Parkfield from continuous seismological observations / F. Brenguier, M. Campillo, C. Hadziioannou, N.M. Shapiro, R.M. Nadeau, E. Larose // Science, 2008. - 321(5895). - P. 14781481.

25. Brenguier, F. Towards forecasting volcanic eruptions using seismic noise / F. Brenguier, N.M.Shapiro, M. Campillo, V. Ferrazzini, Z. Duputel, O. Coutant, A. Nercessian// Nat. Geosci., 2008. - 1(2). - P. 126-130.

26. Hedlin, M.A.H. Infrasound: connecting the solid Earth, oceans, and atmosphere / M.A.H. Hedlin, K. Walker, D.P. Drob, C.D. de Groot-Hedlin // Ann. Rev. Earth planet. Sci., 2012. - 40. - P. 327-354.

27. Evers, L.G. Listening to sounds from an exploding meteor and oceanic waves / L.G. Evers, H.W. Haak // Geophys. Res. Lett., 2001. - 28. - P. 41-44.

28. Stevens, J.L. Constraints on infrasound scaling and attenuation relations from soviet explosion data / J.L. Stevens, I.I. Divnov, D.A. Adams, J.R. Murphy, V.N. Bourchik // Pure appl. Geophys., 2002. - 159. - P. 1045-1062.

29. Smirnov A.A. Explanation of the nature of coherent low-frequency signal sources recorded by monitoring station network of the NNC RK / A.A. Smirnov, V.I. Dubrovin, L.G. Evers, S. Gibbons // CTBTO Science and Technology2011. - Vienna, Austria. 
30. Cansi, Y. An automatic seismic event processing for detection and location: the P.M.C.C. method / Y. Cansi // Geophys. Res. Lett., 1995 - 22. - P. 1021-1024.

31. Mikhailova, N., Komarov, I., Glacial earthquakes of the Central Tien-Shan, RK Bull., (3), 120 - 126, 2009.

32. Poleshko, N., Mikhailova, N., Earthquake focal mechanisms in the area of the Central Tien-Shan glaciers, NNC RK Bull., (1), 61 - 67, 2012.

33. Website ECMWF: https://www.ecmwf.int/

34. Belyashov, A., Dontsov, V., Dubrovin, V., Kunakov, V., Smirnov, A., New infrasound array "Kurchatov", NNC RK Bull., (2), 24 - 30, 2013.

35. Edwards, W. Effect of interarray elevation differences on infrasound beamforming / W. Edwards, N. Green // Geophys. J. Int., 2012. - 190(1). - P. 335-346.

36. Le Pichon, A. Recent Enhancements of the PMCC Infrasound Signal Detector / A. Le Pichon, R.S.N.B. Matoza, Y. Cansi // Inframatics, 2010. - 26. - P. 5-8.

37. Matoza, R.S., Coherent ambient infrasound recorded by the International Monitoring System / R.S. Matoza, M. Landes,

A. Le Pichon, L. Ceranna, D. Brown // Geophys. Res. Lett., 2013. - 40. - P. 429-433.

38. Hasselmann, K. A statistical analysis of the generation of microseisms / K. Hasselmann // Rev. Geophys., 1963. - 1. 177-210.

39. Hasselmann, K. Feynman diagrams and interaction rules of wave-wave scattering processes / K. Hasselmann // Rev. Geophys., 1966. - 4(1). - P. 1-32.

40. IFREMER Website: WW3 data ftp://ftp.ifremer.fr/ifremer/ww3/HINDCAST/GLOBAL/ .

41. Le Pichon, A., Ceranna, L. \& Vergoz, J. Incorporating numerical modeling into estimates of the detection capability of the IMS infrasound network / A. Le Pichon, L. Ceranna, J. Vergoz // J. Geophys. Res. (Atmospheres), 2012. - 117. - 5121. - doi:10.1029/2011JD016670.

42. Labonne, C. Detailed analysis of the far-regional seismic coda in Kazakhstan using array processing / C. Labonne, O. Sèbe, A. Smirnov, S. Gaffet, Y. Cansi, N. Mikhailova // Bulletin of the Seismological Society of America, 2017. - 107(2), - P. 611- 623. - doi:10.1785/0120160015. 
Solid Earth, 12, 503-520, 2021

https://doi.org/10.5194/se-12-503-2021

(C) Author(s) 2021. This work is distributed under the

Creative Commons Attribution 4.0 License.

\title{
Characterizing the oceanic ambient noise as recorded by the dense seismo-acoustic Kazakh network
}

\author{
Alexandr Smirnov ${ }^{1,2}$, Marine De Carlo ${ }^{3}$, Alexis Le Pichon ${ }^{3}$, Nikolai M. Shapiro ${ }^{4,5}$, and Sergey Kulichkov ${ }^{6}$ \\ ${ }^{1}$ Institute of Geophysical Research, National Nuclear Center, Almaty, 050020, Kazakhstan \\ ${ }^{2}$ Institut de Physique du Globe de Paris, Sorbonne Paris Cité, 75005 Paris, France \\ ${ }^{3}$ CEA, DAM, DIF, 91297 Arpajon, France \\ ${ }^{4}$ Institut de Sciences de la Terre, Université Grenoble Alpes, CNRS (UMR5275), Grenoble, France \\ ${ }^{5}$ Schmidt Institute of Physics of the Earth, Russian Academy of Sciences, Moscow, 123242, Russia \\ ${ }^{6}$ A.M. Obukhov Institute of Atmospheric Physics, Russian Academy of Sciences, Moscow, 119017, Russia
}

Correspondence: Alexandr Smirnov (smirnov@ipgp.fr)

Received: 22 January 2020 - Discussion started: 3 March 2020

Revised: 12 January 2021 - Accepted: 13 January 2021 - Published: 25 February 2021

Abstract. In this study, the dense seismo-acoustic network of the Institute of Geophysical Research (IGR), National Nuclear Centre of the Republic of Kazakhstan, is used to characterize the global ocean ambient noise. As the monitoring facilities are collocated, this allows for a joint seismo-acoustic analysis of oceanic ambient noise. Infrasonic and seismic data are processed using a correlation-based method to characterize the temporal variability of microbarom and microseism signals from 2014 to 2017. The measurements are compared with microbarom and microseism source model output that are distributed by the French Research Institute for Exploitation of the Sea (IFREMER). The microbarom attenuation is calculated using a semi-empirical propagation law in a range-independent atmosphere. The attenuation of microseisms is calculated taking into account seismic attenuation and bathymetry effect. Comparisons between the observed and predicted infrasonic and seismic signals confirm a common source mechanism for both microbaroms and microseisms. Multi-year and intraseasonal parameter variations are analyzed, revealing the strong influence of long-range atmospheric propagation on microbarom predictions. In winter, dominating sources of microbaroms are located in the North Atlantic and in the North Pacific during sudden stratospheric warming events, while signals observed in summer could originate from sources located in the Southern Hemisphere; however, additional analyses are required to consolidate this hypothesis. These results reveal the strengths and weaknesses of seismic and acoustic methods and lead to the conclusion that a fusion of two techniques brought the investigation to a new level of findings. Summarized findings also provide a perspective for a better description of the source (localization, intensity, spectral distribution) and bonding mechanisms of the ocean-atmosphere-land interfaces.

\section{Introduction}

Since the original research of Bertelli (1872), many investigations have confirmed a close connection between microseisms and disturbed ocean weather conditions (Longuet- Higgins, 1950). The primary microseism peak (around $0.07 \mathrm{~Hz}$ ) is generated when ocean waves reach shallow water near the coast and interact with the sloping seafloor (Hasselmann, 1963). The secondary peak of microseisms (between 0.1 and $0.2 \mathrm{~Hz}$ ) is generated by the interaction of ocean waves of similar frequencies traveling in opposite directions(Longuet-Higgins, 1950). LonguetHiggins' theory explainshow counter-propagating ocean waves can generate propagating acoustic waves and create secondary microseisms by exciting the sea floor. Hasselmann (1963, 1966) generalized Longuet-Higgins' theory to random waves by investigating non-linear forcing of acoustic waves.

Microseism modeling was introduced by Kedar et al. (2008). The good correlation between the observed microseism amplitudes and their predicted values was shown 
(Shapiro, 2005; Shapiro and Campillo, 2004; Stehly et al., 2006; Stutzmann et al., 2012; Weaver, 2005). The different patterns between microseismic body and surface waves, resulting from the amplification of ocean wave-induced pressure perturbation and seismic attenuation, have been studied with implications for seismic imaging and climate studies (Obrebski et al., 2013). Coastal reflections also play an important role in the generation of microseisms, but modeling ocean wave reflections off the coast still remains a major source of model uncertainty (Ardhuin et al., 2013a). Ardhuin and Herbers (2013b) developed a numerical model based on Longuet-Higgins-Hasselmann's theory for the generation of Rayleigh waves, by considering an equivalent pressure source at the undisturbed ocean surface.

Inaudible low-frequency sound, known as infrasound waves, propagates through the atmosphere for distances of thousands of kilometers without substantial loss of energy. Below $1 \mathrm{~Hz}$, infrasound has been observed since the early nineteenth century at different locations distributed around the globe. Gutenberg (1953) first pointed out the relation between microseisms, meteorological conditions, ocean waves, and microbaroms. Donn and Naini (1973) suggested a common source mechanism of microbaroms and microseisms from the same ocean storms demonstrating that the only mechanism capable of transmitting energy into both the atmosphere and the sea bottom is associated with surface wave propagation.

There is a significant difference between microseisms and microbaroms. While propagation paths for microseisms can be either along the Earth's surface as Rayleigh waves, or through the Earth as body waves (Gerstoft et al., 2008), microbarom observations are typically along propagation paths that have undergone multiple bounces on the Earth's surface. As for microseisms, microbaroms are not impulsive signals but quasi-monochromatic sequences of permanent waves (Olson and Szuberla, 2005); therefore, it is not possible to detect their onset and identify their propagation paths. However, these signals are well detected using standard array processing techniques, such as beam-forming methods (Capon, 1972; Haubrich and McCamy, 1969; Toksöz and Lacoss, 1968). Several studies demonstrated the efficiency of beam-forming approaches (e.g., Evers and Haak, 2001), or correlation-based methods (e.g., Garcès, 2004; Landès et al., 2012), to detect and characterize microbarom signals globally. Posmentier (1967) started developing a theory of microbaroms based on the LonguetHiggins' theory. A microbarom source model was first developed by Brekhovskikh (1960), later extended by Waxler and Gilbert (2006), Waxler et al. (2007), and more recently extended by de Carlo (2020).

Losses along the propagation path control the ability to observe microbaroms. Thus, in order to accurately assess the microbarom source intensity, it is necessary to take into account a realistic description of the middle atmosphere. Several studies have been conducted to characterize the ambi- ent infrasound noise. Smets et al. (2014) compared microbarom observations with predicted values to study the life cycle of sudden stratospheric warming (SSW). Landès et al. (2014) compared the modeled source region with microbarom observations at operational stations of the International Monitoring System (IMS). A first-order agreement between the observed and modeled trends of microbarom backazimuth was shown. Le Pichon et al. (2015) compared observations and modeling over a 7 -month period to assess middle atmospheric wind and temperature models distributed by the European Centre for Medium-Range Weather Forecasts (ECMWF). It was shown that infrasound measurements can provide additional integrated information about the structure of the stratosphere where data coverage is sparse. More recently, Hupe at al. (2018) showed a first-order agreement between the modeled and observed microbarom back-azimuth and amplitude in the North Atlantic.

In this paper, we develop a synergetic approach to better constrain microbarom source regions and evaluate propagation effects. To this end, we apply the method developed by Hupe et al. (2018) to the dense Kazakhstani seismo-acoustic network. The considered network is operated by the Institute of Geophysical Research (IGR) of the National Nuclear Centre of the Republic of Kazakhstan. It includes both seismic and infrasound arrays. Since the pioneering work of Donn and Naini (1973), to our knowledge, this study is the first multiyear comparisons between observed and modeled ambient noise at collocated seismo-acoustic arrays. In the first part, we have presented the observation network and the methods used. In the second part, the processing and modeling results of microseism and microbarom signals recorded by the IGR seismo-acoustic network from 2014 to 2017 are shown. In the last part, comparisons between the observed and modeled microbaroms and microseism are discussed.

\section{Observation network and methods}

\subsection{Observation network}

\subsubsection{Infrasound array network}

The Kazakhstani seismo-acoustic network (KNDC, 2019) contains five seismic and three infrasound arrays (Fig. 1). The signal correlation in such a dense network is significantly higher compared to sparser networks like the IMS. The infrasound network consists of the IMS station IS31 located in northwestern Kazakhstan (2.1 km aperture, 8 elements) and two national arrays of $1 \mathrm{~km}$ aperture: KURIS (4 elements) near Kurchatov and MKIAR ( 9 elements) near the village of Makanchi (Belyashov et al., 2013). KURIS and MKIAR have been operating since 2010 and 2016, respectively. Microbarometers MB2000 and MB2005 are used at IS31 and KURIS, and Chaparral Physics Model 25 microbarometers are installed at MKIAR. All arrays are equipped 


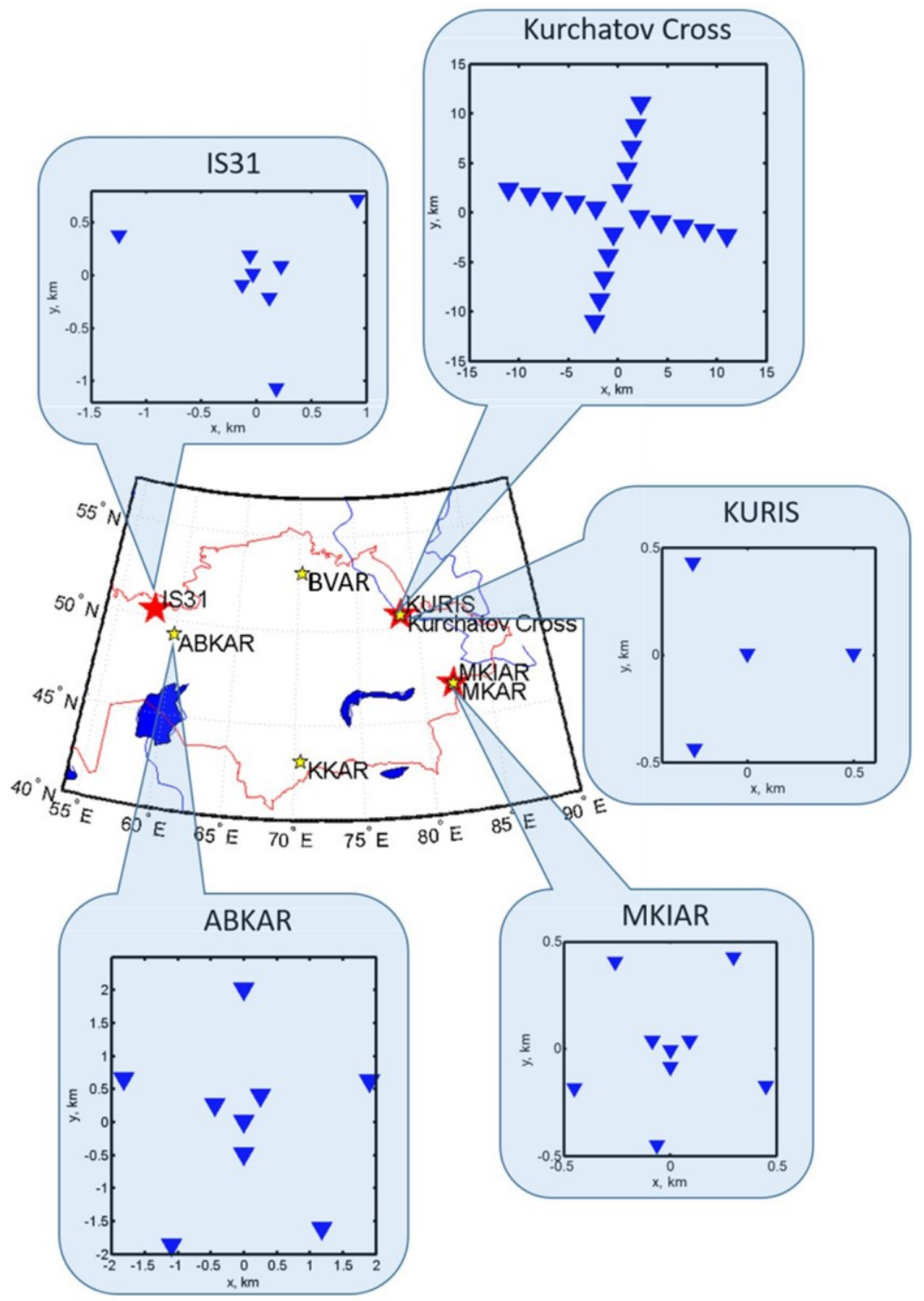

Figure 1. IGR monitoring network. Yellow and red stars are seismic and infrasound arrays, respectively. Seismic and infrasound arrays are collocated at Kurchatov (Kurchatov Cross/KURIS) and Makanchi (MKAR/MKIAR). IS31 infrasound and ABKAR seismic arrays are located $200 \mathrm{~km}$ apart. The inset graphs show the array configurations. The configurations for KKAR and MKAR seismic arrays are notshown as they are similar to ABKAR's one.

with a 24-bit digitizer with a sampling frequency of $20 \mathrm{~Hz}$ at IS31 and KURIS and $40 \mathrm{~Hz}$ at MKIAR. Data logger parameters are listed in Table A1 (Appendix A). All stations are equipped with a 96-port wind noise-reducing system with pipe rosettes, except L1, L2, L3, and L4 elements at IS31 which are connected to 144 inlet ports (Marty, 2019). The frequency responses of the microbarometers are shown in Fig. A1a and b. By associating infrasound observables over the network, both natural and anthropogenic infrasound sources can be detected and characterized (Smirnov, 2015; Smirnov et al., 2010, 2018).

\subsubsection{Seismic array network}

The seismic network consists of a Kurchatov Cross array and MKAR that are part of the IMS network, as well as ABKAR and KKAR arrays which are part of the Air Force Technical Applications Centre (AFTAC, USA) network (Fig. 1 and Table 1). The Kurchatov Cross array consists of 20 Guralp CMG-3V sensors with an aperture of $22.5 \mathrm{~km}$ (Fig. 1). ABKAR, BVAR, KKAR, and MKAR arrays consistof nine elements with an aperture of $5 \mathrm{~km}$. These arrays are equipped with Geotech Instruments GS21 short-period vertical sensors with a flat response for frequencies above $1 \mathrm{~Hz}$. 
The frequency response of the sensors at MKAR, ABKAR, and KKAR is not flat in the $0.1-0.3 \mathrm{~Hz}$ band; however, as the response information is given, one can correct for the drop in amplitude; the phase shift difference between instruments that are part of the same array is assumed negligible. Figure A1c and d show the frequency response of GS-21 and CMG$3 \mathrm{~V}$ sensors between 0.1 and $0.4 \mathrm{~Hz}$. All arraysare equipped with 24-bit digitizers, sampling data at $40 \mathrm{~Hz}$. Surface waves from the ocean storms are well recorded by broadband seismometers. Body waves are also registered byGS21 short period sensors. Although in the frequency band of interest the signal attenuation is about $30 \mathrm{~dB}$, all stations detect microseisms due to their large amplitude above the background noise.

A peculiarity of the network is that infrasound and seismic arrays are collocated at two sites (KURIS and Kurchatov Cross; MKIAR and MKAR), or installed relatively close to each other (IS31 and ABKAR are $220 \mathrm{~km}$ apart; Fig. 1). Figure B1 shows typical power spectral density (PSD) of theambient noise at infrasound and seismic arrays, and at collocated Kurchatov cross seismic and KURIS infrasound arrays. PSD calculation was carried out using a $1 \mathrm{~h}$ time window during calm periods in October, December, and July. The microbarom peak is more pronounced in October and December. In summer, this peak is only visible at IS31. As opposed to the infrasound noise, the seismic noise spectra exhibit the microseismic peak in both seasons with an overall noise level in October approximately $10 \mathrm{~dB}$ higher than in July.

\subsection{Processing method}

Microseisms are detected using the progressive multichannel correlation (PMCC) method (Cansi, 1995; Cansi and Klinger, 1997; Smirnov et al., 2010) in 10 linearly spaced frequency bands between 0.05 and $0.4 \mathrm{~Hz}$. A fixed time window length of $200 \mathrm{~s}$ is used for each band. For the infrasound processing, the frequency band is broadened to $0.01-4 \mathrm{~Hz}$ using 15 logarithmically scaled sub-bands, and a time window length varying from 30 to $200 \mathrm{~s}$ (Matoza et al., 2013). Such a setting allows computationally efficient broadband processing and accurate estimates of frequency-dependent wave parameters useful for source separation and characterization. In the microbarom frequency range covering the $0.1-0.6 \mathrm{~Hz}$ interval, wave parameters can be detailed in six different frequency bands (Ceranna et al., 2019). It is important to take into account uncertainties in azimuth and apparent velocity estimations identified in microbarom studies. The uncertainties of the estimated wave parameters of microseisms can be large due to the relatively small aperture of the arrays. Uncertainties in wave parameter estimates are calculated considering the array geometry of the abovementioned infrasound and seismic arrays, assuming perfectly coherent signals and time delay errors bounded by twice the sampling period (Szuberla and Olson, 2004) (Table 1). For the infrasound arrays, the horizontal speed is set to
$0.34 \mathrm{~km} \mathrm{~s}^{-1}$. For the seismic arrays, a typical Rayleigh wave speed of $3 \mathrm{~km} \mathrm{~s}^{-1}$ is chosen. The uncertainties for the seismic arrays are significantly higher for the body waves due to higher velocities. It should be noted that these errors are optimistic as the estimation does not take into account the siteand time-dependent signal-to-noise ratio.

\subsection{Source modeling}

The microseism source model used (IFREMER, 2018), referred to as "p21", is calculated from the wave-action WAVEWATCH III model (WW3) developed by the National Oceanic and Atmospheric Administration (NOAA). While the bathymetry strongly affects the source intensity in microseism modeling (Ardhuin et al., 2011; Ardhuin and Herbers, 2013b; Kedar et al., 2008), a recent modeling study by De Carlo (2020) suggests that bathymetry has negligible impact on microbarom source strength in contrast to predictions from the model by Waxler et al. (2007). In this study, the source term for microseisms ("p2l") which does not include coupling with the bathymetry is taken as a proxy to model microbaroms. While microseisms propagate through the static structure of the solid Earth, long-range microbarom propagation is controlled by the strong spatiotemporal variability of the temperature and wind structure of the atmosphere. Therefore, the geometrical spreading and seismic attenuation are the main effects to account for microseism modeling (e.g., Kanamori and Given, 1981; Stutzmann et al., 2012), while the dynamical properties of the middle atmosphere should be taken into account for microbarom modeling.

\subsubsection{Microbarom source modeling}

As previously stated, both microseisms and microbaroms originate from second-order non-linear wave interactions. Their source term can be written as a function of the secondorder equivalent surface pressure $F_{p}\left(f_{2}=2 f\right)$ (Hasselmann, 1963; Ardhuin et al., 2011)

$$
F_{p}\left(f_{2}=2 f\right)=\frac{1}{2} \rho_{w}^{2} g f_{2} H(f)
$$

where $\rho_{w}$ is the water density, $g$ is the gravitational acceleration, $f_{2}$ is the microseisms and microbarom frequency. The Hasselmann integral $H(f)=\int_{0}^{2 \pi} E(f, \theta) E(f, \theta+\pi) d \theta$ (Hasselmann, 1963) represents the amount of opposite propagative wave interactions, with $E(f, \theta)$ the directional spectrum of waves. The IFREMER distribution of the wave action model WAVEWATCHIII ${ }^{\circledR}$ (WW3 Development Group, 2016; ftp://ftp.ifremer.fr/ifremer/ww3/HINDCAST/SISMO, last access: 4 May 2020) includes the calculation of $F_{p}\left(f_{2}=\right.$ $2 f$ ) with a $0.5^{\circ} \times 0.5^{\circ}$ spatial resolution and $3 \mathrm{~h}$ temporal resolution.

Longuet-Higgins (1950) showed that these pressure fluctuations in the water do not attenuate with depth but are transmitted to the ocean bottom as acoustic waves. Depending 
Table 1. Uncertainties of azimuth and apparent velocity estimates.

\begin{tabular}{|l|l|l|l|l|l|l|l|}
\hline ter & IS31 & KURIS & MKIAR & ABKAR & KKAR & MKAR & Kurchatov Cross \\
\hline $\begin{array}{l}\text { Horizontal } \\
\text { Vel., } \mathrm{m} / \mathrm{s}\end{array}$ & 340 & 340 & 340 & 3000 & 3000 & 3000 & 3000 \\
\hline$\delta \Theta\left({ }^{\circ}\right)$ & $0.55-0.74$ & $2.05-2.34$ & $0.58-0.67$ & $4.89-5.64$ & $5.14-6.30$ & $4.55-6.84$ & $0.48-0.49$ \\
\hline$\delta \mathrm{V}(\mathrm{m} / \mathrm{s})$ & $3.8-4.4$ & $12-14$ & $3.5-3.9$ & $250-290$ & $270-330$ & $220-380$ & $25-26$ \\
\hline
\end{tabular}

on the ratio between the wavelength of the acoustic waves and the ocean depth, resonance effects can occur leading to a modulation of the pressure fluctuations at the sea floor (Stutzmann et al., 2012). Therefore, microseisms are strongly affected by the bathymetry (Ardhuin et al., 2011; Ardhuin and Herbers, 2013b; Kedar et al., 2008). The corresponding seismic source power spectral density at the ocean bottom is as follows (Longuet-Higgins, 1950; Eq. 184):

$$
S_{D F}\left(f_{s}=f_{2}\right)=\frac{2 \pi f_{s}}{\rho_{s}^{2} \beta^{5}}\left[\sum_{m=1}^{m=N} c_{m}^{2}\right] F_{p}\left(f_{2}=2 f\right)
$$

where SDF is in $m \mathrm{~Hz}^{-1}, \rho$ s and $\beta$ are respectively the density and S-wave velocity in the crust, and the coefficient $\mathrm{cm}$ corresponds to the compressible ocean amplification factor. $\mathrm{cm}$ is a non-dimensional number varying between 0 and 1 as a function of the ratio $2 \pi f 2 h / \beta$, where $h$ is the water depth. In this study, the crustal density $\rho s=2600 \mathrm{~kg} \mathrm{~m}-3$ and the S-wave velocity $\beta=2800 \mathrm{~m} \mathrm{~s}-1$. The microbarom source term developed by De Carlo (2020) is essentially a scaled version of the second-order equivalent surface pressure $F p(f 2=2 f)$, which serves as proxy of microbarom source term.

\subsubsection{Microbaroms propagation}

For the propagation modeling, we use a semi-empirical frequency-dependent attenuation relation derived from massive parabolic equation simulations (Le Pichon et al., 2012). Atmospheric specifications are extracted at the station from the high-resolution forecast (HRES) that is part of ECMWF's Integrated Forecast System (IFS) cycle 38r2 (http://www. ecmwf.int, last access: 15 February 2021) and are assumed to be constant along the propagation path. This approach, already used by De Carlo et al. (2018) and Hupe et al. (2018) to model microbaroms generated in the Northern Hemisphere, can predict the observed back-azimuths with an error less than $\sim 10^{\circ}$. The correlation coefficient between the observed and predicted seasonal patterns is calculated following metrics elaborated by Landès et al. (2014). The correlation is evaluated for the back-azimuths and amplitudes. Two different metrics are derived: (i) $S_{\text {corr_Az, }}$, which defines the correlation between the observed $\left(N_{\text {obs }}\right)$ and predicted $\left(N_{\text {pred }}\right)$ marginal detection number in the direction $\theta_{\text {Amax }}$ versus time $(t)$,

$S_{\text {corr__Az }}=C_{\text {corr }}\left[N_{\text {obs }}\left(\theta_{\text {Amax }}, t\right), N_{\text {pred }}\left(\theta_{\text {Amax }}, t\right)\right]$

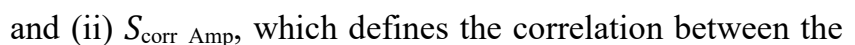
predicted and observed amplitude $A_{\max }$,

$S_{\text {corr_Amp }}=C_{\text {corr }}\left[N_{\text {obs }}\left(A_{\text {max }, t}\right), N_{\text {pred }}\left(A_{\text {max }, t}\right)\right]$.

\section{Results}

\subsection{Processing results}

Signals from the ocean storms are extracted from detections at all IGR infrasound and seismic arrays, and filtered between 0.1 and $0.4 \mathrm{~Hz}$. Diagrams in this section show the backazimuths of the signals as a function of time. Distributions of the maximum amplitudes are included as well. The amplitude maxima are averaged over a $6 \mathrm{~h}$ time window for the entire period from 2014 to 2017.

\subsubsection{Microbaroms}

Figure 2 shows the temporal variation of the dominant microbarom signals at IS31, KURIS, and MKIAR. The graphs show pronounced seasonal variations for both back-azimuths and amplitudes. The largest amplitudes at IS31 are observed during the winter months with a dominant period ranging from 3.5 to $5.5 \mathrm{~s}$ (Fig. C1), when signals with back-azimuths of $320 \pm 20^{\circ}$ prevail (Fig. 2a-b). A few detections with backazimuths of $35 \pm 15^{\circ}$ are also detected. In winter, microbarom amplitudes range from 0.005 to $0.5 \mathrm{~Pa}$, the largest values being observed in winter. During summer months, signals with back-azimuths of $210 \pm 50^{\circ}$ dominate with a period ranging from 4 to $6.5 \mathrm{~s}$ and lower amplitude $(0.01 \mathrm{~Pa})$, suggesting waves propagating over longer epicentral distances. Figure 2e-h show the observations at KURIS. The back-azimuths measured at this station are similar to those recorded at IS31, with slightly higher values in winter $\left(325 \pm 15^{\circ}\right)$ and two clusters in summer at $230 \pm 30^{\circ}$ and $120 \pm 30^{\circ}{ }^{\circ}$

In summer, back-azimuths of $210 \pm 50^{\circ}$ also dominate at IS31, KURIS, and MKIAR. MKIAR started recording microbaroms in August 2016 with cyclical seasonal variations (Fig. 2i-e).

\subsubsection{Microseisms}

Figure 3a-d show the detection results at ABKAR. In addition to the observations, the diagrams represent the simulated 
(a)

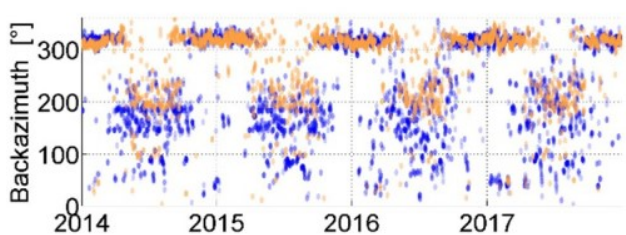

(c)

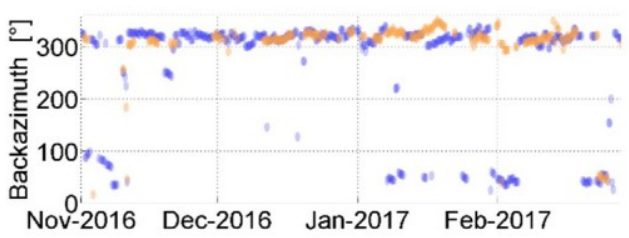

(e)

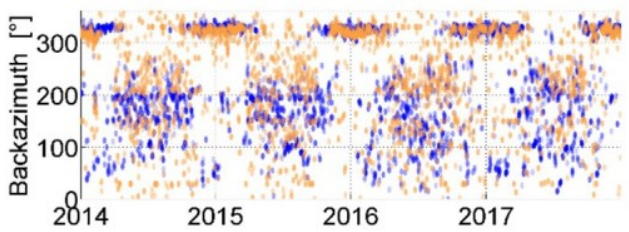

(g)

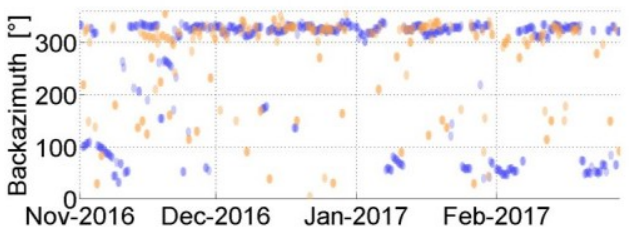

(i)

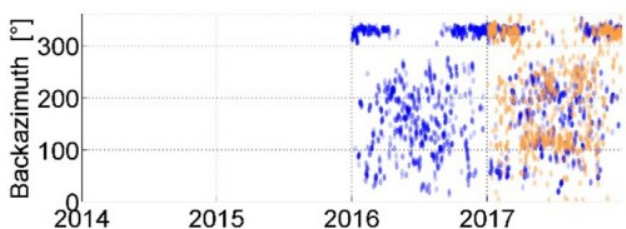

(k)

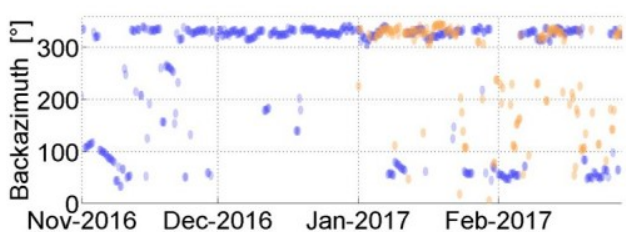

IS31

(b)

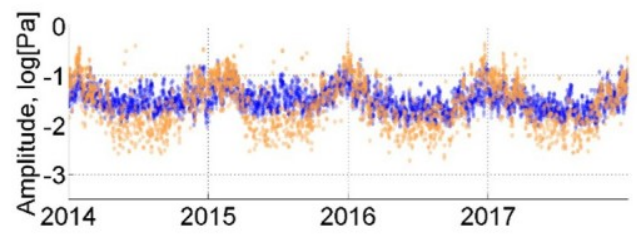

(d)

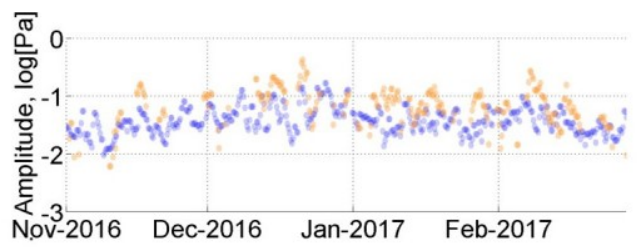

KURIS

(f)

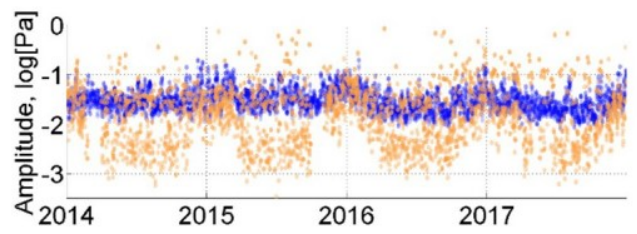

(h)

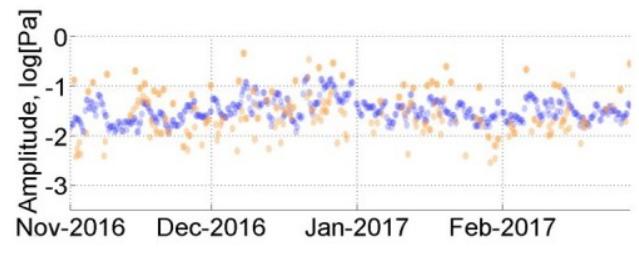

(j)

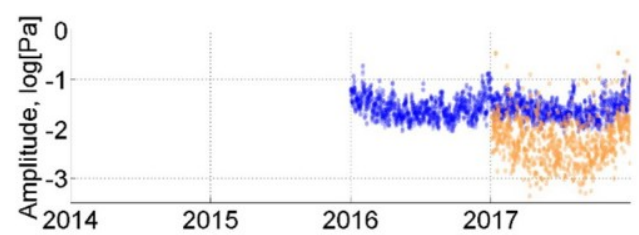

(I)

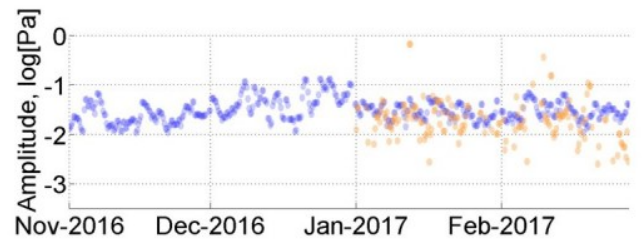

\section{Observations}

Simulations

Figure 2. Time variations of observed back-azimuths and amplitudes of microbaroms at IS31 (a-d), KURIS (e-h), and MKIAR (i-l), with a time resolution of $6 \mathrm{~h}$ from 1 January 2014 to 31 December 2017 (orange circles). Blue circles denote simulated values. Details at IS31 (c, d), KURIS $(\mathbf{g}, \mathbf{h})$, and MKIAR (k-l).

microseism parameters. The largest amplitudes are observed in winter where detections at $340 \pm 20^{\circ}$ prevail. In summer, signals at $290 \pm 20^{\circ}$ dominate. The amplitudes range from $\sim 250$ to $\sim 10000 \mathrm{~nm} \mathrm{~s}^{-1}$. Figure $3 \mathrm{e}-\mathrm{h}$ show the results at KKAR. Two clusters of detections at $330 \pm 20^{\circ}$ and $5 \pm 5^{\circ}$ are observed in winter, and at $160 \pm 20^{\circ}$ and $190 \pm 15^{\circ}$ in summer.
The seasonal amplitude variation is $\sim 250$ to $\sim 9000 \mathrm{~nm} \mathrm{~s}^{-1}$. Figure $3 \mathrm{i}-1$ show the results at Kurchatov Cross. In winter, back-azimuths of microseisms are $300 \pm 20^{\circ}$.A small number of detections at $50 \pm 50^{\circ}$ is observed in summer. The amplitudes range from $\sim 250$ to $\sim 9000 \mathrm{~nm} \mathrm{~s}^{-1}$, reaching their maximum values in winter. Figure $3 \mathrm{~m}-\mathrm{p}$ show results at MKAR. 
(a)

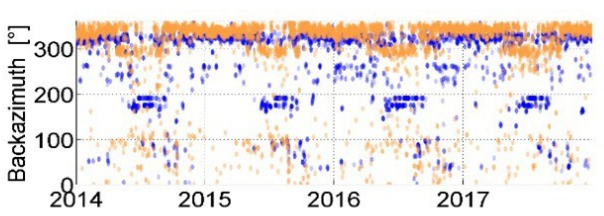

(c)

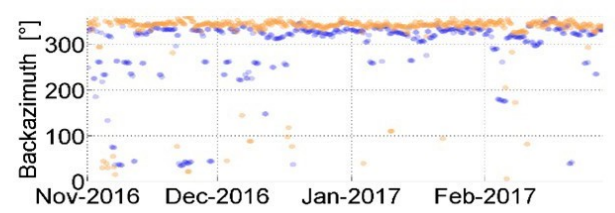

(e)

(g)
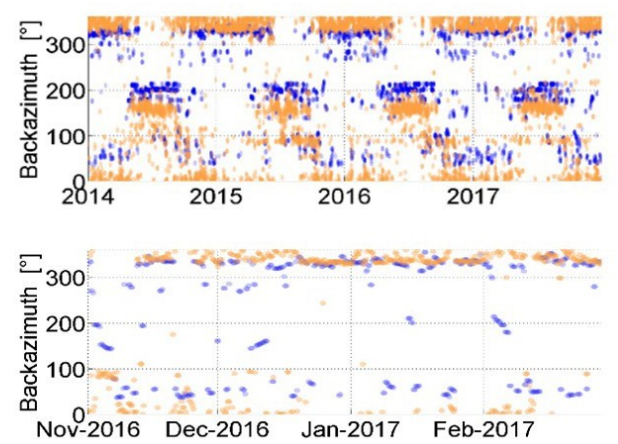

(i)

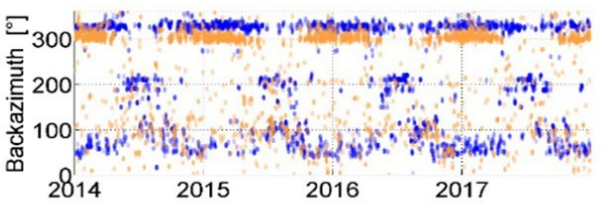

(k)

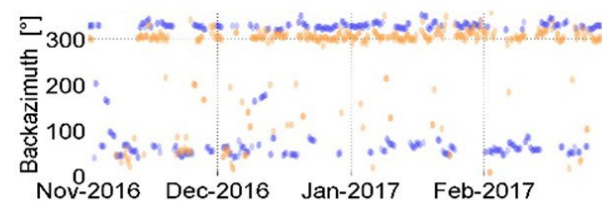

(m)

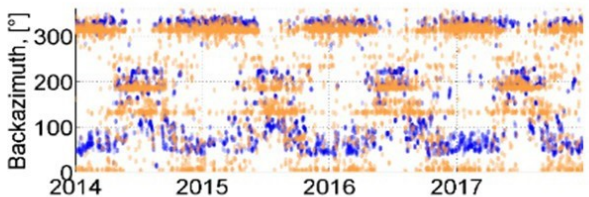

(o)

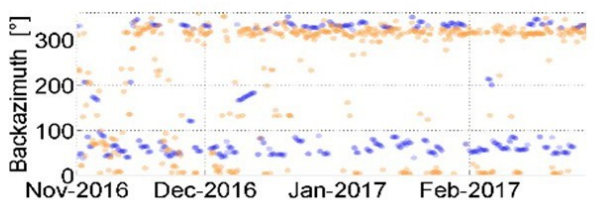

ABKAR

(b)

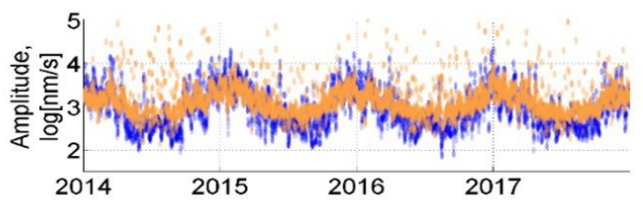

(d)

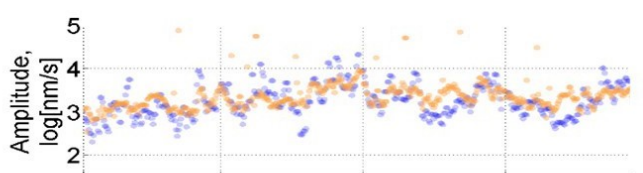

Nov-2016 Dec-2016 Jan-2017 Feb-2017

KKAR

(f)

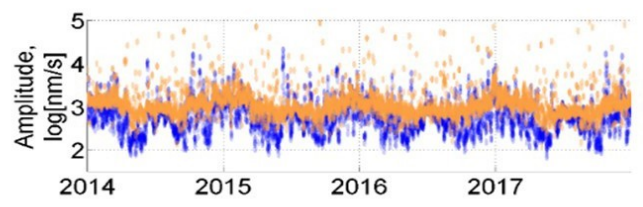

(h)

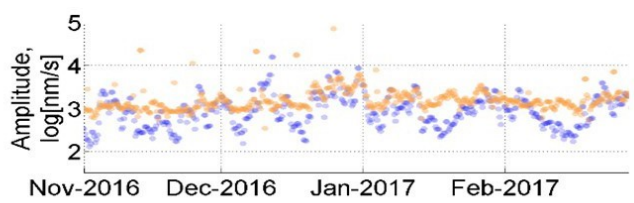

\section{Kurchatov Cross}

(j)

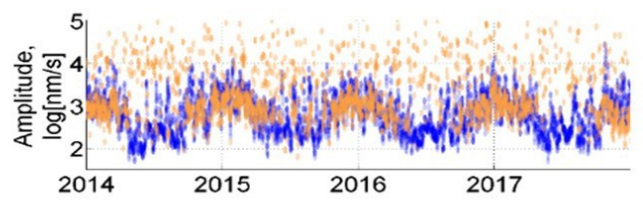

(I)

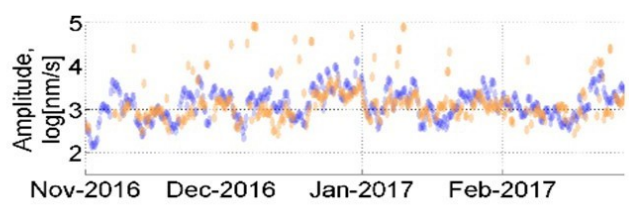

MKAR

(n)

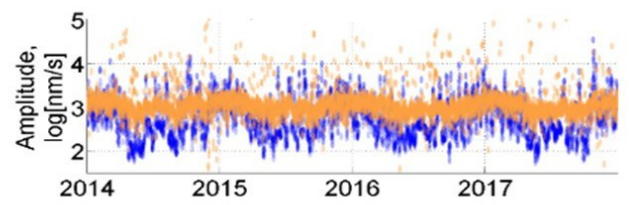

(p)

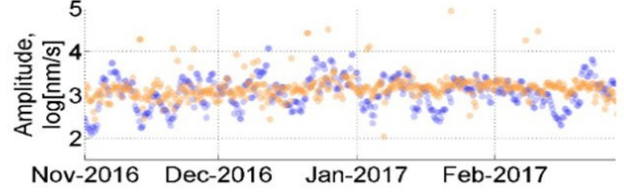

\section{Observations \\ Simulations}

Figure 3. Same as Fig. 2 at ABKAR (a-d), KKAR (e-h), Kurchatov Cross (i-l), and MKAR (m-p). 
Two clusters at $310 \pm 20^{\circ}$ and $5 \pm 5^{\circ}$ are observed in winter, and at $130 \pm 10^{\circ}$ and $180 \pm 10^{\circ}$ in summer. The seasonalamplitude variation is 250 to $3000 \mathrm{~nm} \mathrm{~s}^{-1}$. The seasonal trend of the microseism amplitudes recorded at all seismic stations is similar, with a maximum observed in winter. At Kurchatov Cross, the small number of detections in summer could be explained by a higher noise level or a loss of signal coherency at this site. The graphs clearly show that the amplitudes vary synchronously even at smaller timescales (Fig. 4). As expected, the maximum amplitudes decrease with increasing distance from the stations to the North Atlantic region (about $\sim 10000, \sim 9000, \sim 9000$, and $\sim 5000 \mathrm{~nm} \mathrm{~s}^{-1}$ for ABKAR, KKAR, Kurchatov Cross, and MKAR, respectively).

\subsection{Modeling results}

The back-azimuths and amplitudes have been predicted at IS31, KURIS, and MKIAR. The distances to the source regions differ essentially from summer to winter. For example, simulations predict three source regions at IS31 in winter. Distances to the two regions in the North Atlantic are around 3500 and $7000 \mathrm{~km}$, and about $7000 \mathrm{~km}$ to the North Pacific.In summer, one source region is located in the Pacific Oceanand two other sources at southern high latitudes are at distances of $12000 \mathrm{~km}$ and $18000 \mathrm{~km}$. However, the calculation of attenuation using a range-independent atmospheric model would inevitably lead to great mistakes in such a situation. Figure 2a-1 compare the observed and predicted arrivals at these stations. In winter, a good agreement is found: IS31 records microbaroms with back-azimuths of $320 \pm 20^{\circ}$ within the predicted range (Fig. 2a-c). A good agreement is also observed at KURIS (Fig. 20-g) and MKIAR (Fig. 2i-k).

In summer, the agreement in azimuths remains satisfactory at all stations within a range of $\pm 30^{\circ}$. IS31 records microbaroms within $210 \pm 50^{\circ}$ with a slight shift compared with the predicted system $\left(185 \pm 50^{\circ}\right)$. At KURIS, the observed systems $230 \pm 30^{\circ}$ and $130 \pm 30^{\circ}$ are different compared with the predicted ones $\left( \pm 10^{\circ}\right.$ and $\left.160 \pm 10^{\circ}\right)$. At MKIAR, during the summer months, microbaroms are predicted with larger discrepancies $\left( \pm 70^{\circ}\right)$. As the used source model was developed for microseisms

(Ardhuin et al., 2011), an empirical scaling factor $(F 1: 2600)$ has been applied to account for the wave coupling effect in the atmosphere, thus allowing qualitative comparisons between the observed and predicted temporal variations of the microbarom amplitudes. Overall, at all stations, there is good agreement between the predicted and observed amplitudes during the winter months (Fig. $2 \mathrm{~d}, \mathrm{~h}, 1$ ), but in summer, the predicted amplitudes are overestimated (Table 2). A first reason is that PMCC cannot detect multiple sources in the same frequency band. A second reason is the limitation of the propagation modeling which considers range-independent atmosphere. It can be noted that the propagation anomaly predicted during the SSW on January-February 2017 is not observed. Wind noise variations at the station, not considered in the simulations, could explain part of these discrepancies.

To summarize, both amplitudes and azimuths of the microbaroms are well predicted in winter as opposed to summer months. Microseism predictions show dominant source regions south of the arrays that are not observed. Quantitative estimations of the prediction quality ( $S_{\text {corr }}$ calculated according to Eqs. 3 and 4) are summarized in Table 2.

\section{Discussion}

Where previous studies analyzed microbarom signals at a single station (Hupe et al., 2018), further investigations are conducted here by considering a multi-year dataset of continuous records collected by the IGR network. Regional features of both microbaroms and microseisms are highlighted. Figure D1a- $\mathrm{n}$ in Appendix D show the azimuthal distribution of infrasound detections with maximum amplitudes. Figure D2a-d show similar histograms for seismic stations. One can distinguish seasonal trends for both infrasonic and seismic observations. In winter, microbaroms and microseisms are detected from the northern and northwestern directions. In summer, southern, southwestern, and southeastern directions dominate; signals from the northwestern direction are also recorded at ABKAR, KKAR, and MKAR. Azimuths differ from one station to another depending on the strongest microbarom and microseism source regions relative to the station locations. Observations and simulations show large temporal variations in the dominating microbarom source regions explained by the seasonal reversal of the prevailing stratospheric winds, which in turn cause the migration of the storm activity area to the winter hemisphere. The histograms of the azimuthal distribution of microbaroms (Fig. D1) clearly show the dominating direction of arrivals in winter with prevailing directions ranging from 270 to $350^{\circ}$. The predicted azimuths are in good agreement with the observed ones as shown by Figs. 2c, g, and $\mathrm{k}$ and D1 and Table 2. In winter, microseism observations exhibit a similar pattern with a larger spread $\left(250-360^{\circ}\right)$, and an additional peak $\left(0-20^{\circ}\right)$ at KKAR and MKAR (Fig. D1d-f). These peaks are explained by North Pacific microseism source regions. In winter, microseisms exhibit similar trends with some differences as shown by Fig. $3 \mathrm{c}, \mathrm{g}, \mathrm{k}$, and $\mathrm{o}$. The dominant di- rections are comparable with a larger spreading: from 250 to $360^{\circ}$ and from 0 to $20^{\circ}$. At KKAR and MKAR, two peaks are noted in the histograms, with a second peak at $0-20^{\circ}$. These peaks are explained by North Pacific microseisms. In summer, microbaroms are predicted mainly from the southern di rection $\left(180-200^{\circ}\right)$. Such a peak is observed only at IS31 and MKIAR (Fig. D1c), although there is a large spreading in the predictions (45$\left.225^{\circ}\right)$. The closest peak observed at KURIS and MKIAR is shifted northwards by $50^{\circ}$. The dominant back-azimuths are close to $90^{\circ}$. In winter, signals from ocean 
ABKAR

(a)

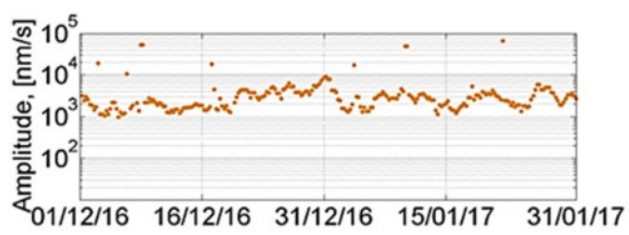

(c)

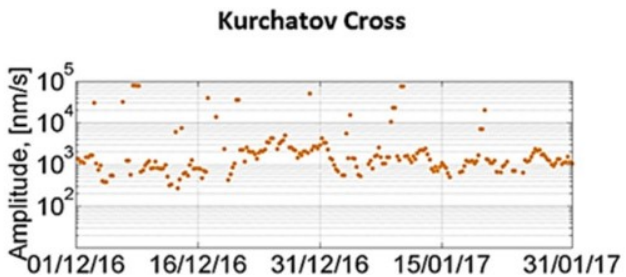

(b)

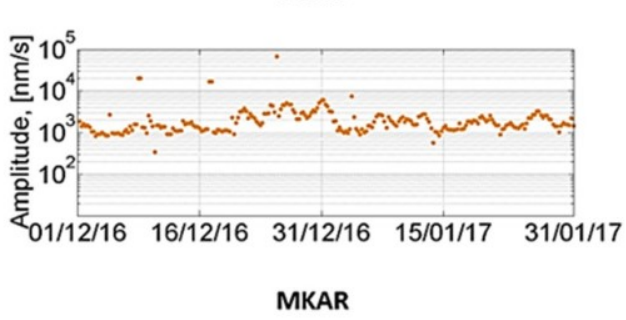

(d)

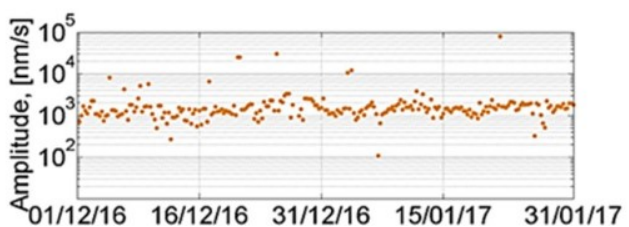

Figure 4. Dominant amplitude of microseisms in the $0.1-0.4 \mathrm{~Hz}$ band detected at ABKAR (a), KKAR (b), Kurchatov Cross (c), and MKAR (d) arrays from 1 December 2016 to 31 January 2017.

Table 2. Estimations of the prediction quality for microbarom amplitudes and azimuths.

\begin{tabular}{|c|c|c|c|c|c|c|c|c|c|}
\hline Station & $\begin{array}{l}\text { Long-term } \\
\text { observation period }\end{array}$ & $S_{\text {corr_Az }}$ & $S_{\text {corr_Amp }}$ & $\begin{array}{l}\text { Observation } \\
\text { period on winter }\end{array}$ & $S_{\text {corr_Az }}$ & $S_{\text {corr_Amp }}$ & $\begin{array}{l}\text { Observation period } \\
\text { on summer }\end{array}$ & $S_{\text {corr_Az }}$ & $S_{\text {corr_Amp }}$ \\
\hline IS31 & 2014-2017 & 0.61 & 0.39 & $\begin{array}{l}\text { December 2016- } \\
\text { February } 2017\end{array}$ & 0.76 & 0.53 & June-August 2017 & 0.44 & 0.26 \\
\hline KURIS & 2014-2017 & 0.52 & 0.23 & $\begin{array}{l}\text { December 2016- } \\
\text { February } 2017\end{array}$ & 0.82 & 0.58 & June-August 2017 & 0.16 & 0.18 \\
\hline MKIAR & $\begin{array}{l}\text { September 2016- } \\
\text { December } 2017\end{array}$ & 0.62 & 0.5 & $\begin{array}{l}\text { December 2016- } \\
\text { February } 2017\end{array}$ & 0.82 & 0.66 & June-August 2017 & 0.34 & 0.39 \\
\hline
\end{tabular}

storms in the North Atlantic dominate at all stations. This is supported by microbarom and microseism simulations. Microbarom sources recorded by the Kazakh network in summer are not fully characterized. The cross-bearing location considering detections at IS31, KURIS, and MKIAR yields a hotspot located southwest of South America (Fig. C2). Since the localization does not include the crosswind effect, the true location may differ significantly from the preliminary estimation. Furthermore, the fact that a signal should pass a considerable portion of the way upwind would prejudice the likelihood of its registration. However, this preliminary location is consistent with the relatively low amplitude values and larger periods in summer than in winter (Fig. C1). Additional studies using more realistic propagation modeling are required to confirm this hypothesis. In this study, the method used to predict the attenuation assumes a range independent atmosphere along the propagation paths. Such an approach cannot be applied to situations involving long propagation ranges where significant along-path variability of wind and temperature profiles may occur (especially when sources and network are located in different hemispheres). Using historical IGR datasets, the spatiotemporal variability of microbarom signals due to changes in the source location and the structure of the atmospheric waveguides can be stud- ied. There is a clear seasonal trend in both directions and amplitudes of microbaroms and microseisms (Fig. 2). Moreover, microseism amplitudes synchronously vary at all stations (Fig. 4). A good agreement between observations and simulations is found for the azimuths. The bathymetry effect plays an important role when calculating the microseism source intensity. As already shown by Evers and Siegmund (2009) and Smets and Evers (2014), SSW events can be inferred from the observed spatiotemporal variations of microbarom parameters. Such observations are noted at IS31 where microbaroms in early and late February 2017 are shifted to easterly directions $\left(\sim 40^{\circ}\right)$, which is consistent with the simulated source regions in the North Pacific (Fig. 2a, c). As noted at IS31, KURIS also recorded signals with back-azimuths of $\sim 40^{\circ}$ in late January 2017 (Fig. 2e, g). Similarly, signals from $\sim 100^{\circ}$ were also recorded during the $2017 \mathrm{SSW}$ event at MKIAR. However, the observed back-azimuths differ from the predicted ones $\left(\sim 60^{\circ}\right)$. It is likely that this station recorded signals from other regions over the Pacific Ocean, which are not described by the ocean wave model used. These findings are consistent with comparisons between the observed and modeled microbaroms carried out by Landès et al. (2014) at IS31. This study shows that modeling 
well describes microbarom sources in the North Atlantic in winter, while signals in summer are poorly explained.

Comparing microbaroms and microseisms at collocated sites highlights similar features. Figure $5 \mathrm{a}-\mathrm{d}$ present the observed back-azimuths and signal amplitudes from 1 January2014 to 31 December 2017 at ABKAR and IS31, located $230 \mathrm{~km}$ apart. Figure $5 \mathrm{e}-\mathrm{h}$ show the detection results for the collocated Kurchatov Cross and KURIS arrays. The comparison of the bulletins in Fig. 5 shows similar seasonal patterns:

- North Atlantic microseisms and microbaroms prevail in winter. Back-azimuths of 300-360 are clearly visible in Fig. 5a, b, e, and g.

- Amplitudes of North Atlantic microbaroms and microseisms observed in winter exceed those observed in summer, as shown in Fig. 5b, d, f, and h.

Specific features are identified:

- Arrays record North Atlantic microseisms more steadily than microbaroms from that region (Fig. 5).

- The range of back-azimuths for North Atlantic microseisms is larger than the ones of microbaroms at ABKAR and MKAR as shown by Fig. 5a, b, e, and g. In winter, at ABKAR, signals with back-azimuth of $\sim 310^{\circ}$ are predicted, while the observed signals dominate at $\sim 340^{\circ}$. In summer, the signals predicted around $\sim 180^{\circ}$ are not observed (Fig. 3a). Such deviations in surface wave back-azimuths were earlier identified during teleseismic events observation at AlpArray (Kolínský and Bokelmann, 2019). To substantiate this hypothesis, source-specific static corrections (SSSCs) are required. However, the SSSC evaluation would require long-term instrumental observations, which is out of the scope of the present study.

- In summer, no correlation is found in the prevailing directions of microseism and microbarom arrivals at collocated arrays.

This study aims at characterizing the oceanic ambient noise using infrasound and seismic methods. The results show that exploiting the synergy between seismic and infrasound ambient noise observations is valuable to (i) better constrain the source strength using seismic records as microseisms propagate through the static structure of the Earth, while microbaroms travel through a highly variable atmosphere both in space in time, (ii) improve the detectability of oceanwave interaction and location accuracy as microbarom wave parameters are less affected by heterogeneities in the propagation medium, and (iii) improve the physical description of seismo-acoustic energy partitioning at the ocean-atmosphere interface. While dominant features of microseisms and microbaroms are successfully recovered, some limitations of the proposed approach are identified.
One limitation is the inability of the PMCC method to detect signals from several sources overlapping in the same frequency band. Another methodological shortcoming is the range-independent atmosphere considered for propagation simulations. Such an approach cannot be applied to situations involving long propagation ranges where significant alongpath variability of wind and temperature profiles may occur, especially when sources and network are located in different hemispheres. Additional studies are also required to further evaluate whether the bathymetry effect could explain discrepancies between the observed microbarom and microseism signals (Longuet-Higgins, 1950; Stutzmann et al., 2012; De Carlo, 2020).

\section{Conclusions}

The IGR seismo-acoustic network is much denser than the global IMS infrasound network. Analyzing multi-year archives of continuous recordings provides a detailed picture of the spatial and temporal variability of the seismic and infrasound ambient noise originating from two hemispheres. In winter, the most intense oceanic storms are modeled in the North Atlantic, and their signature prevails on infrasound and seismic records. During minor SSW events, bi-directional conditions may occur which may have strong impacts on the retrieved microbarom signals (Assink et al., 2014). Simulated and observed microbarom parameters are consistent, as shown by moderate correlation coefficients. In summer, the location of microbarom signals using detections at IS31, KURIS, and MKIAR is found southwest of South America, at a distance larger than $15000 \mathrm{~km}$, near the peri-Antarctic belt where strong ocean storms circulate. This location is consistent with the relatively low amplitude and frequency of the recorded signals.

Further numerical investigations are needed to define the most suitable detection parameters in terms of missed events and the false alarm rate and estimate wave parameter uncertainties accounting for the response functions at all arrays. In this study, the discrepancies between observations and predictions motivate the use of high-resolution detection methods to identify multiple propagation paths from which microbarom energy can reach the array (e.g., Assink et al., 2014). Exploring the capability of high-resolution detection processing techniques to extract multi-directional overlapping coherent energy would be valuable to provide a more realistic picture of the recorded ocean ambient noise (e.g., den Ouden et al., 2020).

For such long propagation ranges, more realistic numerical simulations could reduce the differences between the observed and modeled amplitude; additional studies are thus required to explore time- and range-dependent full-wave propagation techniques while still maintaining computational efficiency (e.g., Waxler and Assink, 2019). Finally, including additional data from other seismo-acoustic networks world- 
ABKAR

(a)

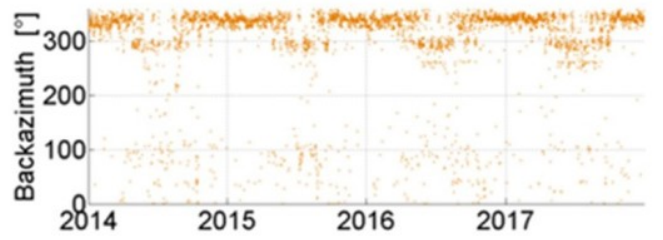

(b)

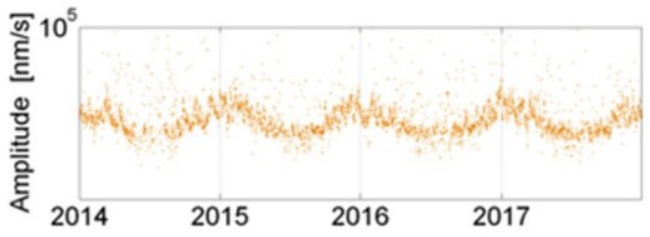

IS31

(c)

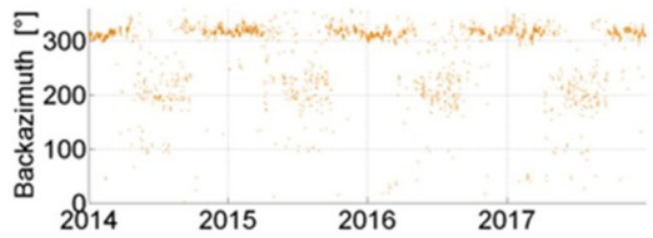

(d)

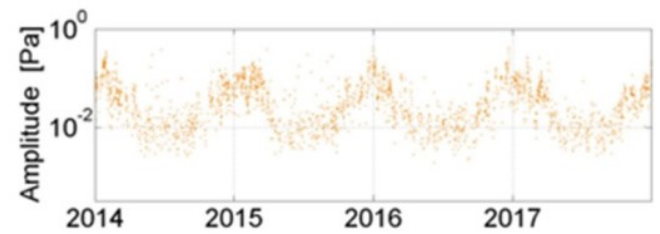

Kurchatov Cross

(e)

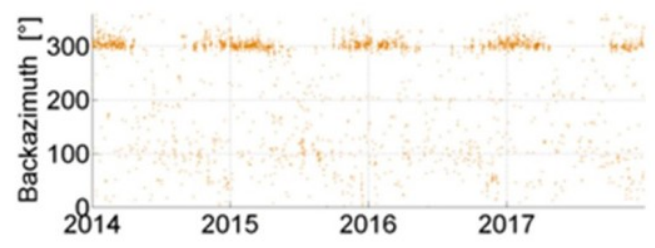

(g)

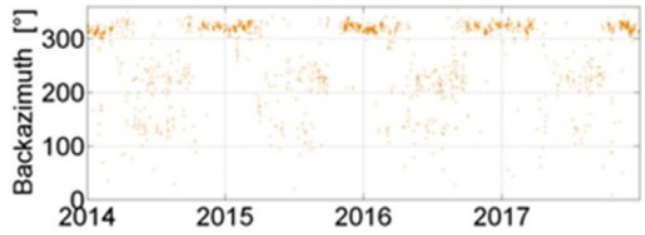

(f)

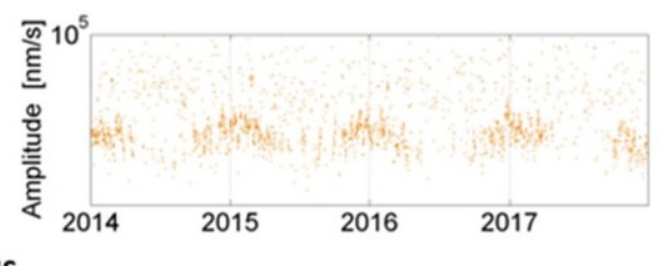

KURIS

(h)

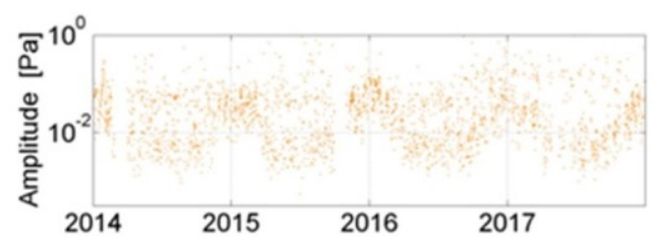

Figure 5. Comparison of the observed back-azimuths and amplitudes at ABKAR (a, b) and IS31 (c, d), $230 \mathrm{~km}$ apart, and collocated Kurchatov Cross (e, $\mathbf{f})$ and KURIS ( $(\mathbf{g}, \mathbf{h})$ arrays.

wide would help constrain the microbarom source location, validating long-range propagation modeling, and better characterize station-specific ambient noise signatures, which is important for a successful verification of the CTBT using the IMS. 
$9 \quad$ Appendix A: Instrument responses

(a)

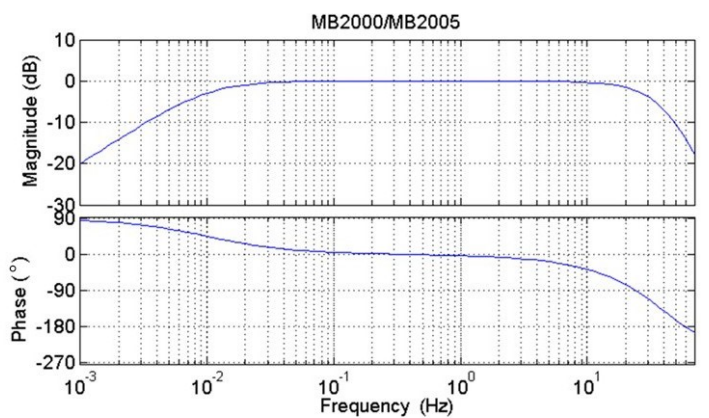

(b)

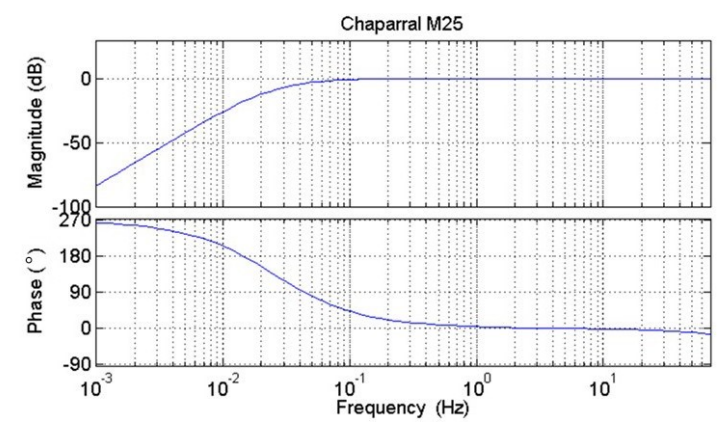

(c)

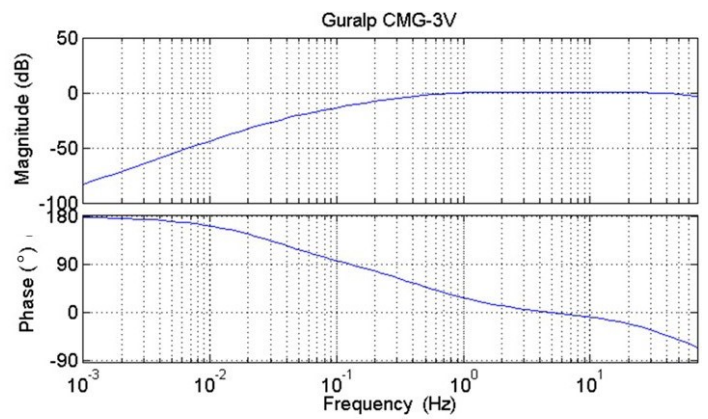

(d)

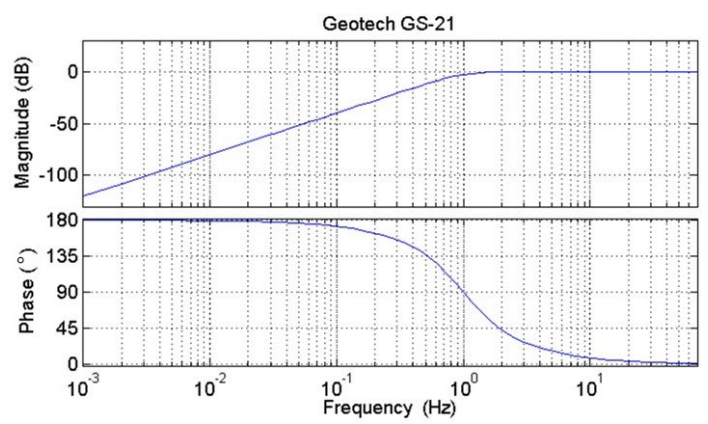

Figure A1. Normalized frequency response of the (a) MB2000 and MB2005, (b) Chaparral M25 microbarometers, (c) Guralp CMG-3V, and (d) Geotech GS-21 seismometers.

Table A1. Description of infrasound and seismic arrays.

\begin{tabular}{llllr}
\hline Array & Sensor & $\begin{array}{l}\text { Response in } \\
\text { units lookup }\end{array}$ & Digitizer & $\begin{array}{l}\text { Sampling } \\
\text { frequency, Hz }\end{array}$ \\
\hline IS31 & MB2000 & $\mathrm{Pa}$ & DASE Aubrac & 20 \\
KURIS & MB2005 & $\mathrm{Pa}$ & Guralp CMG-DM24S6EAM & 20 \\
MKIAR & Chaparral M25 & $\mathrm{Pa}$ & Science Horizons AIM24 & 40 \\
ABKAR, KKAR, MKAR & Geotech GS-21 & $\mathrm{m} \mathrm{s}^{-1}$ & Science Horizons AIM24 & 40 \\
Kurchatov Cross & Guralp CMG 3-V & $\mathrm{m} \mathrm{s}^{-1}$ & Nanometrics Europa-T & 40 \\
\hline
\end{tabular}


Appendix B: Noise spectra
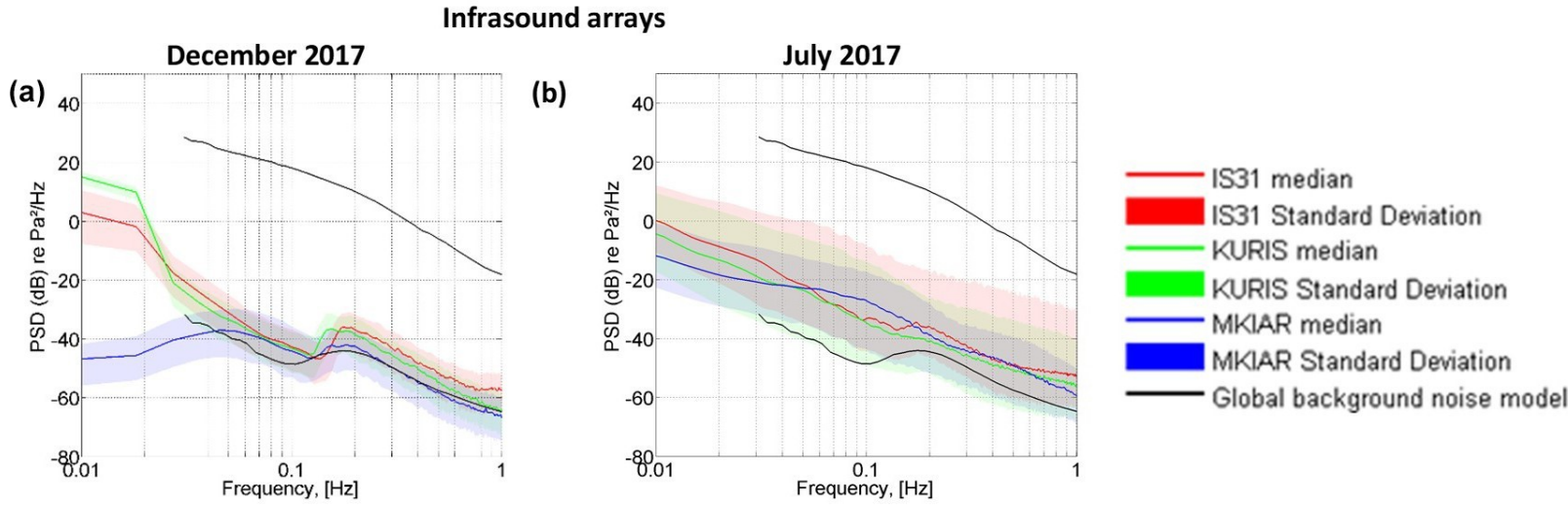

Seismic arrays

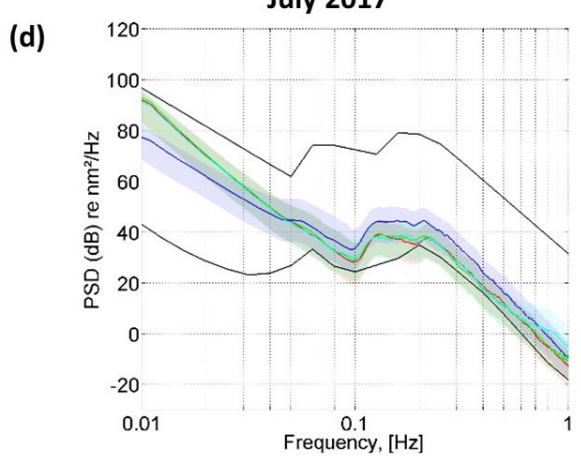

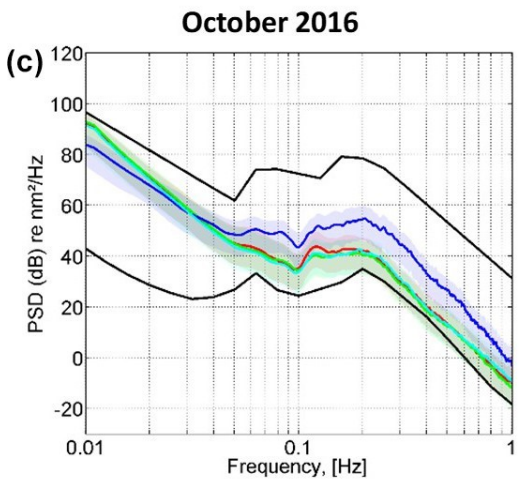

July 2017

Collocated infrasound and seismic arrays

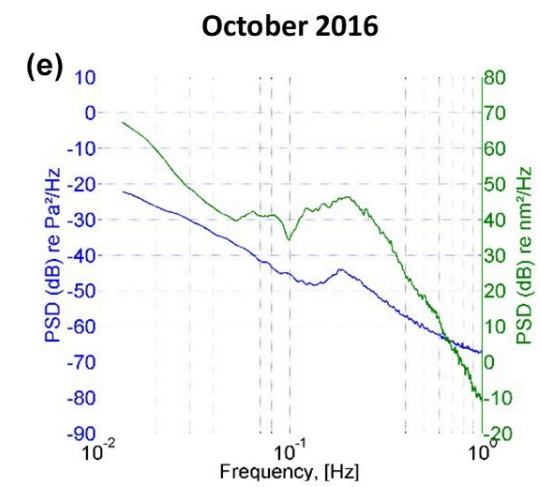

(f)

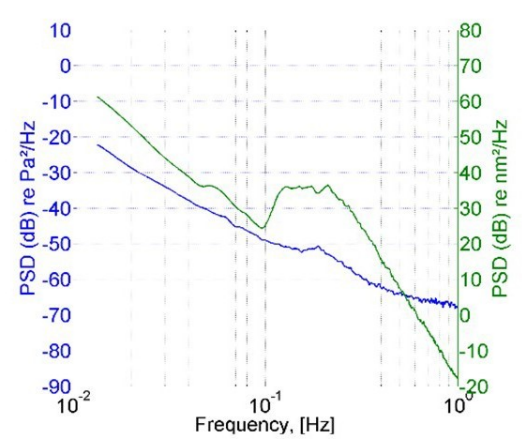

- Kurchatov infrasound array Kurchatov Cross seismic array

Figure B1. PSD noise spectra at infrasound arrays (a, b) and seismic arrays (c, d). Comparison of noise spectra at collocated KURIS and Kurchatov Cross arrays. 
11 Appendix C: The distribution of the epicenters of thepredicted microbarom sources

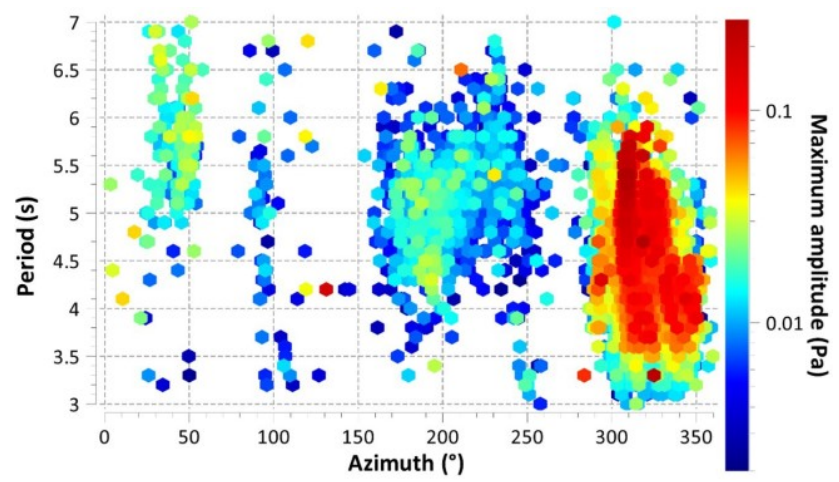

Figure C1. Signal periods versus back-azimuths at IS31 observations in 2017. The amplitude is color coded (in Pa).

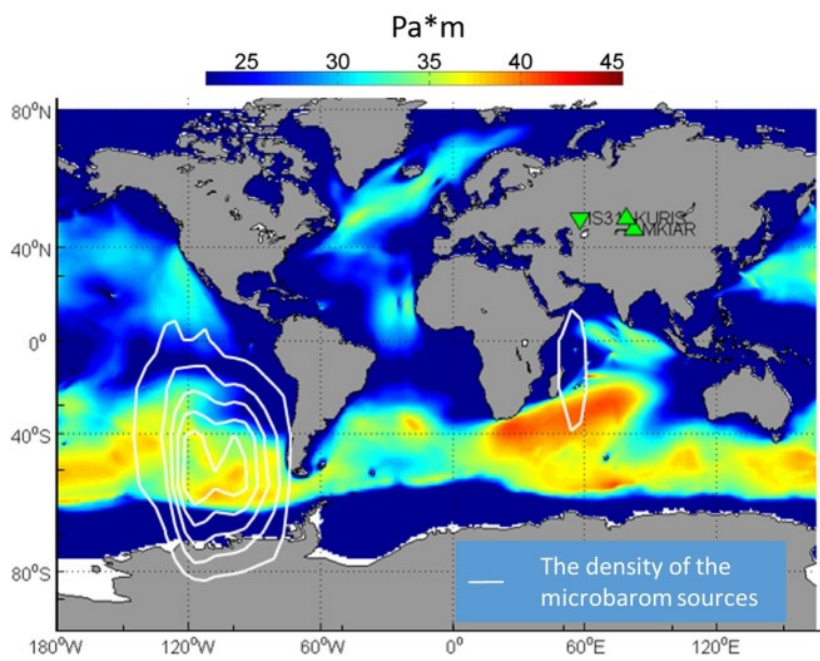

Figure C2. Spatial distribution of the epicenters of microbarom sources in July-August 2017. White contours represent the density of the microbarom source locations obtained via cross-bearing using detections at IS31, KURIS, and MKIAR, during same time periods. At each station, back-azimuths are daily averaged. 
12 Appendix D: Comparison of back-

azimuths atcollocated seismic and infrasound arrays

(a)

\section{Entire year 2017}

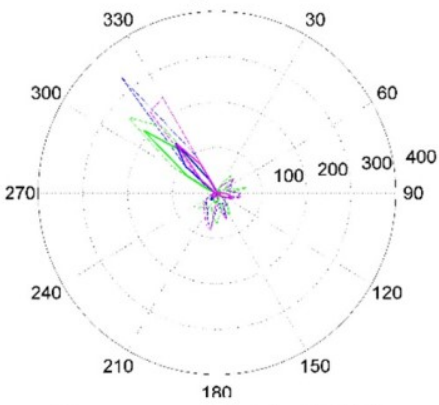

Summer months 2017

(c)

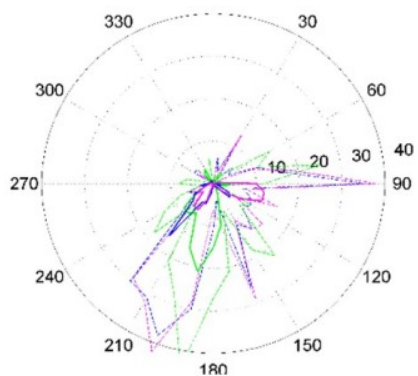

Entire year 2017

(d)

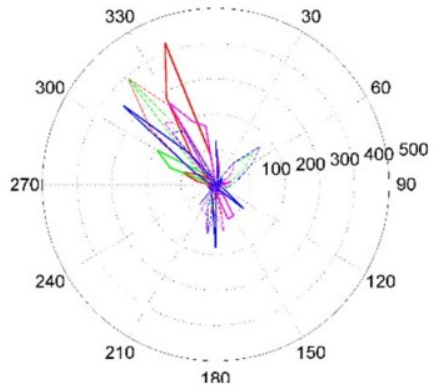

Summer months 2017

(f)

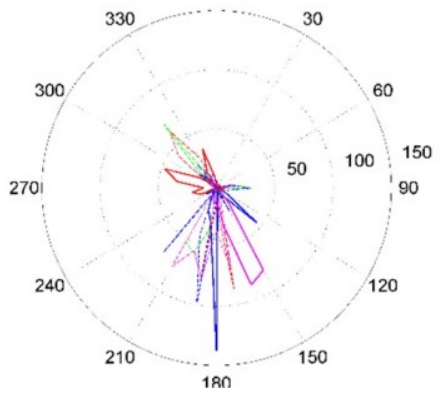

Infrasound arrays

(b)

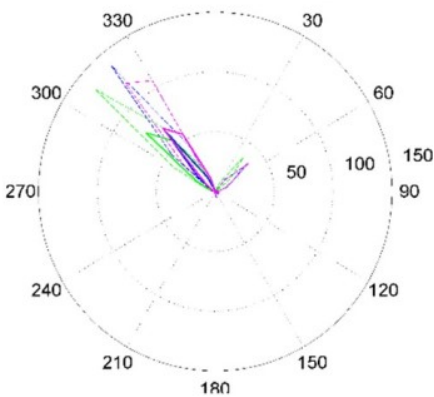

Seismic arrays

(e)
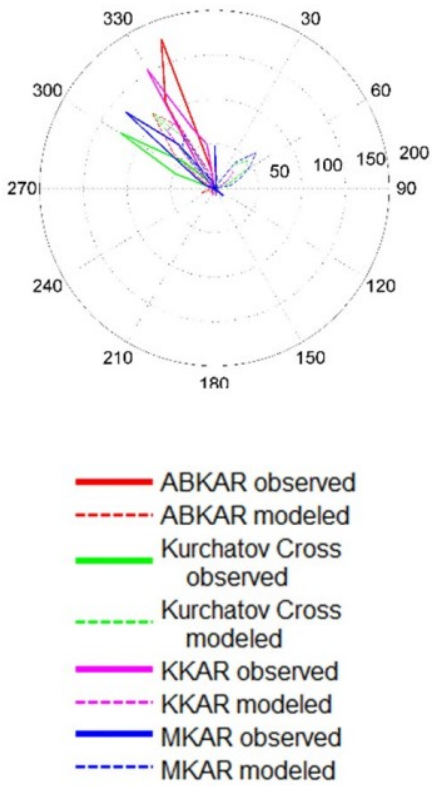

Figure D1. Azimuthal distribution of infrasound detections throughout 2017 (a), from 1 December 2016 to 28 February 2017 (b), and from 1 June to 31 August 2017 (c). Azimuthal distribution of seismic detections throughout 2017 (d), from 1 December 2016 to 28 February 2017 (e), and from 1 June to 31 August 2017 (f). 
Code availability. The code is available by request.

Data availability. Atmospheric wind and temperature profiles are derived from operational high-resolution atmospheric model analysis, defined by the Integrated Forecast System of the ECMWF, available at https://www.ecmwf.int/ (last access: 2 September 2019; ECMWF, 2018). Seismic and infrasound waveforms from the IMS network (https://www.ctbto.org/, last access: 2 September 2019) used in this study are available to the authors, being members of the National Data Centres for the CTBTO. Data of the Kazakhstani national seismic and infrasound arrays are available under request to the Institute of Geophysical Research, National Nuclear Centre of Kazakhstan. Microseism and microbarom detections of the seismoacoustic Kazakh network and microbarom simulations are available at the ISC repository (Smirnov et al., 2020).

Author contributions. NMS and ALP suggested the main outlines of the paper. AS and ALP prepared the historical dataset for processing. MDC and ALP developed the microbarom source model. AS performed microbarom and microseism detections and propagation simulations. AS prepared the paper with contributions from all coauthors. ALP, MDC, and SK made critical reviews and comments to improve the paper.

Competing interests. The authors declare that they have no conflictof interest.

Acknowledgements. This research has been supported by the Commissariat à l'Energie Atomique (CEA, France). The authors also thank Anna Smirnova for support in the manuscript preparation; Jelle Assink, whose comments and suggestions helped improve and clarify the paper; Eleonore Stutzmann for the useful advice on the bathymetry excitation effect; Inna Sokolova and Pavel Martysevich for valuable input on the instrumentation part; and Sven Peter Näsholm and Ekaterina Vorobeva for microbarom model scaling. Massive numerical computations were performed on the S-CAPAD platform of IPGP in France.

Financial support. This research has been supported by the European Research Council (ERC) under the European Union Horizon 2020 Research and Innovation Programme (grant agreement 787399SEISMAZE), the Russian Ministry of Education and Science (grant no. 14.W03.31.0033), and the Russian Foundation for Basic Research (project no. 18-05-00576).

Review statement. This paper was edited by CharLotte Krawczyk and reviewed by Jelle Assink and one anonymous referee.
13

\section{References}

Ardhuin, F., Stutzmann, E., Schimmel, M., and Mangeney, A.: Ocean wave sources of seismic noise, J. Geophys. Res., 116, C09004, https://doi.org/10.1029/2011jc006952, 2011.

Ardhuin, F., Lavanant, T., and Obrebski, M.: A numerical model for ocean ultra-low frequency noise: wave-generated acousticgravity and Rayleigh modes, J. Acoust. Soc. Am., 134, 3242-3259, https://doi.org/10.1121/1.4818840, 2013a.

Ardhuin, F. and Herbers, T. H. C.: Noise generation in the solid Earth, oceans and atmosphere, from nonlinear interacting surface gravity waves in finite depth, J. Fluid Mech., 716, 316-348, https://doi.org/10.1017/jfm.2012.548, 2013b.

Assink, J. D., Waxler, R., Smets, P., and Evers, L. G.: Bidi-rectional infrasonic ducts associated with sudden stratospheric warming events, J. Geophys. Res.-Atmos., 119, 1140-1153, https://doi.org/10.1002/2013jd021062, 2014.

Belyashov, A., Dontsov, V., Dubrovin, V., Kunakov, V., and Smirnov, A.: New infrasound array "Kurchatov", NNC RK Bull., 2, 24-30, 2013.

Bertelli, T.: Osservazioni sui piccoli movimenti dei pendoli in relazione ad alcuni fenomeni meteorologiche, Boll. Meteorol. Osserv. Coll. Roma, 9, 1872.

Brekhovskikh, L. M.: Waves in Layered Media, Applied Mathematics and Mechanics, Academic Press, London, UK, https://doi.org/10.1002/zamm.19620420308, 1960.

Cansi, Y.: An automatic seismic event processing for detection and location: The P.M.C.C. Method, Geophys. Res. Lett., 22, 10211024, https://doi.org/10.1029/95g100468, 1995.

Cansi, Y. and Klinger, Y.: An Automated Data Processing Method for Mini-Arrays, Newsl. Eur. Seismol. Cent., 11, 1021-1024, 1997.

Capon, J.: Long-Period Signal Processing Results for LASA, NORSAR and ALPA, Geophys. J. Int., 31, 279-296, https://doi.org/10.1111/j.1365-246x.1972.tb02370.x, 1972. Ceranna, L., Matoza, R., Hupe, P., Le Pichon, A., and Landès,

M.: Systematic array processing of a decade of global IMS infrasound data, in: Infrasound monitoring for atmospheric studies, edited by: Le Pichon, A., Blanc, E., and Hauchecorne, A., Springer, Dordrecht, The Netherlands, 471-484, 2019.

De Carlo, M., Le Pichon, A., Ardhuin, F., and Näsholm, S.: Characterizing and modelling ocean ambient noise using infrasound network and middle atmospheric models, NNC RK Bull., 2, 144151, 2018.

De Carlo, M., Ardhuin, F., and Le Pichon, A.: Atmospheric infrasound generation by ocean waves in finite depth: unified theory and application to radiation patterns, Geophys. J. Int., 21, 569585, https://doi.org/10.1093/gji/ggaa015, 2020.

den Ouden, O., Assink, J. D., Smets, P., Shani-Kadmiel, S., Averbuch, G., and Evers, L.: CLEAN beamforming for the enhanced detection of multiple infrasonic sources, Geophys. J. Int., 221, 305-317, https://doi.org/10.1093/gji/ggaa010, 2020.

Donn, W. L. and Naini, B.: Sea wave origin of micro-baroms and microseisms, J. Geophys. Res., 78, 4482-4488, https://doi.org/10.1029/JC078i021p04482, 1973.

Evers, L. G. and Haak, H. W.: Listening to sounds from an exploding meteor and oceanic waves, Geophys. Res. Lett., 28, 41-44, https://doi.org/10.1029/2000g1011859, 2001. 
Evers, L. G. and Siegmund, P.: Infrasonic signature of the 2009 major sudden stratospheric warming, Geophys. Res. Lett., 36, L23808, https://doi.org/10.1029/2009g1041323, 2009.

Garcés, M.: On using ocean swells for continuous infrasonic measurements of winds and temperature in the lower, mid-dle, and upper atmosphere, Geophys. Res. Lett., 31, L19304, https://doi.org/10.1029/2004gl020696, 2004.

Gerstoft, P., Shearer, P. M., Harmon, N., and Zhang, J.:Global $\mathrm{P}$, PP, and PKP wave microseisms observed from distant storms, Geophys. Res. Lett., 35, L23306, https://doi.org/10.1029/2008g1036111, 2008.

Gutenberg, B.: Microseisms, microbaroms, storms, and waves in western North America, Eos Trans. AGU, 34, 161-173, https://doi.org/10.1029/TR034i002p00161, 1953.

Hasselmann, K.: A statistical analysis of the gen-eration of microseisms, Rev. Geophys., 1, 177, https://doi.org/10.1029/rg001i002p00177, 1963.

Hasselmann, K.: Feynman diagrams and interaction rulesof wave-wave scattering processes, Rev. Geophys., 4, 1, https://doi.org/10.1029/rg004i001p00001, 1966.

Haubrich, R. A. and McCamy, K.: Microseisms: Coastal and pelagic sources, Rev. Geophys., 7, 539, https://doi.org/10.1029/rg007i003p00539, 1969.

Hupe, P., Ceranna, L., Pilger, C., De Carlo, M., Le Pi-chon, A., Kaifler, B., and Rapp, M.: Assessing mid-dle atmosphere weather models using infrasound detec-tions from microbaroms, Geophys. J. Int., 216, 1761-1767, https://doi.org/10.1093/gji/ggy520, 2018.

IFREMER: Wave Watch 3, available at: ftp://ftp.ifremer.fr/ifremer/ ww3/ (last access: 3 October 2018), 2018.

Kanamori, H. and Given, J. W.: Use of long-period surface waves for rapid determination of earthquake-source parameters, Phys. Earth Planet. Inter., 27, 8-31, https://doi.org/10.1016/00319201(81)90083-2, 1981.

Kedar, S., Longuet-Higgins, M., Webb, F., Graham, N., Clayton, R., and Jones, C.: The origin of deep ocean microseisms in the North Atlantic Ocean, Proc. R. Soc. A, 464, 777-793, https://doi.org/10.1098/rspa.2007.0277, 2008.

KNDC: Observation network of the Institute of Geophysical Research of the National Nuclear Centre of the Republic of Kazakhstan, available at: http://www.kndc.kz/index.php?option= com_content\&view=article\&id=45\&Itemid=147\&lang=en (last access: 3 October 2019), 2019.

Kolínský, P. and Bokelmann, G.: Arrival angles of teleseismic fundamental mode Rayleigh waves across the AlpArray, Geophys. J. Int., 218, 115-144, https://doi.org/10.1093/gji/ggz081, 2019.

Landès, M., Ceranna, L., Le Pichon, A., and Matoza, R.S.: Localization of microbarom sources using the IMS in- frasound network, J. Geophys. Res.-Atmos., 117, D06102, https://doi.org/10.1029/2011jd016684, 2012.

Landès, M., Le Pichon, A., Shapiro, N. M., Hillers, G., and Campillo, M.: Explaining global patterns of microbarom obser- vations with wave action models, Geophys. J. Int., 199, 1328-1337, https://doi.org/10.1093/gji/ggu324, 2014.

Le Pichon, A., Ceranna, L., and Vergoz, J.: Incorporating numerical modeling into estimates of the detection capability of the IMS infrasound network, J. Geophys. Res.-Atmos., 117, D05121, https://doi.org/10.1029/2011jd016670, 2012.
Le Pichon, A., Assink, J. D., Heinrich, P., Blanc, E., Charlton- Perez, A., Lee, C. F., Keckhut, P., Hauchecorne, A., Rüfenacht, R., Kämpfer, N., Drob, D. P., Smets, P. S. M., Evers, L. G., Ceranna, L., Pilger, C., Ross, O., and Claud, C.: Compari-son of colocated independent ground-based middle atmosphericwind and temperature measurements with numerical weather prediction models, J. Geophys. Res.-Atmos., 120, 8318-8331, https://doi.org/10.1002/2015jd023273, 2015.

Longuet-Higgins, M. S.: A Theory of the origin of microseisms, Philos. T. R. Soc. A, 243, 1-35, https://doi.org/10.1098/rsta.1950.0012, 1950.

Marty, J.: The IMS Infrasound Network: Current Status and Technological Developments, in: Infrasound Monitor-ing for Atmospheric Studies, edited by: Le Pichon, A., Blanc, E., and Hauchecorne, A., Springer, Cham, 3-62, https://doi.org/10.1007/978-3-319-75140-5, 2019.

Matoza, R. S., Landès, M., Le Pichon, A., Ceranna, L., and Brown, D.: Coherent ambient infrasound recorded by the Inter- national Monitoring System, Geophys. Res. Lett., 40, 429-433, https://doi.org/10.1029/2012g1054329, 2013.

Obrebski, M., Ardhuin, F., Stutzmann, E., and Schimmel, M.: Detection of microseismic compressional (P)body waves aided by numerical modelling of oceanic noise sources, J. Geophys. Res.Sol. Ea., 118, 4312-4324, https://doi.org/10.1002/jgrb.50233, 2013.

Olson, J. V. and Szuberla, C. A. L.: Distribution of wave packet sizes in microbarom wave trains observed in Alaska, J. Acoust. Soc. Am., 117, 1032-1037, https://doi.org/10.1121/1.1854651, 2005.

Posmentier, E. S.: A Theory of Microbaroms, Geophys. J. Int., 13, 487-501, https://doi.org/10.1111/j.1365-246x.1967.tb02301.x, 1967.

Shapiro, N. M.: High-Resolution Surface-Wave Tomography from Ambient Seismic Noise, Science, 307, 1615-1618, https://doi.org/10.1126/science.1108339, 2005.

Shapiro, N. M. and Campillo, M.: Emergence of broad-band Rayleigh waves from correlations of the ambi-ent seismic noise, Geophys. Res. Lett., 31, L07614, https://doi.org/10.1029/2004g1019491, 2004.

Smets, P. S. M. and Evers, L. G.: The life cycle ofa sudden stratospheric warming from infrasonic ambientnoise observations, J. Geophys. Res.-Atmos., 119, 84-99, https://doi.org/10.1002/2014jd021905, 2014.

Smirnov, A.: The variety of infrasound sources recorded by Kazakhstani stations, in: CTBT: Science and Technology, Vienna, available at: https://www.ctbto.org/fileadmin/user_upload/ SnT2015/SnT2015_Posters/T2.3-P20.pdf (last access: 27 October 2015), 2015.

Smirnov, A., Dubrovin, V., and Evers, L. G.: Explanation of the nature of coherent low-frequency signal sources recorded by monitoring station network of the NNC RK, NNC RK Bull, 3, 76-81, 2010.

Smirnov, A., De Carlo, M., Le Pichon, A., and Shapiro, N. M.: Signals from severe ocean storms in North Atlantic as it detected in Kazakhstan: observations and modelling, NNC RK Bull., 2, 152-160, 2018.

Smirnov, A., De Carlo, M., Le Pichon, A., Shapiro, N., and Kulichkov, S.: Results of the microseism and micro- barom detections by the seismo-acoustic Kazakh network 
and of the microbarom simulation for the infrasound ar- rays of the network, ISC Seismological Dataset Repository, https://doi.org/10.31905/DSW7L5BV, 2020.

Stehly, L., Campillo, M., and Shapiro, N. M.: A study of the seismic noise from its long-range correlation properties, J. Geophys. Res., 111, B10306, https://doi.org/10.1029/2005jb004237, 2006.

Stutzmann, E., Ardhuin, F., Schimmel, M., Mangeney, A., and Patau, G.: Modelling long-term seismic noise in various environments, Geophys. J. Int., 191, 707-722,

https://doi.org/10.1111/j.1365-246x.2012.05638.x, 2012. Szuberla, C. A. L. and Olson, J. V: Uncertainties associated with pa-

rameter estimation in atmospheric infrasound arrays, J. Acoust. Soc. Am., 115, 253-258, https://doi.org/10.1121/1.1635407, 2004.

Toksöz, M. N. and Lacoss, R. T.: Microseisms: mode structure and sources, Science, 159, 872-873, https://doi.org/10.1126/science.159.3817.872, 1968.
WAVEWATCH III Development Group: User manual andsystem documentation of WAVEWATCH III version 5.16, NOAA/NWS/NCEP/MMAB Technical Note 329, College Park, MD, 326 pp. Appendices, 2016.

Waxler, R. and Assink, J.: Propagation modeling through realis-tic atmosphere and benchmarking, in: Infrasound monitoring for atmospheric studies, edited by: Le Pichon, A., Blanc, E., and Hauchecorne, A., Springer, Cham, pringer Nature, Dordrecht, the Netherlands, 509-550, 2019.

Waxler, R. and Gilbert, K. E.: The radiation of atmospheric microbaroms by ocean waves, J. Acoust. Soc. Am., 119, 2651-2664, https://doi.org/10.1121/1.2191607, 2006.

Waxler, R., Gilbert, K., Talmadge, C., and Hetzer, C.: The effects of finite depth of the ocean on microbarom signals, in: 8th International Conference on Theoretical and Computational Acoustics (ICTCA), 2-6 July 2007, Crete, Greece, 2007.

Weaver, R. L.: GEOPHYSICS: Information from Seismic Noise, Science, 307, 1568-1569, https://doi.org/10.1126/science.1109834, 2005. 